ENHANCING DYNAMICS COURSES WITH MODEL ELICITING ACTIVITIES

\author{
A Thesis \\ presented to \\ the Faculty of California Polytechnic State University, \\ San Luis Obispo
}

\author{
In Partial Fulfillment \\ of the Requirements for the Degree \\ Master of Science in Mechanical Engineering \\ by \\ Lawrence Fong
}

November 2009 


\section{(C) 2009 \\ Lawrence Fong \\ ALL RIGHTS RESERVED}




\section{COMMITTEE MEMBERSHIP}

TITLE:

AUTHOR:

DATE SUBMITTED:

COMMITTEE CHAIR:

COMMITTEE MEMBER: Andrew Kean

COMMITTEE MEMBER: James Widmann

Lawrence Fong

$11 / 02 / 09$

Brian Self
Enhancing Dynamics Courses with Model Eliciting Activities 


\title{
ABSTRACT \\ ENHANCING DYNAMICS COURSES WITH MODEL ELICITING ACTIVITIES
}

\author{
Lawrence Fong
}

Model eliciting activities are assignments which require students to develop models to describe realistic situations. Every MEA follows six principles: model-construction, reality, selfassessment, model documentation, generalizability, and effective prototype. The six principles provide a solid guideline in which instructors can develop more MEAs, which can then be shared and used among several participating universities. Under NSF CCLI Grant \#0717595, Cal Poly is currently developing Model Eliciting Activities for the subject of Mechanical Engineering.

This report documents the undertakings to implement and enhance two Model Eliciting Activities (MEAs) into the Cal Poly curriculum. Specifically, the development of the Vehicle Accident Reconstruction (VAR) MEA and the Catapult MEA will be covered in detail.

The VAR MEA was a project assigned in ME212 "Engineering Dynamics," which required students to apply momentum principles to a two-vehicle collision. Because of the heavy development time experienced by the MEA research team, a MatLab program which accepted user inputs via a graphical user interface (GUI) was developed. This GUI solved for initial velocities during two-vehicle collisions by applying appropriate momentum and work-energy principles. With this program, instructors can more easily develop crash scenarios, as well as check student work.

The Catapult MEA was also a project assigned to ME212 students. It required them to analyze the launch trajectory of an actual scaled catapult using angular motion and work-energy principles. This scaled-catapult was instrumented with one ADXL278 dual-axis accelerometer and four CEA-06-240UZ-120 strain gages. This instrumentation allowed for the experimental data acquisition of the catapult angular velocity, acceleration, and strains. By postprocessing this experimental data using a MatLab program, the experimental results can then be compared to theoretical results.

The overall goal for the VAR MEA GUI programming was to reduce instructor workload in order to promote usage the MEA through a broader range of universities. The goal of the Catapult instrumentation was to provide students with actual experimental data, which could then be used to confirm their theoretical model. The system was set up so that they could easily record their own experimental data for each catapult launch. 


\section{ACKNOWLEDGMENTS}

I would like to thank all the members of my thesis committee for their guidance and support during this past year. I would also like to acknowledge NSF CCLI Grant \#0717595 which made this research possible. 


\section{Table of Contents}

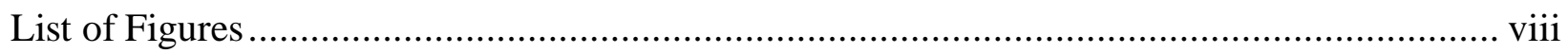

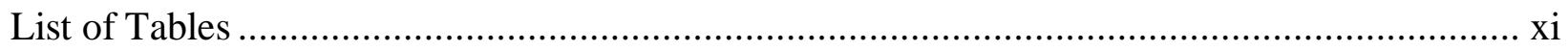

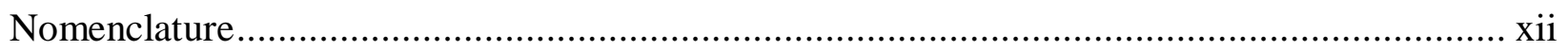

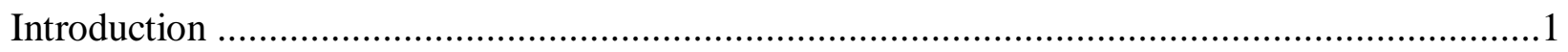

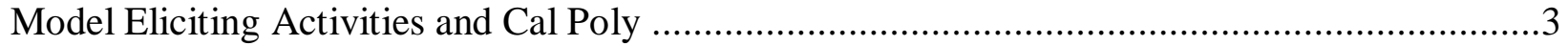

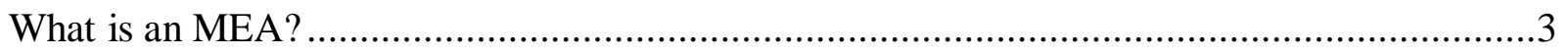

Difference between MEAs and Traditional Assignments .....................................................5

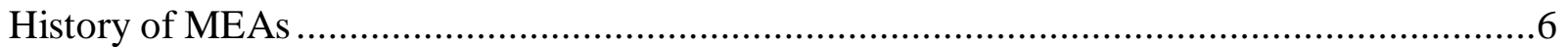

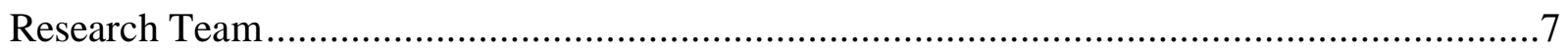

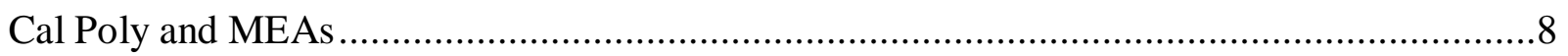

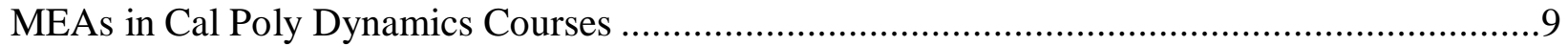

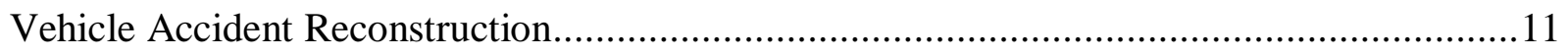

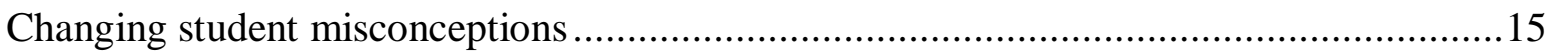

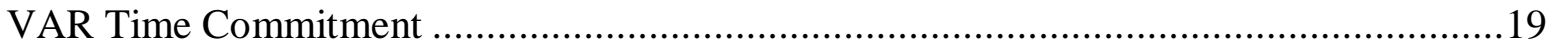

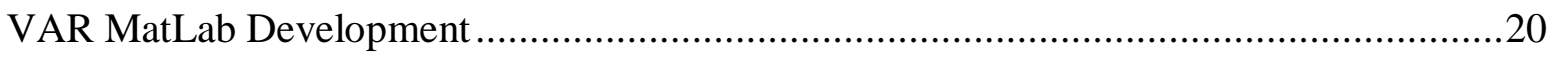

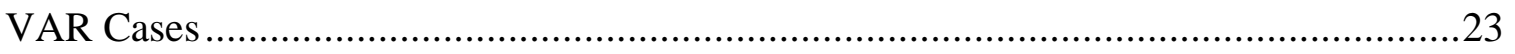

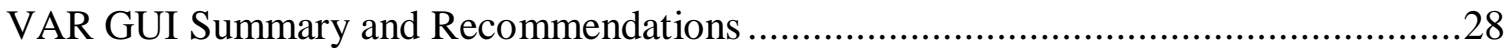

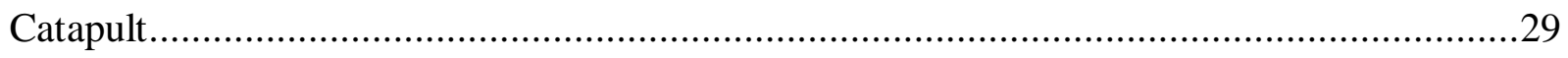

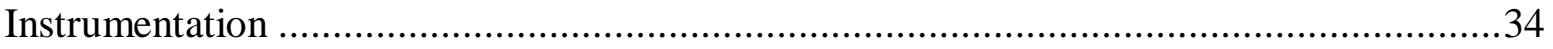

Angular Position, Velocity, and Acceleration............................................................... 36

Switching to CompactRIO ................................................................................. 40

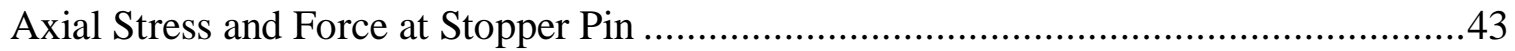

Data From the CompactRIO ……………………….................................................49

MatLab, Post-processing, and Results....................................................................50

Catapult Instrument Summary and Recommendations .................................................58

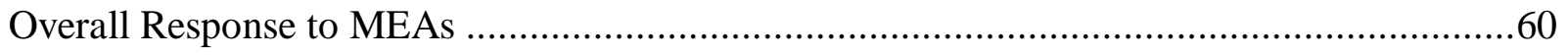

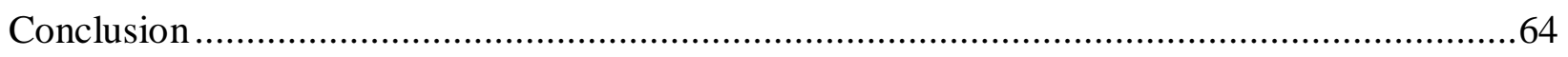

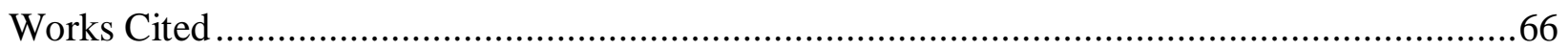




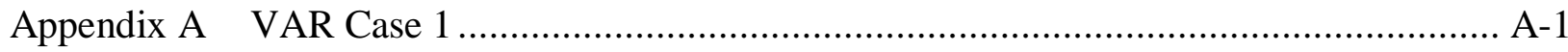

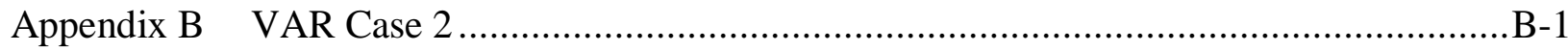

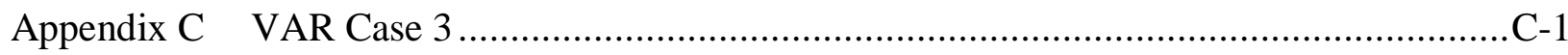

Appendix D VAR Case 4 ................................................................................... D-1

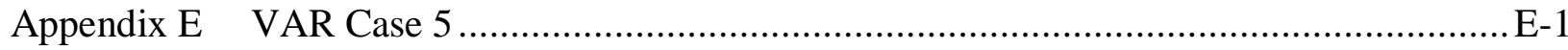

Appendix F MatLab GUI User Guide ................................................................

Appendix G VAR MatLab GUI ..................................................................... G-1

Appendix H Derivation for VAR Cases ............................................................... H-1

Appendix I Catapult Postprocessing Code ............................................................. I-1

Appendix J Catapult Theoretical Code ....................................................................... J-1

Appendix K Selected Catapult Hand Calculations ..................................................... K-1

Appendix L ADXL-278 Specifications ................................................................... L-1 


\section{List of Figures}

Figure 1. Difference between traditional word problems and Model Eliciting Activities. (Lesh, Beyond Constructivism: Models and Modeling Perspectives on

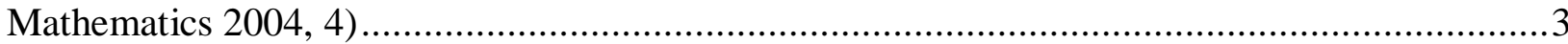

Figure 2. Catapult built by Grand Valley State University students...................................... 10

Figure 3. Background information provided for VAR MEA. ........................................... 12

Figure 4. Memorandum provided for VAR MEA. ............................................................ 13

Figure 5. One of the cases assigned for the VAR MEA. ..................................................... 15

Figure 6. Question 18 of the DCI testing students' understanding of an impact........................ 17

Figure 7. Question 20 of the DCI testing students' understanding of an impact........................ 18

Figure 8. Input-window for VAR development program............................................ 21

Figure 9. MatLab GUI for VAR MEA development. .........................................................22

Figure 10. Velocity vector plot for instantaneous pre and post collision velocities,

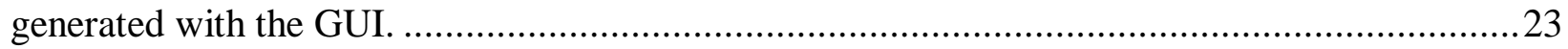

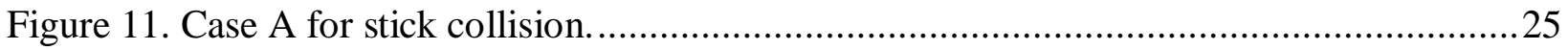

Figure 12. Case A for non-stick collision.......................................................................25

Figure 13. VAR GUI iteration for Case F. convY and convX indicate the percent difference between initial and final momentum magnitudes, in the $\mathrm{Y}$ and $\mathrm{X}$

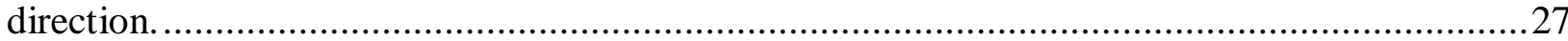

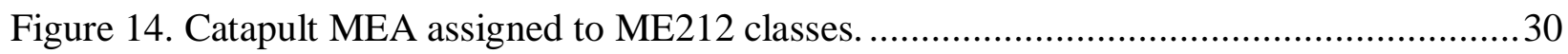

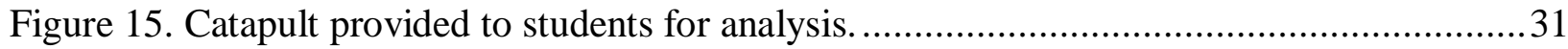

Figure 16. Force versus displacement curve for rubber band......................................... 32

Figure 17. Diagram of catapult locations. ................................................................... 33

Figure 18. Broken catapult arm after some initial trials with two rubber bands. .......................36

Figure 19. Catapult with accelerometer. The accelerometer is highlighted in yellow. The blue and red arrows represent the directions of tangential and normal

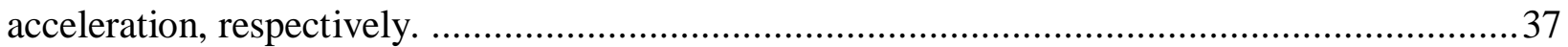

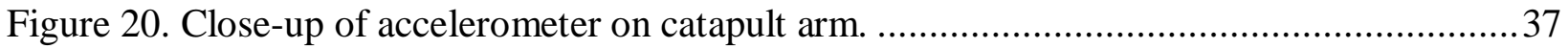

Figure 21. Circuit diagram for 5V voltage regulator \& hardware accelerometer

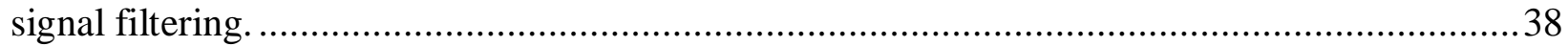

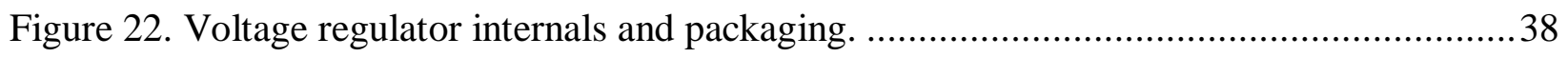

Figure 23. Angular velocity data for multiple runs, using NI-6008 .................................. 39

Figure 24. Experimental results for angular velocity and position. Position was

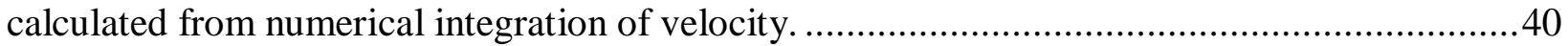

Figure 25. Trial for testing reduced sampling rate of $1000 \mathrm{~Hz}$, using CompactRIO and NI-9205.

Figure 26. (Top) Comparison between experimental angular velocity and integrated angular velocity from experimental angular acceleration. (Bottom) 
Comparison between experimental angular acceleration and derived angular acceleration using experimental angular velocity......................................................... 43

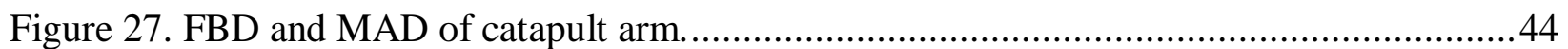

Figure 28. "Full" Wheatstone bridge configuration for strain gages. For axial strain: (1) and (3) represent mounted gages, while (2) and (4) represent external precision resistors. For bending strain: (1) and (4) represent mounted gages, while

(2) and (3) represent internal precision resistors. 45

Figure 29. Strain gages curing under pressure from c-clamps.

Figure 30. Illustration of catapult with associated instrumentation. Strain gage 3

(not visible) is mounted directly opposite of strain gage 1. Strain gage 4 (not

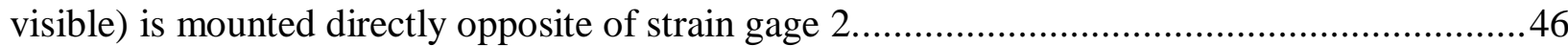

Figure 31. Catapult with mounted strain gages. ..............................................................4 47

Figure 32. Static loading of catapult arm to determine modulus of elasticity..........................48

Figure 33. Stress - strain relationship for catapult arm under axial loading.............................49

Figure 34. LabView VI for obtaining signals in producer-consumer format............................50

Figure 35. MatLab output for raw voltages obtained from LabView......................................51

Figure 36. MatLab output of tangential acceleration, normal acceleration, angular velocity, and angular acceleration with corresponding theoretical results for a catapult pullback angle of $180^{\circ}$ and stopper angle of $125^{\circ}$.

Figure 37. Diagram of unstretching and unchanged portions of rubber band during catapult motion. .53

Figure 38. Residual axial strain study for catapult arm for five catapult launches. .54

Figure 39. MatLab output of axial strain and moment strain with corresponding theoretical results for a catapult pullback angle of $180^{\circ}$ and stopper angle of $125^{\circ}$.....

Figure 40. MatLab output of axial strain, moment strain, angular acceleration, and angular velocity magnitude during the impact, with catapult pullback angle of $180^{\circ}$ and stopper angle of $125^{\circ}$..... .56

Figure 41. Student responses for the MEA projects for Spring quarter. 60

Figure 42. Student responses for HW assignments for Spring quarter.

Figure 43. Responses to the survey question "What did you like about the [VAR]

Project and why?"

Figure 44. Responses to the survey question "What didn't you like about the

[VAR] Project and why?"

Figure 45. MatLab GUI at startup.

Figure 46. Angle dimension for vehicle traveling in southwest direction. The arrow shown in blue represents the direction vector of the vehicle. The red dimension indicates the corresponding angle. F-3

Figure 47. User-input syntax for VAR GUI. F-4

Figure 48. Convention for entering pre-collision velocity. F-5

Figure 49. Convention for entering a pre-collision increase in height F-5 
Figure 50. Convention for entering a pre-collision decrease in height............................. F-5

Figure 51. Convention for entering post-collision velocity. ....................................... F-6

Figure 52. Convention for entering a post-collision change in height. (same as

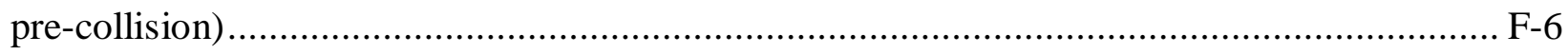

Figure 53. Input window prior to running. ............................................................ F-7

Figure 54. Input window with calculated results. ...................................................... F-8 
Table 1. Roster of MEA team. ........................................................................................

Table 2. Total pre and post DCI scores for all MEA and non-MEA participants. .................... 17

Table 3. Pre and post DCI scores for MEA and non-MEA participants considering only the DCI questions directly related to MEA topic (questions 18 and 20).......................... 18

Table 4. Cases for 2 vehicle collisions where vehicles do not stick together post-

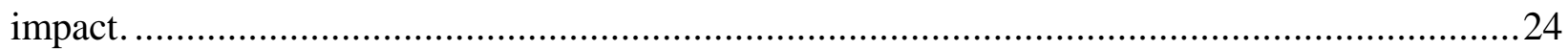

Table 5. Cases for 2 vehicle collisions where vehicles stick together post-impact....................24

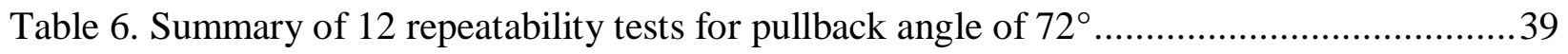

Table 7. Comparison of experimental published value for catapult arm and published elastic modulus for oak.................................................................................. 48

Table 8. Supported cases for 2 vehicle collisions where vehicles do not stick together post-impact

Table 9. Supported cases for 2 vehicle collisions where vehicles stick together post-impact. 


\section{Nomenclature}

\begin{tabular}{|c|c|}
\hline$\alpha$ & angular acceleration \\
\hline$a_{n}$ & normal acceleration \\
\hline$a_{t}$ & tangential acceleration \\
\hline$\varepsilon$ & strain \\
\hline E & elastic modulus \\
\hline$\mu F$ & capacitance (micro-Farad) \\
\hline$F$ & force \\
\hline$H$ & angular momentum \\
\hline$I$ & second moment of inertia \\
\hline$m$ & mass \\
\hline$M$ & moment \\
\hline$\sigma$ & stress \\
\hline$r$ & radius \\
\hline$S_{g}$ & gage factor \\
\hline$t$ & time \\
\hline$v$ & velocity \\
\hline$V$ & voltage \\
\hline$\omega$ & angular velocity \\
\hline
\end{tabular}




\section{Introduction}

The problem solving aspect of engineering classes has always been an emphasis at Cal Poly. With Cal Poly’s “Learn by Doing” philosophy, students are expected to possess fundamental engineering knowledge and design intuition. However, the current coursework assigned to students often omits exercises that nurture real-world analysis. Most textbooks require students to have only a superficial understanding of equations and symbols - without a deep conceptual understanding. By implementing Model Eliciting Activities (MEA) into the Dynamics curriculum, we hoped to enhance student learning and overall student performance.

A Model Eliciting Activity aims to build solid engineering fundamentals for students by requiring them to analyze open-ended scenarios and apply appropriate analysis. Every MEA follows six principles: model construction, reality, generalizablility, self-assessment, modeldocumentation, and effective prototype. By following these principles during problem development, we ensure that students are presented with a realistic client-driven problem which solidifies engineering principles and is applicable towards other situations. Cal Poly is currently responsible for the development of Mechanical Engineering MEAs in NSF CCLI Grant \#0717595: Collaborative Research: Improving Engineering Students' Learning Strategies through Models and Modeling. The overall goals of this grant include expanding MEA usage into more universities and disciplines as well as analyzing the effect of MEAs on student learning. At Cal Poly, we have been working primarily on developing MEAs for use in sophomore and junior level Mechanical Engineering courses. These activities are currently being implemented into some sections of Engineering Dynamics (ME212), Thermodynamics I (ME302), and Thermal System Design (ME440). 
In this paper, I will focus primarily on the Dynamics MEA development within the Mechanical Engineering Department at Cal Poly. In particular, the vehicle accident reconstruction (VAR) and catapult MEAs will be covered in extensive detail. The development of these MEAs constituted a large portion of my work in the MEA research team. This work includes the instrumentation and interface of the catapult, as well as programming of a MatLab GUI (graphical user interface) for the vehicle accident reconstruction MEA.

We propose that adding MEAs to the Cal Poly curriculum does in fact boost student understanding of engineering fundamentals. The MEAs have been evaluated every quarter through student surveys and exam performance. Exam scores indicate a possible increase in student performance in the conceptual areas reinforced with MEAs. Surveys indicate that despite the increased workload, students did in fact enjoy these projects. Because of this positive response, we have been encouraged to further develop the MEAs that will be discussed in this paper. 


\section{Model Eliciting Activities and Cal Poly}

\section{What is an MEA?}

Model Eliciting Activities, which were first started in the mathematics community, are team-based activities which require students to analyze real-world, open-ended problems. Figure 1 highlights the difference between traditional word problems and Model Eliciting Activities. Traditionally, students are asked to solve problems mathematically and apply their solution to the real world. In contrast, MEAs require students to derive mathematical models from realistic situations.

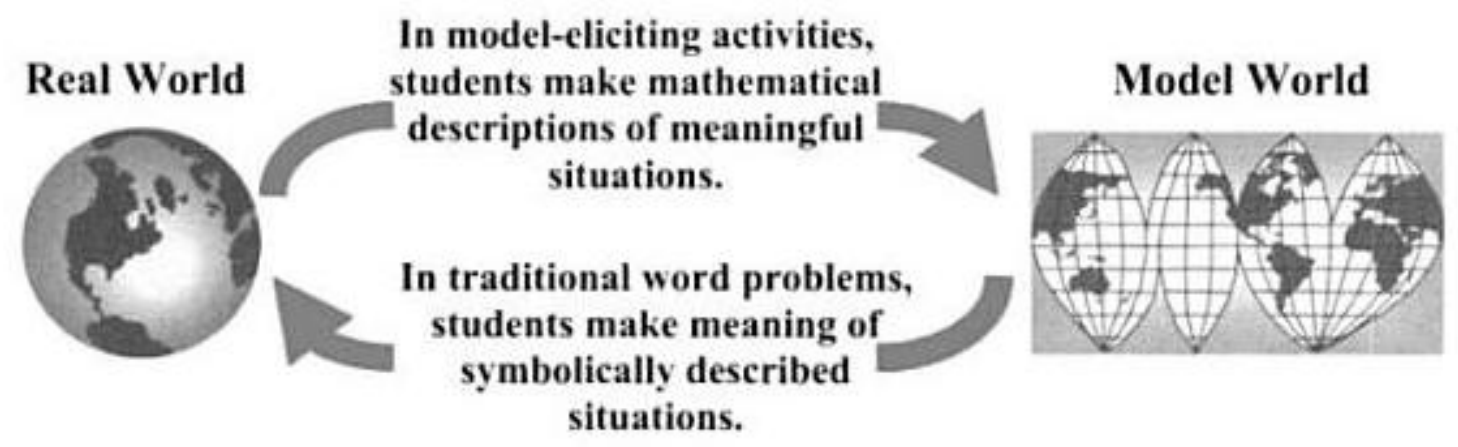

Figure 1. Difference between traditional word problems and Model Eliciting Activities. (Lesh, Beyond Constructivism: Models and Modeling Perspectives on Mathematics 2004, 4)

In a report from the Carnegie Foundation, "Reinventing Undergraduate Education: A Blueprint for American's Research Universities," an academic bill of rights for students is presented. Some of these rights include: “(1) Providing opportunities to learn throughout inquiry rather than simple transmission of knowledge, (2) Training in the skills necessary for oral and written communication, and (3) Preparing students carefully and comprehensively for whatever may lie beyond graduation" (Boyer Commission on Education Undergraduates in the Research University 1998, 12). The goals of MEAs are closely aligned with these rights, and are reflected in its six principles. 
The following are those six principles that every MEA should follow, which provides an instructor's guideline for problem development (Self 2007). Each one of these principles serves to promote a more applicable type of learning for students. These six principles are summarized below:

1. The Model-Construction Principle requires students to develop a mathematical system as a deliverable to an indicated client.

2. The Reality Principle requires the activity to be set in a realistic engineering setting, and allows students to connect their real-world experience to the problem. Students should be allowed and encouraged to make realistic assumptions based on their existing knowledge.

3. The Self-Assessment Principle allows students to evaluate their own work and revise their models accordingly. Students should be encouraged to test their models and improve them for their client. They should also be able to assess when their work is complete.

4. The Model Documentation Principle requires students to carefully detail their process in developing the model. Typically this includes a memo to their client describing a walkthrough of their analysis. This allows both instructors and students alike to see a logical progression of the model, and to see the thought process behind it. From this, instructors can more easily identify any areas of difficulty students have.

5. The Generalizability Principle requires students to develop models that have a value outside of a specific scenario. These models should be easily modified and applicable to similar scenarios outside of the ones that were assigned. 
6. The Effective Prototype Principle requires that the developed models have an intellectual significance and impact on the future professional lives of students. The models should provide for a useful mental foundation to interpret similar situations in the future.

MEAs go beyond the commonly requested numerical answers that are so commonly asked from students. For most problems or exercises that are presented in textbooks, the student is merely required to reproduce a brief answer to a question that was formulated by others (Lesh, Handbook of Research Design in Mathematics and Science Education 2000, 594). This results in only a superficial understanding of the material - the student disregards his process and focuses instead on if his answer was correct.

\section{Difference between MEAs and Traditional Assignments}

Instead of basing learning on the "correctness" of the final answer, MEAs require students to focus on the method that they use to arrive at their solution. The description, explanations, and constructions are not simply processes that students go through in order to produce final answer - they are the most important aspect of their analysis (Lesh, Beyond Constructivism: Models and Modeling Perspectives on Mathematics 2004). Since these activities are also team based, students are also exposed to working in small groups. In this team environment, students are expected to eloquently share their ideas with other members, and work cohesively to produce a working model.

As will be discussed in further detail later in the paper, the VAR and catapult MEAs were evaluated not primarily on correctness of a student team's final answer, but on the thought process that they carefully documented through the project. By requiring careful model documentation, we were able to more easily identify student misconceptions - allowing instructors to allocate more time to areas of student difficulty. 


\section{History of MEAs}

The concept of Model Eliciting Activities is not a new one - problem based learning (PBL) has existed since the 1960s, and has garnered much support from educators. A PBL is defined as "an instructional learner-centered approach that empowers learners to conduct research, integrate theory and practice, and apply knowledge and skills to develop a viable solution to a defined problem" (Savery 2006). Problem based learning shares a great number of similarities with MEAs. These similarities include realistic problems, open-ended tasks, higher order thinking, self-directed learning, self-assessment, group work, and structure of the problems (Chamberlin 2008).

Because of these similarities, several parallels can be drawn from PBL to MEAs. Although the large variations in the practicing of PBLs make the analysis of its effectiveness difficult, one of the most widely accepted findings is that PBL promotes positive student attitudes (Prince 2004). In our own experience, we have found that student attitudes and performance have been improved by implementing MEAs at Cal Poly. In addition to this positive benefit on students, MEAs set forth a solid structural framework, which is used as criteria for instructors to develop new MEAs. Although not much data on MEA effectiveness is currently available, this framework provides a unified guideline so that MEAs across universities can be compared. In this manner, correlations between student performance and MEA implementation can be more easily drawn. 


\section{Research Team}

The Cal Poly MEA research team is part of a four-year effort by a team of researchers from seven universities. These researchers utilize previous mathematics MEA development as a foundation for undergraduate STEM curriculum and assessment for engineering (Self 2007). At Cal Poly, the goal is to develop new Mechanical Engineering MEAs for implementation into either laboratory activities or in-class projects.

The MEA research team at Cal Poly currently consists of a combination of professors and students. The past and current participants are listed in the following table. Every week the MEA team met to discuss future and present MEAs. This entailed discussing the implementation of current projects, student difficulties, and potential future projects.

Table 1. Roster of MEA team.

\begin{tabular}{|c|c|c|c|}
\hline & & \multicolumn{2}{|c|}{ Academic Year } \\
\hline Name & Position & $2007-2008$ & $2008-2009$ \\
\hline Brian Self & Professor & Fall, Winter, Spring & Fall, Winter, Spring \\
\hline Andrew Kean & Professor & Fall, Winter, Spring & Fall, Winter, Spring \\
\hline Jim Widmann & Professor & & Fall, Winter \\
\hline Lawrence Fong & Graduate Student & & $\begin{array}{l}\text { Fall, Winter, Spring, } \\
\text { Summer }\end{array}$ \\
\hline Teresa Ogletree & Undergraduate Student & Summer & Fall, Winter \\
\hline Lora Powers & Undergraduate Student & & Fall, Winter \\
\hline Frank Schreiber & Undergraduate Student & Spring & Fall, Winter, Spring \\
\hline Annamarie Usher & Undergraduate Student & & Spring \\
\hline Rosalie Mangione & Undergraduate Student & & Spring \\
\hline
\end{tabular}




\section{Cal Poly and MEAs}

NSF CCLI Grant \#0717595 lists Cal Poly as the prime on developing Model Eliciting Activities for Mechanical Engineering. This entails developing MEAs in common disciplinary topics such as fluids, thermodynamics, energy conversion, heat and mass transfer, mechanics, and structural analysis, in addition to machine design (Self 2007). Of these possible topics, we chose to start with ME212, because it has a very broad engineering student population and is also a very problematic class in terms of fail rate.

It is also one of the most demanded classes - up to 9 sections of over 30 students each are taught each quarter. Nearly all engineering majors are required to take ME212 during their career at Cal Poly, resulting in a very diverse group of students within each class. Future MEA developments are also targeted at these sophomore-level courses because they have a broad audience and can be easily distributed to other engineering universities for use in their curriculum. At Cal Poly, the MEAs we have generated have followed this basic structure:

\section{Instructor Provides:}

- Some background information is provided using a current news excerpt or headline. This makes students understand the significance of their efforts and allows them to put their analysis into a real-world context.

- A client requests the students to develop a procedure for solving a particular engineering issue. This is typically set in a professional tone - using a company memo.

\section{Student Provides:}

- Detailed methodology to solve the engineering problem.

- Supporting calculations to demonstrate the application of their engineering process.

- Summary in memo format. 


\section{MEAs in Cal Poly Dynamics Courses}

Cal Poly lists ME212, "Engineering Dynamics", as a course which focuses on the concepts of velocity, acceleration, relative motion, work, energy, impulse, and momentum. As mentioned previously, MEAs were first implemented in this class because of its high failure rate and broad student population. In Cal Poly's quarter system of 10 weeks, students often struggle to fully understand each of these concepts - resulting in poor performance. Some professors indicate failure rates of approximately $15-30 \%$.

Instructors from other universities also observed this problem and attempted to combat it in different ways. For example, in Worchester Polytechnic Institute in Massachusetts, instructors integrated the use of LEGO ${ }^{\circledR}$ kits into an introductory Dynamics course. Students were required to develop models to describe the kinematics and kinetics of a linkage. Since a major difficulty of learning Dynamics is caused by the lack of a physical model, this hands-on approach was seen as a great tool for learning (Jolley 2003).

Another example is Grand Valley State University's catapult-design contest. Here, students were required to design and build a catapult to clear a vertical height and hit a target at a specified distance (Reffeor 2002). This required selection of materials, springs, and associated calculations. Shown in Figure 2 is a student-built catapult from the competition. 


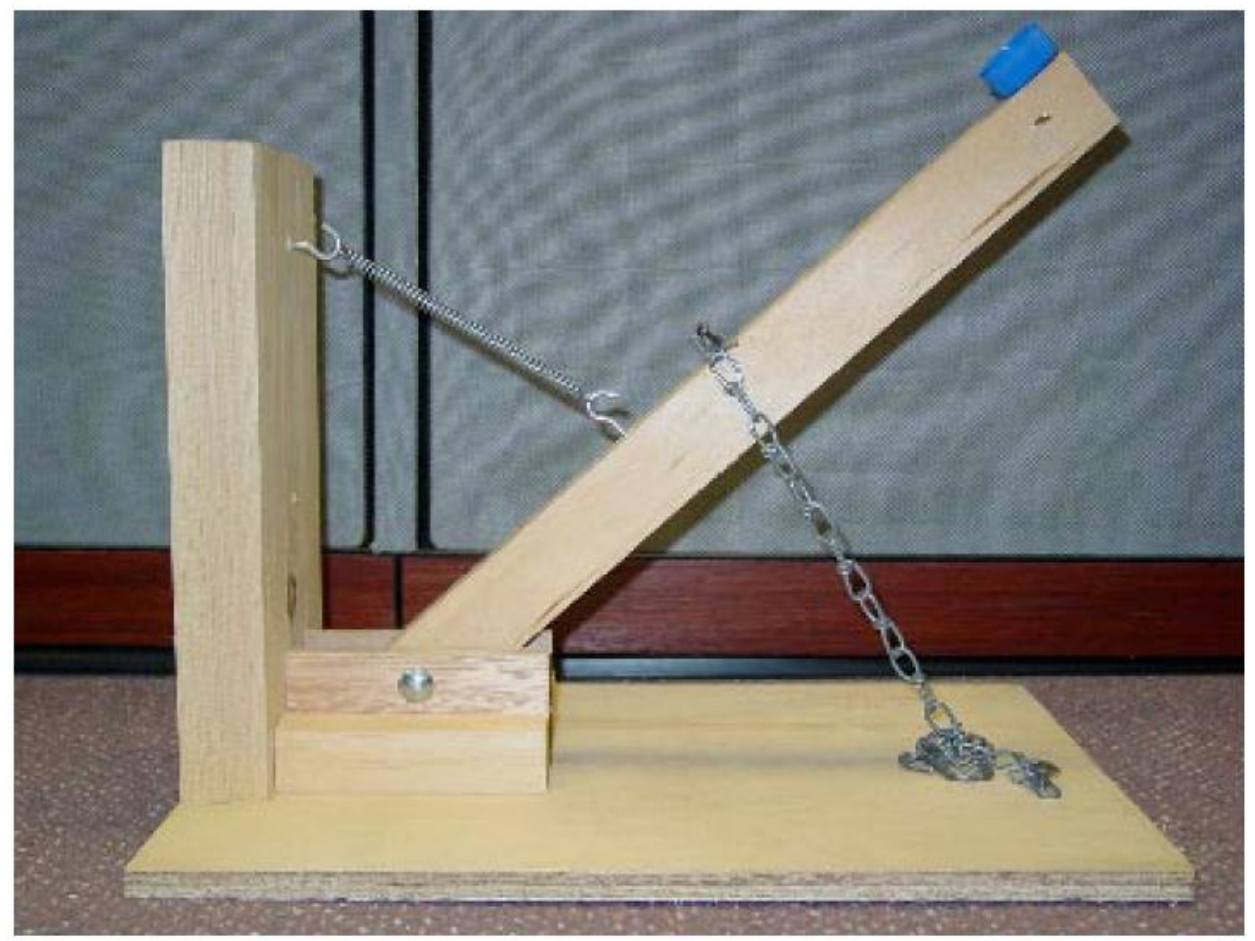

Figure 2. Catapult built by Grand Valley State University students.

Students at Grand Valley were critiqued on the correlation between their theoretical predictions and the actual results. As will be discussed in the Catapult section, the Catapult MEA at Cal Poly was similar to this project. However instead of requiring students to actually build the catapult, we instead focused on the development of the theoretical model and the comparison to the physical results. We have found that MEAs can be very time intensive, so simpler MEAs that convey the same idea can be beneficial to students and teachers alike. In this manner, more subject matter can be taught with a wider variety of projects.

Our overall goal was to motivate students by providing a realistic project with the VAR MEA and a very hands-on project with the Catapult MEA. By doing so, we hoped to see increased student performance and willingness to learn. 


\section{Vehicle Accident Reconstruction}

Application of momentum principles is one of the fundamental concepts introduced in early physics courses, and solidified in ME212. Because of students' previous exposure to the topic of momentum, and its direct applicability toward real-world scenarios, we developed an MEA to further solidify this concept with students.

The vehicle accident reconstruction project (VAR) was the first MEA that was developed by the research team at Cal Poly. During the fall quarter of 2008, with the newly assembled team, the VAR MEA was refined and assigned to the first dynamics class. The client of this MEA was a Sri Lanka police station which was developing an investigation protocol to determine fault in vehicular collisions. We chose this particular context in the hopes that it would capture the interest of students by including engineering analysis with a meaningful social impact.

Listed in the following figures are the background information and memorandum handouts given to students. The background information serves to provide students with preliminary information, pertinence to current events, and importance of their analysis. The memorandum presents a client-driven problem in a professional tone - setting up students to appropriately develop their model. 


\section{$\underline{\text { Background: }}$}

\section{Vehicle Accident Reconstruction Project}

* Sri Lanka Police Department plans to set up police stations in recently captured areas

Saturday, September 13, 2008, 6:23 GMT, ColomboPage News Desk, Sri Lanka.

Sept 13, Colombo: Sri Lanka Police Department has planned to set up police stations in recently captured areas and the territories to be freed from Tamil Tiger rebels, police chief, Inspector General Jayantha Wickramarathna announced.

The Police chief said that a large number of new police officers would be needed to man these new police stations that would be set up from Mannar to Mullaitivu. New recruitment has already commenced amidst positive response from the society, he said. The Inspector General of Police revealed these facts at a function held in Colombo yesterday to launch a programme to improve the productivity of the police service by 2009

\section{Excerpt from Introduction to Forensic Engineering by Randal Noon Vehicle Accident Reconstruction}

The reconstruction of vehicle accidents can be a very difficult task. In most cases, the engineer will be asked to reconstruct the events of an accident long after the accident has occurred. Sometimes, the actual accident scene will be prohibitively far away from the engineer or will have changed by the time he is given the reconstruction assignment.

Relying upon the often conflicting information provided by witnesses or the accident participants can be confusing and misleading. Often, the witnesses will report their own conclusions and opinions instead of objective observations; sometimes the accident participants will knowingly or unknowingly lie about the events. Under these circumstances, obtaining factual information with which to work can be trying.

However, the engineer will usually have the following reasonably objective information available to him at the outset:

1. The police accident report. The police report will contain the usual basic Identification information of the accident participants. It will also note the position of the vehicles after the accident as found by the police, the location of skid marks, the point of impact, the general layout of the scene, weather and conditions data, and the general travel pattem of the vehicles before the accident.

2. Photographs of the damaged vehicles. This is usually available from the insurance companies involved or their adjuster agents. They are used in evaluating insurance compensation to the accident participants.

The engineer may be asked to provide information or opinions about many aspects of the case, including some that are not related to the mechanical collision events. However, the engineer is nearly always asked to determine the initial velocities of the vehicles.

As discussed in the attached memo, your team will solve two different accident scenarios and provide a step-by-step approach for accident reconstruction. Upload a draft step-by-step approach to the Digital Dropbox on Thursday, April $23^{\text {rd }}$ by 5PM. At that time, two new scenarios will be posted. You will then apply your step-by-step approach to solve these accidents. Your final tum-in with an analysis of all four accidents, your step-by-step procedure (which can be modified from your Thursday submission) and you cover memo are due on Monday, April $27^{\text {th }}$.

Figure 3. Background information provided for VAR MEA. 


\title{
Memorandum
}

\author{
To: Forensic Engineering Team \\ From: H. M. B. G. Kotakadeniya, Senior Deputy Inspector General of Police, \\ Sri Lanka Police Service \\ RE: Traffic Accident Reconstruction Protocol \\ Priority: [Urgent]
}

Since 2003 your country has been providing ascistance toward development and economic ctabilization here in Sri Lanka. Relations have gotten even closer with the invaluable help we received following the devactating tcunami in 2004. As a recult, we have been able to become an important figure in the fight againet terror in South-Central Asia.

As you may already know, the Sri Lanka Police Service has recently launched a new programme to update and modernize the cervice we provide to the public. One key area for improvement is in the Traffic Police Division. This division was establiched in 1953 to ascist in making decisione on traffic policies and implementing them. Every currently existing ctation maintains a traffic branch, but the growing number of drivers on the island and our intention to build new ctations demand that we immediately improve our accident invectigation protocol. I am charging you with the task of compiling a new cet of forensic engineering guidelines that can be used in this divicion.

At the moment the main focus of this task is to develop a procedure for determining if a driver hac violated the epeed limit. Our officers must often decide whether a percon may have been speeding immediately after they are called to the scene of an accident. We need to have a ctep-by-step procedure for the investigator to use when he/she arrives at the scene of an accident. Please include parameters that the officer chould record, as well a $\varepsilon$ an easy-to-uce guide on calculating an ectimate of the initial speeds of the vehicles involved. In addition to this step-by-step accident invectigation protocol, please provide me a cover memo deccribing your overall approach.

My officers will provide you a set of two abridged incident reports that are characteristic of typical accidents that we regularly investigate - please refer to our online cite on April 18, 2009 for these reports. For legal reacons, sections of the reports have been omitted and the names of those involved have been replaced. In each report you will find a general description of the accident followed by more detailed information pertaining to poscibly relevant parameters in the accident. In your cover memo, please discuse your conclusions regarding these two accidente and any additional incidents that my officers may forward to you (detailed analysis can be provided in an appendix).

I am confident that your team will exceed our expectations.

A. Rotatadiong

H. M. B. G. Kotakadeniya

Figure 4. Memorandum provided for VAR MEA.

The main deliverable from the VAR project was a tool for police officers to determine if vehicles were violating posted speed limits prior to collisions. With the help of Teresa Ogletree's father, who was a police officer, we were able to provide problem statements in the form of 
actual police reports. Students were first presented with two out of the four cases. With these two cases, they developed a generalizable model to determine which vehicle was "at fault" for each collision. Students then applied their model to two more scenarios. They could then refine their models to adequately represent the new cases if anything was previously lacking. This resulted in a model that was not only applicable to certain cases, but to crashes in general. Figure 5 shows an example of one of the cases, while all of the cases are attached in Appendix A through Appendix E

While applying their models to each case, students were required to provide a detailed explanation of all equations, assumptions, and procedures used. This allowed the MEA team to easily follow their thought processes, and to identify any common mistakes.

Most students provided a typed sheet with a method to determine pre-crash velocities. However, some students decided to use MatLab scripts or Excel spreadsheets. 

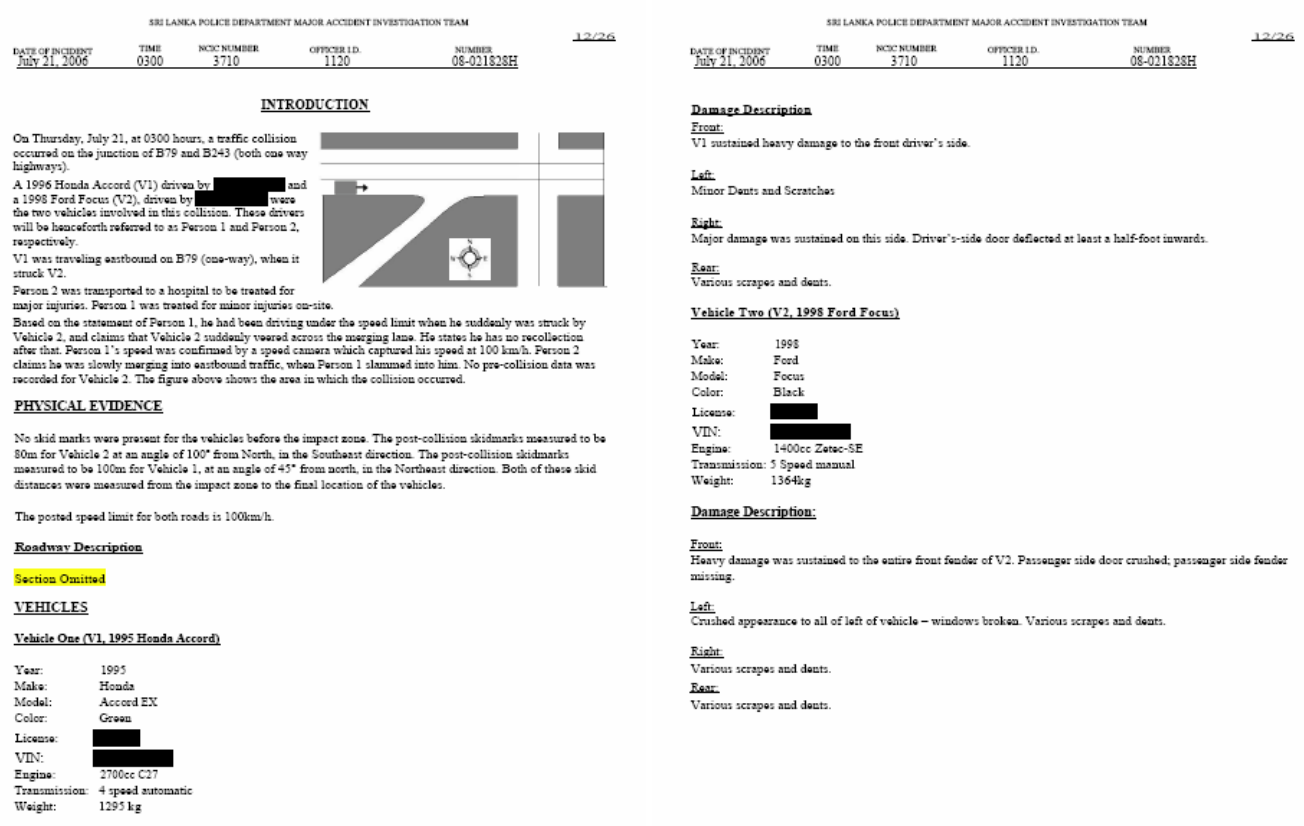

Figure 5. One of the cases assigned for the VAR MEA.

The main purpose of the VAR project was to provide a meaningful exercise for students to use impulse-momentum and work-energy principles. One of the most common student misconceptions is applying the conservation of mechanical energy through an impact. Through the VAR project, we hoped that students would recognize that they should instead apply momentum principles to find initial velocities. As will be discussed, they seemed to have a better understanding of momentum and impact principles after completing the MEA.

\section{Changing student misconceptions}

In order to gage the effectiveness of the VAR project, we compared the Dynamics Concepts Inventory (DCI) scores from classes that used the project versus classes that did not. The Dynamics Concepts Inventory is a set of 29 conceptual multiple choice questions related to 
the fundamental concepts presented in the Dynamics course (Gray 2005). The following statistics are taken from "Is There a Correlation between Conceptual Understanding and Procedural Knowledge in Introductory Dynamics.” Lora Goodwin, a member of our research team, submitted this paper to the 2009 ASEE PSW conference (Goodwin 2009). The following table displays the DCI performance of students that have been exposed to MEAs in their coursework along with those who had not. 
Table 2. Total pre and post DCI scores for all MEA and non-MEA participants.

\begin{tabular}{|c|c|c|c|c|c|c|}
\hline & $\mathbf{N}$ & Value & $\begin{array}{c}\text { Pre DCI } \\
\text { Results } \\
{[\%]}\end{array}$ & $\begin{array}{c}\text { Post } \\
\text { DCI } \\
\text { Results } \\
{[\%]}\end{array}$ & $\begin{array}{c}\text { Overall } \\
\text { Average } \\
\text { Normalized } \\
\text { Gain } \\
{[\%]}\end{array}$ & $\begin{array}{c}\text { Overall } \\
\text { Average } \\
\text { Percent } \\
\text { Improvement } \\
\text { [\%] }\end{array}$ \\
\hline \multirow{3}{*}{$\begin{array}{l}\text { MEA in } \\
\text { Coursework }\end{array}$} & \multirow{3}{*}{149} & Mean & 29.85 & 49.97 & \multirow{3}{*}{29.6} & \multirow{3}{*}{20.11} \\
\hline & & Median & 27.59 & 48.28 & & \\
\hline & & Standard Deviation & 14.55 & 17.20 & & \\
\hline \multirow{3}{*}{$\begin{array}{l}\text { No MEA's in } \\
\text { Coursework }\end{array}$} & \multirow{3}{*}{80} & Mean & 32.97 & 46.64 & \multirow{3}{*}{21.1} & \multirow{3}{*}{13.66} \\
\hline & & Median & 31.03 & 44.83 & & \\
\hline & & Standard Deviation & 14.19 & 18.33 & & \\
\hline
\end{tabular}

As shown in Table 2, a higher normalized gain is present for students that had been assigned MEAs in their coursework. However, to highlight the effect of the VAR MEA itself, the two questions from the DCI relating to impact and momentum were studied. The questions are shown in the following figures.

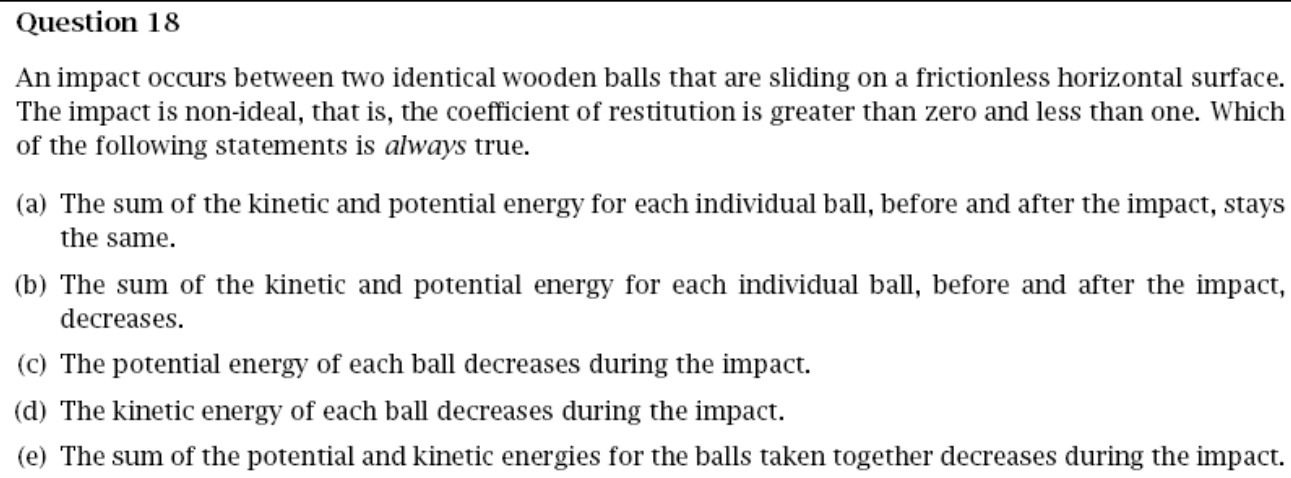

(a) The sum of the kinetic and potential energy for each individual ball, before and after the impact, stays the same.

(b) The sum of the kinetic and potential energy for each individual ball, before and after the impact, decreases.

(c) The potential energy of each ball decreases during the impact.

(d) The kinetic energy of each ball decreases during the impact.

(e) The sum of the potential and kinetic energies for the balls taken together decreases during the impact.

Figure 6. Question 18 of the DCI testing students' understanding of an impact. 


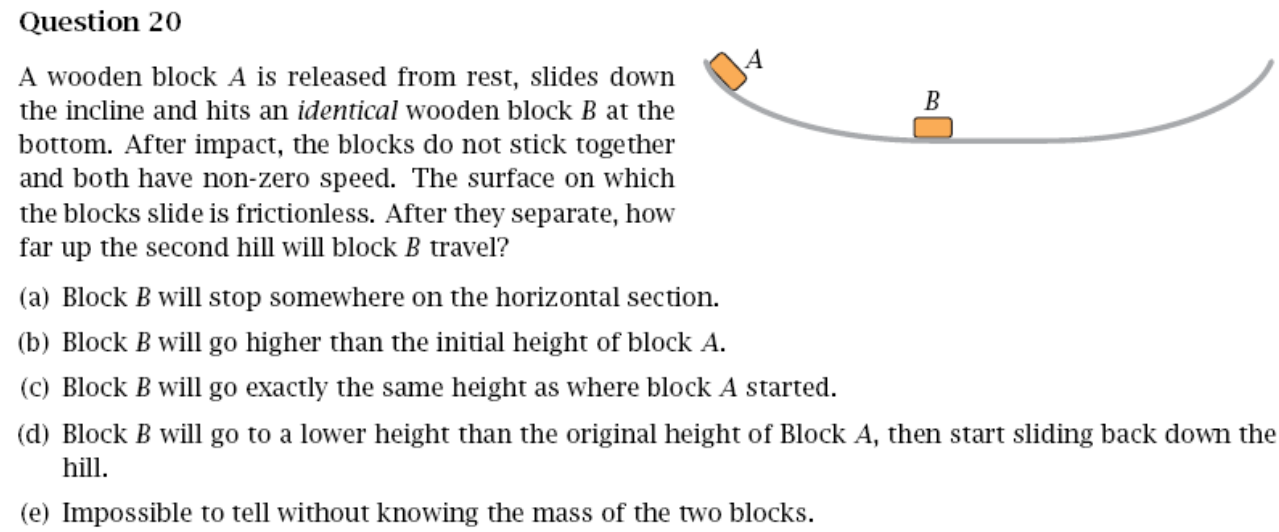

(a) Block B will stop somewhere on the horizontal section.

(b) Block $B$ will go higher than the initial height of block $A$.

(c) Block $B$ will go exactly the same height as where block $A$ started.

(d) Block $B$ will go to a lower height than the original height of Block $A$, then start sliding back down the hill.

(e) Impossible to tell without knowing the mass of the two blocks.

Figure 7. Question 20 of the DCI testing students' understanding of an impact.

Table 3 highlights the performance on DCI questions 18 and 20. Students who had MEAs in their coursework had an average normalized gain of $41.1 \%$, compared to $14.8 \%$ for students with no MEAs in their coursework. One can conclude that the MEAs did, in fact, have a significant performance on the topic covered.

Table 3. Pre and post DCI scores for MEA and non-MEA participants considering only the DCI questions directly related to MEA topic (questions 18 and 20).

\begin{tabular}{|l|c|c|c|c|c|}
\cline { 2 - 5 } & \multicolumn{1}{c|}{$\begin{array}{c}\text { DCI } \\
\text { Question } \\
\text { Number }\end{array}$} & $\begin{array}{c}\text { Mean } \\
\text { DCI Pre } \\
\text { Score } \\
{[\%]}\end{array}$ & $\begin{array}{c}\text { Mean } \\
\text { DCI Post } \\
\text { Score } \\
{[\%]}\end{array}$ & $\begin{array}{c}\text { Normalized } \\
\text { Gain } \\
{[\%]}\end{array}$ & $\begin{array}{c}\text { Average } \\
\text { Normalized } \\
\text { Gain } \\
{[\%]}\end{array}$ \\
\hline \multirow{2}{*}{ MEA in Coursework } & Q 18 & 26.7 & 45.6 & 25.74 & \multirow{2}{*}{41.1} \\
\cline { 2 - 5 } $\begin{array}{l}\text { No MEA's in } \\
\text { Coursework }\end{array}$ & Q 20 & 47.6 & 77.2 & 56.48 & \multirow{2}{*}{14.8} \\
\cline { 2 - 5 } & Q 18 20 & 19.1 & 32.2 & 16.18 & \\
\hline
\end{tabular}


Table 2 shows overall student performance on the entire DCI. Students with MEAs in coursework still had a higher overall average normalized gain than those without MEAs in coursework. However, when compared to the normalized gain only for questions 18 and 20 shown in Table 3, the gain is much smaller. This shows that students performed much better on the concepts that did have MEA reinforcement.

\section{VAR Time Commitment}

One of the greatest challenges for implementing the VAR project was the time involved for both the teachers and the students in the MEA team. Developing the problem cases required producing a new solution for every new case. Because the assignments were modified for each quarterly ME212 class, this required making a new solution set every time the VAR was assigned.

Contrary to Scott Chamberlin's “How Does the Problem Based Learning Approach Compare to the Model-Eliciting Activity Approach in Mathematics?" we found that the implementation time of the VAR MEA took significantly longer than his stated " $1-2$ hours required". However, Chamberlin's interpretation of the time allotted for MEAs may not be applicable to the engineering environment since engineering MEAs that we have developed were much more complex. For example, some MEAs that require only a basic statistical analysis can be conducted in less than a single class period. However, in our case, students and instructors must dedicate much more time deriving and interpreting these models. For the VAR MEA, students worked several hours outside of the allotted lecture period, and the research team spent over twenty hours grading approximately forty turn-ins. 


\section{VAR MatLab Development}

In order to reduce some of this workload for instructors, I developed a MatLab code that would automatically solve for pre-collision velocities. By having this program available, we could easily change the parameters of our VAR cases and instantly have a supporting solution. It also greatly aided in the development of new cases - we could check and modify values to yield realistic solutions. The MatLab program and supporting user guide are shown in Appendix $\mathrm{F}$ and Appendix G. The overall goal was to have an easy-to-use program for the VAR MEA development, which could be distributed to universities that were interested in using our MEAs. Because of this, the program was revised and rewritten several times to promote ease of use.

The first version of the VAR MatLab program was a line-by-line user input script. The input-window version is shown in Figure 8 below. Although functional, this line-by-line script lacked the amount of functionality I wanted for a program that would be distributed to a range of universities. It proved very cumbersome for the team when we attempted to use it to solve our own cases. Another large issue we encountered was that when we made any error in typing values in, we were unable to correct our changes - instead we had to terminate the program and reenter all the parameters again. 


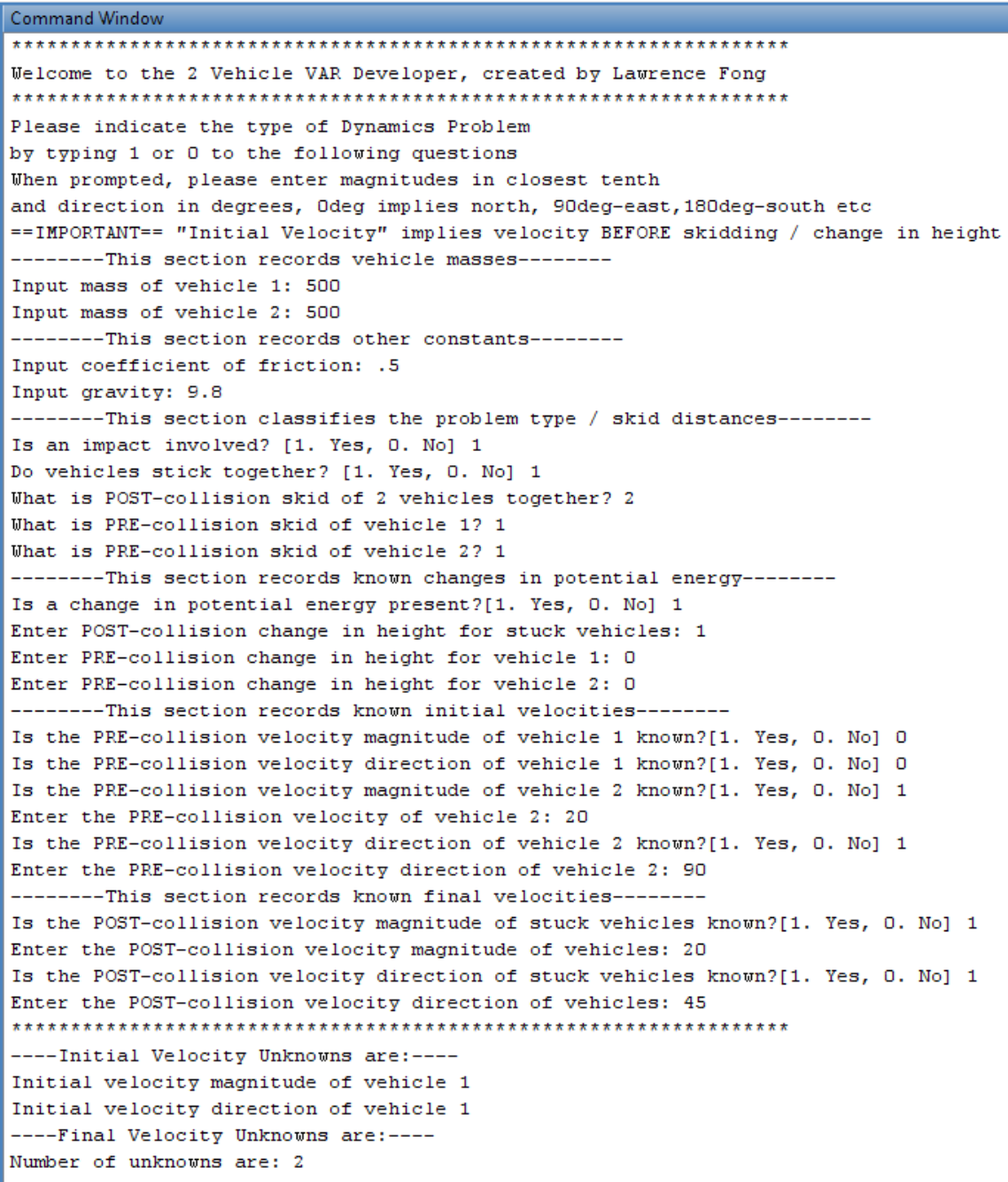

Figure 8. Input-window for VAR development program.

\section{Because of these issues, I decided to reprogram the script into a GUI format. Although}

the code itself became a bit more cluttered, a GUI was far more intuitive to use. Revision 5 of

the MatLab GUI is shown in Figure 9. This program allowed testing of VAR cases much more quickly - errors could be corrected easily, and all parameters could be inputted before the calculation code executed. 


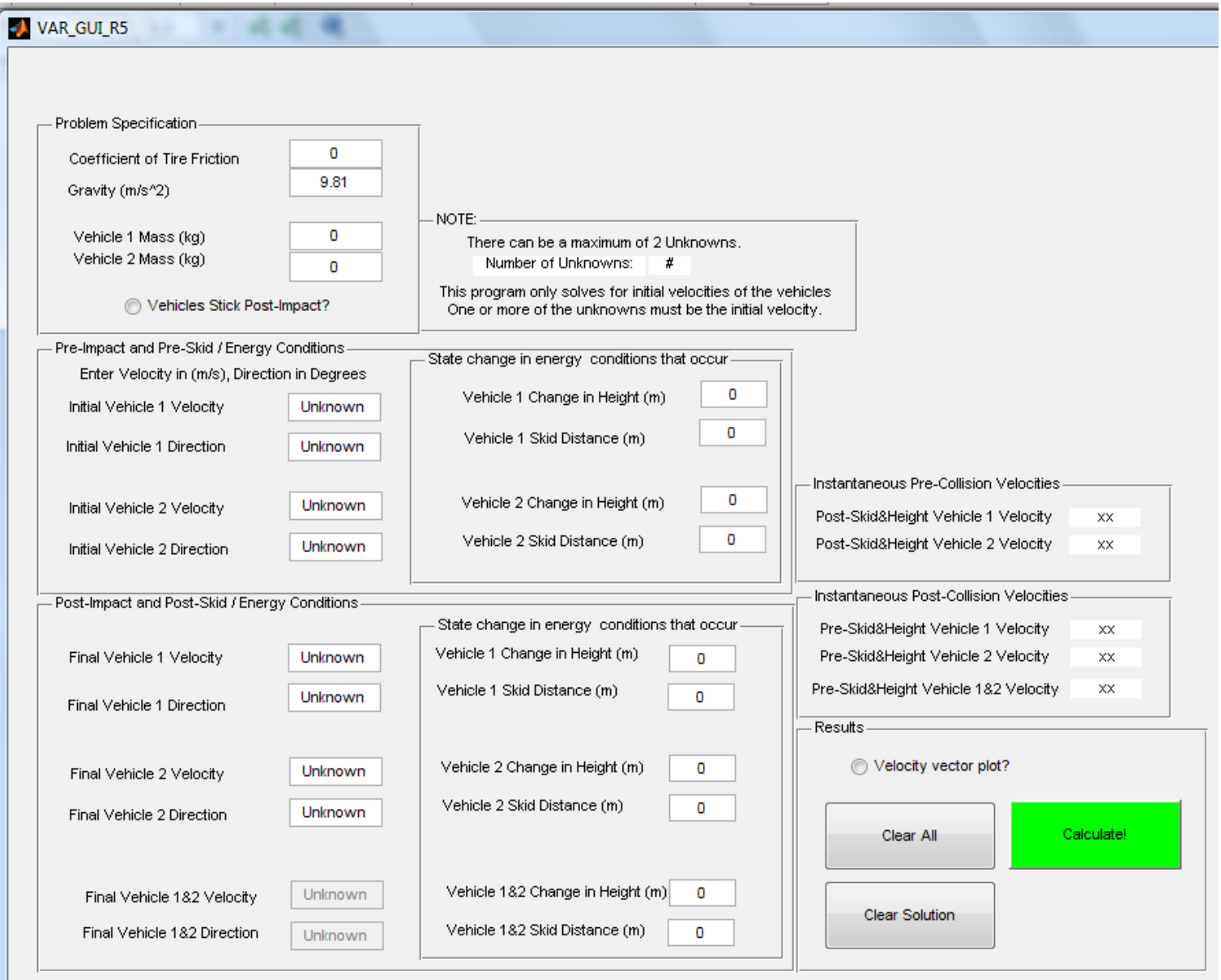

Figure 9. MatLab GUI for VAR MEA development.

Figure 10 shows the output of the GUI program when the velocity vector plot is requested as an output. This vector plot indicates the instantaneous velocities immediately before and after an impact. In the case shown in the figure, vehicle 1 is traveling northbound, while vehicle 2 is traveling eastbound. The two vehicles collide and stick together, resulting in a postcollision velocity in the northeast direction. 


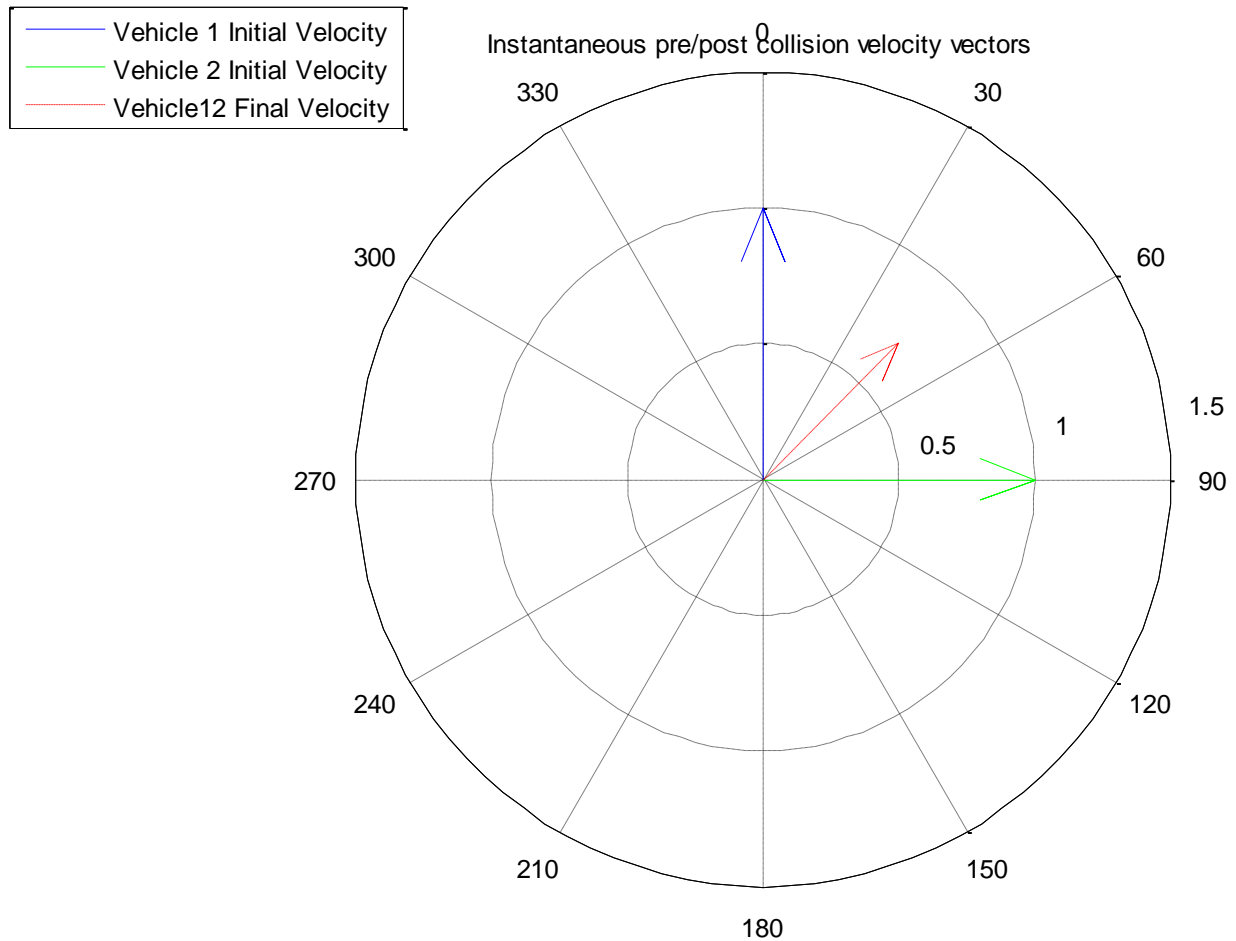

Figure 10. Velocity vector plot for instantaneous pre and post collision velocities, generated with the GUI.

\section{VAR Cases}

The VAR cases were broken down into several cases for MatLab to properly solve.

MatLab has the capability of solving systems of equations using an add-in called "Symbolic Toolbox". However, I tried to avoid using any plug-ins when programming these cases so that all universities with a normal version of MatLab could use this program.

The crash scenarios were broken down into the cases shown in Table 4 and Table 5. Note that whenever possible, cases were consolidated for both post collision stick and non-stick conditions. A "stick" scenario is defined as two vehicles joining together post-collision to form a single mass - an inelastic collision. A "non-stick" scenario is defined as the two vehicles having independent masses and velocities post-collision. The equations used for solving the "stick" and "non-stick" collisions are shown in equations (1) and (2), respectively. 
Table 4. Cases for 2 vehicle collisions where vehicles do not stick together post-impact.

\begin{tabular}{|c|c|c|c|c||c|c|c|c|}
\cline { 2 - 9 } \multicolumn{1}{c|}{} & \multicolumn{3}{c||}{ Pre-Collision } & \multicolumn{3}{c|}{ Post-Collision } \\
\cline { 2 - 10 } \multicolumn{1}{c|}{} & \multicolumn{2}{c|}{ V1 } & \multicolumn{2}{c|}{ V2 } & \multicolumn{2}{c|}{ V1 } & \multicolumn{2}{c|}{ V2 } \\
\hline Case & Mag & Dir & Mag & Dir & Mag & Dir & Mag & Dir \\
\hline \hline A & 1 & 1 & 0 & 0 & 1 & 1 & 1 & 1 \\
\hline G & 1 & 1 & 0 & 1 & 1 & 1 & 1 & 0 \\
\hline D & 1 & 1 & 0 & 1 & 1 & 1 & 0 & 1 \\
\hline F & 1 & 0 & 0 & 1 & 1 & 1 & 1 & 1 \\
\hline C & 0 & 1 & 0 & 1 & 1 & 1 & 1 & 1 \\
\hline E & 1 & 1 & 0 & 1 & 1 & 1 & 1 & 1 \\
\hline
\end{tabular}

Table 5. Cases for 2 vehicle collisions where vehicles stick together post-impact.

\begin{tabular}{|c|c|c|c|c||c|c|}
\cline { 2 - 7 } \multicolumn{1}{c|}{} & \multicolumn{3}{c||}{ Pre-Collision } & \multicolumn{2}{c|}{ Post-Collision } \\
\cline { 2 - 7 } \multicolumn{1}{c|}{} & \multicolumn{2}{c|}{ V1 } & \multicolumn{2}{c|}{ V2 } & \multicolumn{2}{c|}{ V12 } \\
\hline Case & Mag & Dir & Mag & Dir & Mag & Dir \\
\hline \hline A & 1 & 1 & 0 & 0 & 1 & 1 \\
\hline B & 1 & 1 & 0 & 1 & 0 & 1 \\
\hline G & 1 & 1 & 0 & 1 & 1 & 0 \\
\hline F & 1 & 0 & 0 & 1 & 1 & 1 \\
\hline C & 0 & 1 & 0 & 1 & 1 & 1 \\
\hline E & 1 & 1 & 0 & 1 & 1 & 1 \\
\hline
\end{tabular}

$$
\begin{gathered}
m_{1} \overline{v_{1 i}}+m_{2} \overline{v_{2 i}}=m_{12} \overline{v_{12 f}} \\
m_{1} \overline{v_{1 i}}+m_{2} \overline{v_{2 i}}=m_{1} \overline{v_{1 f}}+m_{2} \overline{v_{2 f}}
\end{gathered}
$$

For all the cases, one of the unknowns was an initial velocity magnitude - as this was the most important criteria for students to determine fault in the accident scenarios. Except for case E, which has 1 unknown, every case has 2 unknowns to avoid overdefining the problem. Case E is a head-on collision, therefore only 1 unknown is allowed. Table 4 and Table 5 illustrate the known and unknown parameters of the problem indicated by " 1 " and " 0 ", respectively. For example Case A, shown in Figure 11 and Figure 12, would be a crash scenario where magnitude 
and direction of one vehicle's initial velocity are unknown, while all the other pre and post collision velocities are known.

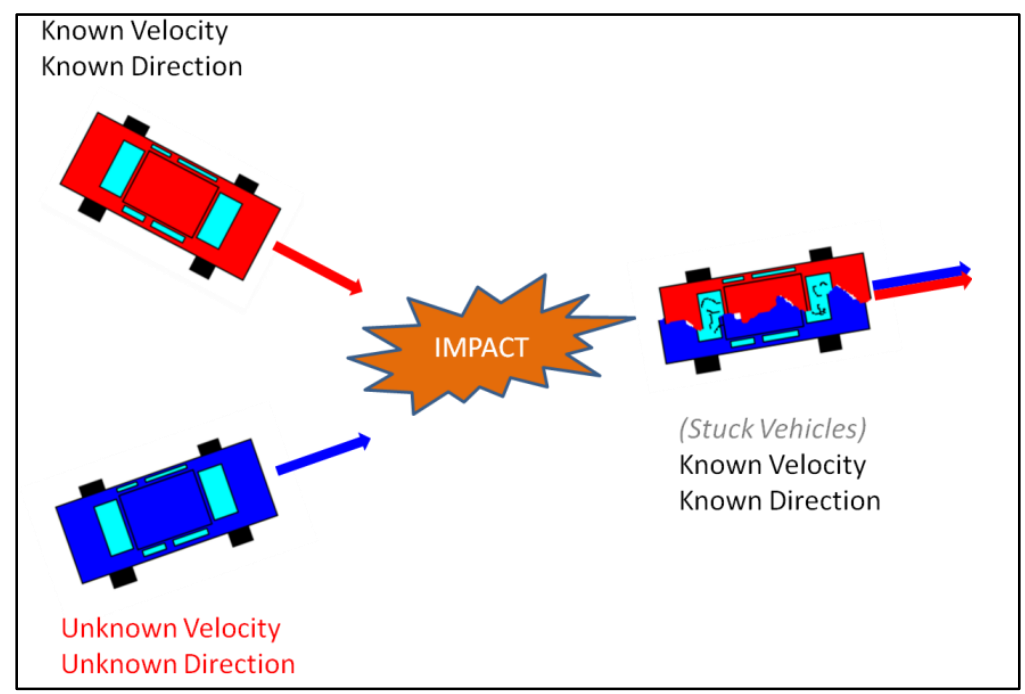

Figure 11. Case A for stick collision.

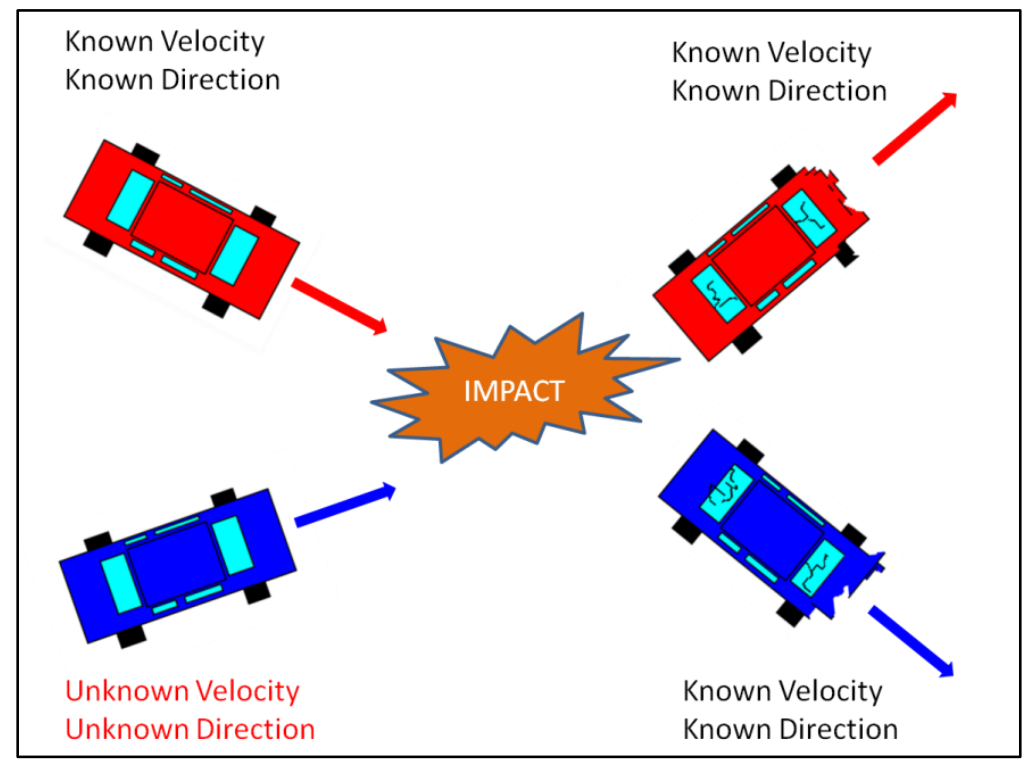

Figure 12. Case A for non-stick collision.

All of the cases, except for G and F, were solved analytically, which produced an exact result. Case A and Case E were easily solved algebraically, using equations (1) and (2). 
However, cases B, C, and D were more calculation intensive, although they were still solved in algebraic form. While attempting to solve by hand, I obtained results that were algebraically correct, but had divide-by-zero errors when implementing them into the MatLab code. This could have been due to the equations not being in the most simplified form. Therefore, I utilized the symbolic toolbox to solve for the corresponding equations for these cases, in their simplest form. These equations were then implemented into the MatLab program. Note that although symbolic toolbox was used to solve for the equations, it was not used in the GUI program itself the symbolic toolbox add-in is not required to run the program. The supported MatLab derivations are shown in Appendix $\mathrm{H}$.

Cases $\mathrm{G}$ and F, highlighted in blue in Table 4 and Table 5, had to be solved iteratively since the unknown variable could not be isolated by itself. This iteration was done by guessing for the unknown direction, solving for the velocities, and checking conservation of momentum within a certain percent error. Because of this, the produced solution was an approximate answer. The initial convergence criteria for initial and final momentum convergence in the $\mathrm{x}$ and $\mathrm{y}$ direction was $0.01 \%$. However, if the solution did not properly converge, the iteration code relaxed the criteria in two stages. The first stage "relaxed" convergence criteria used $1 \%$ between the final and initial momentum, in both directions. The second stage used $2 \%$. If neither of these criteria were met, the code exited out, producing an error. 


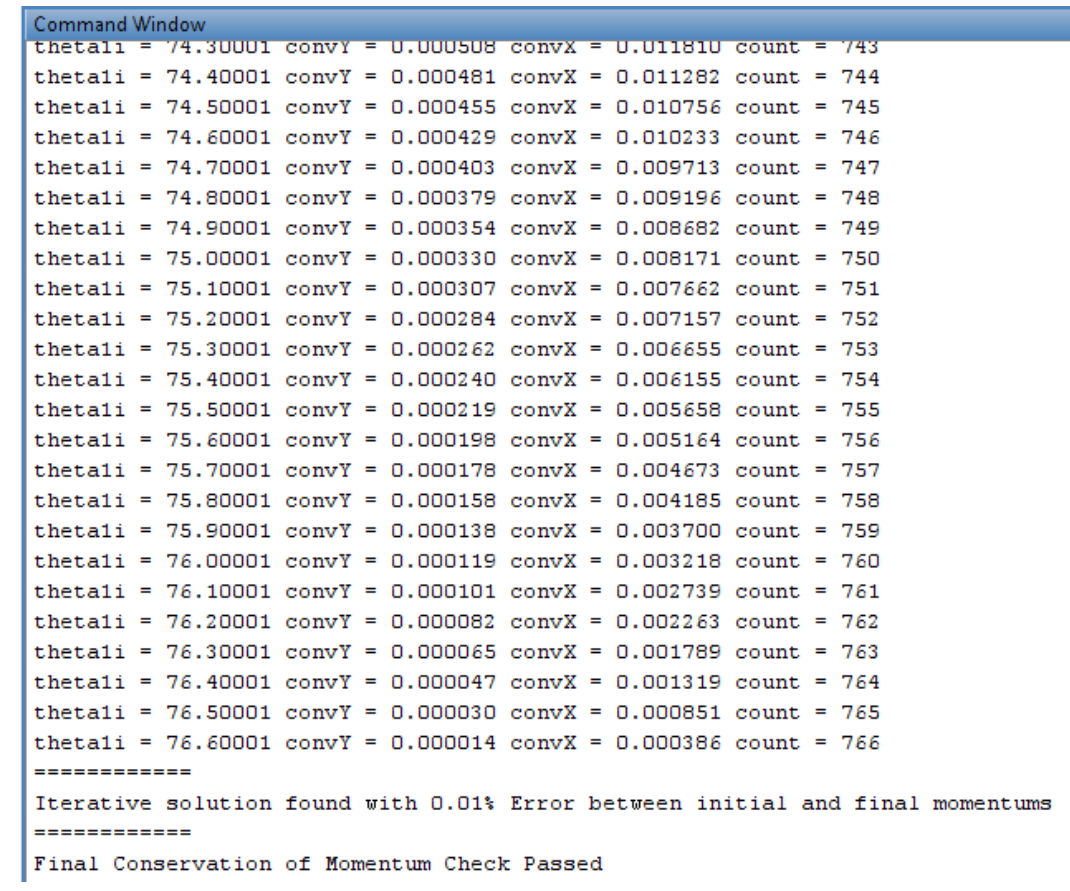

Figure 13. VAR GUI iteration for Case F. convY and convX indicate the percent difference between initial and final momentum magnitudes, in the $\mathrm{Y}$ and $\mathrm{X}$ direction. 


\section{VAR GUI Summary and Recommendations}

The VAR GUI was used to solve many test cases as well as various momentum problems from the ME212 textbook. So far, it has properly solved for all supported cases, however as with all software, some bugs will likely be discovered when it is put to repeated use. The GUI performs all necessary calculations, and does a final check for conservation of momentum in the $x$ and $y$ directions. If conservation of momentum is not passed, the code will error out with an appropriate message, which will greatly speed up troubleshooting in the future.

In retrospect, the code could be greatly simplified if all the cases were solved iteratively. However, this would result in a much greater computation time, and all the solutions would be only approximate answers, rather than analytical solutions. Overall, the GUI is a convenient tool to develop and check VAR scenarios. We intend to distribute it to other universities that are using our VAR MEAs, so that they can also reduce the workload on their instructors. 


\section{Catapult}

The Catapult MEA was introduced in some sections of ME212, 'Dynamics' after the concepts of work-energy and angular velocity/acceleration were introduced in lecture. It was also implemented in some sections of ME326, "Intermediate Dynamics", although not yet formulated into an appropriate MEA format. Professors Dr. Brian Self, Dr. Jim Widmann, and Dr. Peter Schuster have successfully implemented this project into ME212, and Dr. Self has used this project in ME326.

Once again, the MEA was placed in a professional client-driven setting. The memo that was presented to students in ME212 is shown in Figure 14. The "client" for this MEA was the Petersborough Museum, who needed a set of guidelines for predicting the range of projectiles

fired from simple catapults. Students were then supplied with a "scaled-model" of the catapult, shown in Figure 15, in order to assist with their analysis. 
To: Cal Poly Dynamacists

From: Peterborough City Council for Peterborough Museum Art Gallery

Date: 05.18 .09

Subject: Catapult design for upcoming Medieval Machines Exhibition

Each year the Peterborough City Council helps sponsor an interactive medieval exhibition at the Peterborough Museum Art Gallery (see links below). Due to the overwhelming success of our most recent Medieval Machines exhibition, we are pleased to announce plans for a similar exhibition this upcoming year. We will use many of our existing medieval displays and activities but are also looking to expand the exhibition.

This year, the Peterborough Museum is planning a competition where participants can design, build, and fire their own simple catapults. Targets will be placed at various distances on a firing range, and competitors will attempt to use their own catapults to hit them. As competitors will only have one shot to hit a target, they will be expected to calculate how far their projectiles will fly based on the laws of physics.

However, since the competitors vary in age and educational background, the Museum plans on providing a guideline on predicting the range of any designed catapult. We have supplied you with a scaled model of the basic structure of the catapults that will be used in the competition. You may use it to help guide your calculations and initial testing.

We are hoping you can develop a set of instructions to be provided to each participant. These instructions would include a list of what measurements they need to measure and an explanation of the calculations they will need to perform. To help convey your message most effectively, please attach your own complete calculations for the scaled model as an Appendix. It would also be helpful if you could inform us of any difficulties or special considerations you discovered when taking the measurements and performing the calculations. We would also like to know how your initial testing went, and possible sources of error in your calculations.

Finally, we are thinking of incorporating a trebuchet competition next year. Do you think this is feasible? Would our contestants be able to model this with basic physics?

Please send us your material by June 5. Thank you for your time and we look forward to reviewing your results.

Fohn Q. Omith

John Smith

Peterborough Museum Art Gallery Program Director

http://www.peterborough.gov.uk/page-1901\&theme

http://www.peterborough.gov.uk/page-3584

Figure 14. Catapult MEA assigned to ME212 classes. 


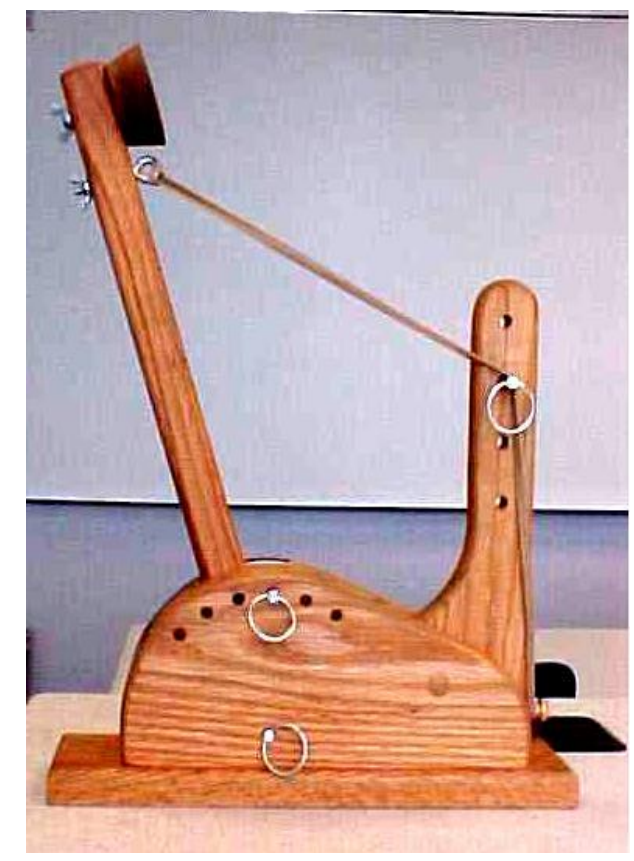

Figure 15. Catapult provided to students for analysis.

Along with the supplied scaled catapult, they were also given rubber bands, rulers, weights, and a scale. With these tools, they were expected to determine all the parameters necessary to model the catapult. In contrast to a typical textbook problem, where all the required values are already explicitly stated, this MEA required students to apply their analytical skills to actually determine what information was needed. Some of these parameters included the dimensions of the catapult arm, dimension from pivot to ammo cup, and the height of the rubber band pin. With these parameters, they had to determine the moment of inertia of the catapult arm, inclusive of the ammo cup and egg. Based on their engineering knowledge, some students made assumptions of point-masses for the egg and cup, and slender rod behavior for the catapult arm. Another important aspect was the behavior of the rubber band. Some students assumed linear behavior, using an average spring constant for their theoretical model. Other students used a curve-fit to the force-displacement data to account for any nonlinearities in rubber band 
stiffness, as shown in Figure 16. We wanted this open-ended aspect to stimulate the kind of critical thinking lacking in many textbook problems.

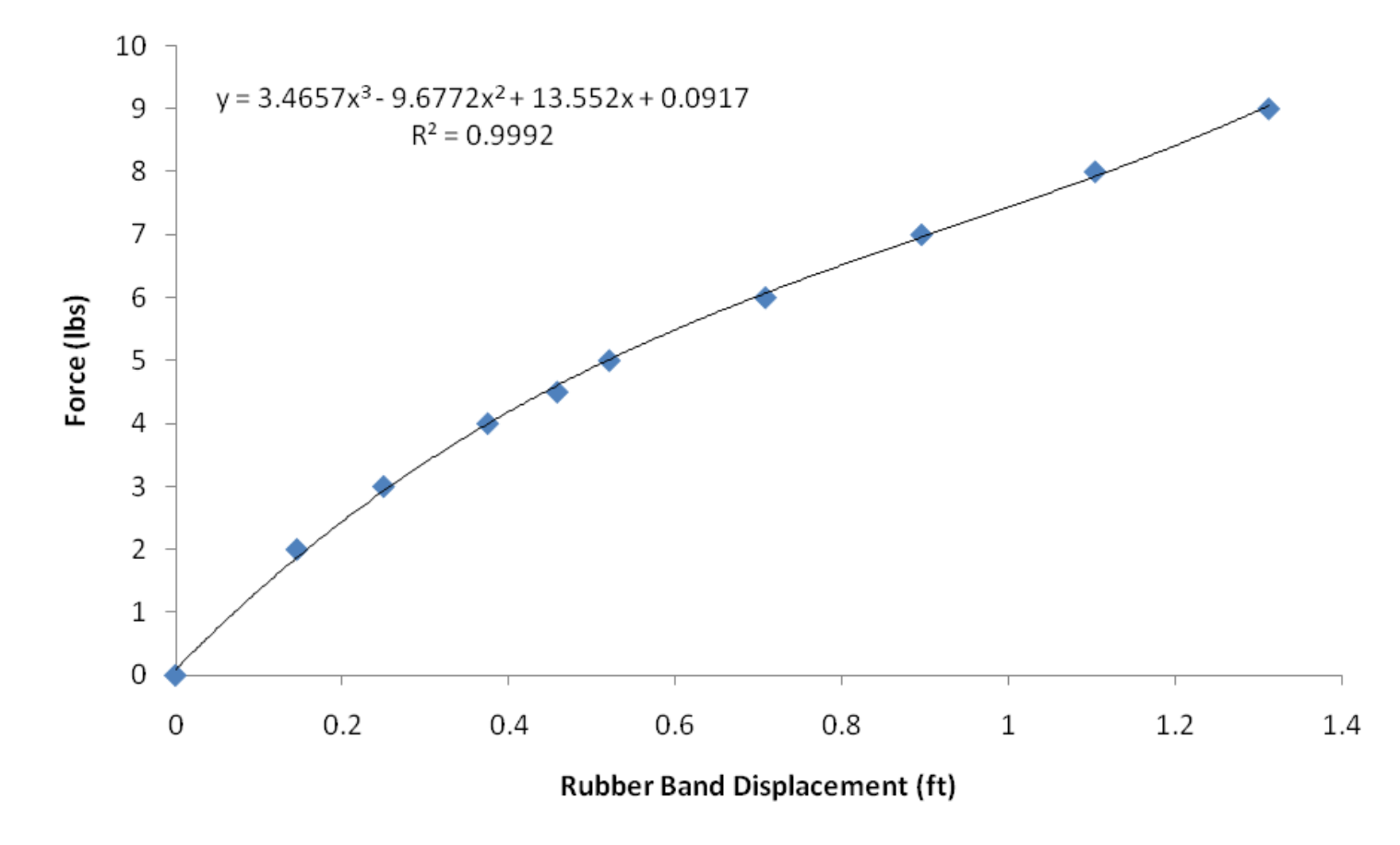

Figure 16. Force versus displacement curve for rubber band.

As their deliverables, students provided a model to predict the range of catapults in general, as well as applying their model specifically to the scaled catapult that was provided. They were required to develop a model using hand calculations that would be applicable to conditions that would be specified later - during launch day. These conditions were: stopper pin angle and pull-back angle, illustrated in Figure 17. Students should have realized that both the trajectory and distance traveled were a function of these two variables. 


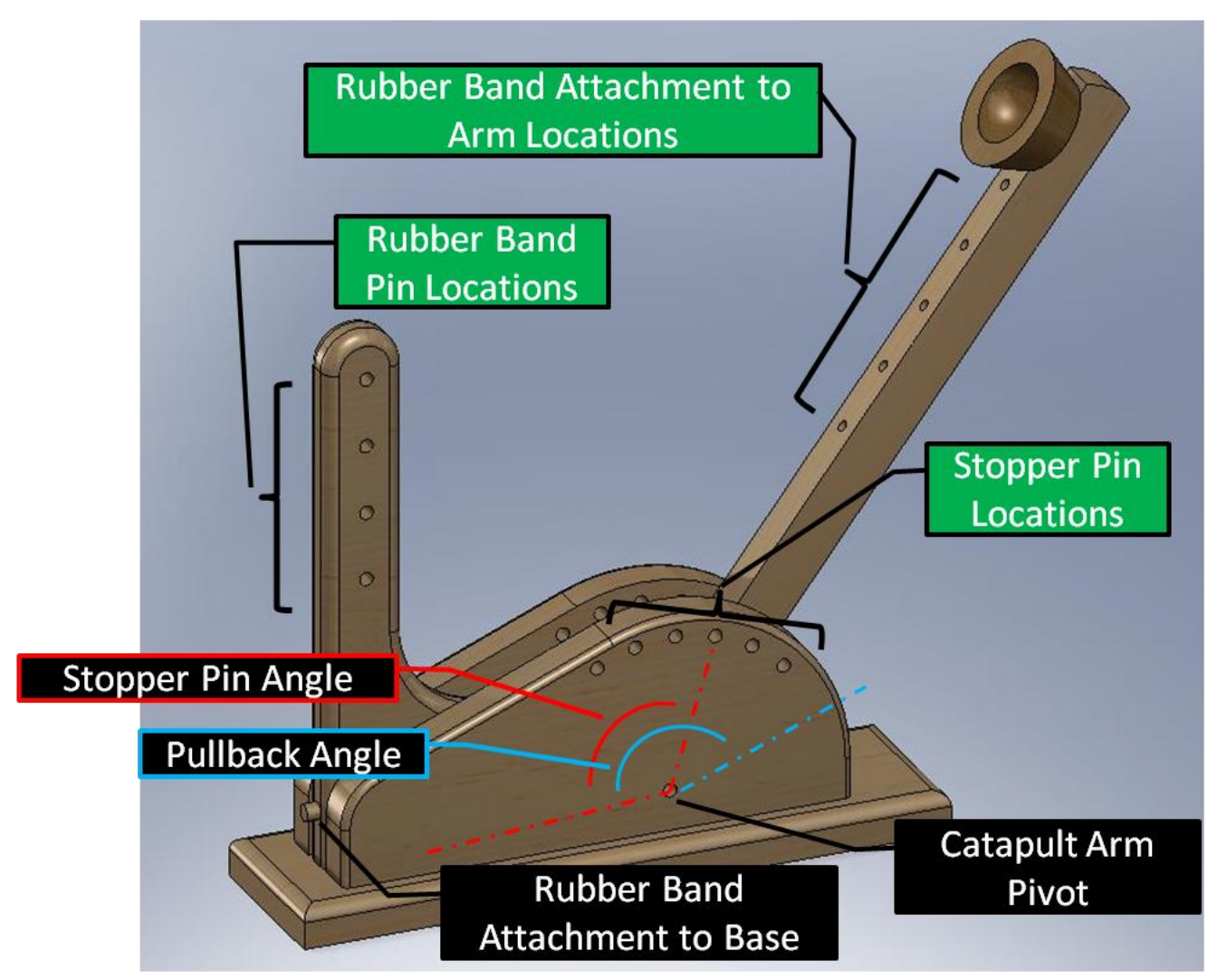

Figure 17. Diagram of catapult locations.

A target was placed in front of the catapult during launch day, and a required pin stopper angle was specified. Students then adjusted the pullback angle of the catapult - based on their model - in order to hit the target. They were able to choose their own rubber band attachment and rubber band pin locations. Judging from where their egg landed, they were able to see where their calculations may have gone awry, which was a significant application of the selfassessment principle. They could then go back and rework their calculations to match up with the physical results. In addition to using their model on launch day, students completed a follow-up homework assignment which also utilized their model. This homework assignment involved finding the force on the stopper pin using impulse-momentum, as well as the force on the pivot pin using the sum of forces and moments. This allowed students to connect an additional concept from lecture to their model. 


\section{Instrumentation}

Although launching the catapult was already a great way of providing validation to students' analysis, we wanted to provide further experimental data. In order to expand upon the "reality" and "self-assessment" principles of this MEA, we outlined parameters that we wanted to measure using instrumentation. By providing students with experimental data, they would be able to validate their theoretical results with physical data. This real-time data would ideally be taken by the students during launch day, where they could visually see the trajectory of the egg. Students could then compare the visual results, the experimental data, and their theoretical results. The parameters that we wanted to measure are:

- Angular Velocity

- Angular Position

- Angular Acceleration

- Axial Stress

- Force at Stopper Pin

To obtain this experimental data, we used a two-axis accelerometer and four strain gages, in conjunction with a data acquisition system. The final equipment list (after several design iterations) is listed below:

- 1x ADXL-278 +50g Dual-Axis iMEMS Accelerometer

- 1x 5V Voltage Supply (inclusive of hardware noise filtering)

○ 1x 5V Voltage Regulator

○ 2 x $10 \mu \mathrm{F}$ capacitor

○ $1 \times 0.1 \mu \mathrm{F}$ capacitor

$\circ \quad 1 \mathrm{x} 0.01 \mu \mathrm{F}$ capacitor

- 4x CEA-06-240UZ-120 Vishay Strain Gages 
- 1x NI-cRIO-9014 Real-Time Controller

- 1x NI-cRIO-9101 4-Slot, 1M Gate CompactRIO Embedded Chassis

- 1x NI-9237 Simultaneous Bridge Module

- 1x NI-9205 Analog Input Module

- 1x NI-9949 NI 9949 RJ-50 to Screw Terminal Adaptor (Strain Bridge)

- 2x $120 \Omega$ Vishay 5-120-01 Precision Resistors

One of the most critical design considerations was the required setup time for gathering data. While proctoring ME212 students during launch day, I was barely able to squeeze all of the student teams' launches into the 50 minute period. I realized that essentially no time would be allotted to set up the instrumentation. Therefore, all of the following instrumentation is designed to record the data with a click of a button in LabView, with no setup time in between. Students can then use the post-processing code to analyze their results.

All of the testing in this section was conducted with one rubber band on the catapult, and no attached egg or other projectile. The reason for this was because many trials were to be conducted in the graduate lab. Launching projectiles could damage other equipment in the lab, and based on my previous experience, two rubber bands could damage the catapult arm, as shown in Figure 18. 


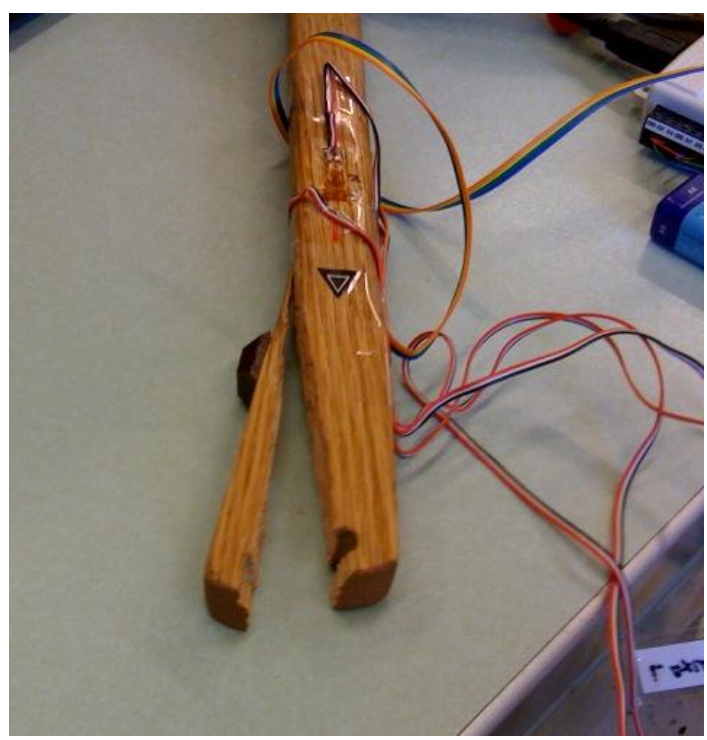

Figure 18. Broken catapult arm after some initial trials with two rubber bands.

\section{Angular Position, Velocity, and Acceleration}

Several techniques to measure angular velocity and acceleration were considered before ultimately arriving at a dual-axis accelerometer. We considered using either a rotary encoder or rotary potentiometer to measure the position of the arm as a function of time. These, however, would require a rigid attachment to both the catapult arm as well as the base. This would require significant machining and would be potentially expensive.

Our solution to measure both angular velocity and acceleration was to use an ADXL-278 accelerometer. This accelerometer was low-cost, measured acceleration in two axes, and required a rigid attachment to only the catapult arm. The full specifications of the accelerometer are provided in Appendix L. The ADXL-278 was oriented to measure both normal acceleration and tangential acceleration of the catapult arm, as shown in Figure 19. From these two accelerations, we could then directly calculate the angular velocity and acceleration of the catapult using the following relations.

$$
\begin{gathered}
\mathbf{a}_{\mathrm{t}}=\boldsymbol{\alpha} \times \mathbf{r} \\
\mathbf{a}_{\mathbf{n}}=\omega \times(\omega \times \mathbf{r})
\end{gathered}
$$




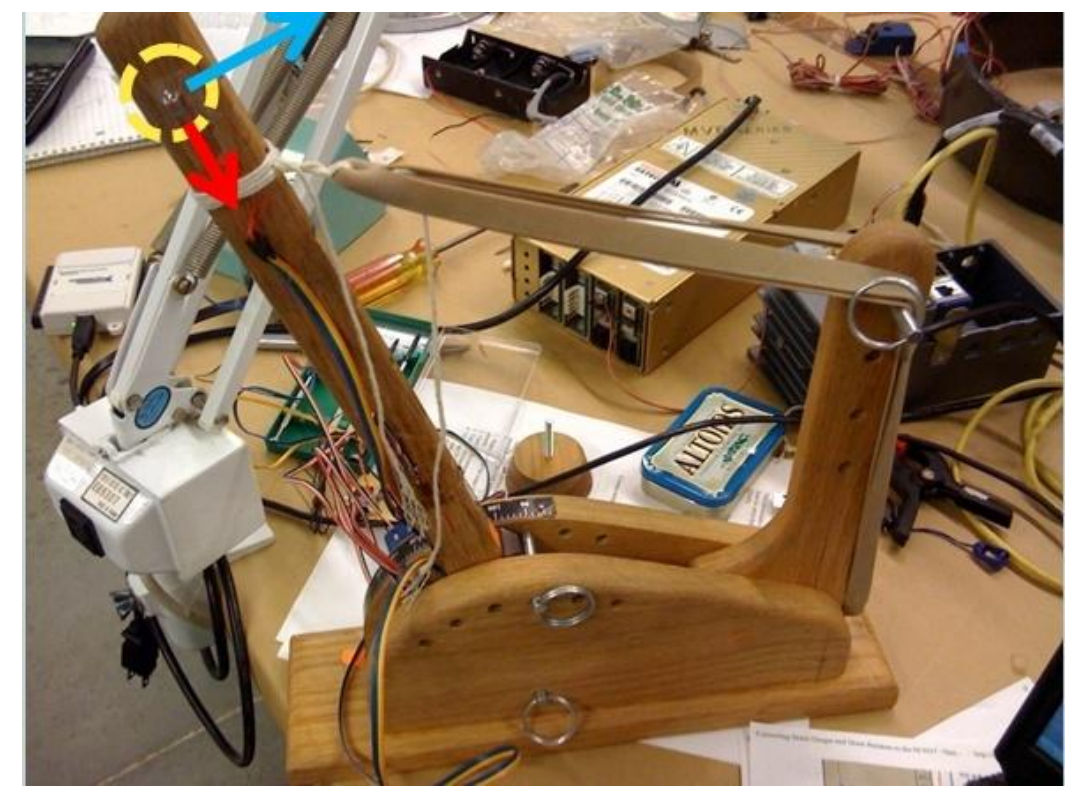

Figure 19. Catapult with accelerometer. The accelerometer is highlighted in yellow. The blue and red arrows represent the directions of tangential and normal acceleration, respectively.

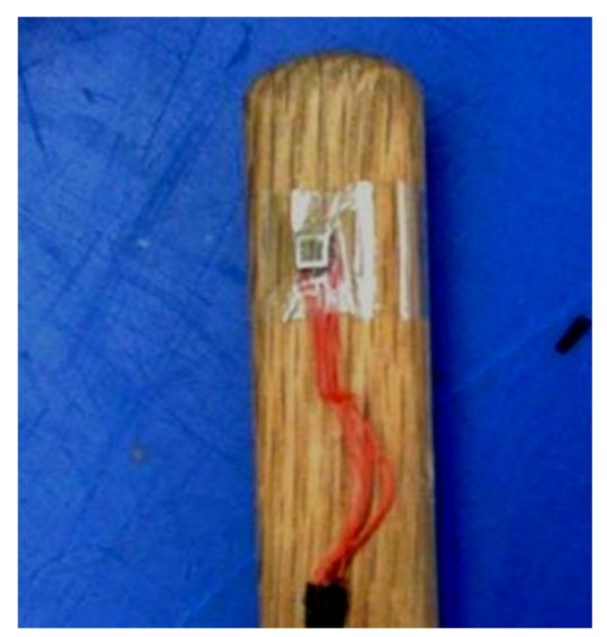

Figure 20. Close-up of accelerometer on catapult arm.

For noise reduction in the power supply, we utilized the circuit shown in Figure 21 to power the accelerometer and for some hardware signal conditioning. The circuit is a combination 
of a $5 \mathrm{~V}$ voltage regulator (with capacitors for noise reduction) and a grounded $0.01 \mu \mathrm{F}$ capacitor at each of the two outputs of the accelerometer. The outputs of both axes are then read into a data acquisition unit.

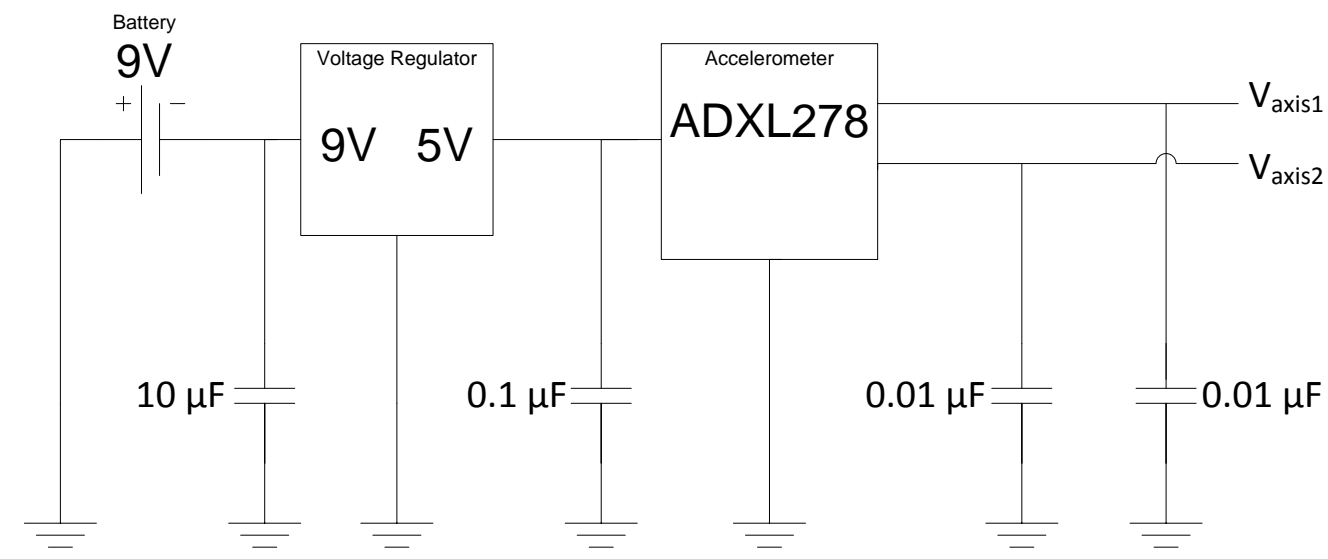

Figure 21. Circuit diagram for $5 \mathrm{~V}$ voltage regulator $\&$ hardware accelerometer signal filtering.
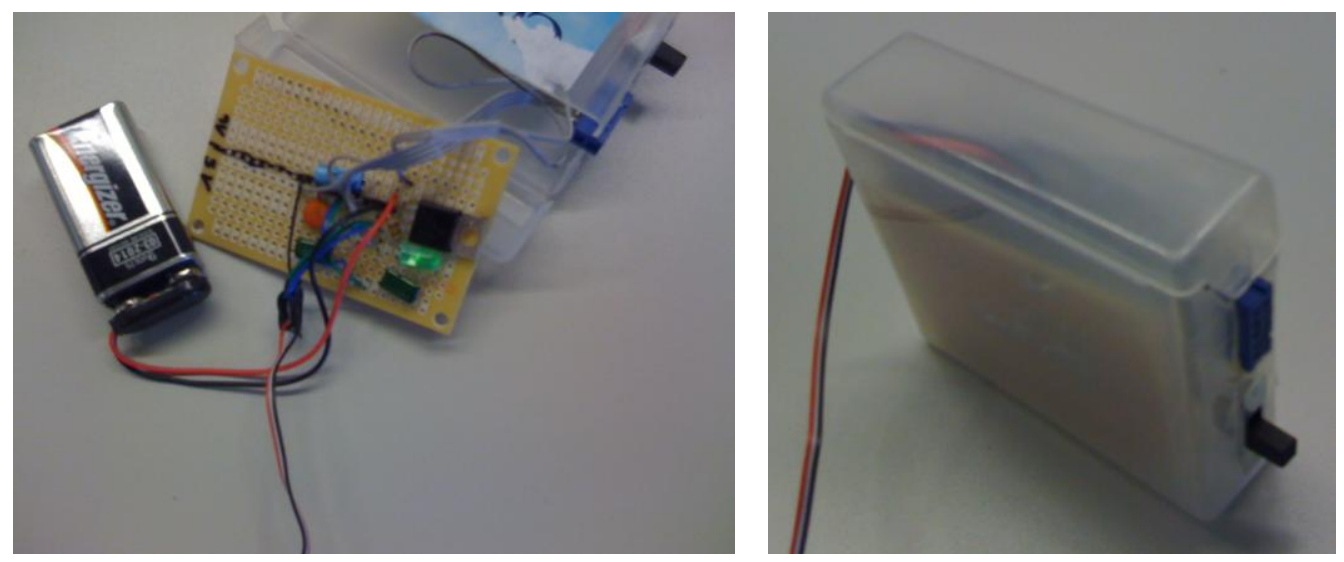

Figure 22. Voltage regulator internals and packaging.

In order to read the analog signal from the accelerometer into the computer, we needed a data acquisition system with an appropriate sample rate. Our first iteration utilized a NI USB6008. This DAQ had a maximum sampling rate of $5000 \mathrm{~Hz}$, which was more than fast enough for our catapult duration of less than 60 milliseconds. The accelerometer was then tested for repeatability, shown in Figure 23. 


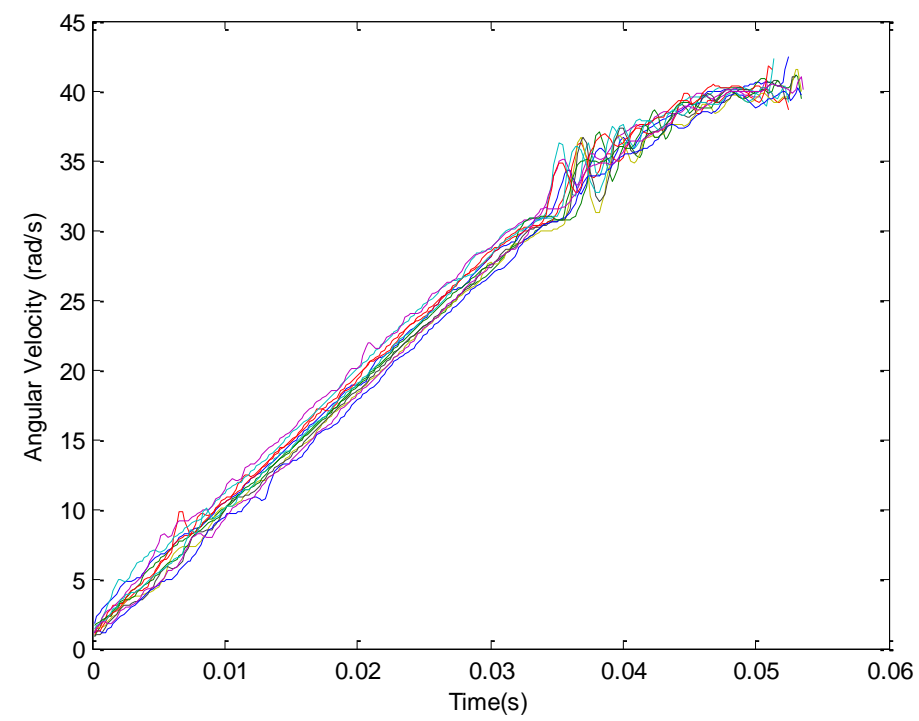

Figure 23. Angular velocity data for multiple runs, using NI-6008.

One of the major drawbacks of using an accelerometer versus an encoder was that the position of the catapult arm had to be calculated by integrating the angular velocity. While this was initially a concern, Figure 24 shows the results of a numerical integration of the angular velocity to yield the corresponding position. A summary of these results is provided in Table 6 .

Table 6. Summary of 12 repeatability tests for pullback angle of $72^{\circ}$

\begin{tabular}{|c|c|c|c|c|}
\hline & $\begin{array}{c}\text { Experimental } \\
\text { Parameter }\end{array}$ & $\begin{array}{c}\text { Average Numerical } \\
\text { Integration Output }\end{array}$ & Percent Difference & $\begin{array}{c}\text { Standard } \\
\text { Deviation }\end{array}$ \\
\hline $\begin{array}{c}\text { Pullback angle }- \\
\text { stopper angle }\end{array}$ & $72^{\circ}$ & $71.2^{\circ}$ & $1 \%$ & $1.025^{\circ}$ \\
\hline
\end{tabular}




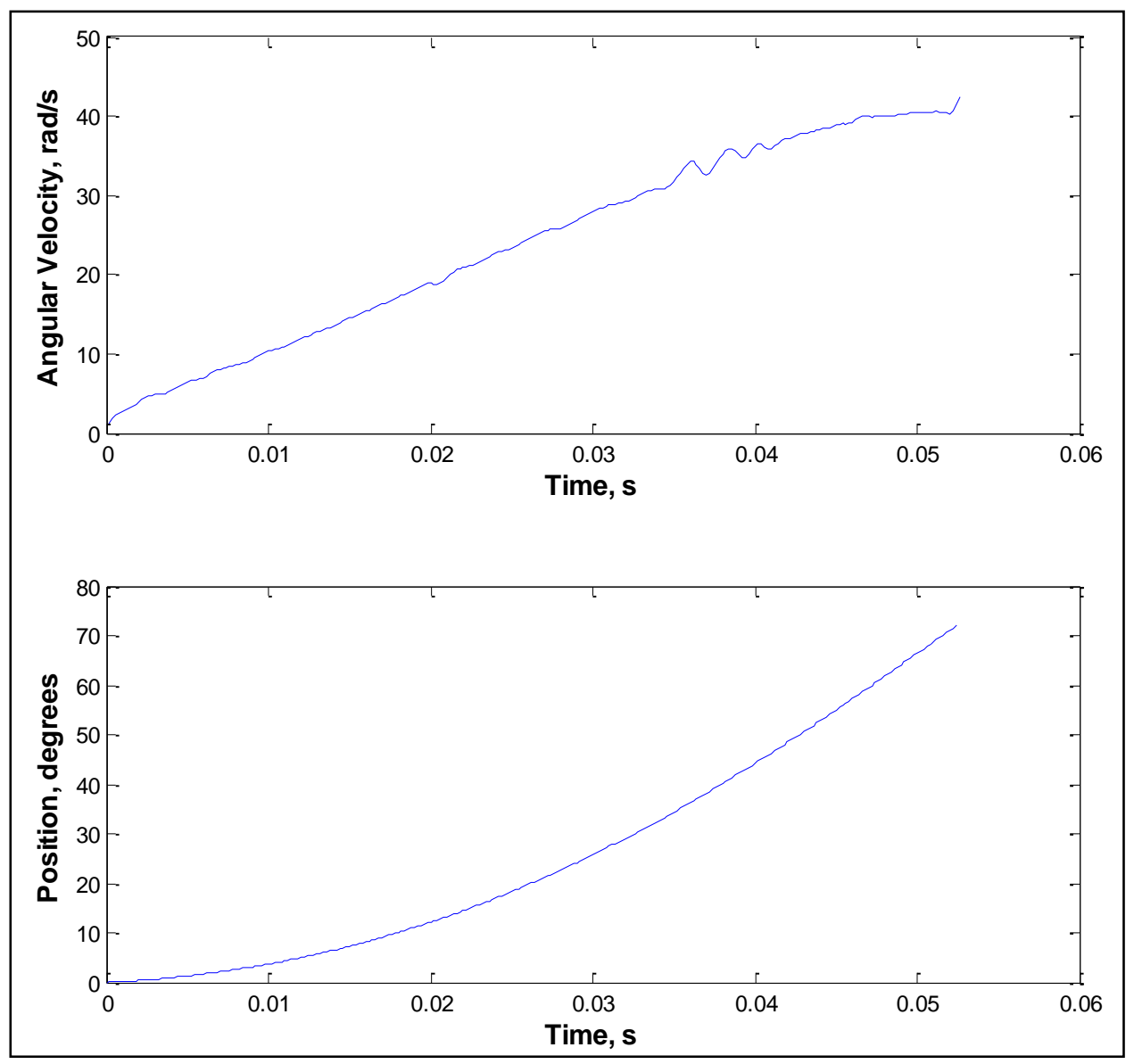

Figure 24. Experimental results for angular velocity and position. Position was calculated from numerical integration of velocity.

\section{Switching to CompactRIO}

Although the USB-NI-6008 was adequate for accelerometer measurements alone, a problem arose when we tried to interface it with a strain measurement. Since the output voltage from any strain gage measurement was well under the minimum voltage that could be read by the USB-NI-6008, a separate module had to be used for the strain voltage. We had originally planned to purchase a USB adapter for the C-Series NI-9237 strain module - in that manner we could hook up both the NI-6008 and the NI-9237 via USB ports, and sample from each in LabView. However, a "lag time" would be present between readings of the two USB devices, which would cause trouble in synchronizing the two signals. This would be less of a problem if 
the event time was long - however since the catapult motion occurs in less than 60 milliseconds, this became a concern.

Rather than purchasing an adapter that may not have worked, we instead turned our attention to a CompactRIO (National Instruments, Austin, TX), which was readily available for me to use. Typically, the CompactRIO modules are used to record data without the need to be hooked up to a computer. However, in our case, we wanted the data to be displayed on the computer screen as the event was occurring. This required the usage of "scan mode" on the CompactRIO, which omits the requirement of any FPGA programming. The configuration of the CompactRIO required us to use the "Using CompactRIO Scan Mode with Unsupported Backplanes", stated on the NI website.

Switching to this CompactRIO required changing the voltage module used to read acceleration from the USB-NI-6008 to the NI-9205 Analog Input Module. This was not a problem, however, the maximum sampling rate was reduced from $5000 \mathrm{~Hz}$ to $1000 \mathrm{~Hz}$. Even so, as shown in Figure 25, an adequate amount of samples was obtained using this reduced sampling rate. 


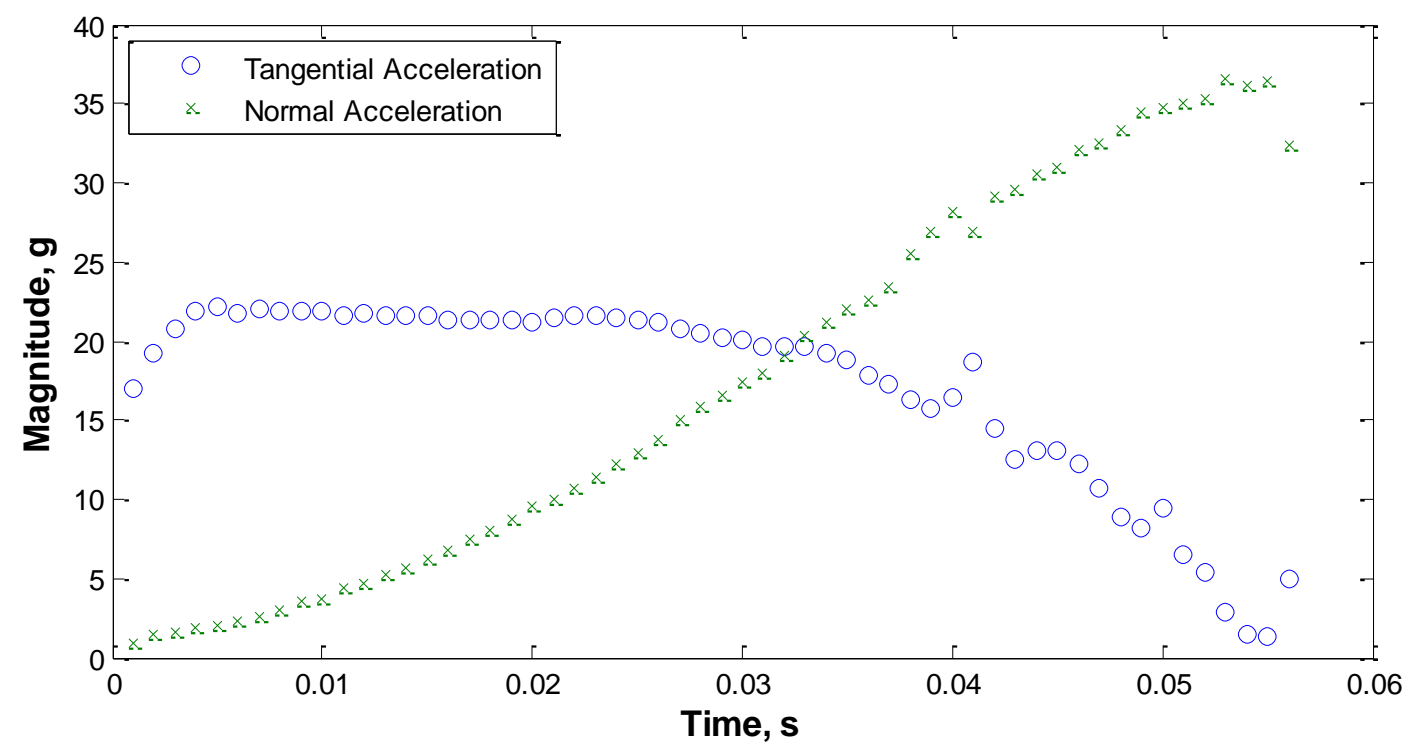

Figure 25. Trial for testing reduced sampling rate of $1000 \mathrm{~Hz}$, using CompactRIO and NI-9205.

The top plot of Figure 26 compares the values of experimental angular velocity with the angular velocity obtained by a rectangular numerical integration of the experimental angular acceleration. The offset between the two values was most likely caused by the orientation of the accelerometer. The bottom plot of Figure 26 compares the values of experimental angular acceleration with the angular acceleration obtained by deriving the experimental angular velocity. Because of the noise in the normal acceleration direction, from which the angular velocity was calculated, calculating the angular acceleration using the two-point backwards difference and four-point central difference methods of numerical differentiation were also noisy. However, the derived results fluctuated about the experimentally obtained value. Therefore, this could potentially be a good method of checking the orientation of the accelerometer. 

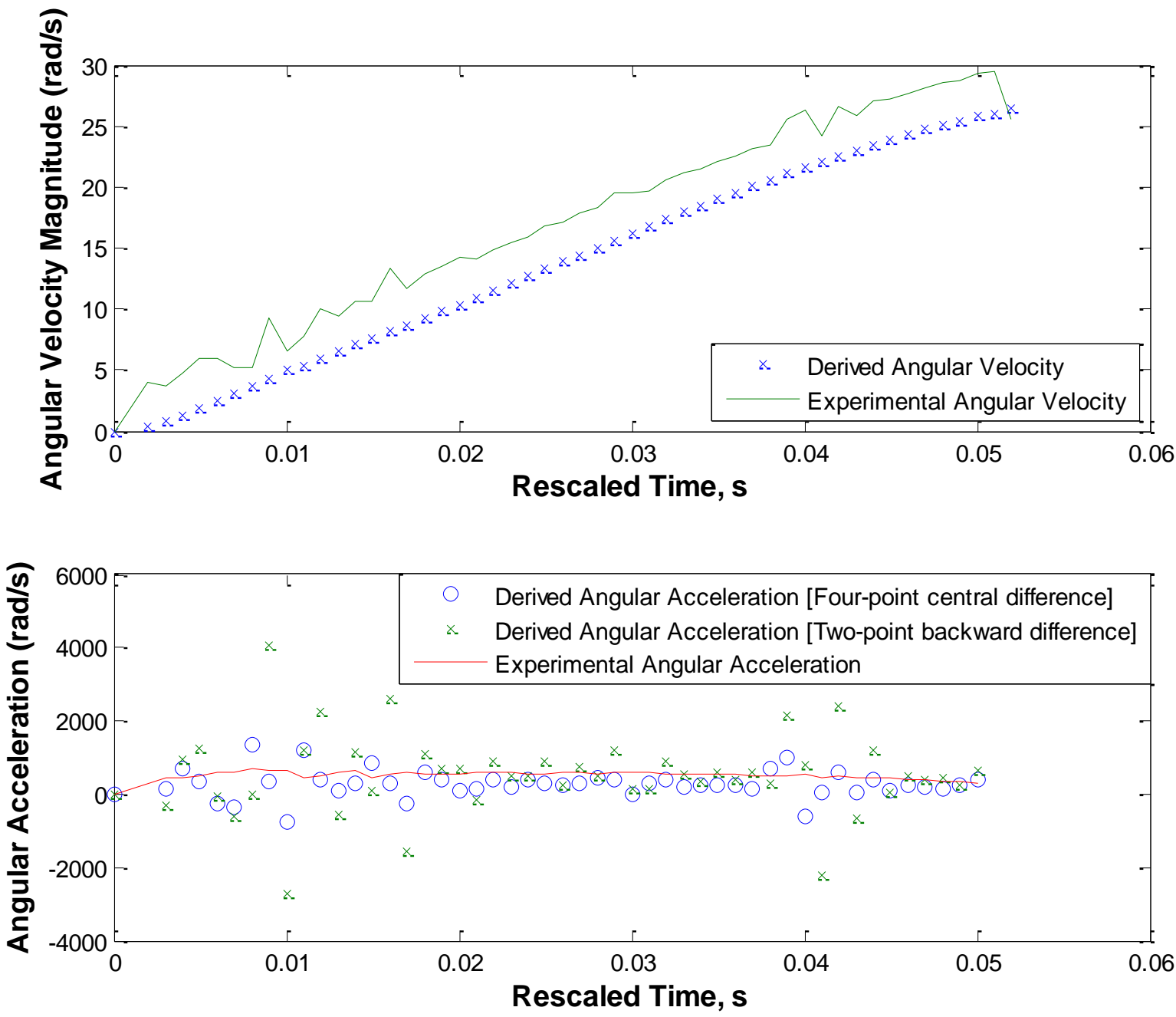

Figure 26. (Top) Comparison between experimental angular velocity and integrated angular velocity from experimental angular acceleration. (Bottom) Comparison between experimental angular acceleration and derived angular acceleration using experimental angular velocity.

\section{Axial Stress and Force at Stopper Pin}

In order to capture the force at the stopper pin and the axial stress, we used strain gages to measure the bending and axial strain of a catapult arm location during launch. The bending strain was caused by the tangential force from the rubber band, which in turn accelerated the catapult arm. A large bending strain was also present during the impact time of the catapult arm with the stopper pin. The axial strain was caused by a combination of the axial force from the catapult 
arm as well as the normal acceleration of the effective center of mass above the mounted gage. An FBD and MAD of the catapult arm are shown in Figure 27.

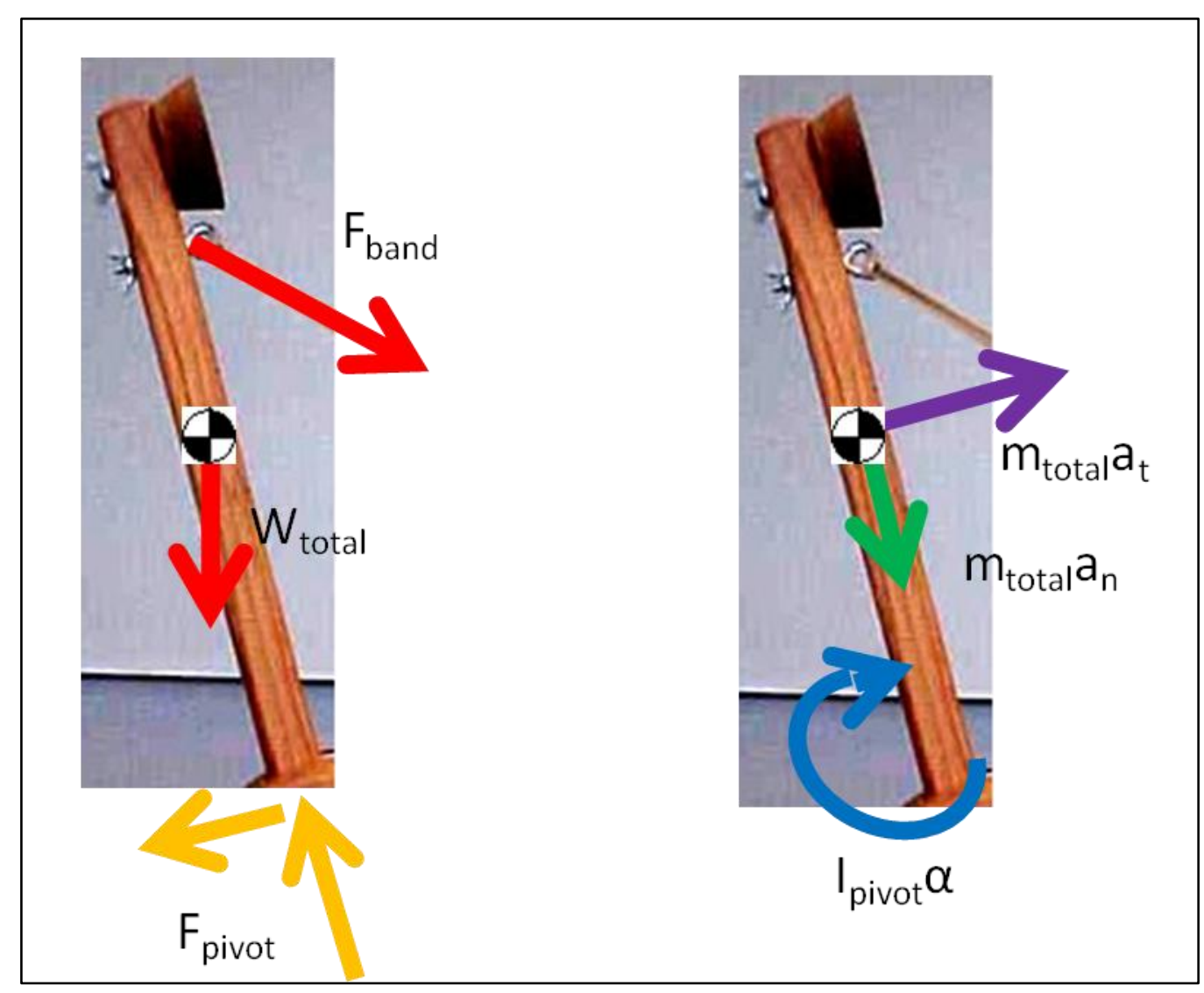

Figure 27. FBD and MAD of catapult arm.

The strain gages were assembled into a "full" Wheatstone bridge as shown in Figure 28. For axial strain, we positioned strain gages at (1) and (3), and placed precision resistors at (2) and (4). This configuration resulted in measuring axial strain only - bending effects were cancelled out. For bending strain, we positioned strain gages at (1) and (4), and used the internal completion NI-9949 resistors at (2) and (3). This configuration resulted in measuring bending strain only - axial effects were cancelled out. The bridge setup and associated equations were taken from James W. Dally's Instrumentation for Engineering Measurements, $2^{\text {nd }}$ edition. During 
any applied load, the resultant axial strain and moment strain could be determined by the following reduced equation:

$$
\frac{V_{o}}{V_{e x}}=\frac{S_{g} \in}{2}
$$

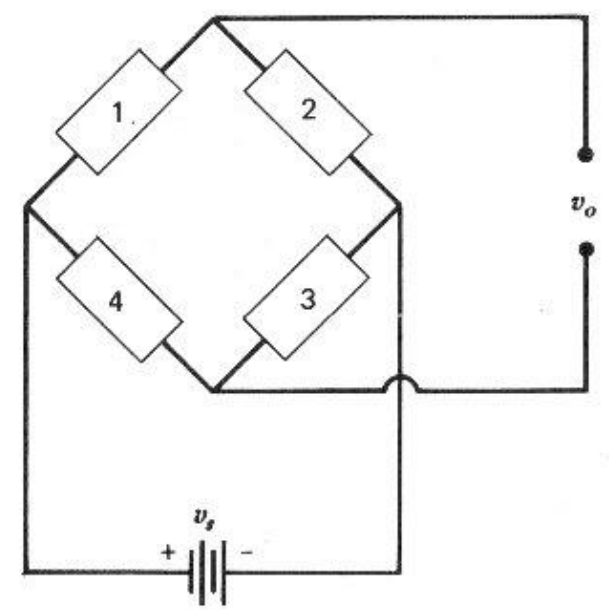

Figure 28. "Full" Wheatstone bridge configuration for strain gages. For axial strain: (1) and (3) represent mounted gages, while (2) and (4) represent external precision resistors. For bending strain: (1) and (4) represent mounted gages, while (2) and (3) represent internal precision resistors.

The strain gages were mounted using m-line AE10 epoxy, as per the instructions in the Vishay manual (Vishay Micro-Measurements 2005). Figure 29 shows the overnight curing of the strain gages under pressure from clamps. An illustration of the strain gage locations is provided in Figure 30 and the actual strain gages are shown in Figure 31. 


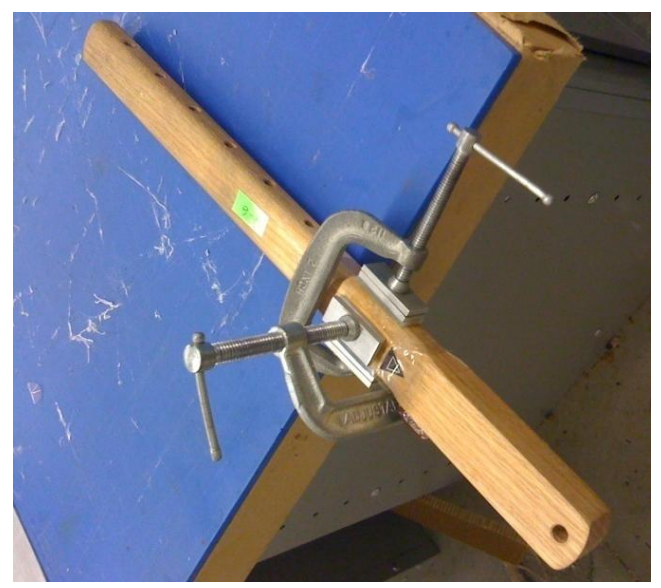

Figure 29. Strain gages curing under pressure from c-clamps.

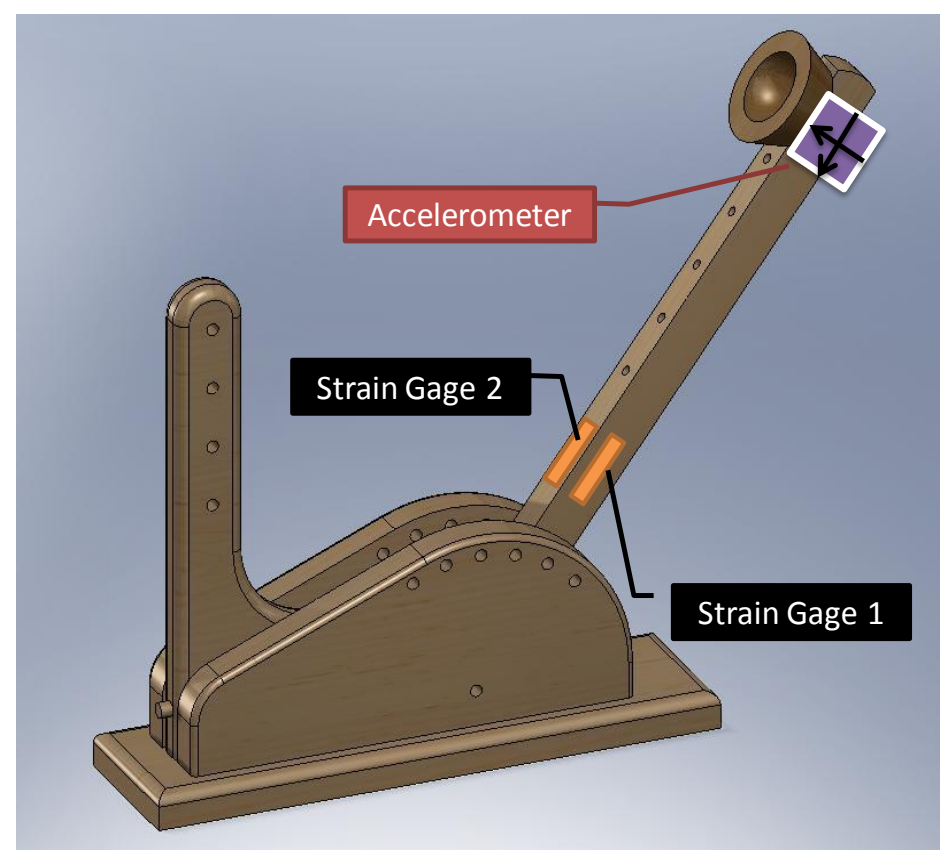

Figure 30. Illustration of catapult with associated instrumentation. Strain gage 3 (not visible) is mounted directly opposite of strain gage 1. Strain gage 4 (not visible) is mounted directly opposite of strain gage 2. 


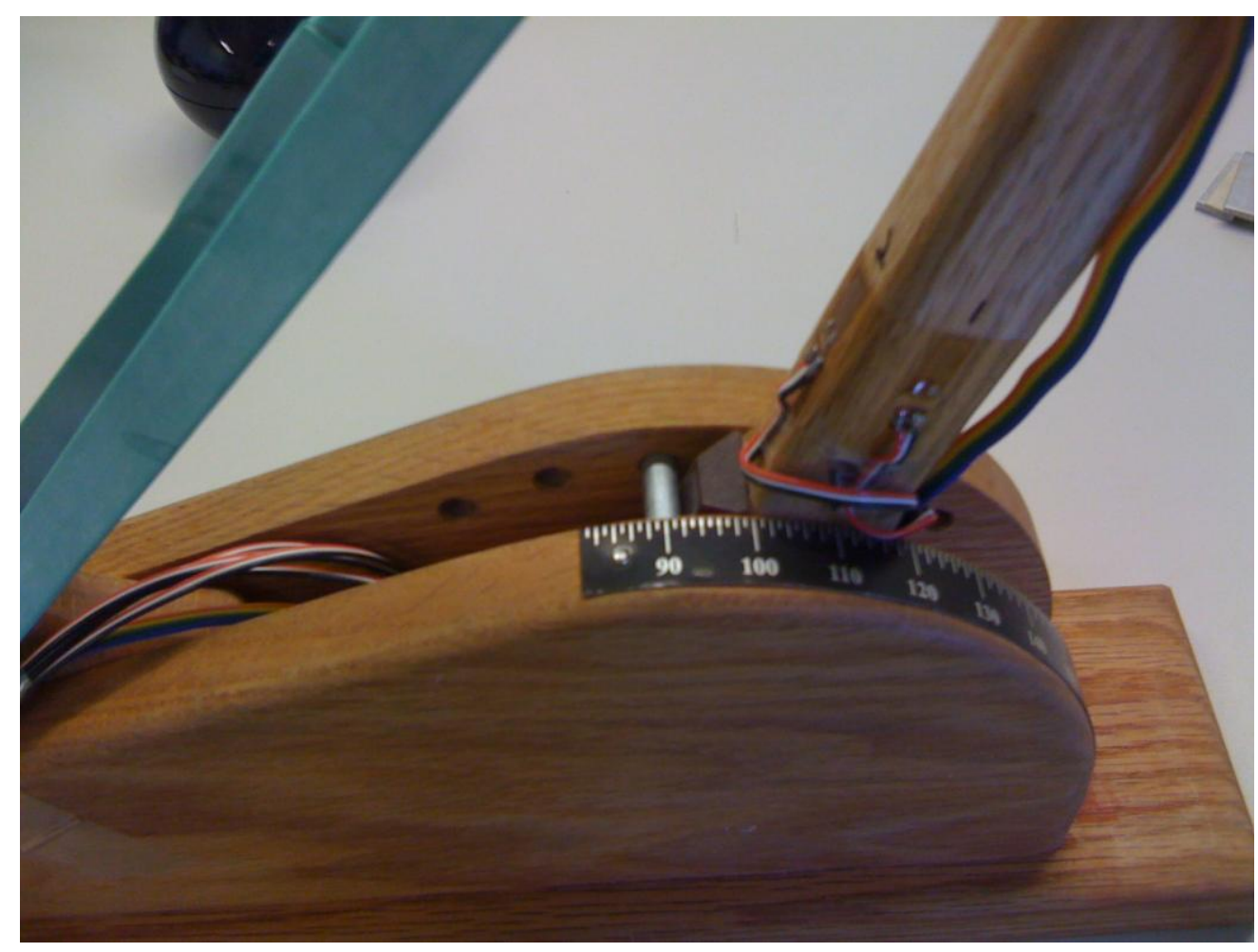

Figure 31. Catapult with mounted strain gages.

Because we were utilizing the strain gages as force/stress transducers, we needed to find the modulus of elasticity of the wood. By experimentally determining this modulus of elasticity, we could then relate the recorded strain to stress using Hooke's Law:

$$
\sigma=E \in
$$

The modulus of elasticity was found by loading the catapult arm axially, and recording resultant strains caused by static loading of weights. This was accomplished by hanging the catapult arm from a ladder, and hanging combinations of $2 \mathrm{lb}$ and $10 \mathrm{lb}$ weights, as shown in Figure 33. The associated strains were measured using a P3 Strain Indicator and Recorder (Vishay). 


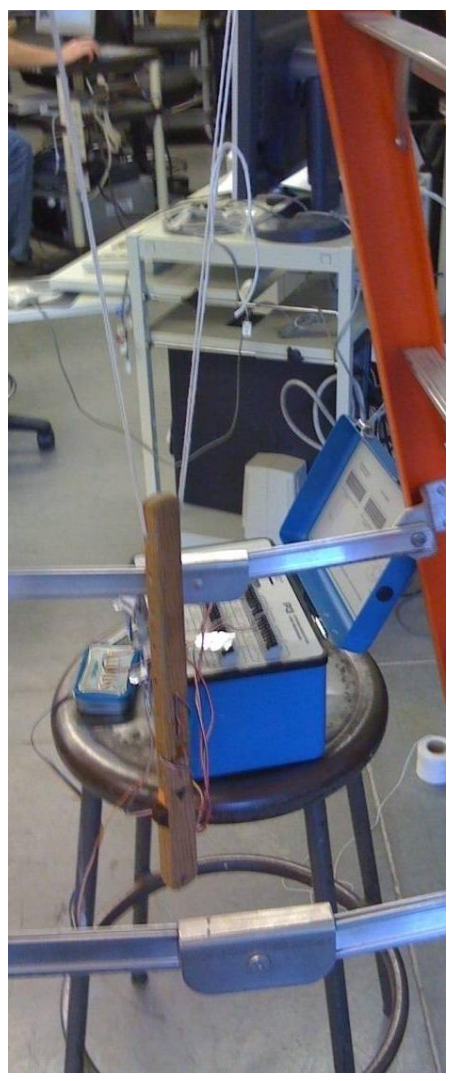

Figure 32. Static loading of catapult arm to determine modulus of elasticity.

The results from the modulus of elasticity test are shown in and Table 7. Wood typically has a nonlinear behavior when not in the direction of the grain structure, but fortunately the grains were oriented in the direction of our applied force. The experimental value for the elastic modulus of the catapult arm were very close to the published value for oak wood of $1.49 \mathrm{Msi}$ (Smithsonian Institution 1969, 246), along the direction of the grain.

Table 7. Comparison of experimental published value for catapult arm and published elastic modulus for oak.

\begin{tabular}{|l|c|c|c|}
\cline { 2 - 4 } \multicolumn{1}{c|}{} & Experimental & Published & \% Difference \\
\hline Elastic Modulus (Msi) & 1.53 & 1.49 & $-2.0 \%$ \\
\hline
\end{tabular}




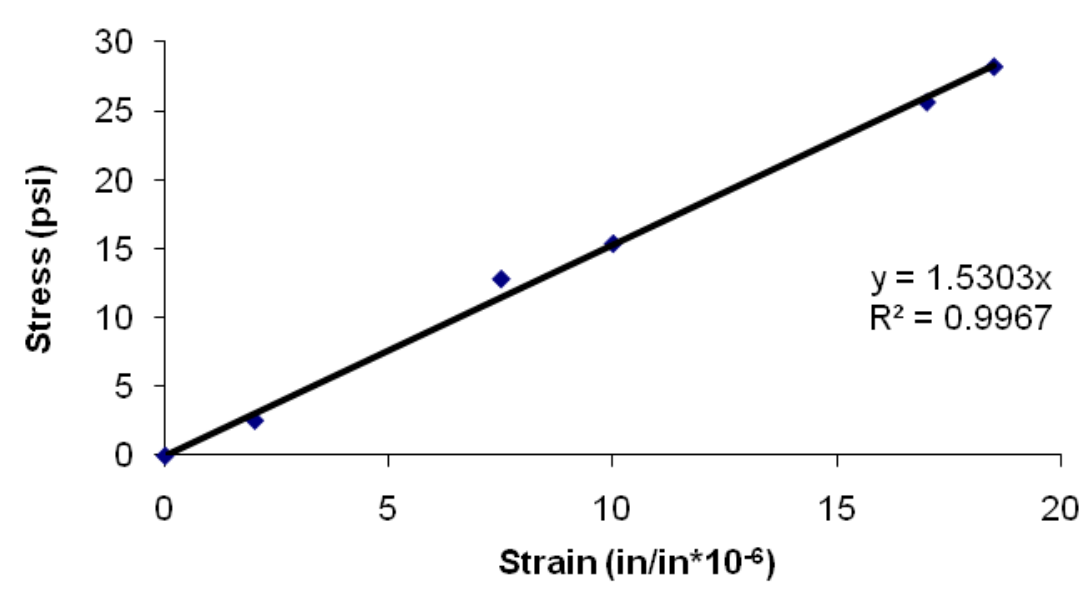

Figure 33. Stress - strain relationship for catapult arm under axial loading.

\section{Data From the CompactRIO}

The LabView program Virtual Instrument (VI) was structured in a producer-consumer loop as shown in Figure 34. The purpose of this structure was to take readings at a very fast sampling rate while writing the data to a text file. We had initially attempted to use just a timed loop structure, however writing to the data file and displaying the measurement on the front panel sometimes interfered with the scan rate. A producer-consumer loop has all time-critical data occurring in the producer loop, which queues up data in memory for the consumer loop. The consumer loop then executes when adequate processing power is present - which doesn't interfere with the sampling rate. In our case, the data sampling occurred in the producer loop, while the data writing and waveform display occurred in the consumer loop. 


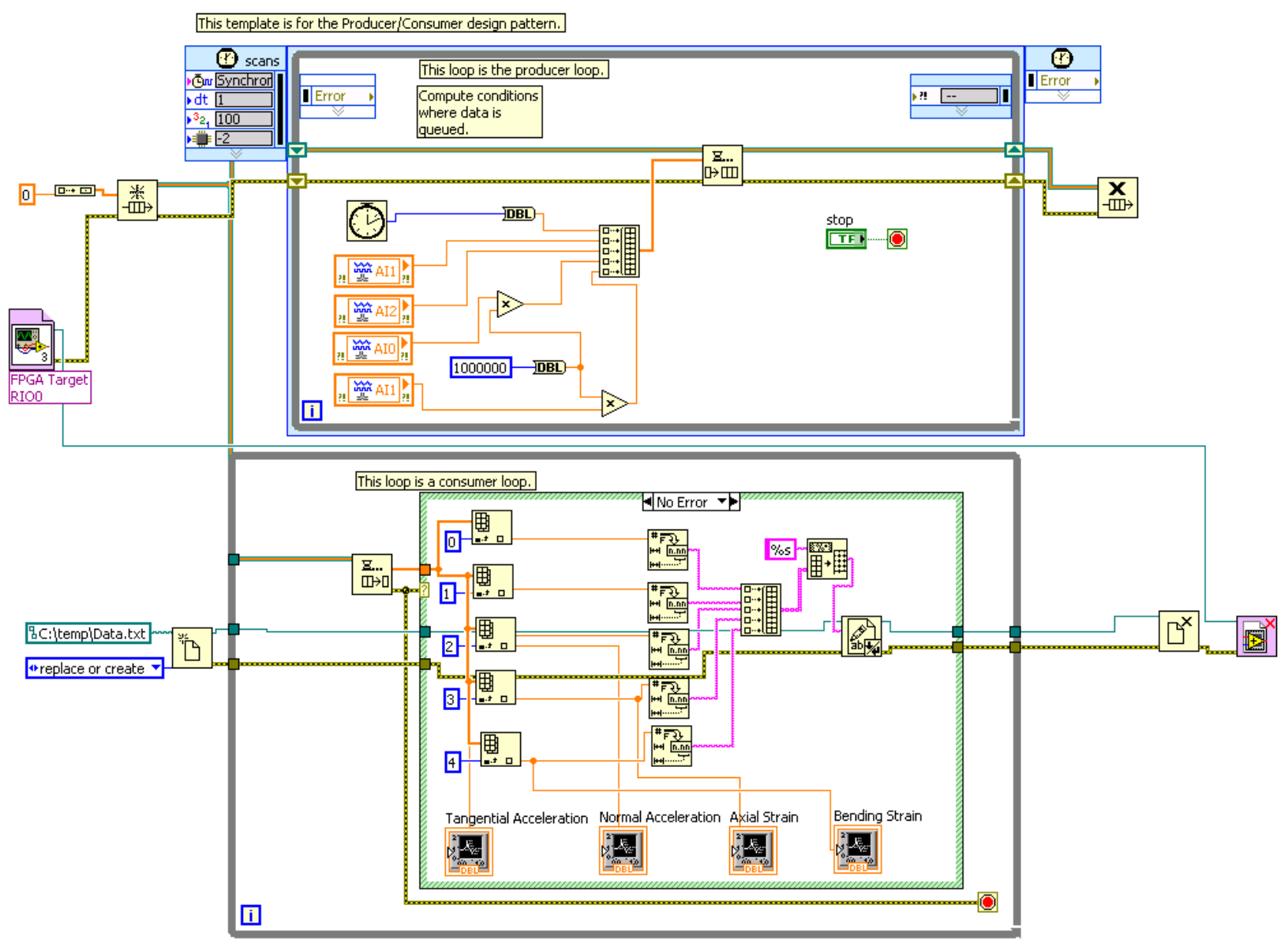

Figure 34. LabView VI for obtaining signals in producer-consumer format.

\section{MatLab, Post-processing, and Results}

After the data were recorded using this producer-consumer structure, a post-processing MatLab code was used to interpret the results. Shown in Figure 35, the actual catapult motion time was only a very small portion of the entire sampling time. This was because each trial was initiated by pressing run, releasing the catapult, and allowing adequate time for the program to write the data. However, we needed a way to easily identify the duration of the catapult motion. 

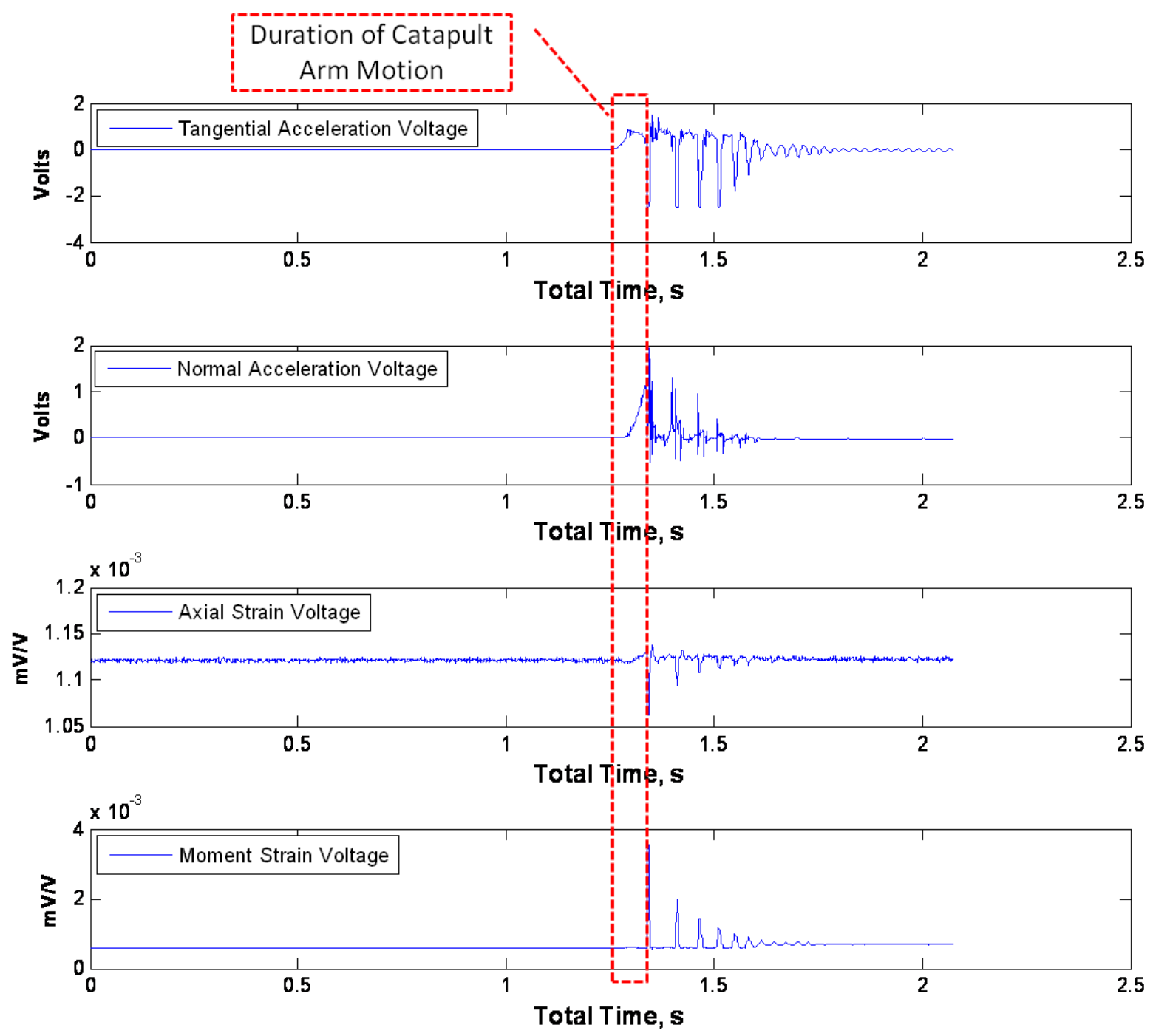

Figure 35. MatLab output for raw voltages obtained from LabView.

We accomplished this by programming the MatLab code attached in Appendix I, which searched for trigger values of normal and tangential acceleration. When both readings for acceleration surpassed their trigger values, the beginning of catapult motion was indicated. When the trigger value for tangential acceleration became negative, this indicated the end of the catapult motion - hitting the stopper pin. The first plot of Figure 36 illustrates the entire recording of catapult acceleration data, from the time the time the LabView recording is started to when it is stopped. This data include the period of no movement, the catapult motion, and the oscillations after the arm has hit the stopper pin. However in this case, the catapult motion itself 
occurs between approximately 1.25 and 1.3 seconds. Using the aforementioned trigger values, the second two plots of Figure 36 show a rescaled time, which highlights the catapult motion by itself, and rescales the time to zero. The experimental angular velocity and angular acceleration were calculated from the experimental tangential and normal accelerations using Equations (3) and (4).

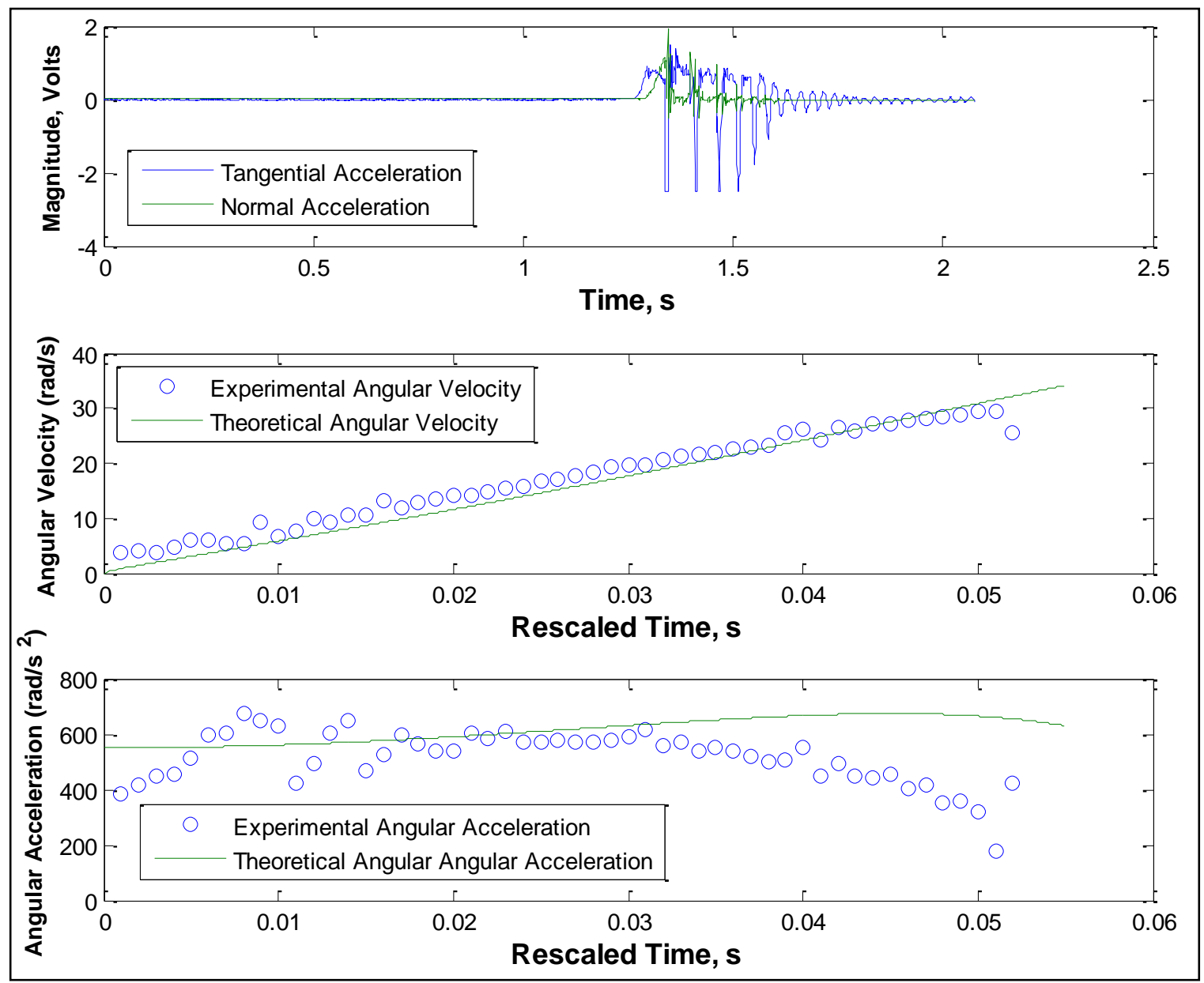

Figure 36. MatLab output of tangential acceleration, normal acceleration, angular velocity, and angular acceleration with corresponding theoretical results for a catapult pullback angle of $180^{\circ}$ and stopper angle of $125^{\circ}$.

As seen in the figure, the experimental angular velocity matches very closely to the theoretical angular velocity obtained using the code in Appendix J . However, both the maximum angular velocity and acceleration are somewhat overestimated by the theoretical model. I believe that this is because during the final part of the catapult motion, a part of the rubber band remains 
in its "stretched" state due to the friction from the rubber band pin, shown in Figure 37. The theoretical model, in contrast, assumes that the entire rubber band unstretches evenly. After analyzing some high-speed catapult footage, it appeared that a section of the rubber band did in fact remain stretched during the catapult motion. Because of this, it is possible that not all the potential energy stored in the entire rubber band length is converted to kinetic angular velocity.

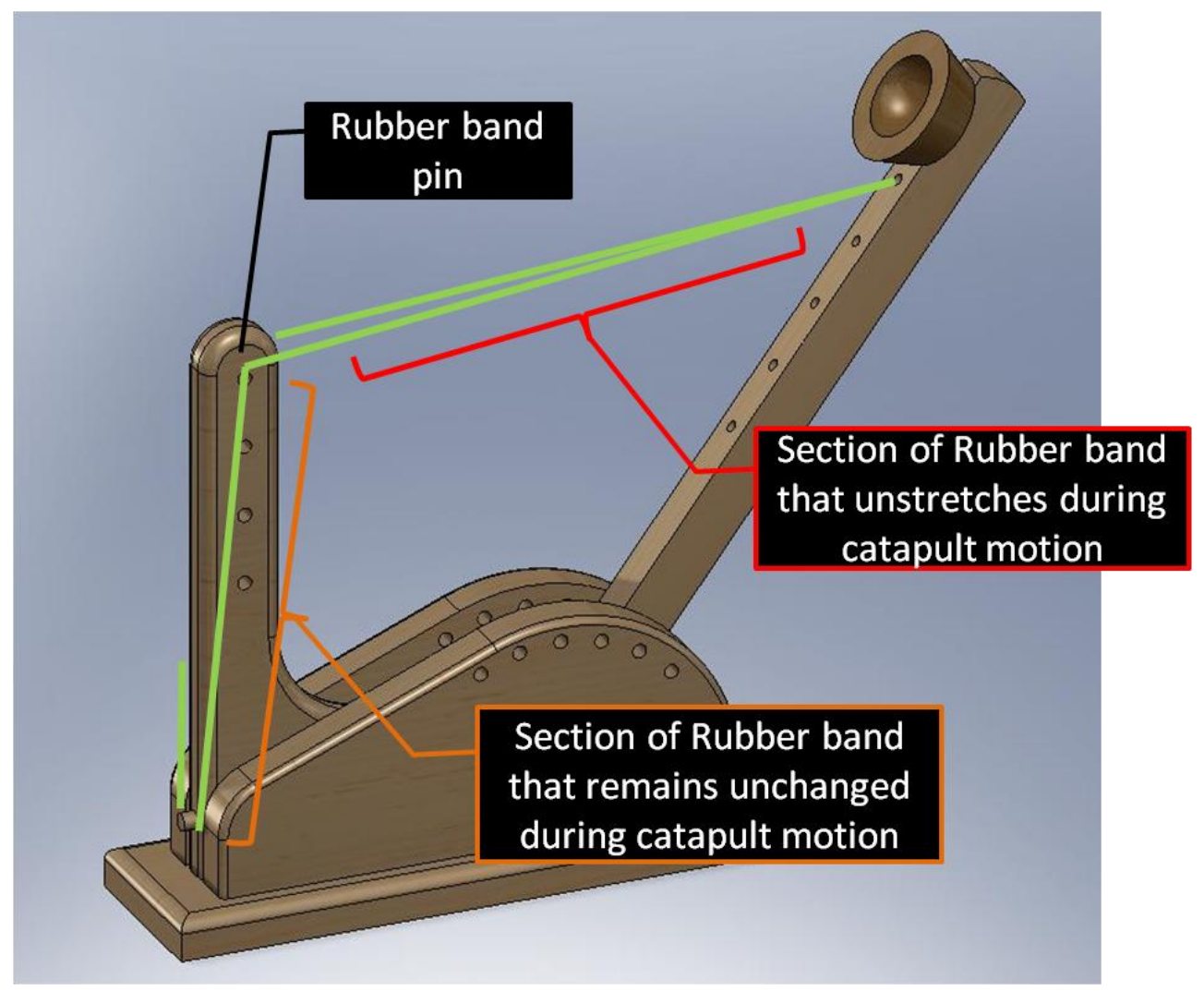

Figure 37. Diagram of unstretching and unchanged portions of rubber band during catapult motion.

After analyzing some initial strain gage results, we realized that the strain measurement for a no-load condition changed every time. There appeared to be an offset after every trial; therefore a study was conducted to see if any residual strain was present after each catapult launch. Shown in Figure 38 is the axial strain study for the catapult arm, using the P3 Strain Indicator and Recorder. We can see a linear strain increase of about $0.5 \mu \varepsilon$ per trial. Ideally, we 
would want to re-zero the catapult every time to the no-load state. However, since many students could potentially be taking the data during launch day, we needed a more efficient way of rezeroing the strains. This could potentially be accomplished by simply matching the initial strain magnitudes of the theoretical and experimental strains.

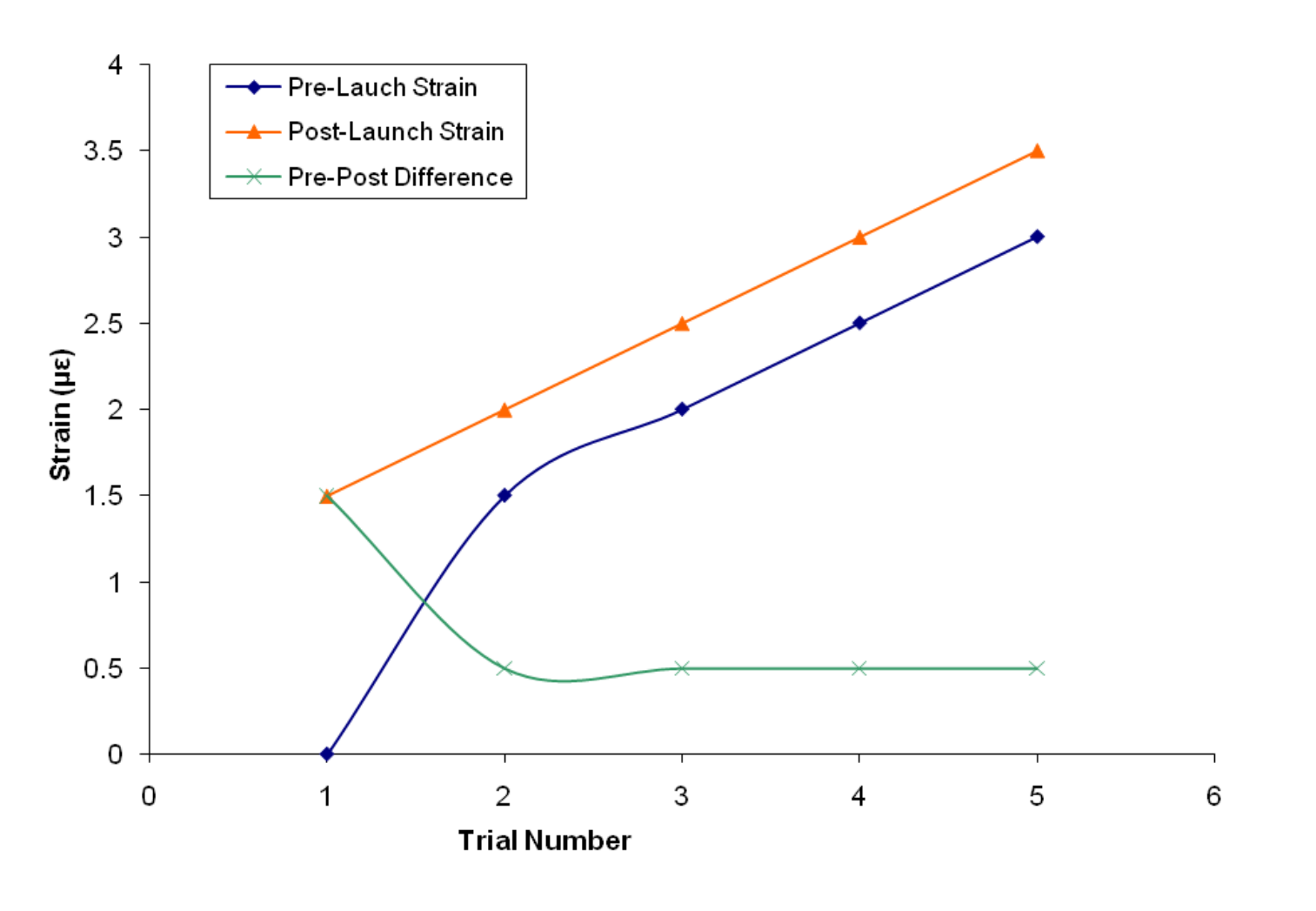

Figure 38. Residual axial strain study for catapult arm for five catapult launches.

Shown in Figure 39 is the MatLab output for the results of the axial and moment strains for a single trial. The first plot in the figure shows the raw voltage in $m V_{\text {output }} / \mathrm{V}_{\text {excitation }}$ for each of the Wheatstone bridges. Shown in the second two plots are the axial strain and moment strain, rescaled as mentioned previously, and calculated using the below equation (National Instruments 2009).

$$
\frac{V_{o}}{V_{\text {excitation }}}=\frac{S_{g} \epsilon}{2}
$$


From the first two plots of Figure 39, it can be seen that strain gages did pick up the impact and the resultant oscillations afterwards. However, as shown in the third and fourth plots, it appeared that the actual axial and moment strain of the catapult arm was much smaller than the theoretical model. Also, a lot of noise was present in the signal, due to the measured strain being so small. Because of this, not very much useful strain data could be obtained from the duration of free catapult motion.

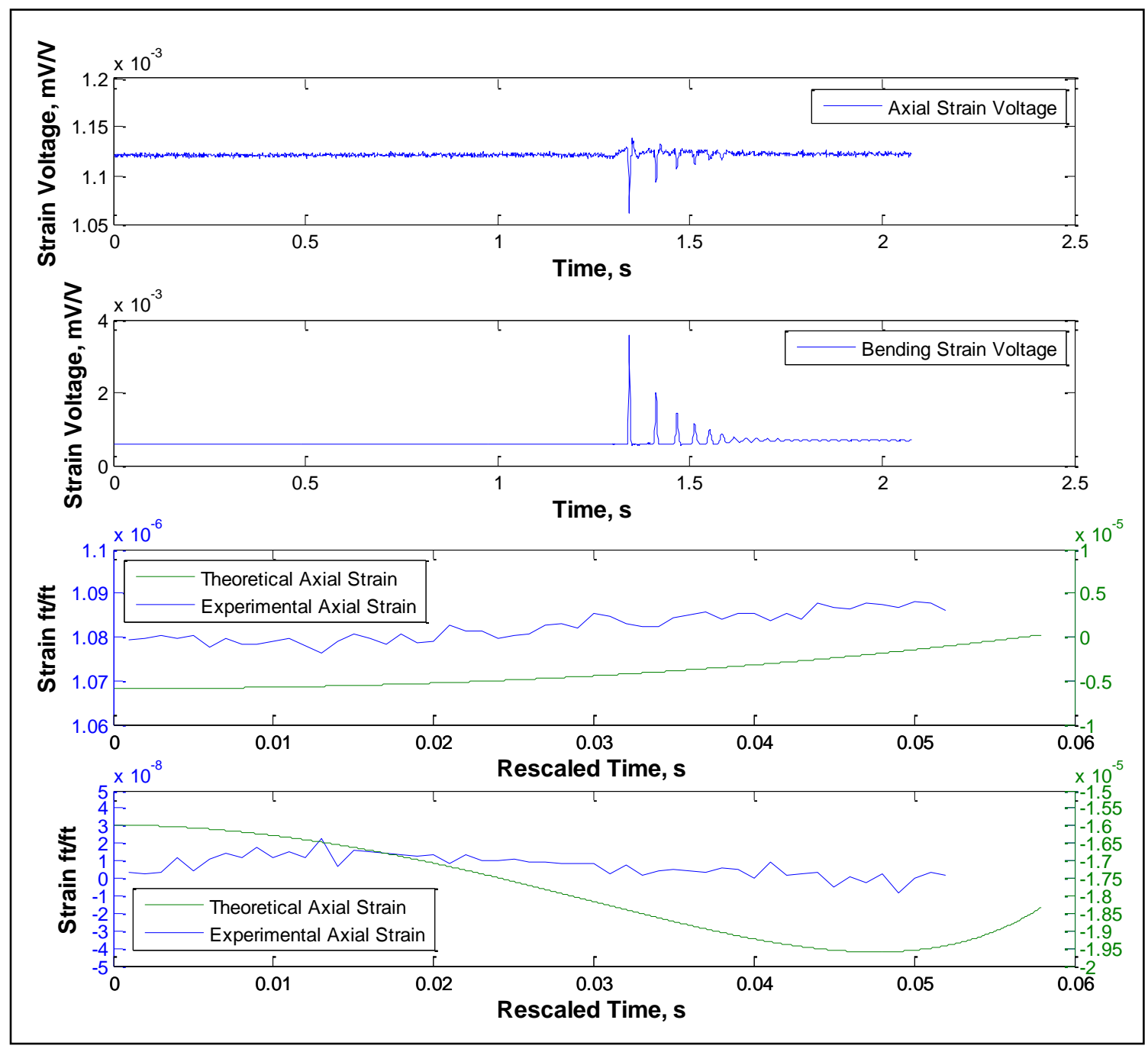

Figure 39. MatLab output of axial strain and moment strain with corresponding theoretical results for a catapult pullback angle of $180^{\circ}$ and stopper angle of $125^{\circ}$. 
Even so, the strain profiles in the third and fourth plots of Figure 39 show a resemblance with the theoretical model, although they are both noisy and off by orders of magnitude. This means that the strain could have been be performing as expected, however the strain gage was not sensitive enough to make a precise measurement. The strains however, despite having an unexpected magnitude, were used to determine useful information about the impact time. Shown in Figure 40 is the estimated duration of impact, using the moment strain output. The start of the plot was obtained by finding the time where the angular acceleration became negative, and ended when the moment strain returned to its pre-impact state.

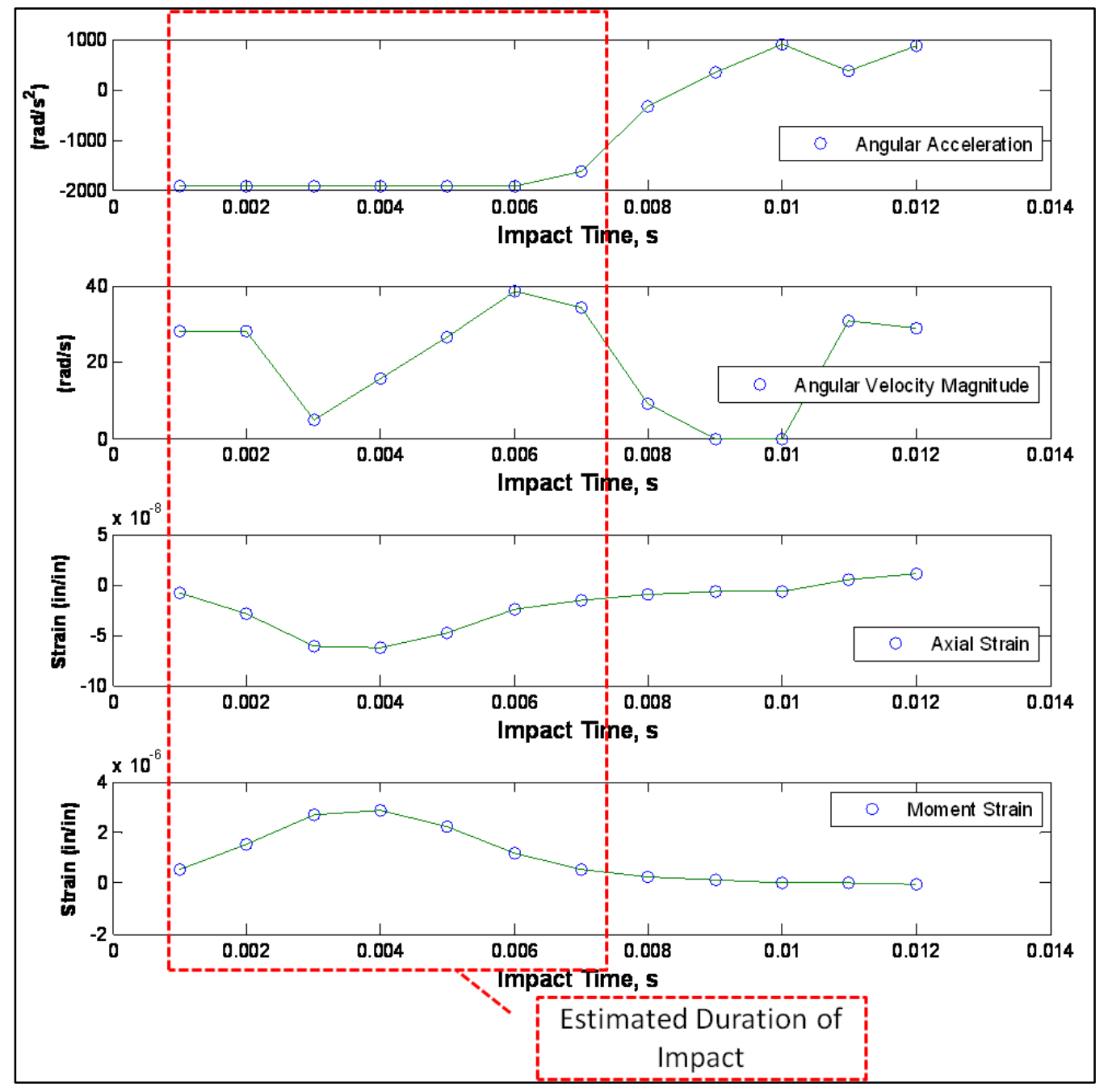

Figure 40. MatLab output of axial strain, moment strain, angular acceleration, and angular velocity magnitude during the impact, with catapult pullback angle of $180^{\circ}$ and stopper angle of $125^{\circ}$. 
The experimental results for angular acceleration were much lower than expected during the impact, shown in the first plot of Figure 40. Theoretically, integrating the angular acceleration from zero to the time it takes for the catapult arm to approach a zero velocity should equal the angular velocity just before the impact. However, since our ADXL-278 is only rated for $\pm 50 \mathrm{~g}$, our angular acceleration is actually outside the maximum range that can be measured by the accelerometer. For example, a linear change from $\omega=35 \mathrm{rad} / \mathrm{s}$ to $0 \mathrm{rad} / \mathrm{s}$ in $0.003 \mathrm{~seconds}$ would correspond to an constant angular acceleration of $3920 \mathrm{rad} / \mathrm{s}^{2}$. Based on the positioning of the accelerometer, this angular acceleration corresponds to a linear tangential acceleration of nearly 400g's. Also, we see that the final angular velocity magnitude is higher than the initial angular velocity magnitude during the impact, which is impossible. This was likely due to the extreme spike in acceleration, which caused the accelerometer to operate outside of its intended rated range. The vibration that occurred during the impact also could have caused incorrect readings.

Because of these incorrect readings of angular acceleration and angular velocity, the time of impact determined from the moment strain profile was used to roughly estimate the force on the stopper pin. Ideally, we would have used the change in the experimentally measured velocity with respect to time. However as we mentioned previously, these values were ultimately incorrect. Instead, using impulse momentum principles, we estimated the impact force by simplifying equation (8) to equation (9). This simplification was done by assuming that the force was constant during impact and that the collision was perfectly elastic, setting $\omega_{\text {impact_final }}=-\omega_{\text {impact_initial }}$. The case shown in Figure 30 would correspond with an average stopper pin force of approximately $250 \mathrm{lbs}$. 


$$
\begin{gathered}
\int_{t_{1}}^{t_{2}} \sum M_{O} d t=\Delta H \\
F_{\text {avg }}=\frac{2 I \omega_{\text {impact_initial }}}{t * L_{\text {stoppe }} r}
\end{gathered}
$$

\section{Catapult Instrument Summary and Recommendations}

Overall, we accomplished the goals of the instrumentation that we initially set out to complete. Although some equipment, such as the strain gages, did not function as we intended, all of the instruments provided meaningful data that were used to quantify the physical catapult. However, there are several recommendations that can be made after my experience with this first attempt. First, another data acquisition system should be used. The task of acquiring the signals could have been more easily done with a CompactDAQ, which is both cheaper and can scan more quickly in real-time mode. An increased scan rate would result in a better position calculation, and could possibly better capture the data during impact time. Second, the strain gages should be set up to measure a larger magnitude of strain, by either hallowing out some material to increase stress and strain, or by using a different strain gage. This would allow for a much better signal-to-noise ratio, which was very high during our trials. In addition to increasing the strain magnitude, some filtering technique could also be investigated. However at the moment, the strain magnitude is too small for any kind of filtering.

We also attempted to compensate for the effect of the nonuniform unstretching of the rubber band by modeling a percentage of energy that was dissipated, as well as changing the theoretical stretch distance. Both methods had a worse result than the original model. For future runs, the rubber band should be pinned at the point of rotation and a force-displacement curve measured. 
The current LabView Virtual Instrument could also be set up for an external trigger if desired. This way of acquiring the data could have LabView constantly taking readings, with an external trigger signaling to write the next few seconds of measurements to a file. This method could become useful if the current system is too slow for students to use during launch day.

The instrumentation should be effective in providing students for an additional means of self-assessment. By furthering the principles of self-assessment and reality, it has the potential to make the catapult project a better and more effective MEA. In addition, we now know the time of impact of the catapult arm, which was previously just assumed. 


\section{Overall Response to MEAs}

The student responses to VAR and Catapult MEAs were assessed by a post-course evaluation survey of 23 questions. The questions asked in Figure 41 and Figure 42 simply asked if a student agreed with the statement shown. As shown in Figure 41, the overall response was positive, with most students agreeing that the MEAs were motivational learning tools. However, when we examined the responses to traditional assignments, students felt that the individual homework assignments helped them learn the material better, shown in Figure 42. We believe that this was because some students were accustomed to a more traditional type of learning, which focused on individual textbook problem solving. Figure 42 also shows some student resistance to team-type assignments, which could have influenced their opinion on MEAs.

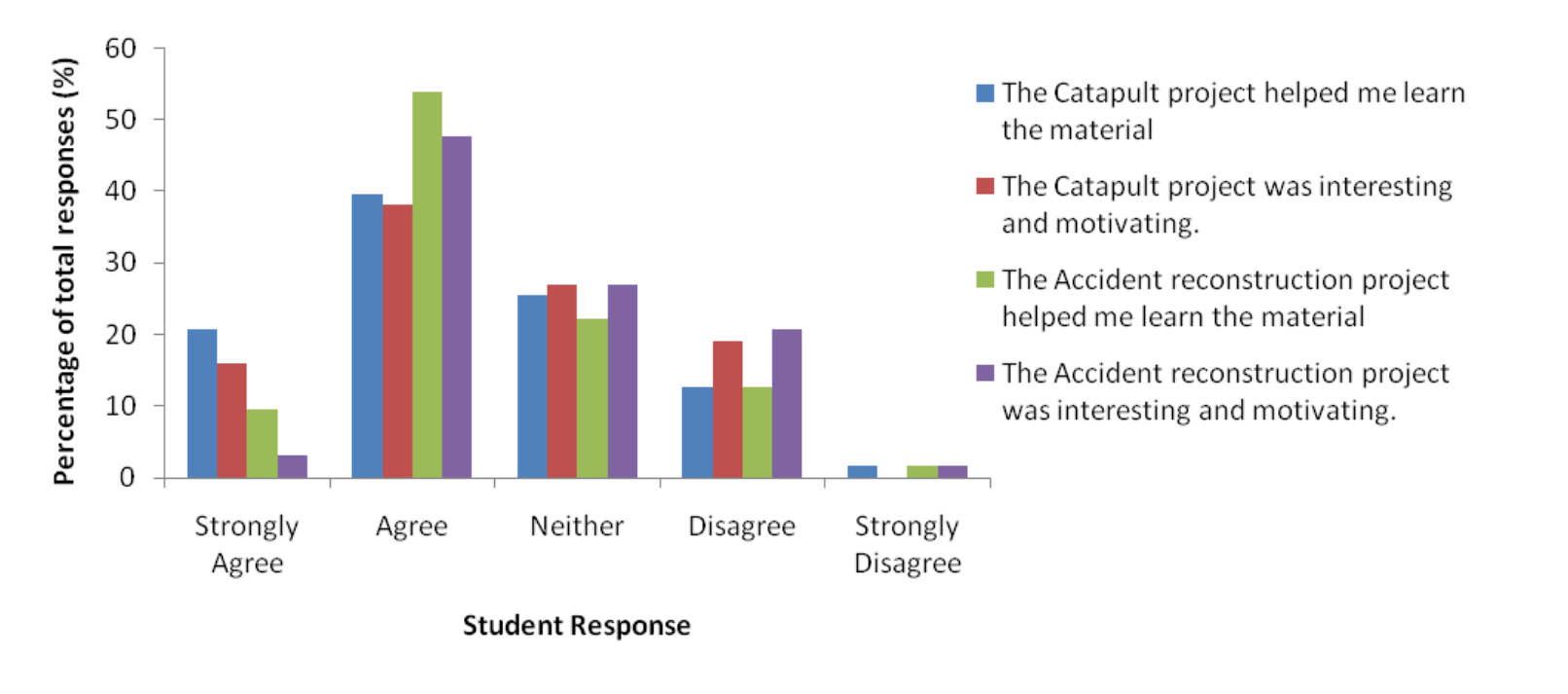

Figure 41. Student responses for the MEA projects for Spring quarter. 


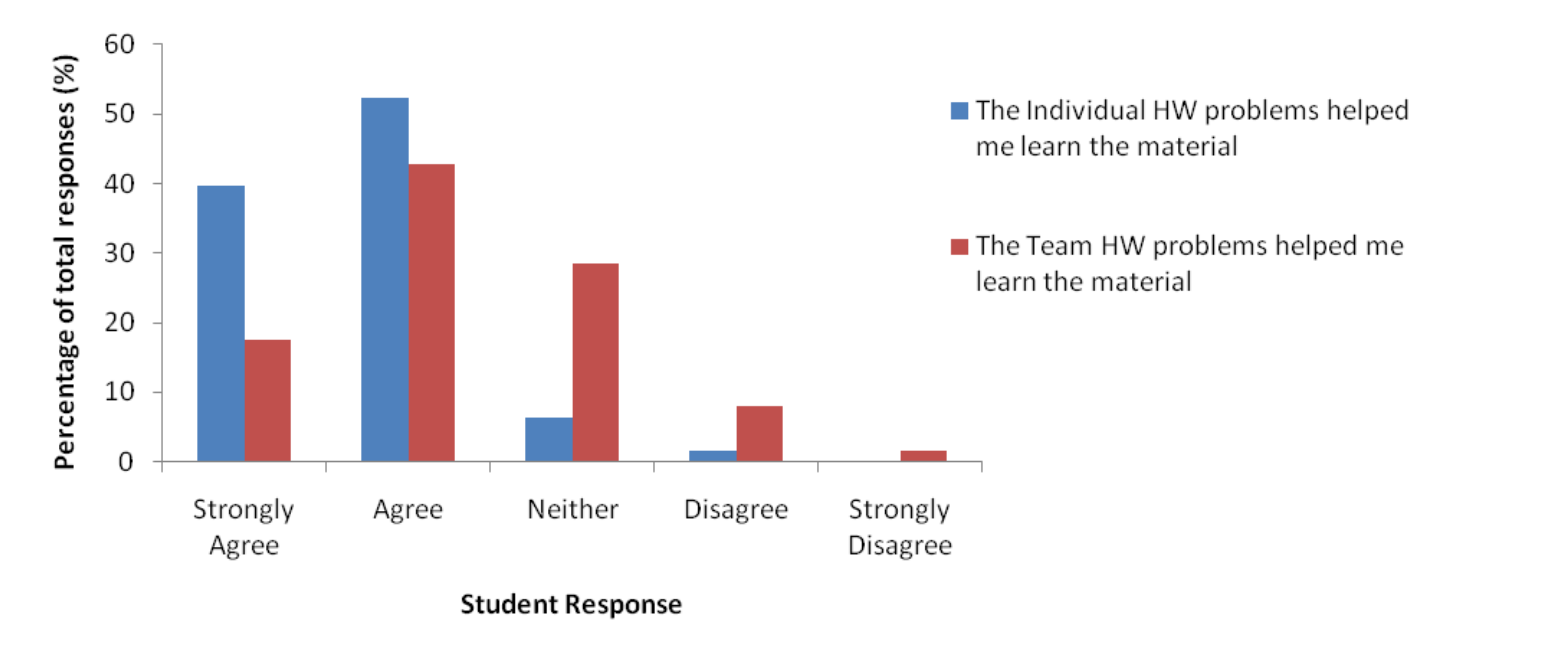

Figure 42. Student responses for HW assignments for Spring quarter.

The post-course survey question "Some students seemed to lack motivation for the class. We tried to do the real world projects and show different applications of the material. What else should we do to increase student motivation?" required a written-response, and generated some very interesting responses. There were three typical student responses to this question. The first was very positive, indicating that the student had benefitted greatly from the projects, and was grateful for the class experience. Several students recognized that those projects required heavy instructor time commitment, and explicitly thanked the professor. The second response was neutral, saying that the projects neither helped nor hindered their learning. Some stated that nothing could motivate them because they were not interested in subject matter at all. The third student response was negative, saying that the project was "too much work" and irrelevant to what he was learning.

Focusing specifically on the VAR MEA, a thematic analysis was conducted for two survey questions. These questions asked for written responses from 258 students in two quarters of Dynamics courses. The first question asked, "What did you like about the [VAR] Project and why?" Shown in Figure 43 are the comments sorted into six major categories. Fifty percent of 
the responses indicated that students enjoyed having a realistic context. Seventeen percent stated specifically that students liked either the case report format, the client setting, or the overall assignment structure. Another seventeen percent of the comments stated that the project helped students learn the principles of work-energy and momentum. The final fifteen percent of the comments stated that students enjoyed the group aspect of the project.

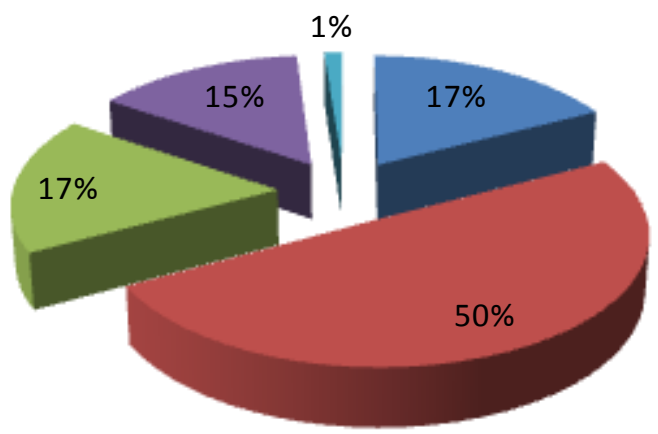

\section{Positive Comments}

Reinforced Concepts

Realistic Problems

Assignment Structure

- Group

- Other

Figure 43. Responses to the survey question "What did you like about the [VAR] Project and why?"

The next question asked, "What didn't you like about the [VAR] Project and why?" These comments were also broken down into six major categories, as shown in Figure 44. Thirty-four percent of the comments were critical of the overall vagueness of the problem statements and the information provided. Twenty-five percent of the comments were complaints of the heavy time commitment or the difficulty of the project. Twenty percent were complaints of the team aspect, with students indicating that they had difficulty working with their groups. The remaining six and seven percent of the comments were critical of the grading criteria and the increased writing efforts of the memo, respectively. 

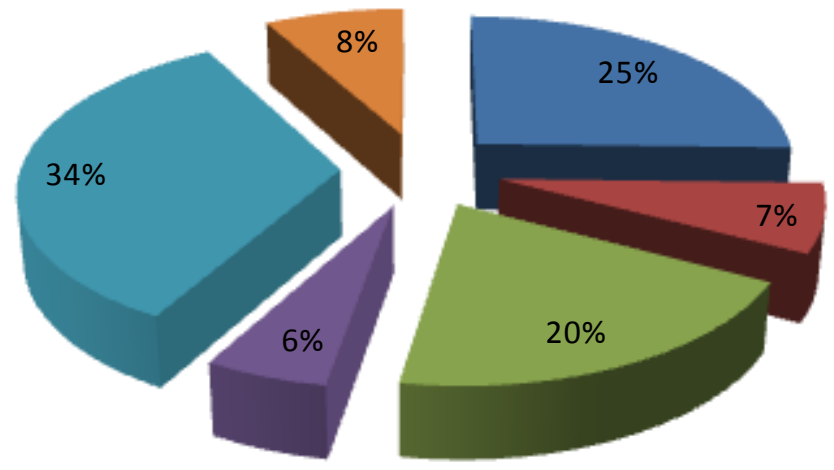

Negative Comments

- Time/Difficulty

- Writing

Group

- Grading

Vagueness

n Other

Figure 44. Responses to the survey question "What didn't you like about the [VAR] Project and why?" 


\section{Conclusion}

The development of the Catapult and VAR MEAs have been a significant task for the research team over the course of the past year. Over the past three quarters, we have been able to refine the projects, making them better teaching tools, and better MEAs. The VAR GUI was intended to reduce instructor time commitment, while facilitating the use of the VAR MEA for other universities. The Catapult instrumentation was intended to expand upon the reality and self-assessment principles of the MEA by allowing students to connect their physical project with experimental data. While we initially thought that VAR GUI and the Catapult instrumentation would be relatively simple, once we began, we quickly realized that they would require some serious time commitment.

Students who were exposed to the VAR MEA scored noticeably higher in the Dynamics Concept Inventory exam than students who were not. Because of this, we were encouraged to develop the VAR GUI to help cut down the instructor and teaching assistant development time. Currently, since we are operating on the CCLI grant, we are able to dedicate several people to developing and assessing the MEA. However, we wanted this project to carry on long after our grant was finished. When only a single instructor is responsible for developing new VAR cases and grading them, the GUI will greatly reduce the amount of time he will have to commit. The GUI can help develop new case scenarios, and check the validity of student models.

The Catapult instrumentation was, by far, one of the most time consuming developments in the MEA program. We were glad to see that we could capture some valid data for the angular acceleration and velocity, despite the strain gages not functioning as we intended. Even so, we believe that it will provide for great self-assessment tool for students to check their theoretical models. Some of the development time could have been reduced by acquiring some new 
equipment. For example, using a simple USB-based multi-channel data acquisition system would have eliminated programming of a relatively complex LabView instrument. However to keep costs down, we utilized what was available. Since the catapult instrumentation has yet to be tested in a classroom, no student responses are available for the instrumentation itself. However, we are confident that students will appreciate being able to validate their own theoretical model with the actual data of their launch. All of the hardware and software has been designed to operate very simply. Ideally, each student team will be able to take an individual set of data for each launch. Using their experimental data, they will be able to validate and refine their model accordingly.

We believe that the MEAs that we have implemented have improved the student experience at Cal Poly. As stated previously, the overall student response to the MEAs have been positive. However, when students are exposed to a different kind of teaching than they are traditionally accustomed to, some resistance to the change is to be expected. Even so, we hope that more students will learn to accept that these MEAs really do have a positive impact on their learning, and better prepare them to their future professions in industry. 


\section{Works Cited}

Boyer Commission on Education Undergraduates in the Research University. Reinventing Undergraduate Education: A Blueprint for America's Research Universities. Stony Brook, NY:

State University of New York at Stony Brook for the Carnegie Foundation for the Advancement of Teaching, 1998.

Chamberlin, Scott A. "How does the Problem-Based Learning Approach Compare to the ModelEliciting Activity Approach in Mathematics Instruction?" International Journal of Mathematics Teaching and Learning, 2008.

Goodwin, Lora. "Is There a Correlation Between Conceptual Understanding and Procedural Knowledge in Introductory Dynamics?" ASEE PSW Conference. San Diego, CA: ASEE, 2009.

Gray, Gary L. "The Dynamics Concept Inventory Assessment Test: A Progress Report and Some Results." American Society for Engineering Education Annual Conference \& Exposition. Portland, Oregon: American Society for Engineering Education, 2005. 1.

J.L. Meriam, L.G. Kraige. Engineering Mechanics Dynamics. New York, NY: John Wiley \& Sons, Inc., 2002.

Jolley, William O. "A Fun and Challenging Engineering Dynamics Project Using a Lego Construction Set." American Society for Engineering Education Annual. Nashville, Tennessee: American Society for Engineering Education, 2003. 1.

Lesh, Richard. Beyond Constructivism: Models and Modeling Perspectives on Mathematics. Mahwah, NJ: Lawrence Erlbaum Associates, 2004.

-. Handbook of Research Design in Mathematics and Science Education. Mahwah, NJ: Lawrence Erlbaum Associates, 2000.

National Instruments. Measuring Strain with Strain Gages. June 26, 2009. http://zone.ni.com/devzone/cda/tut/p/id/3642 (accessed August 18, 2009).

-. Using CompactRIO Scan Mode with Unsupported Backplanes. November 13, 2008. http://digital.ni.com/public.nsf/allkb/122E971F52FD081A86257500007A046C (accessed August 16, 2009).

Prince, Michael. "Does Active Learning Work? A Review of the Research." Journal of Engineering Education, 2004.

Reffeor, Wendy. "Incorporating Design in an Introduction to Dynamics Course." ASEE Annual Conference and Exposition. Montréal, Quebec, Canada: ASEE, 2002. 
Savery, John R. "Overview of Problem-based Learning: Definitions and Distinctions." Interdisciplinary Journal of Problem-based Learning: Vol. 1: Issue 1, Article 3, 2006.

Self, Brian. National Science Foundation: Collaborative Research: Improving Engineering Students' Learning Strategies through Models and Modeling. August 31, 2007.

http://www.nsf.gov/awardsearch/showAward.do?AwardNumber=0717595 (accessed August 18, 2009).

Smithsonian Institution. Smithsonian Physical Tables. Washington, D.C.: Smithsonian Institution Press, 1969.

Vishay Micro-Measurements. Instruction Bulletin B-137-16: Strain Gage Applications with MBond AE-10, AE-15, and GA-2 Adhesive Systems. Don Mills, ON, February 4, 2005. 


\section{Appendix A VAR Case 1}

SRI LANKA POLICE DEPARTMENT MAJOR ACCIDENT INVESTIGATION TEAM

\begin{tabular}{lcccc} 
DATE OF NCIDENT & TME & NCIC NUMBER & OFFICER I.D. & NUMBER \\
April 29.2006 & 0422 & 3710 & 1120 & $06-015741$ \\
\hline
\end{tabular}

\section{INTRODUCTION}

This traffic collision occurred on Saturday April 29, 2006, at approximately 0422 hours. This traffic collision occurred on Pallamadu Rd, within the City of Colombo.

The collision involved a 1994 white Ford Explorer driven by

henceforth referred to as Driver A.

The Ford was traveling northbound on Pallamadu Rd in the number 1 lane of travel at an unknown speed when the driver somehow lost control of the vehicle. The vehicle rolled over onto its top side in the number 2 lane of travel and proceeded to skid 255 feet on the asphalt roadway.

Driver A received minor injuries to the arms and head by broken glass and was treated on the scene by emergency personnel.

\section{SCENE :}

Section omitted.

\section{Weather Condition}

The following weather conditions were noted at Colombo Airport. The airport is located about $1 / 4$ mile from the scene.

\begin{tabular}{|l|l|l|l|l|l|l|l|}
\hline Time & Temperature & Dew Point & Humidity & Pressure & Visibility & Wind & Conditions \\
\hline 0352 & $66.8^{\circ} \mathrm{F}$ & $64.7^{\circ} \mathrm{F}$ & $81 \%$ & 29.95 in & 8 miles & Calm & Clear \\
\hline 0452 & $66.2^{\circ} \mathrm{F}$ & $64.3^{\circ} \mathrm{F}$ & $83 \%$ & 29.96 in & 8 miles & Calm & Clear \\
\hline 0552 & $65.7^{\circ} \mathrm{F}$ & $60.2^{\circ} \mathrm{F}$ & $92 \%$ & 29.95 in & 8 miles & $3.2 \mathrm{mph}$ NNW & Clear \\
\hline
\end{tabular}

\section{$\underline{\text { Traffic Control }}$}

The posted speed for the road in the area of this collision is $45 \mathrm{mph}$. The speed limit is clearly posted for both sides with Type R $45 \mathrm{MPH}$ speed limit signs. The speed limit was established by a traffic engineering and speed survey.

$\begin{array}{lcccc}\text { MALT PREPARER'S NAME } & \text { I.D. NUMBER } & \text { DATE } & \text { REVIEWER'S NAME } & \text { DATE } \\ \text { A. Ahubudu } & 1120 & 4 / 29 / 06 & & \end{array}$


SRI LANKA POLICE DEPARTMENT MAJOR ACCIDENT INVESTIGATION TEAM

\begin{tabular}{llccc} 
DATE OF DNCIDENT & TME & NCIC NUMBER & OFFICER I.D. & NUMBER \\
April 29.2006 & 0422 & 3710 & 1120 & $06-015741$ \\
\hline
\end{tabular}

\section{VEHICLES}

Vehicle One (1994 Ford Explorer)

\section{$\underline{\text { Description }}$}

$\begin{array}{ll}\text { Year: } & 1994 \\ \text { Make: } & \begin{array}{l}\text { Ford } \\ \text { Model: }\end{array} \\ \text { License: } & \\ \text { VIN: } & \\ \text { Engine: } & 1.5 \mathrm{~L} \mathrm{V4} \\ \text { Transmission: } & 5 \text { speed Manual } \\ \text { Color: } & \text { White } \\ \text { Type: } & 2 \text { door } \\ \text { Weight: } & 4580 \text { pounds } \\ \text { Length: } & 174.5 \text { inches (4673 mm) } \\ \text { Height: } & 67.5 \text { inches (1714 mm) } \\ \text { Width: } & 70.2 \text { inches (1778 mm) } \\ \text { Center of gravity: } & 24.1 \text { inches (height) }\end{array}$

\section{Damage Description:}

Front:

Minor to moderate damage was sustained to the front right portion of V1.

$\underline{\text { Right }}$

Minor to moderate damage was sustained to this portion of V1. This damage consisted of scrapings where V1 was in contact with the road and broken side windows.

$\underline{\text { Left }}$

I did not observed any damage to this portion of V1.

$\underline{\text { Rear }}$

I did not observed any damage to this portion of V1.

$\underline{\text { Roof }}$

Moderate damage was sustained to the roof of V1 but the average height of V1 remained unchanged.

$\begin{array}{llll}\text { MALT PREPARER'S NAME } & \text { ID. NUMBER DATE REVIEWER'S NAME }\end{array}$

A. Ahubudu $\quad 1120 \quad 4 / 29 / 06$




\section{Appendix B VAR Case 2}

SRI LANMA POLICE DEPARTMENT MAJOR ACCIDENT INVESTGGATION TEAM

\begin{tabular}{lcccc} 
DATE OF INCDENT & TME & NCIC NUMBER & OFFICER I.D. & NUMBER \\
June 20.2006 & 0518 & 3710 & 1120 & $06-017742$ \\
\hline
\end{tabular}

\section{INTRODUCTION}

This traffic collision occurred on Friday June 20, 2006, at approximately 0518 hours. This traffic collision occurred on Jawatte Rd, within the City of Colombo.

The collision involved a 1999 red Nissan Super Saloon driven by Fiesta driven by

and a 1994 black Ford

The Nissan was traveling northbound on Jawatte Rd up a 7\% grade. As the Nissan reached the top of the grade it collided head on with the Ford which was traveling southbound. The road north of the collision point, on which the Ford had been traveling, had a $0 \%$ grade. After impact, both vehicles slid together with locked wheels 5.8 meters down the hill.

Prior to the accident, a third driver reported that the Nissan was travelling approximately $18-25 \mathrm{~km} / \mathrm{h}$. The officer then left to respond to another incident on Kelaniya Rd.

Physical evidence at the scene indicated that the driver of the Ford was aware that he was about to impact Nissan. Wheel locked skid marks just prior to the collision were measured to be 9.4 meters in length and matched the tire pattern of the Ford. Roadway conditions at the time of the accident were slightly wet.

\section{SCENE :}

Section omitted.

\section{Weather Condition}

The following weather conditions were noted at Colombo Airport. The airport is located about $3.2 \mathrm{~km}$ from the scene.

\begin{tabular}{|l|l|l|l|l|l|l|l|}
\hline Time & Temperature & Dew Point & Humidity & Pressure & Visibility & Wind & Conditions \\
\hline 0452 & $19.3^{\circ} \mathrm{C}$ & $18.2^{\circ} \mathrm{C}$ & $81 \%$ & $760.7 \mathrm{~mm} \mathrm{H}_{2} 0$ & $12.9 \mathrm{~km}$ & Calm & Light Rain \\
\hline 0552 & $16.8^{\circ} \mathrm{C}$ & $17.9^{\circ} \mathrm{C}$ & $83 \%$ & $761.0 \mathrm{~mm} \mathrm{H}_{2} 0$ & $12.9 \mathrm{~km}$ & Calm & Foggy \\
\hline 0652 & $18.7^{\circ} \mathrm{C}$ & $15.7^{\circ} \mathrm{C}$ & $92 \%$ & $760.7 \mathrm{~mm} \mathrm{H}_{2} 0$ & $12.9 \mathrm{~km}$ & $5.1 \mathrm{~km} / \mathrm{h} \mathrm{NNW}$ & Foggy \\
\hline
\end{tabular}

\section{$\underline{\text { Traffic Control }}$}

The posted speed for the road in the area of this collision is $40 \mathrm{~km} / \mathrm{h}$. The speed limit is clearly posted for both sides with Type R $40 \mathrm{KM} / \mathrm{H}$ speed limit signs. The speed limit was established by a traffic engineering and speed survey.

\section{VEHICLES}

$\begin{array}{lcccc}\text { MALT PREPARER'S NAME } & \text { ID. NUMBER } & \text { DATE } & \text { REVIEWER'S NAME } & \text { DATE } \\ \text { A. Ahubudu } & 1120 & 6 / 20 / 06 & \end{array}$


SRI LANKA POLICE DEPARTMENT MAJOR ACCIDENT INVESTGATION TEAM

DATE OF INCIDENT

June 20,2006

TINE

NCIC NUMBER

OFFICER I.D

3710

1120

NUMBER

06-017742

Vehicle One (1999 Nissan Super Saloon)

\section{Description}

$\begin{array}{ll}\text { Year: } & 1999 \\ \text { Make: } & \text { Nissan } \\ \text { Model: } & \text { Super Saloon } \\ \text { License: } & \\ \text { VIN: } & \\ \text { Engine: } & 2200 \mathrm{cc} \mathrm{V4} \\ \text { Transmission: } & 5 \text { speed Manual } \\ \text { Color: } & \text { Red } \\ \text { Type: } & 4 \text { door } \\ \text { Weight: } & 1225 \mathrm{~kg}\end{array}$

Damage Description:

Front:

There was moderate to severe damage to this portion of V 1. There was crumpling and creasing to the hood and sub-frame, along with breaks to the plastic front grill. Both headlights were broken out. An examination of the broken bulbs showed oxidation and melting to the filament. This indicated that the headlights were in the "On" position at the time of this collision. Some of the engine fluids (oil, coolant, brake fluid, etc.) had spilled onto the roadway at the collision scene.

\section{$\underline{\text { Right }}$}

V1 sustained no visible damage to this end.

$\underline{\text { Left }}$

V1 sustained no visible damage to this end.

$\underline{\text { Rear }}$

V1 sustained no visible damage to this end.

$\underline{\text { Roof }}$

V1 sustained no visible damage to this end.

\section{VEHICLES (Continued)}

$\begin{array}{lcccc}\text { MALT PREPARER'S NAME } & \text { ID. NUMBER } & \text { DATE } & \text { REVIEWER'S NAME } & \text { DATE } \\ \text { A. Ahubudu } & 1120 & 6 / 20 / 06 & & \end{array}$




\title{
Appendix C VAR Case 3
}

\author{
SRI LANKA POLICE DEPARTMENT MAJOR ACCIDENT INVESTIGATION TEAM
}

\begin{tabular}{|c|c|c|c|c|}
\hline $\begin{array}{l}\text { DATE OF INCDENT } \\
\text { June } 24.2006\end{array}$ & $\begin{array}{l}\text { TDME } \\
0445\end{array}$ & $\begin{array}{c}\text { NCIC NUMBER } \\
3710\end{array}$ & $\begin{array}{c}\text { OFFICER ID. } \\
1120\end{array}$ & $\begin{array}{l}\text { NUMBER } \\
06-014874\end{array}$ \\
\hline
\end{tabular}

\section{INTRODUCTION}

This traffic collision occurred on Saturday June 24, 2006, at approximately 0445 hours. This collision occurred within the intersection of Route A4 and Benet Rd, within the incorporated City of Colombo.

This collision involved a 2006 Acura TSX (V1) and a 2004 Ford Sterling Cement Truck (V2). The Acura was driven by henceforth referred to as Person 1. The Ford was driven by henceforth referred to as Person 2. The passenger in the Acura, seated in the front right seat, was

The Acura was traveling eastbound on Route A4, in the number two lane of travel. The Ford had just entered the intersection, from the right turn lane, southbound Benet Rd to westbound Route A4. At impact, the Ford was in second gear. Maximum speed for a vehicle of this size, in second gear is $11-16 \mathrm{~km} / \mathrm{h}$. This data can be supported by several case studies from the American National Highway Traffic Safety Administration and other related studies involving vehicles of this size.

Witnesses indicated that the Ford was halfway through its turn, facing the southwest direction, when it was struck by the Acura.

\section{PHYSICAL EVIDENCE}

I documented the scene, walking from east to west. On the south side of Route A4 in the number two lane of eastbound traffic, I noticed skid from V1. This skid was measured by a roll meter with a distance of 20 meters. An additional 6 meters of skid was within the intersection, caused by the two vehicles sliding together. This evidence leads me to believe that P1 noticed V2 turning in the intersection and applied his brakes in a "Panic" situation.

At the collision scene, there was evidence of V 1 and V2's impact within the intersection. V1 was still impacted with the front left tire of V2. There was a mixture of engine fluids, vehicle parts, and glass. Using marking paint, I painted both V1 and V2 in their original positions before they were moved by tow trucks.

An interior inspection of V2 showed that it was "locked" in second gear and even when depressing the clutch, I could not remove the vehicle out of second gear. The tow driver had to manually unlock the transmission to move V2.

MAIT PREPARER'S NAME

A. Ahubudu
I.D. NUMBER 1120
DATE 6/24/06
REVIEWER'S NAME

DATE 


\begin{tabular}{|c|c|c|c|c|}
\hline $\begin{array}{l}\text { DATE OF INCDENT } \\
\text { June } 24,2006\end{array}$ & $\begin{array}{l}\text { TDME } \\
0445\end{array}$ & $\begin{array}{c}\text { NCIC NUMBER } \\
3710\end{array}$ & $\begin{array}{c}\text { OFFICER ID. } \\
1120\end{array}$ & $\begin{array}{l}\text { NUMBER } \\
06-014874\end{array}$ \\
\hline
\end{tabular}

\section{VEHICLES (Continued)}

\section{Damage:}

Front:

The damage sustained to this portion of V 1 consisted of the entire front bumper being removed from the vehicle. The right side headlight assembly was completely broken out. An inspection of the broken headlight assembly, with the exposed headlight bulb filament, showed signs of oxidation and melting of the filament. This evidence showed that P1 had the headlights of V1 in the "On" position. The hood and right quarter panel was crumpled and dented. V1 had also expelled some of its engine fluids, i.e. Radiator fluid, oil, brake fluid.

Right:

The only damage sustained on this side of V 1 was the front right quarter panel. This damage consisted of the quarter panel being dented and crushed.

Left:

Besides slight crumpling and warping to the front left quarter panel, no other damage was sustained to this side of V1.

$\underline{\text { Rear: }}$

I did not observe any damage to this portion of V1.

$\underline{\text { Roof: }}$

I did not observe any damage to this portion of V1.

MAIT PREPARER'S NAME

A. Ahubudu
I.D. NUMBER

1120
DATE

$6 / 24 / 06$
REVIEWER'S NAME

DATE 
SRI LANKA POLICE DEPARTMENT MAJOR ACCIDENT INVESTIGATION TEAM

\begin{tabular}{|c|c|c|c|c|}
\hline DATE OF INCIDENT & TDME & NCIC NUMBER & OFFICER ID. & NUMBER \\
\hline June 24,2006 & 0445 & 3710 & 1120 & $06-014874$ \\
\hline
\end{tabular}

\section{VEHICLES (Continued)}

Vehicle 2(V2, 2004 Ford Sterling)

\section{Description:}

$\begin{array}{ll}\text { Year: } & 2004 \\ \text { Make: } & \text { Ford } \\ \text { Model: } & \text { Sterling } \\ \text { License: } & \\ \text { VIN: } & \\ \text { Engine: } & \text { Mercedes MBE 4000 } 450 \\ \text { Transmission: } & 8 \mathrm{LL} \\ \text { Color: } & \text { White } \\ \text { Vehicle Type: } & 3 \text { Axle Short Pour Cement Mixer } \\ \text { Weight: } & \text { 8436 kg } \\ & \\ \text { Damage: } & \end{array}$

Front:

No visible damage had occurred to this side.

$\underline{\text { Left: }}$

No visible damage had occurred to this side.

$\underline{\text { Right: }}$

Besides the front right wheel assembly being broken, with several air and fluid lines broken, no other visible damage occurred to this side.

Rear:

No visible damage had occurred to this side.

MAIT PREPARER'S NAME

A. Ahubudu
I.D. NUMBER

1120
DATE

$6 / 24 / 06$
REVIEWER'S NAME

DATE 


\section{Appendix D VAR Case 4}

\section{SRI LANKA POLICE DEPARTMENT MAJOR ACCIDENT NVESTIGATION TEAM}

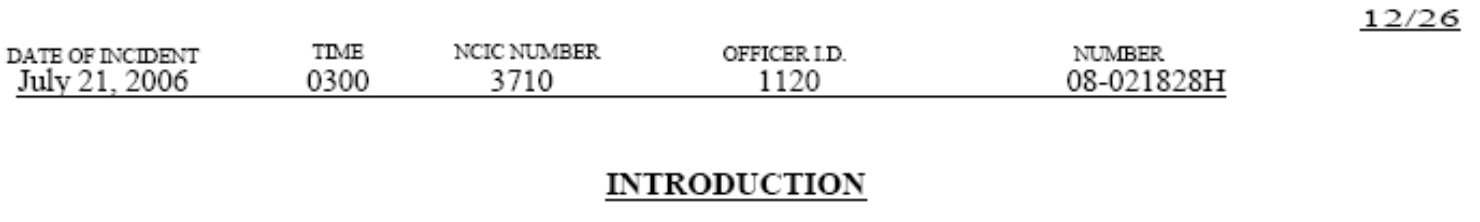

On Thursday, July 21, at 0300 hours, a traffic collision occurred on the junction of B79 and B243 (both one way highways).

A 1996 Honda Accord (V1) driven by and a 1998 Ford Focus (V2), driven by were the two vehicles involved in this collision. These drivers will be henceforth referred to as Person 1 and Person 2, respectively.

V1 was traveling eastbound on B79 (one-way), when it struck V2.

Person 2 was transported to a hospital to be treated for

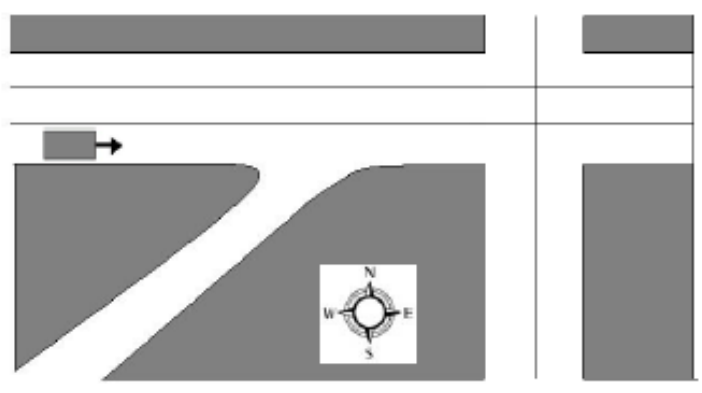
major injuries. Person 1 was treated for minor injuries on-site.

Based on the statement of Person 1, he had been driving under the speed limit when he suddenly was struck by Vehicle 2, and claims that Vehicle 2 suddenly veered across the merging lane. He states he has no recollection after that. Person 1's speed was confirmed by a speed camera which captured his speed at $100 \mathrm{~km} / \mathrm{h}$. Person 2 claims he was slowly merging into eastbound traffic, when Person 1 slammed into him. No pre-collision data was recorded for Vehicle 2. The figure above shows the area in which the collision occurred.

\section{PHYSICAL EVIDENCE}

No skid marks were present for the vehicles before the impact zone. The post-collision skidmarks measured to be $80 \mathrm{~m}$ for Vehicle 2 at an angle of $100^{\circ}$ from North, in the Southeast direction. The post-collision skidmarks measured to be $100 \mathrm{~m}$ for Vehicle 1 , at an angle of $45^{\circ}$ from north, in the Northeast direction. Both of these skid distances were measured from the impact zone to the final location of the vehicles.

The posted speed limit for both roads is $100 \mathrm{~km} / \mathrm{h}$.

\section{Roadway Description}

Section Omitted

\section{VEHICLES}

\section{Vehicle One (Vl. 1995 Honda Accord)}

Year: $\quad 1995$

Make: Honda

Model: Accord EX

Color: Green

License:

VIN: $\quad 2700 \mathrm{ccC} 27$

Engine: $\quad 2700 \mathrm{cc} \mathrm{C27}$

Transmission: 4 speed automatic

Weight: $\quad 1295 \mathrm{~kg}$ 
SRI LANKA POLICE DEPARTMENT MAJOR ACCDENT INVESTIGATION TEAM

\begin{tabular}{|c|c|c|c|c|c|}
\hline & & & & & $12 / 26$ \\
\hline $\begin{array}{l}\text { DATE OF INCIDENT } \\
\text { July } 21,2006\end{array}$ & $\begin{array}{l}\text { TDME } \\
0300\end{array}$ & $\begin{array}{c}\text { NCIC NUMBER } \\
3710 \\
\end{array}$ & $\begin{array}{c}\text { OFFICER ID. } \\
1120 \\
\end{array}$ & $\begin{array}{l}\text { NUMBER } \\
08-021828 \mathrm{H}\end{array}$ & \\
\hline
\end{tabular}

\section{Damage Description}

Front:

V1 sustained heavy damage to the front driver's side.

Left:

Minor Dents and Scratches

$\underline{\text { Right: }}$

Major damage was sustained on this side. Driver's-side door deflected at least a half-foot inwards.

Rear:

Various scrapes and dents.

\section{Vehicle Two (V2, 1998 Ford Focus)}

$\begin{array}{ll}\text { Year: } & 1998 \\ \text { Make: } & \text { Ford } \\ \text { Model: } & \text { Focus } \\ \text { Color: } & \text { Black } \\ \text { License: } & \\ \text { VIN: } & \\ \text { Engine: } & 1400 \mathrm{cc} \text { Zetec-SE } \\ \text { Transmission: } & 5 \text { Speed manual } \\ \text { Weight: } & \text { 1364kg }\end{array}$

\section{Damage Description:}

Front:

Heavy damage was sustained to the entire front fender of V2. Passenger side door crushed; passenger side fender missing.

Left:

Crushed appearance to all of left of vehicle - windows broken. Various scrapes and dents.

$\underline{\text { Right: }}$

Various scrapes and dents.

Rear:

Various scrapes and dents. 


\section{Appendix E VAR Case 5}

SRI LANKA POLICE DEPARTMENT MAJOR ACCIDENT NVESTIGATION TEAM

\begin{tabular}{|c|c|c|c|c|}
\hline $\begin{array}{l}\text { DATE OF INCDENT } \\
\text { Jan } 11.2006\end{array}$ & $\begin{array}{c}\text { TDME } \\
1057\end{array}$ & $\begin{array}{c}\text { NCIC NUMBER } \\
3710\end{array}$ & $\begin{array}{c}\text { OFFICER I.D. } \\
1120\end{array}$ & $\begin{array}{l}\text { NUMBER } \\
07-000863\end{array}$ \\
\hline
\end{tabular}

\section{INTRODUCTION}

On Thursday, January 11, 2007 at approximately 1057 hours, a traffic collision occurred within the intersection of Tikali Dr. and Vihara Rd. A 1995 Volkswagen Jetta, which was traveling westbound on Tikali Dr, struck a 1992 Saturn SL-1 broadside, which was traveling southbound on Vihara Road.

The 1992 Saturn SL-1 (V1) was driven by henceforth referred to as Person 1, who sustained major injuries in this collision and was transported, via ambulance, to Colombo Trauma Center.

The 1995 Volkswagen Jetta (V2) was driven by henceforth referred to as Person 2, who sustained minor injuries in this collision and was transported, via ambulance, to Kelaniya Medical Center for treatment. P2 was later released from the hospital.

Based on the statement of P2 and three independent witnesses, P1 had run the red light for southbound Vihara Rd. P2 had a green light for westbound Tikali Dr. Evidence at the scene showed that P1 may have been aware that P2's vehicle was about to impact with him. There were front wheel locked skid marks, just prior to the collision. The force of the collision caused the two vehicles to skid together to rest.

\section{PHYSICAL EVIDENCE}

At the Area of Impact, I observed locked wheel skid from the front tires of V1 prior to the area of impact. This wheel skid was measured to be 10 feet. The skid marks post-collision measured to be 35 feet in the southwest direction $\left[220^{\circ}\right.$ Azimuth].

\section{$\underline{\text { Roadway Description }}$}

Section Omitted

MAIT PREPARER'S NAME

A. Ahubudu
I.D. NUMBER

1120
DATE

$1 / 11 / 07$
REVIEWER'S NAME

DATE 
SRI LANKA POLICE DEPARTMENT MAJOR ACCIDENT INVESTIGATION TEAM

\begin{tabular}{|c|c|c|c|c|}
\hline $\begin{array}{l}\text { DATE OF INCIDENT } \\
\text { Jan } 11,2006\end{array}$ & $\begin{array}{l}\text { TMME } \\
1057\end{array}$ & $\begin{array}{c}\text { NCIC NUMBER } \\
3710\end{array}$ & $\begin{array}{c}\text { OFFICER ID. } \\
1120\end{array}$ & $\begin{array}{l}\text { NUMRER } \\
07-000863\end{array}$ \\
\hline
\end{tabular}

\section{Weather Conditions}

The following weather conditions were noted at the Colombo Airport.

\begin{tabular}{|l|l|l|l|l|l|l|l|}
\hline Time & Temperature & Dew Point & Humidity & Pressure & Visibility & Wind & Conditions \\
\hline $10: 29 \mathrm{AM}$ & $60.8^{\circ} \mathrm{F} / 16.0^{\circ} \mathrm{C}$ & $48.2^{\circ} \mathrm{F} / 9.0^{\circ} \mathrm{C}$ & $63 \%$ & $\begin{array}{l}29.96 \mathrm{in} / \\
1014.4 \mathrm{hPa}\end{array}$ & $\begin{array}{l}9.0 \mathrm{miles} / \\
14.5 \mathrm{~km}\end{array}$ & $\begin{array}{l}8.1 \mathrm{mph} / 13.0 \mathrm{~km} / \mathrm{h} \\
\text { South }\end{array}$ & Overcast \\
\hline $10: 52 \mathrm{AM}$ & $61.0^{\circ} \mathrm{F} / 16.1^{\circ} \mathrm{C}$ & $48.0^{\circ} \mathrm{F} / 8.9^{\circ} \mathrm{C}$ & $62 \%$ & $\begin{array}{l}29.96 \mathrm{in} / \\
1014.4 \mathrm{hPa}\end{array}$ & $\begin{array}{l}9.0 \mathrm{miles} / \\
14.5 \mathrm{~km}\end{array}$ & $\begin{array}{l}9.2 \mathrm{mph} / 14.8 \mathrm{~km} / \mathrm{h} \\
\text { South }\end{array}$ & Overcast \\
\hline $11: 42 \mathrm{AM}$ & $60.8^{\circ} \mathrm{F} / 16.0^{\circ} \mathrm{C}$ & $46.4^{\circ} \mathrm{F} / 8.0^{\circ} \mathrm{C}$ & $59 \%$ & $\begin{array}{l}29.93 \mathrm{in} / \\
1013.4 \mathrm{hPa}\end{array}$ & $\begin{array}{l}10.0 \mathrm{miles} / \\
16.1 \mathrm{~km}\end{array}$ & $\begin{array}{l}9.2 \mathrm{mph} / 14.8 \mathrm{~km} / \mathrm{h} \\
\text { South }\end{array}$ & Overcast \\
\hline
\end{tabular}

\section{VEHICLES}

\section{Vehicle One (VI, 1992 Saturn SL-1)}

$\begin{array}{ll}\text { Year: } & 1992 \\ \text { Make: } & \text { Saturn } \\ \text { Model: } & \text { SL-1 } \\ \text { Color: } & \text { Brown } \\ \text { License: } & \\ \text { VIN: } & \\ \text { Engine: } & \text { 1.9L } 85 \text { hp 14 } \\ \text { Transmission: } & 4 \text { speed automatic } \\ \text { Weight: } & \text { 2313 pounds }\end{array}$

\section{Damage Description:}

Front:

V1 sustained no visible damage to this end.

Left:

The majority of the damage sustained by V1 occurred on this side. At the deepest intrusion, the crush measured $36 "$. The entire left side from the driver's side door to the passenger side door was crushed. There was minor to moderate crushing to the front and rear quarter panels.

Right:

Besides the removing of the passenger front and rear doors by SLFD with the Jaws of Life, no visible collision damage was observed on this side.

\section{VEHICLES (Continued)}

$\begin{array}{cccc}\text { MAIT PREPARER'S NAME } & \text { I.D. NUMBER } & \text { DATE } & \text { REVIEWER'S NAME } \\ \text { A. Ahubudu } & 1120 & 1 / 11 / 07 & \text { DATE }\end{array}$


SRI LANKA POLICE DEPARTMENT MAJOR ACCIDENT INVESTIGATION TEAM

\begin{tabular}{|c|c|c|c|c|}
\hline $\begin{array}{l}\text { DATE OF INCIDENT } \\
\text { Jan } 11,2006\end{array}$ & $\begin{array}{l}\text { TDME } \\
1057\end{array}$ & $\begin{array}{c}\text { NCIC NUMBER } \\
3710\end{array}$ & $\begin{array}{c}\text { OFFICER I.D. } \\
1120\end{array}$ & $\begin{array}{l}\text { NUMBER } \\
07-000883\end{array}$ \\
\hline
\end{tabular}

\section{Damage (Continued)}

Rear:

V1 sustained no visible damage to this end.

\section{Vehicle Two (V2,1995 Volkswagen Jetta III Celebration Edition)}

$\begin{array}{ll}\text { Year: } & 1995 \\ \text { Make: } & \text { Volkswagen } \\ \text { Model: } & \text { Jetta III Celebration Edition } \\ \text { Color: } & \text { Black } \\ \text { License: } & \\ \text { VIN: } & \\ \text { Engine: } & 2.0 \mathrm{~L} 115 \mathrm{hp} \mathrm{I} 4 \\ \text { Transmission: } & 5 \text { Speed manual } \\ \text { Weight: } & \text { 2648 pounds }\end{array}$

\section{Damage Description:}

Front:

The majority of the damage sustained by V2 was isolated to this side. There was moderate crushing to the front bumper and hood. The length of crush to the front end was $6 "$ at its deepest point. The both headlight and lighting assemblies were broken and knocked out.

Left:

Besides minor crush and dents to the front portion of the front quarter panel, no other visible damage was observed to this side.

Right:

Besides minor crush and dents to the front portion of the front quarter panel, no other visible damage was observed to this side.

$\underline{\text { Rear: }}$

V2 sustained no visible damage to this end.

MAIT PREPARER'S NAME

A. Ahubudu
I.D. NUMBER

1120
DATE

$1 / 11 / 07$
REVIEWER'S NAME

DATE 


\section{Appendix F MatLab GUI User Guide}

This guide serves as an overview on how to use the VAR GUI to solve for two vehicle impacts. Figure 45 below shows the input window of the MatLab GUI upon startup.

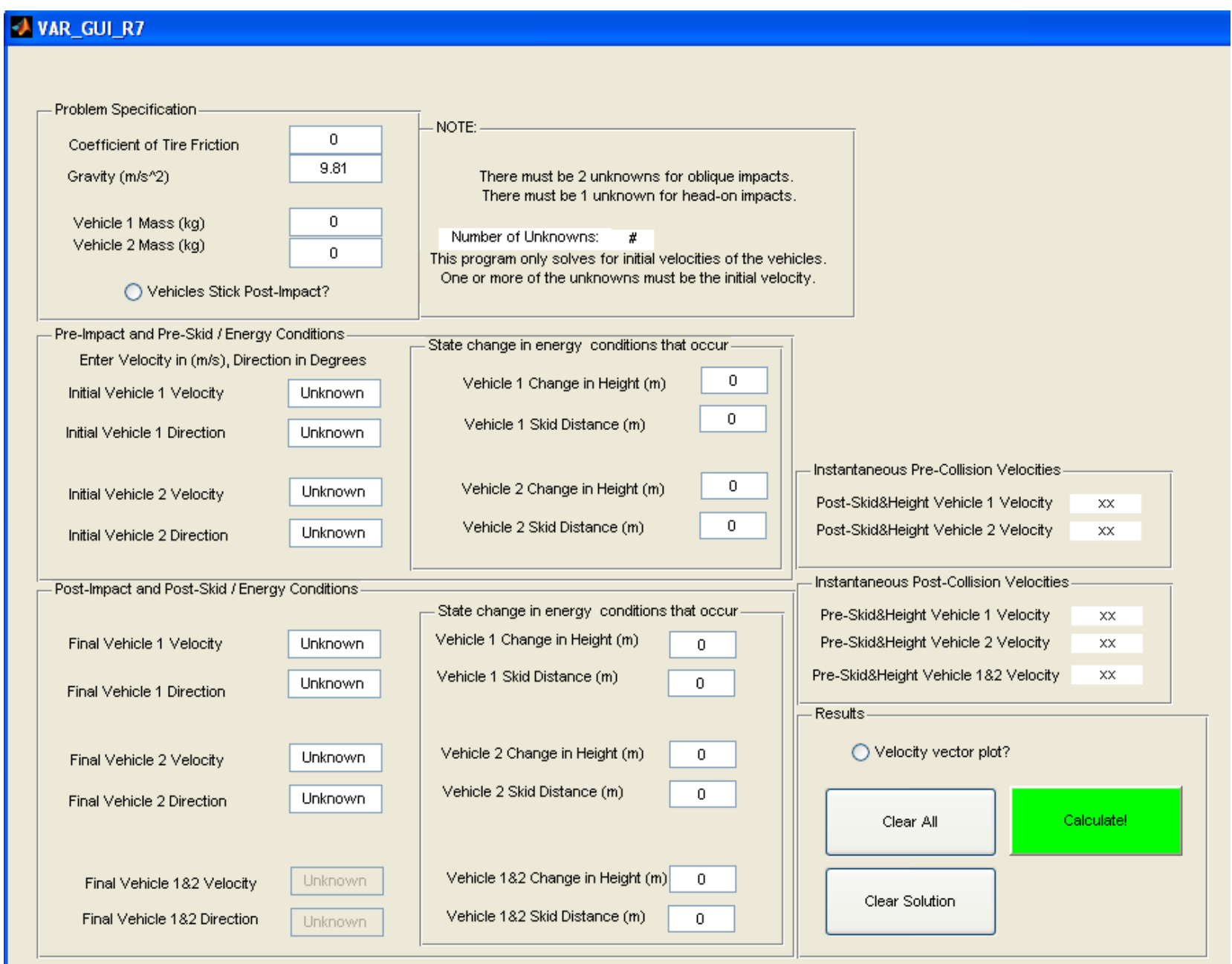

Figure 45. MatLab GUI at startup. 
The MatLab code will automatically calculate for parameters left as "unknown", for the supported scenarios shown in Table 8 and Table 9. These tables illustrate the known and unknown parameters of the problem indicated by " 1 " and " 0 ", respectively. V1, V2, and V12 indicate velocities of vehicle 1 , vehicle 2 , and vehicle $1 \& 2$ stuck, respectively.

Table 8. Supported cases for 2 vehicle collisions where vehicles do not stick together post-impact.

\begin{tabular}{|c|c|c|c|c||c|c|c|c|}
\cline { 2 - 9 } \multicolumn{1}{c|}{} & \multicolumn{3}{c||}{ Pre-Collision } & \multicolumn{3}{c|}{ Post-Collision } \\
\cline { 2 - 10 } \multicolumn{1}{c|}{} & \multicolumn{2}{c|}{ V1 } & \multicolumn{2}{c|}{ V2 } & \multicolumn{2}{c|}{ V1 } & \multicolumn{2}{c|}{ V2 } \\
\hline Case & Mag & Dir & Mag & Dir & Mag & Dir & Mag & Dir \\
\hline \hline A & 1 & 1 & 0 & 0 & 1 & 1 & 1 & 1 \\
\hline G & 1 & 1 & 0 & 1 & 1 & 1 & 1 & 0 \\
\hline D & 1 & 1 & 0 & 1 & 1 & 1 & 0 & 1 \\
\hline F & 1 & 0 & 0 & 1 & 1 & 1 & 1 & 1 \\
\hline C & 0 & 1 & 0 & 1 & 1 & 1 & 1 & 1 \\
\hline E & 1 & 1 & 0 & 1 & 1 & 1 & 1 & 1 \\
\hline
\end{tabular}

Table 9. Supported cases for 2 vehicle collisions where vehicles stick together post-impact.

\begin{tabular}{|c|c|c|c|c||c|c|}
\cline { 2 - 7 } \multicolumn{1}{c|}{} & \multicolumn{3}{c||}{ Pre-Collision } & \multicolumn{2}{c|}{ Post-Collision } \\
\cline { 2 - 7 } \multicolumn{1}{c|}{} & \multicolumn{2}{c|}{ V1 } & \multicolumn{2}{c|}{ V2 } & \multicolumn{2}{c|}{ V12 } \\
\hline Case & Mag & Dir & Mag & Dir & Mag & Dir \\
\hline \hline A & 1 & 1 & 0 & 0 & 1 & 1 \\
\hline B & 1 & 1 & 0 & 1 & 0 & 1 \\
\hline G & 1 & 1 & 0 & 1 & 1 & 0 \\
\hline F & 1 & 0 & 0 & 1 & 1 & 1 \\
\hline C & 0 & 1 & 0 & 1 & 1 & 1 \\
\hline E & 1 & 1 & 0 & 1 & 1 & 1 \\
\hline
\end{tabular}




\section{Syntax}

\section{Angle Convention}

All angles should be inputted with North as the zero angle reference point, east as $90^{\circ}$, south as $180^{\circ}$, and west as $270^{\circ}$. For example, a vehicle traveling southwest would correspond to a direction of $225^{\circ}$, shown below.

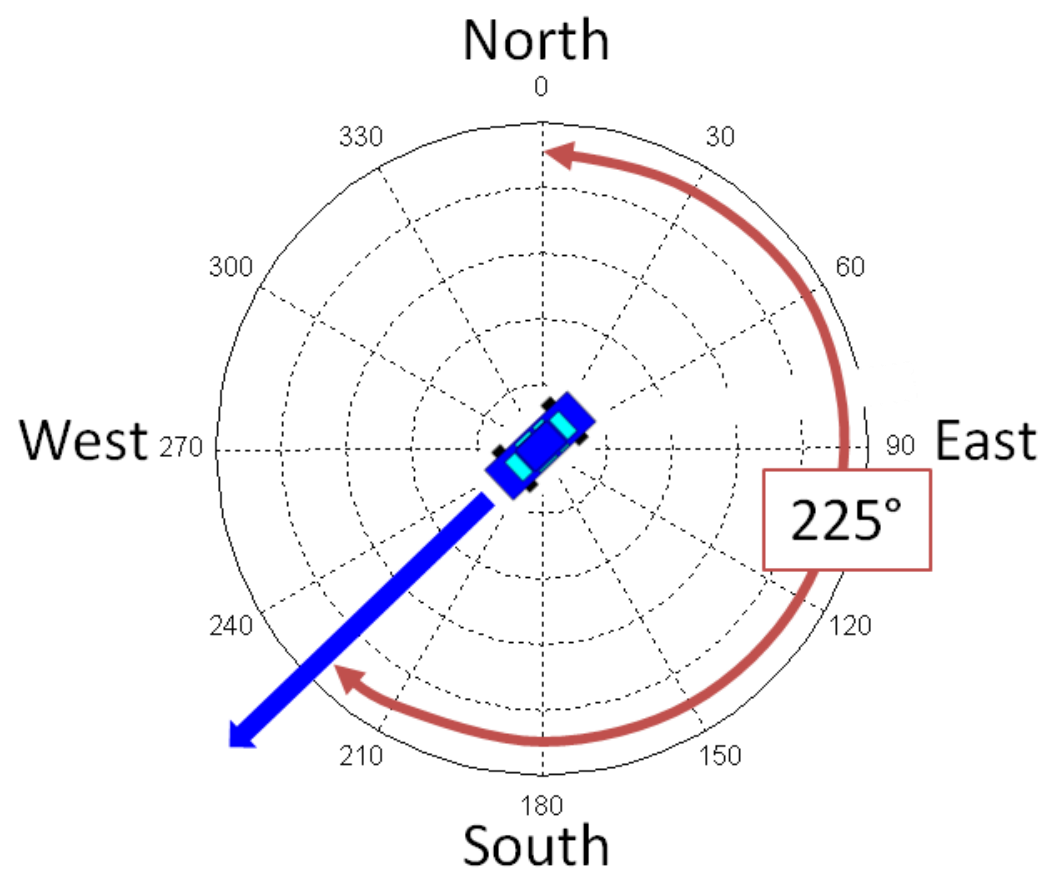

Figure 46. Angle dimension for vehicle traveling in southwest direction. The arrow shown in blue represents the direction vector of the vehicle. The red dimension indicates the corresponding angle. 
The program is set up to accept all user inputs as summarized in the figure below. This section will provide a quick overview on the sign convention and entry of the parameters.

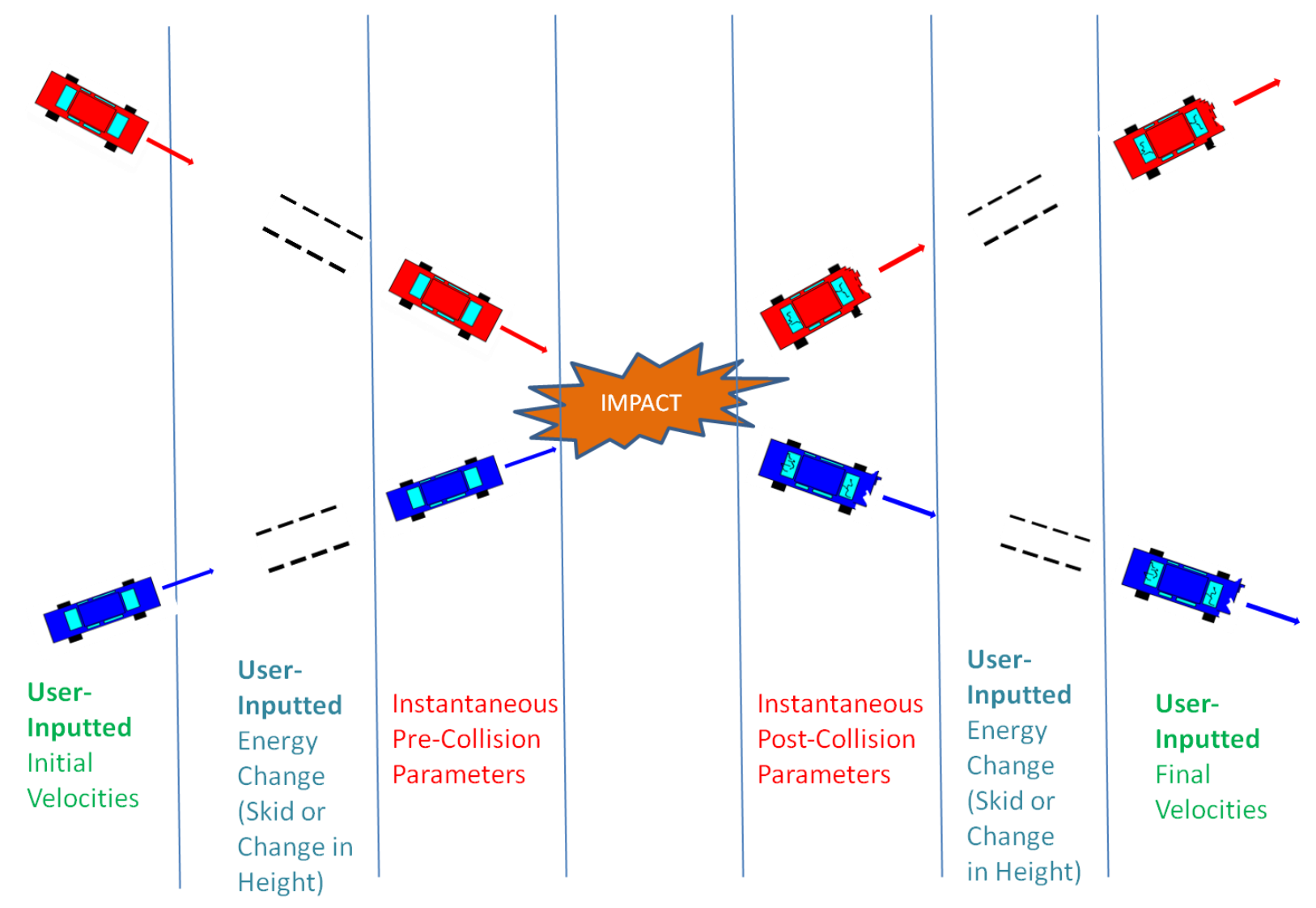

Figure 47. User-input syntax for VAR GUI.

\section{Pre-Collision Velocity and Changes in Height}

The MatLab program refers to all entered initial velocities as pre-skid and pre-change-in-height velocities. That is, it assumes all pre-collision velocities are stated before any skidding or change in height has occurred. When the user inputs a pre-skid initial velocity, skid distance, and change in height, MatLab will calculate the post-skid and post-change-in-height initial velocity as an intermediate step. If the post-skid/post-change-in-height initial velocity is known, simply input zero for skid distance and zero for height. A positive change in height indicates a vehicle has increased in elevation before impact, a negative implies it has descended. 

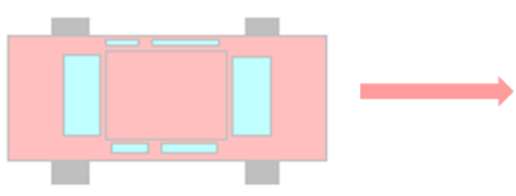

Pre-skid Initial Velocity (Enter this value)

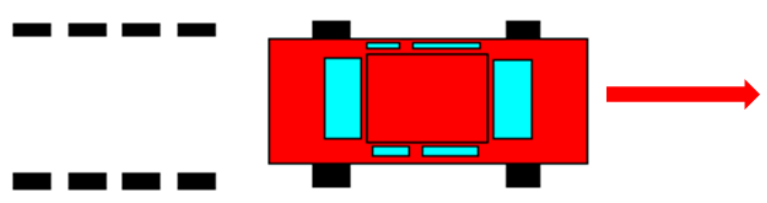

Post-skid Initial Velocity

Figure 48. Convention for entering pre-collision velocity.

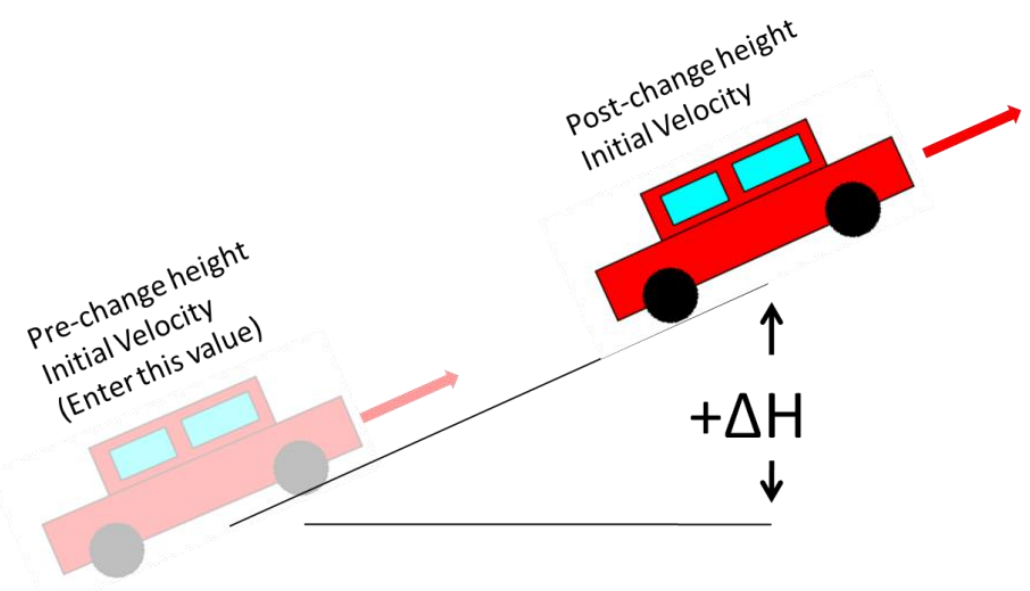

Figure 49. Convention for entering a pre-collision increase in height.

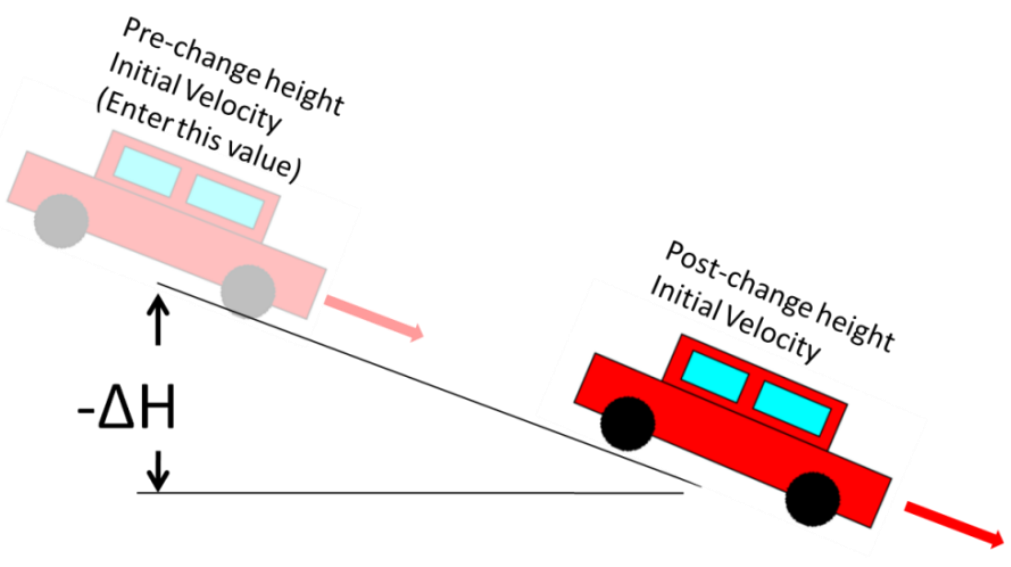

Figure 50. Convention for entering a pre-collision decrease in height.

\section{Post-Collision Velocity}

The program refers to all entered final velocities as post-skid velocities. That is, it assumes all user-entered post-collision velocities are stated after any skidding or change in height has 
occurred. If the pre-skid/pre-change-in-height final velocity is known, simply input zero for skid distance and height.

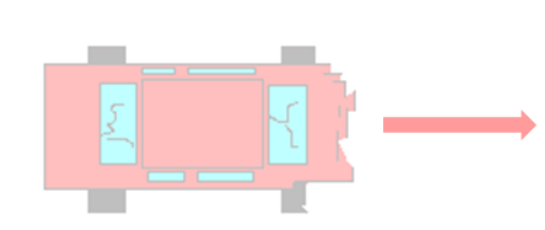

Pre-skid Final Velocity

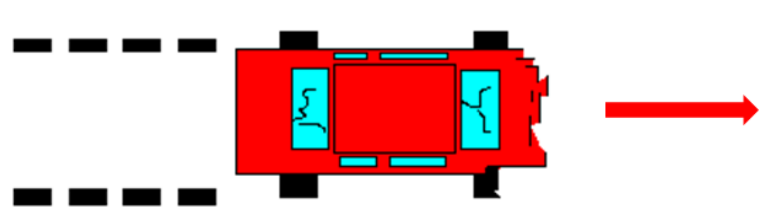

Post-skid Final Velocity (Enter this value)

Figure 51. Convention for entering post-collision velocity.

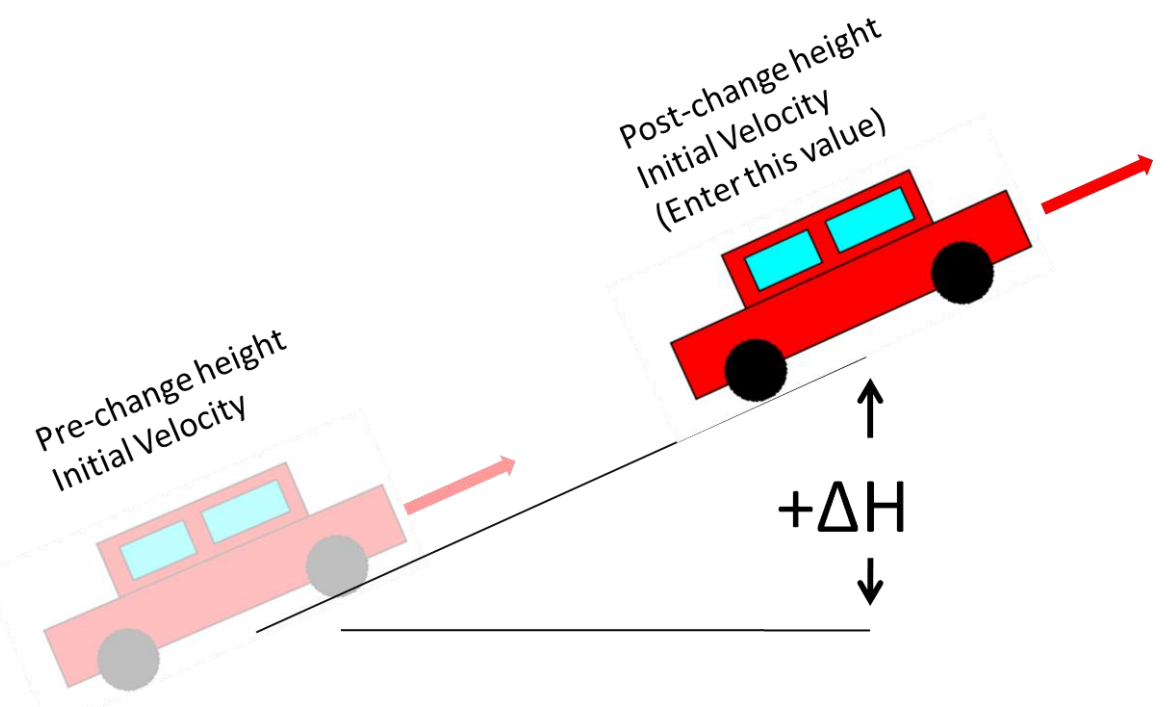

Figure 52. Convention for entering a post-collision change in height. (same as pre-collision)

\section{Reasoning}

In order to apply momentum laws for our collision, we need to know the instantaneous velocities of the vehicles right before and right after the impact. These velocities correspond to the postskid and post-change-in-height initial velocities and the pre-skid and pre-change-in-height final velocities. By setting up the inputs as shown, the code can automatically take into account skid distances when solving for unknown velocities. Essentially, this allows us to account for any energy loss/gain between the inputted velocities and the instantaneous velocities before or after impact. 
Example

Shown in Figure 53 is the MatLab GUI window with all user-inputs entered. The variables to be solved are left as "unknowns" and will be automatically solved for.

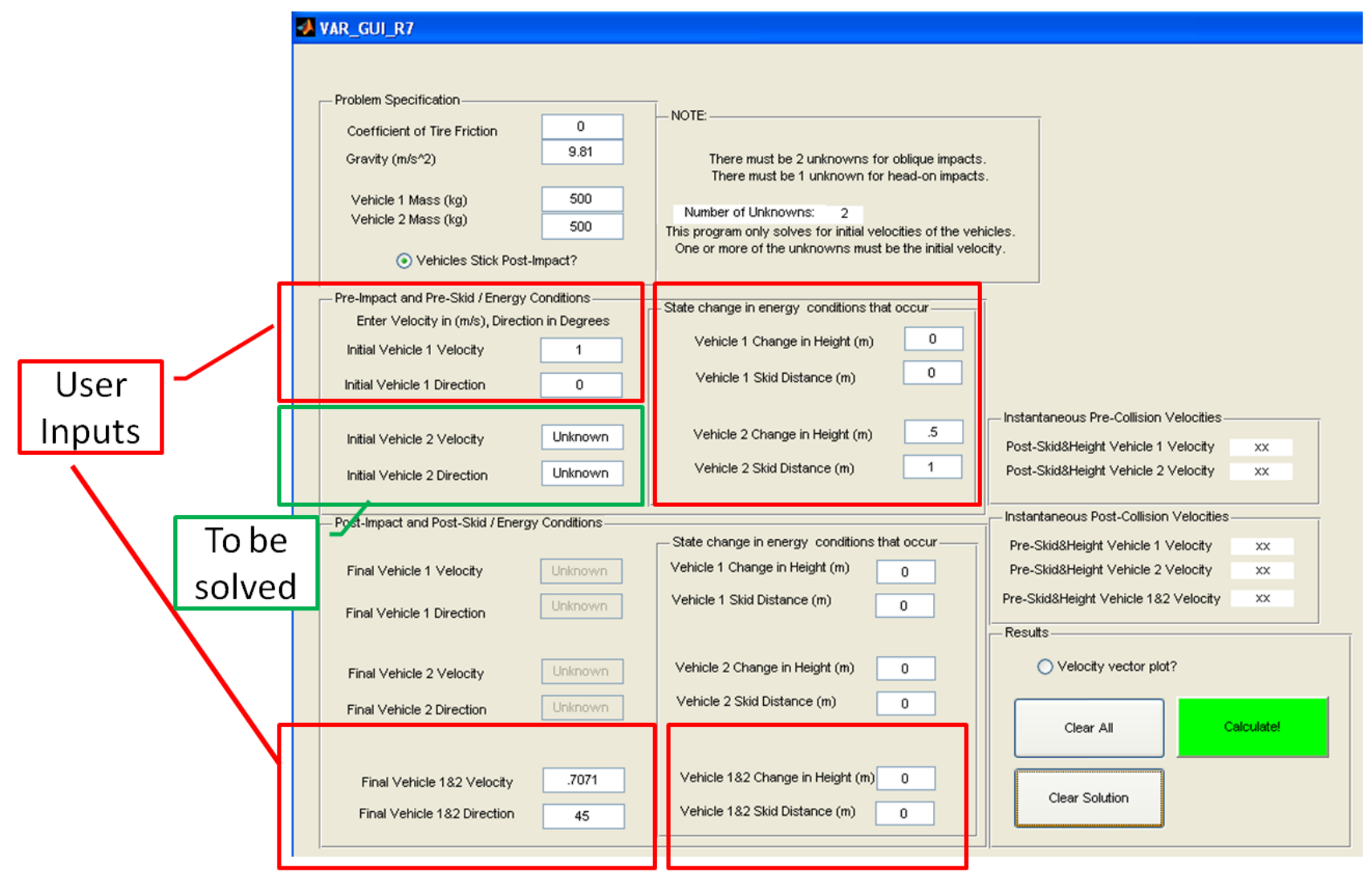

Figure 53. Input window prior to running. 
Shown in Figure 54 is the MatLab GUI window right after "Calculate!" is pressed. Highlighted in green are the solved variables. Highlighted in blue are the variables just before and after the collision occurs, as explained in Figure 47.

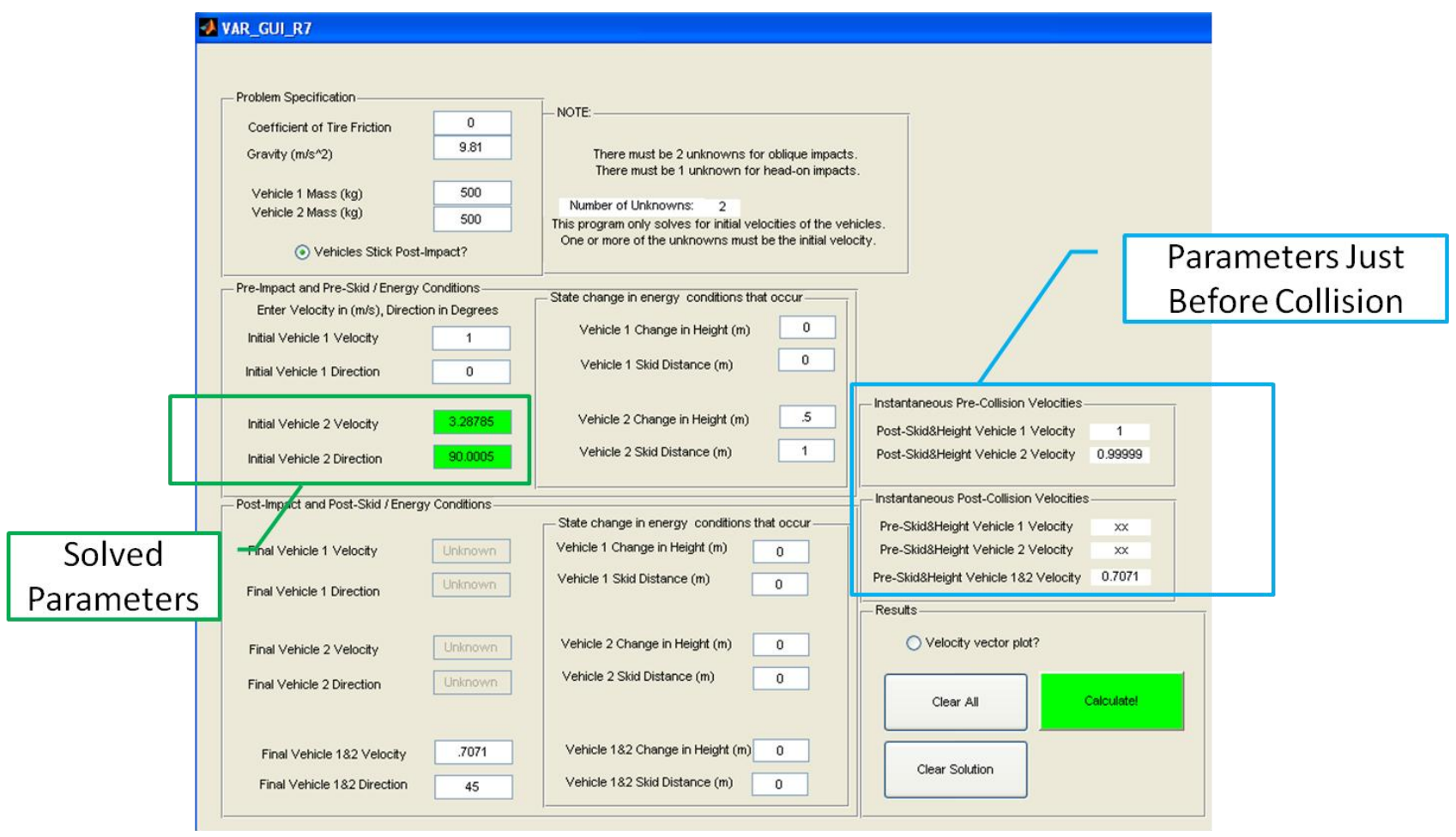

Figure 54. Input window with calculated results. 


\section{Appendix G VAR MatLab GUI}

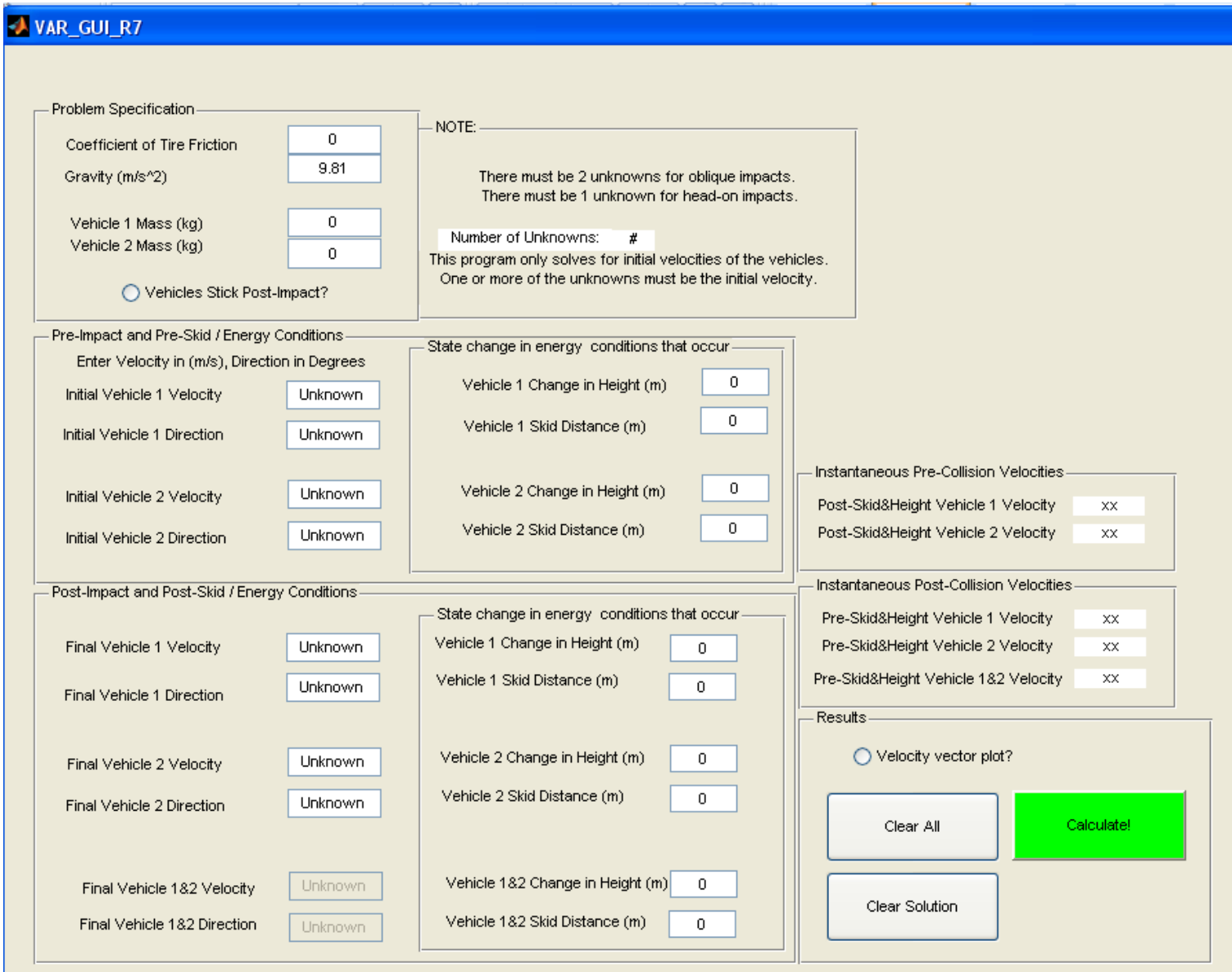


VAR MEA 2-Vehicle Collision Solver

oCal Poly State University, San Luis Obispo

\%Lawrence Fong (lhfong@calpoly.edu)

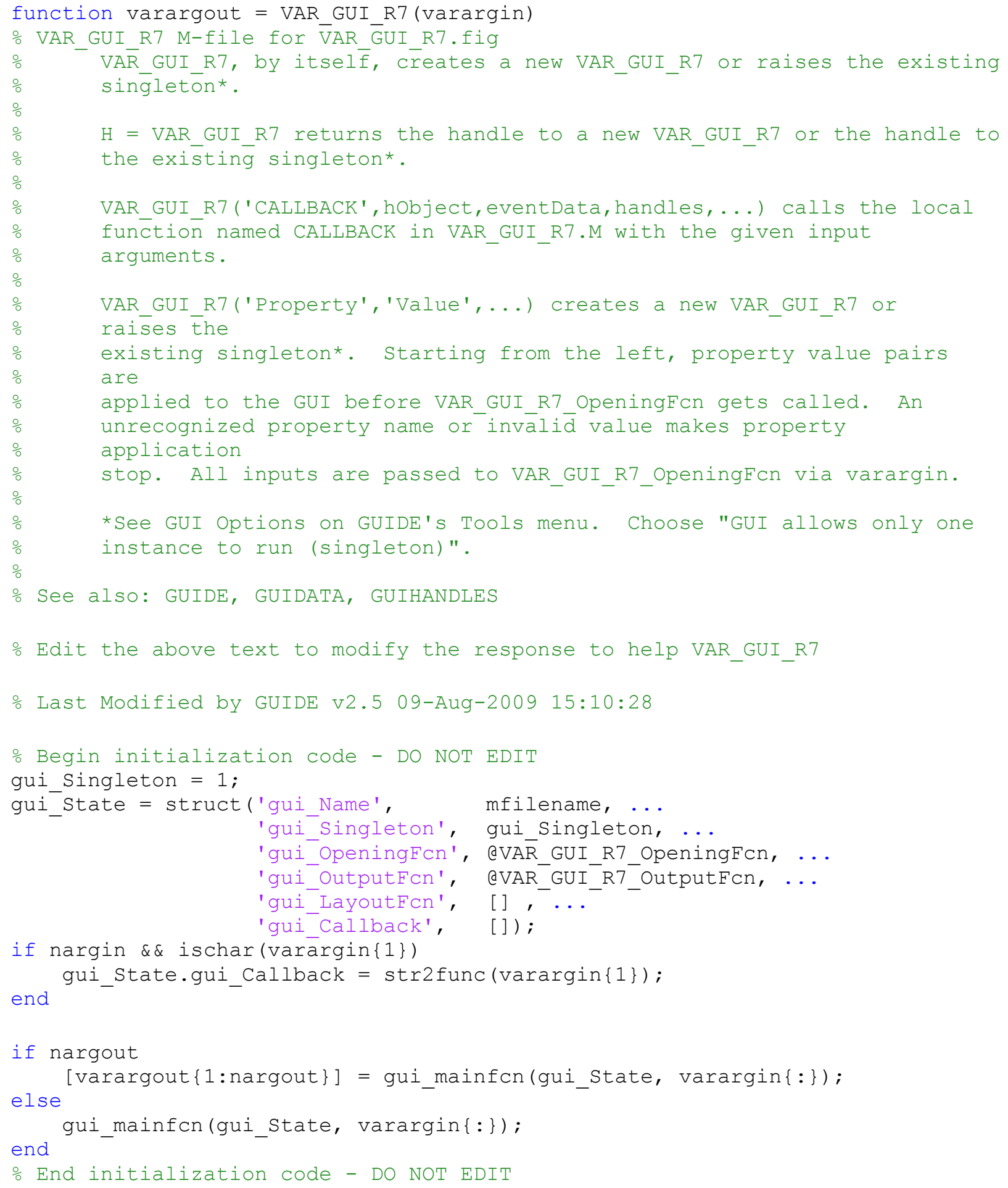




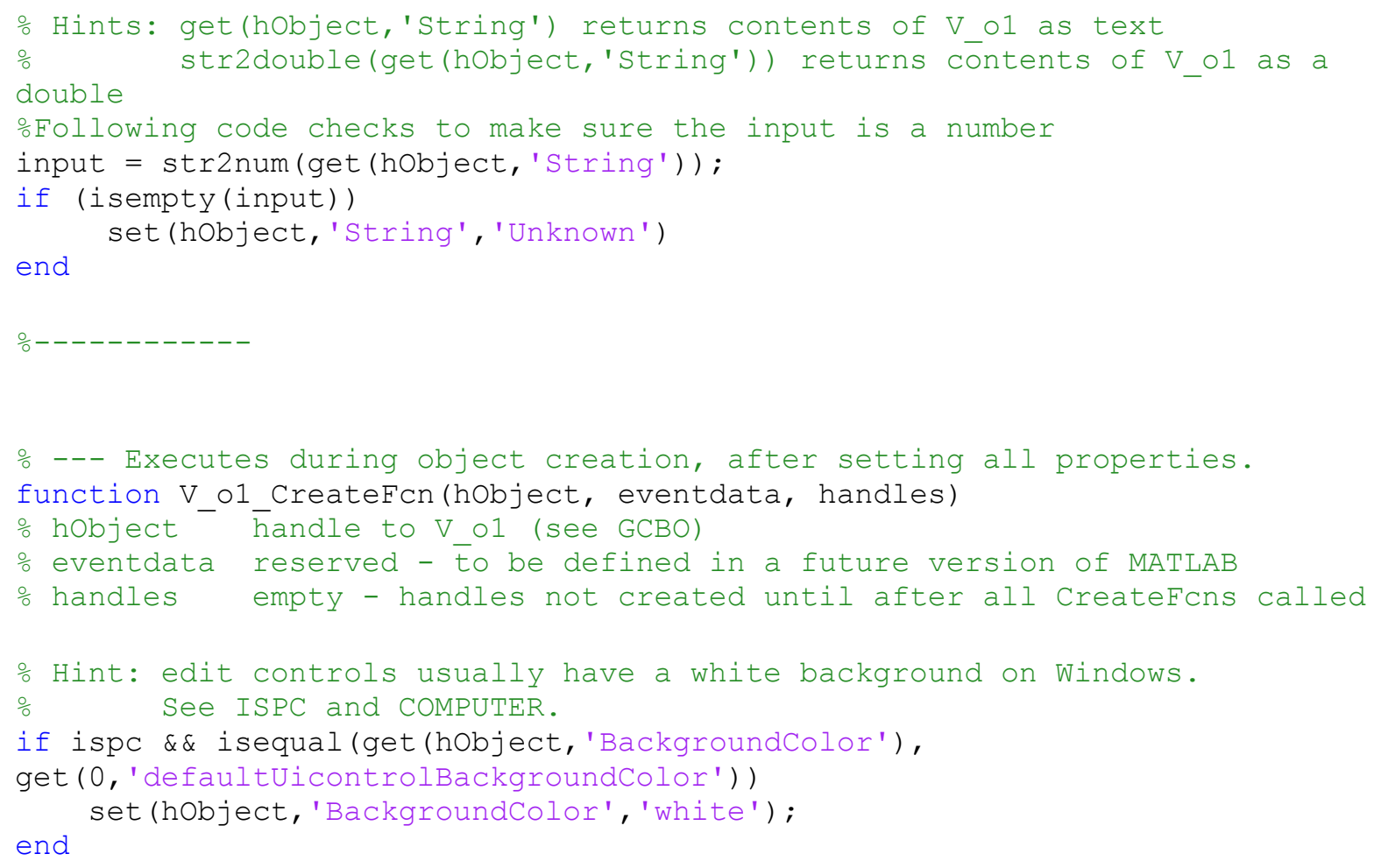


end

은-----------

\% --- Executes during object creation, after setting all properties. function gravity CreateFcn(hobject, eventdata, handles)

\% hobject hand̄le to gravity (see GCBO)

\% eventdata reserved - to be defined in a future version of MATLAB

\% handles empty - handles not created until after all createFcns called

\% Hint: edit controls usually have a white background on Windows.

ㄴ. See ISPC and COMPUTER.

if ispc \&\& isequal (get (hobject, 'BackgroundColor'), get ( 0 , 'defaultuicontrolBackgroundColor')) end set (hobject, 'BackgroundColor', 'white') ;

\% --- Executes on button press in stickYes.

function stickYes Callback(hobject, eventdata, handles)

\% hobject handle to stickYes (see GCBO)

\% eventdata reserved - to be defined in a future version of MATLAB

\% handles structure with handles and user data (see GUIDATA)

o Hint: get(hobject, 'Value') returns toggle state of stickYes

if get (hobject, 'Value') ==1 set (handles.V_f1, 'String', 'Unknown') ; set (handles. ${ }^{-}$fld, 'String', 'Unknown') ; set (handles.V_f2, 'String', 'Unknown') ; set (handles.V_f2D, 'String', 'Unknown') ; set (handles.V_f12, 'String', 'Unknown') ; set (handles.V_f12D, 'String', 'Unknown') ;

set (handles.V f12, 'Enable', 'on') ; set (handles.V-f12D, 'Enable', 'on'); set (handles. $\mathrm{V}^{-} \mathrm{fl}$, 'Enable', 'off'); set (handles.V_fld, 'Enable', 'off'); set (handles.V_f2, 'Enable', 'off'); set (handles.V_f2D, 'Enable', 'off');

else

set (handles. V f1, 'String', 'Unknown') ; set (handles. ${ }^{-}$fld, 'String', 'Unknown') ; set (handles.V-f2, 'String ', 'Unknown') ; set (handles. V_f2D, 'String', 'Unknown') ;

set (handles.V_f12, 'String', 'Unknown') ; set (handles.V_f12D, 'String', 'Unknown') ;

set (handles.V_f12, 'Enable', 'off'); set (handles.V f12D, 'Enable', 'off'); set (handles. $V^{-} f 1$, 'Enable', 'on'); set (handles.V_fld, 'Enable', 'on') ; 


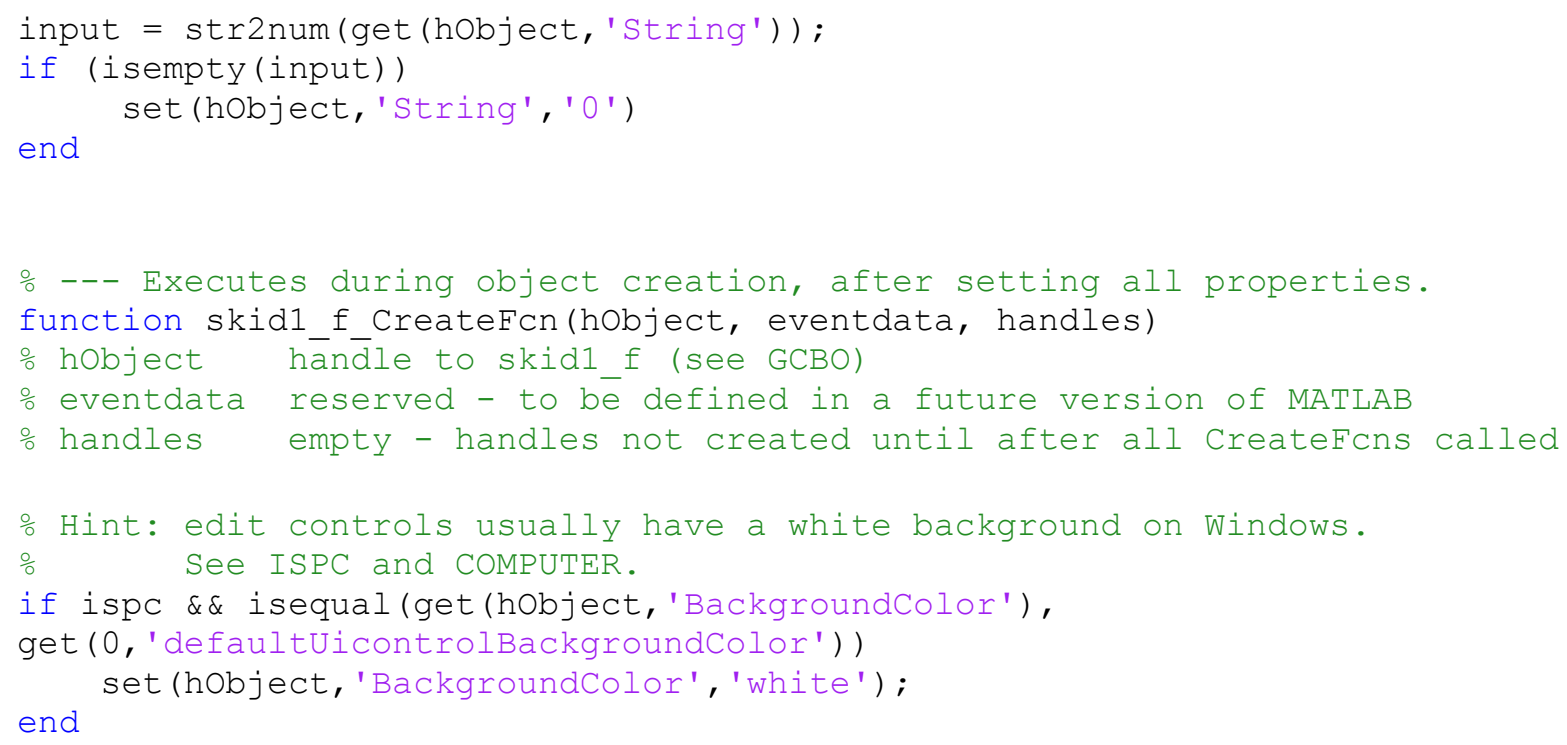




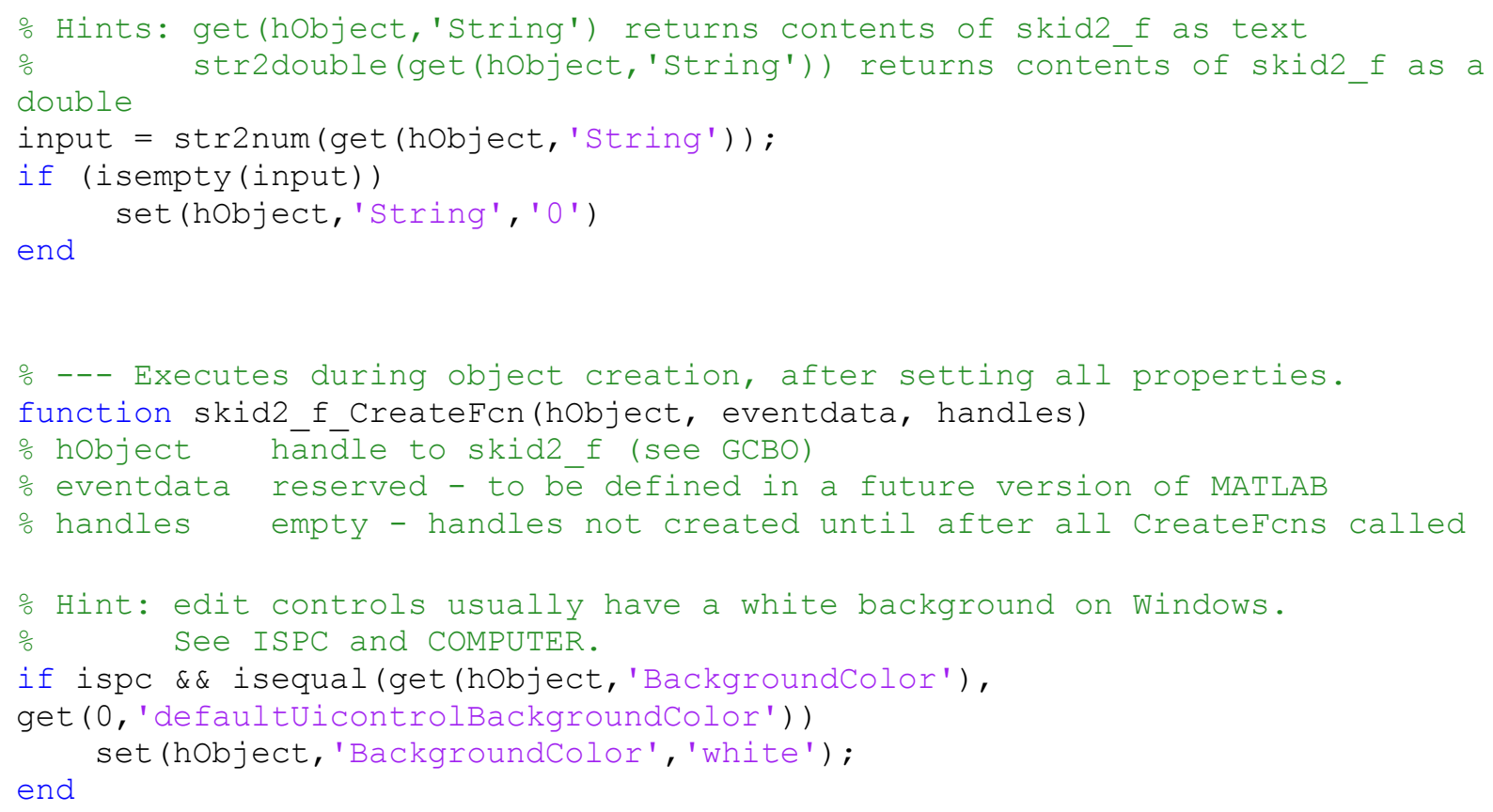




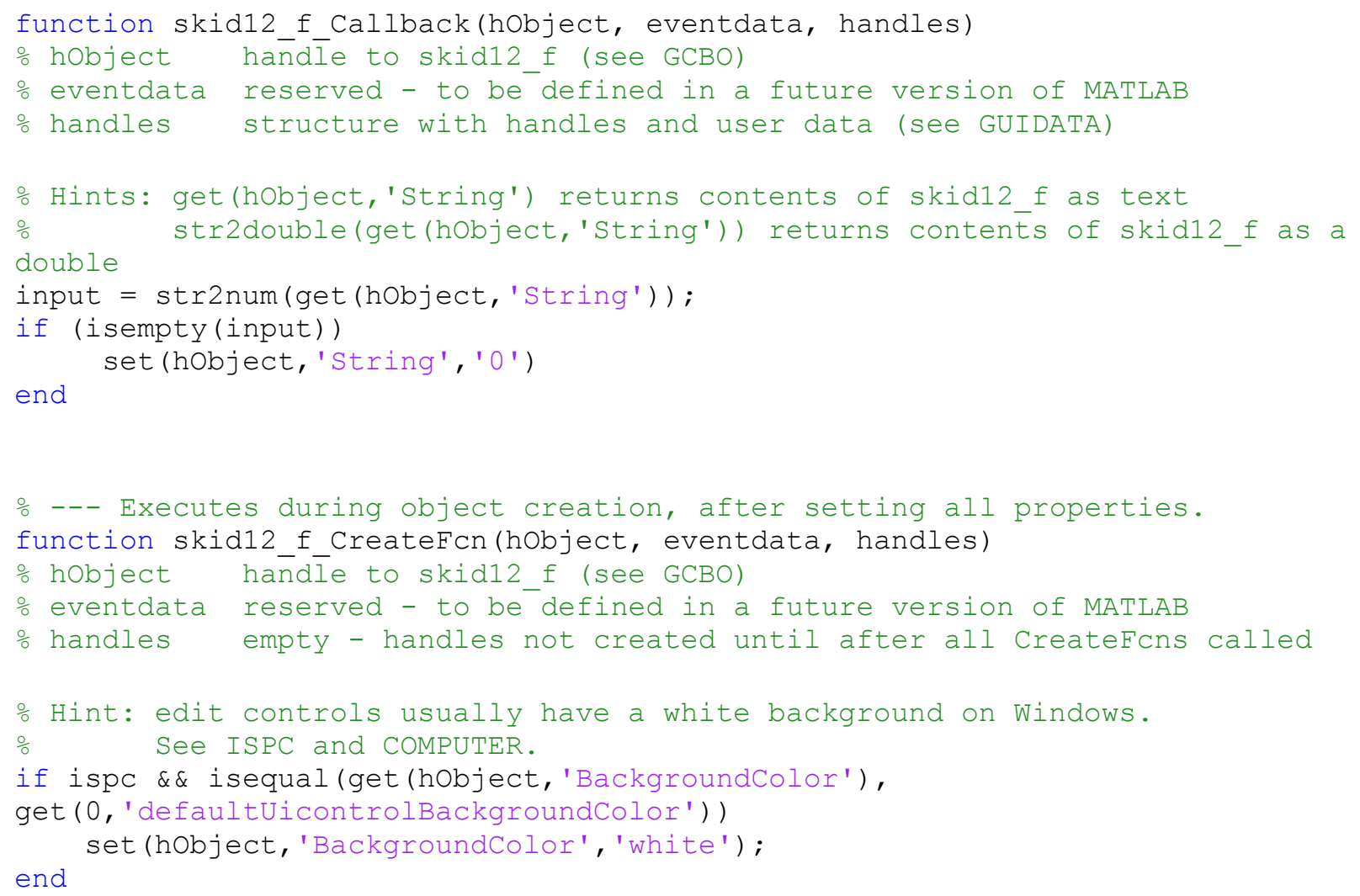




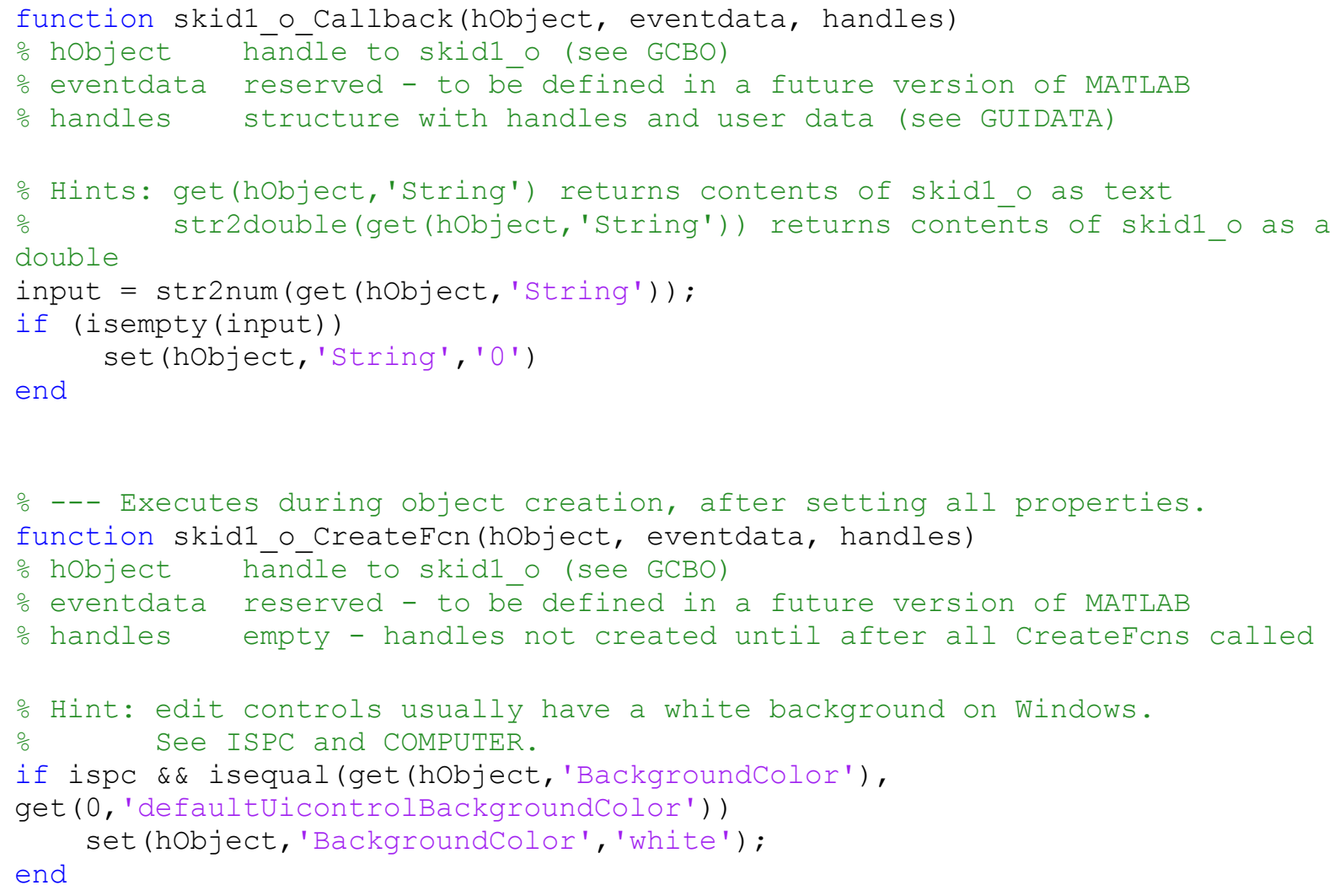




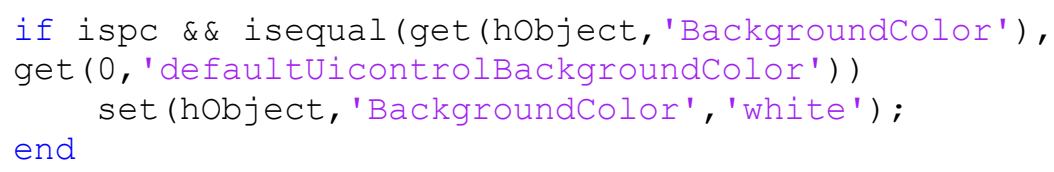




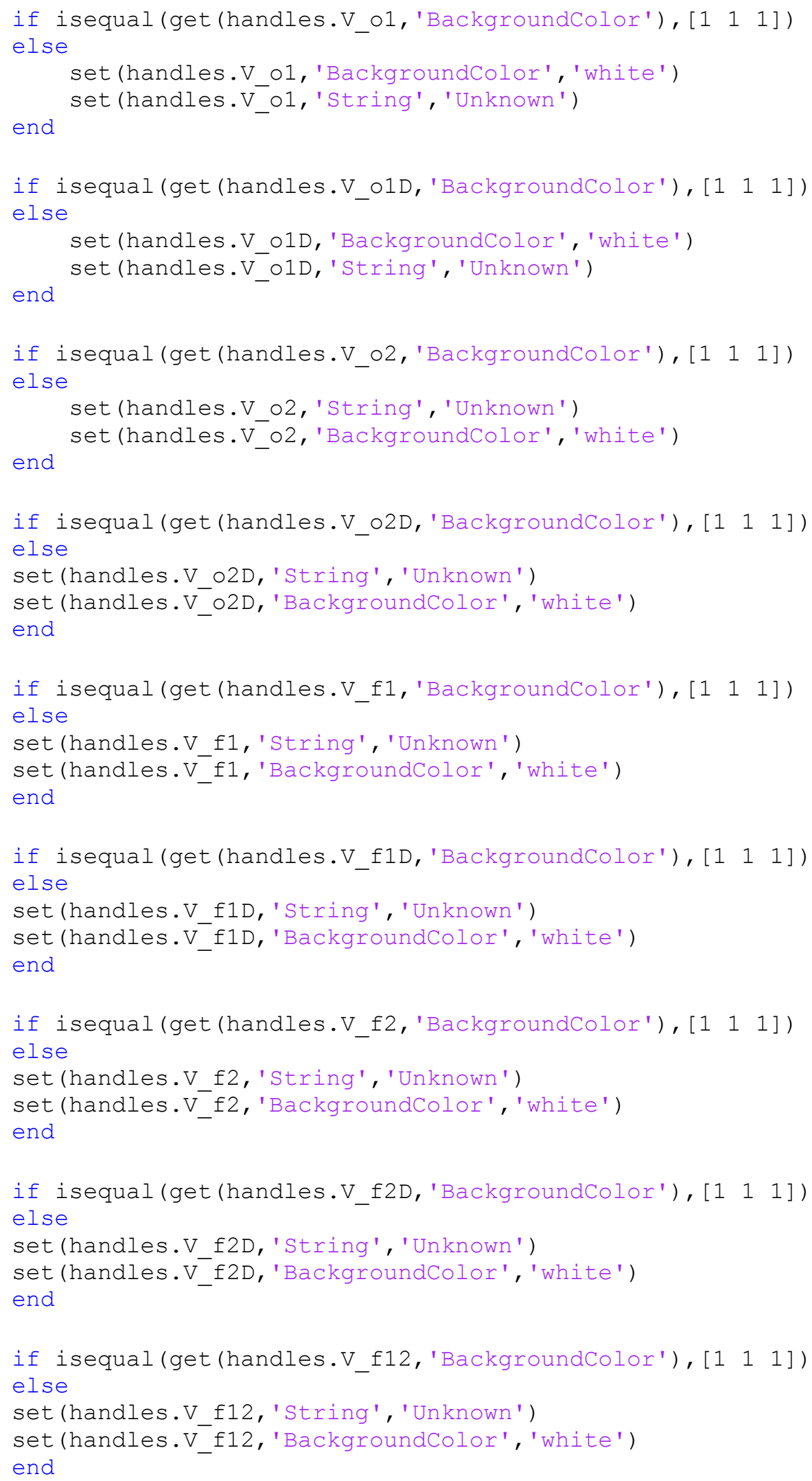




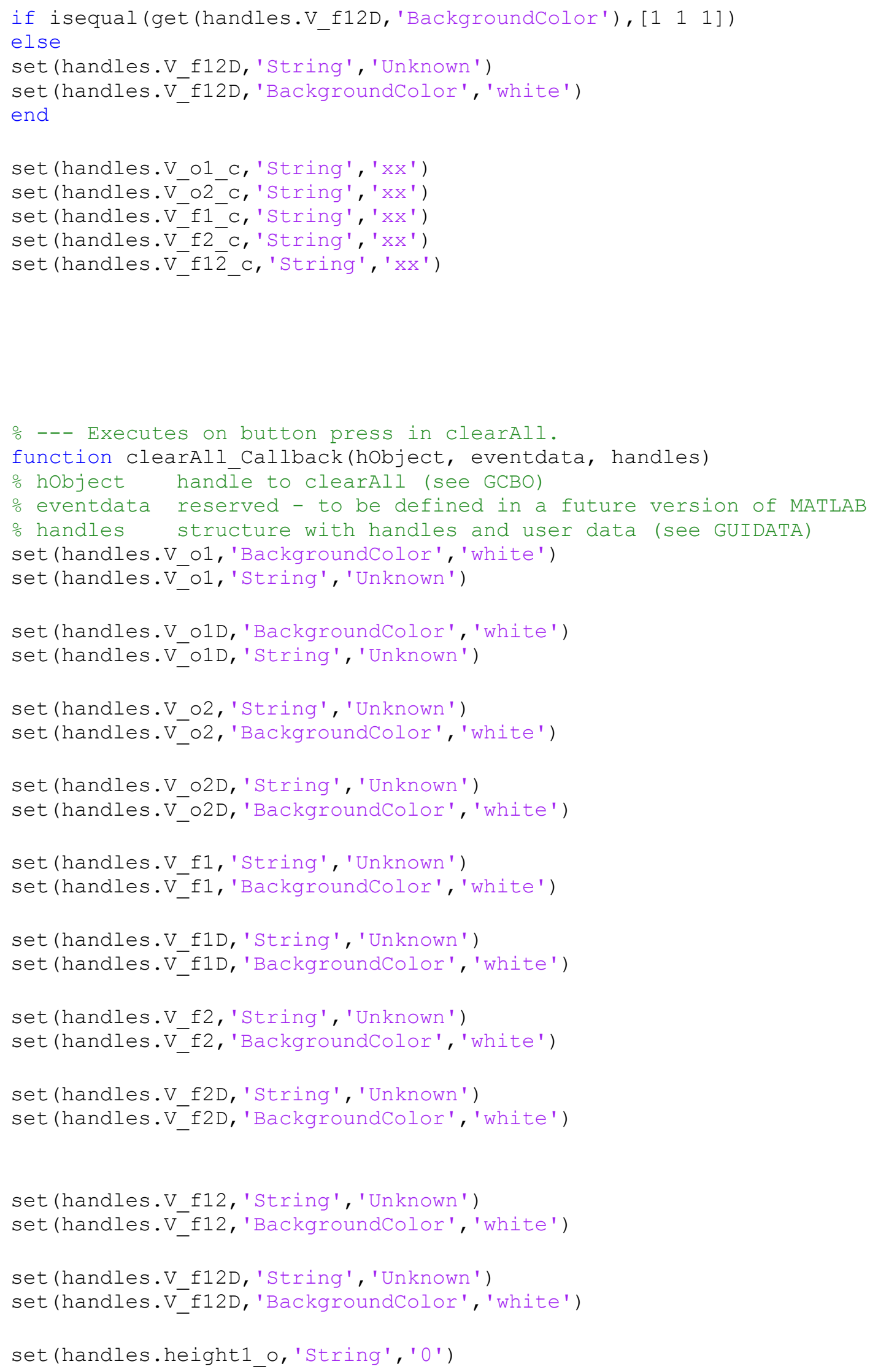




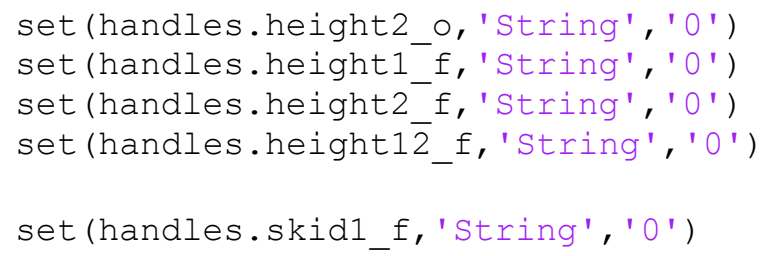




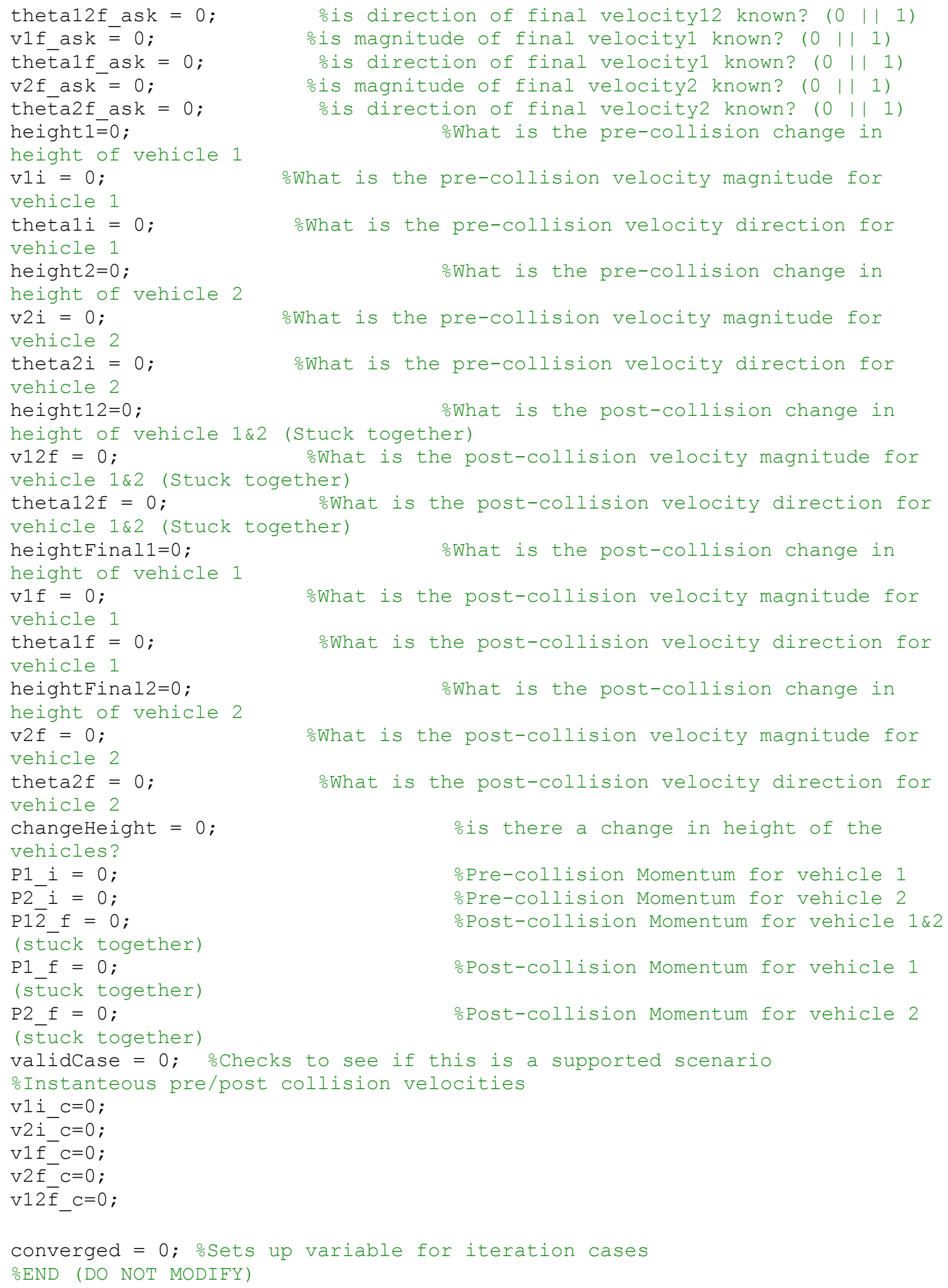




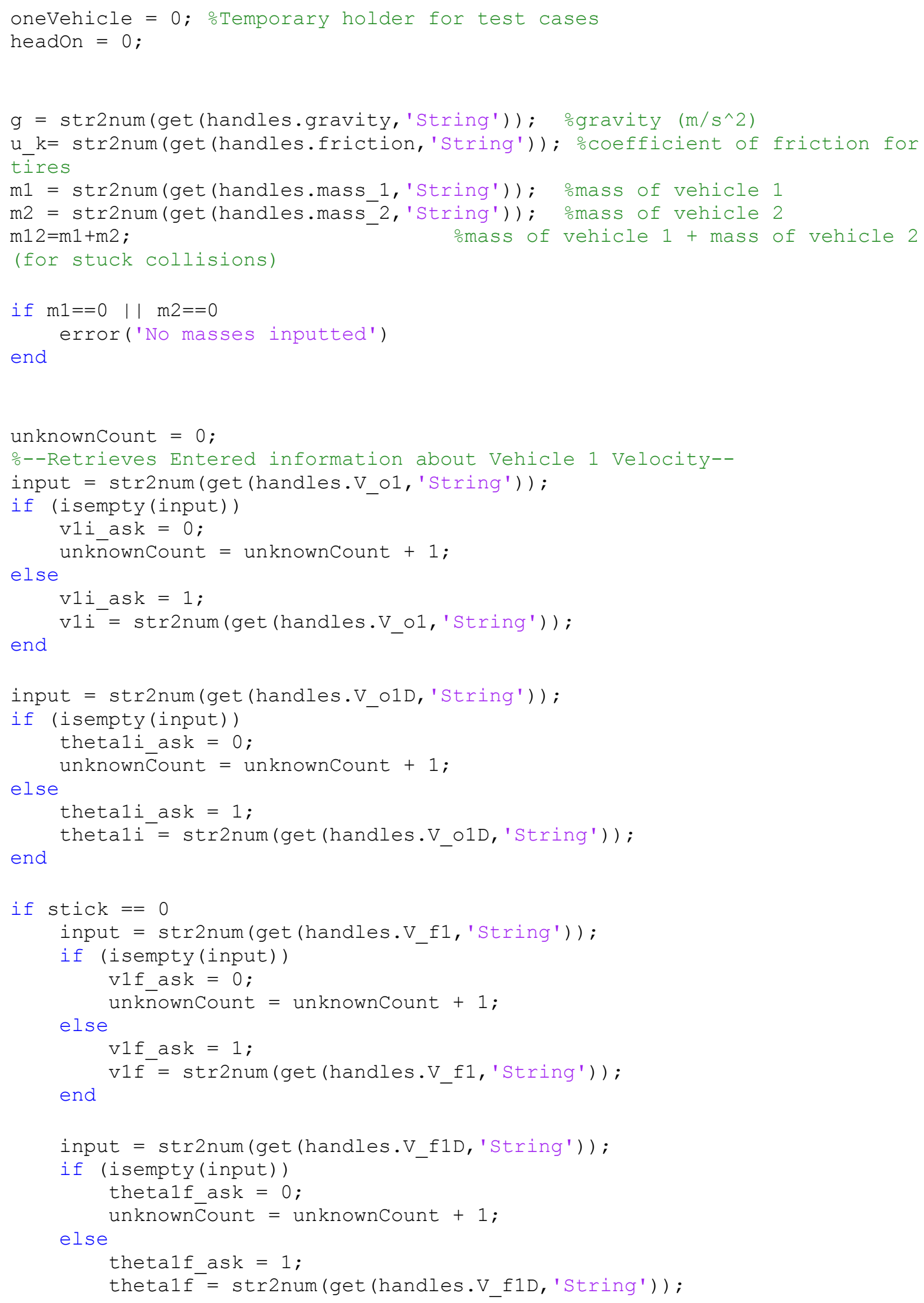




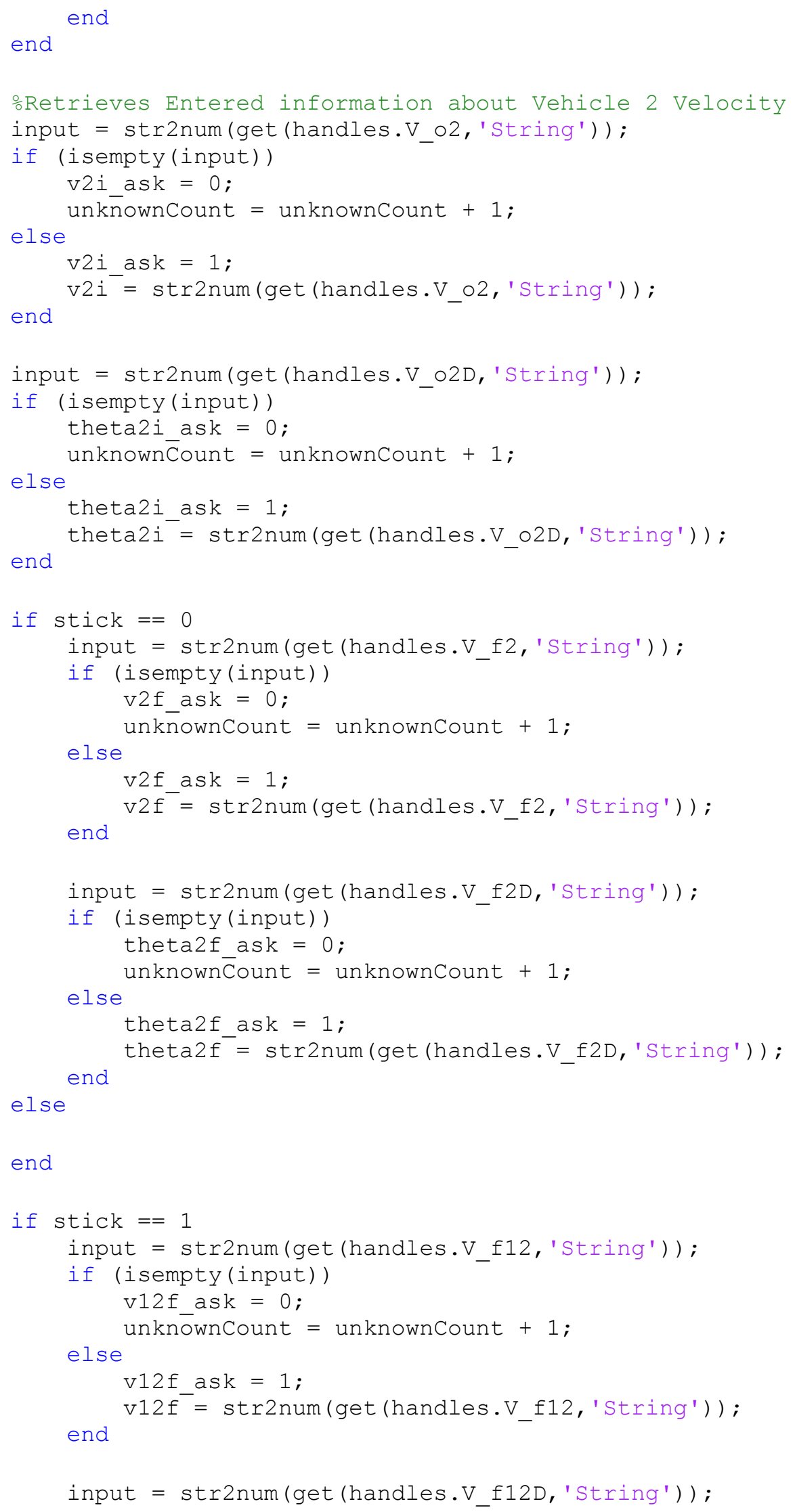




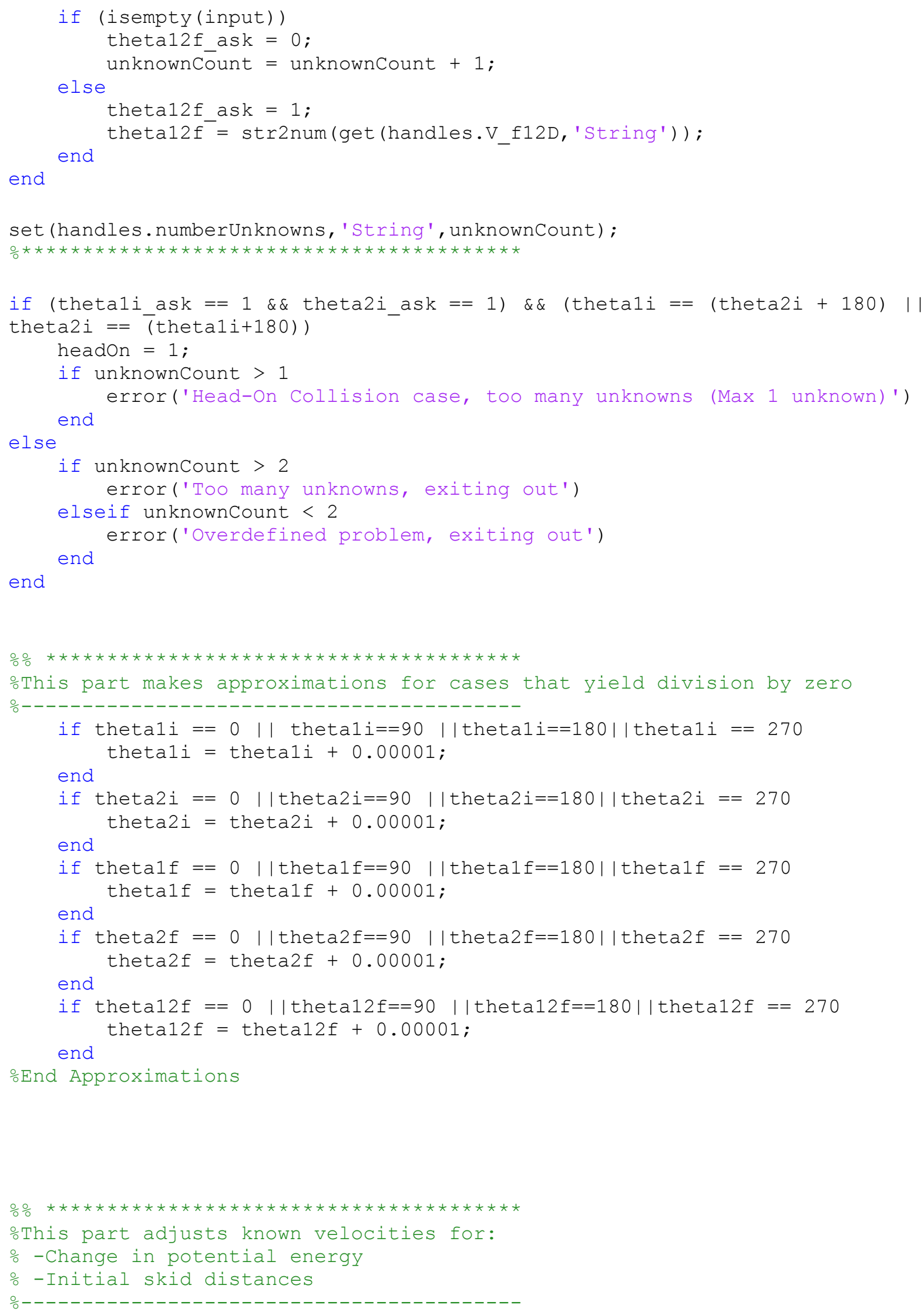




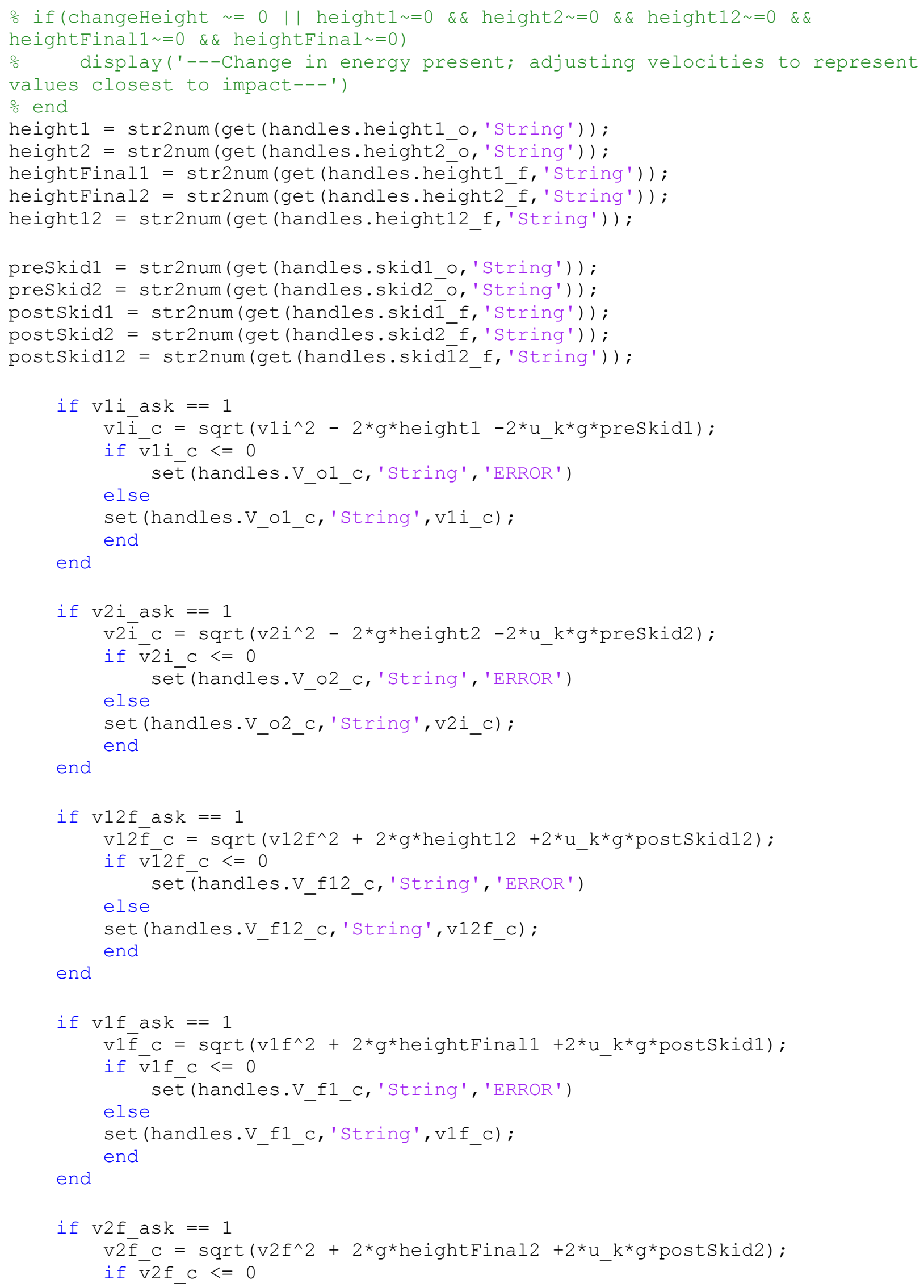




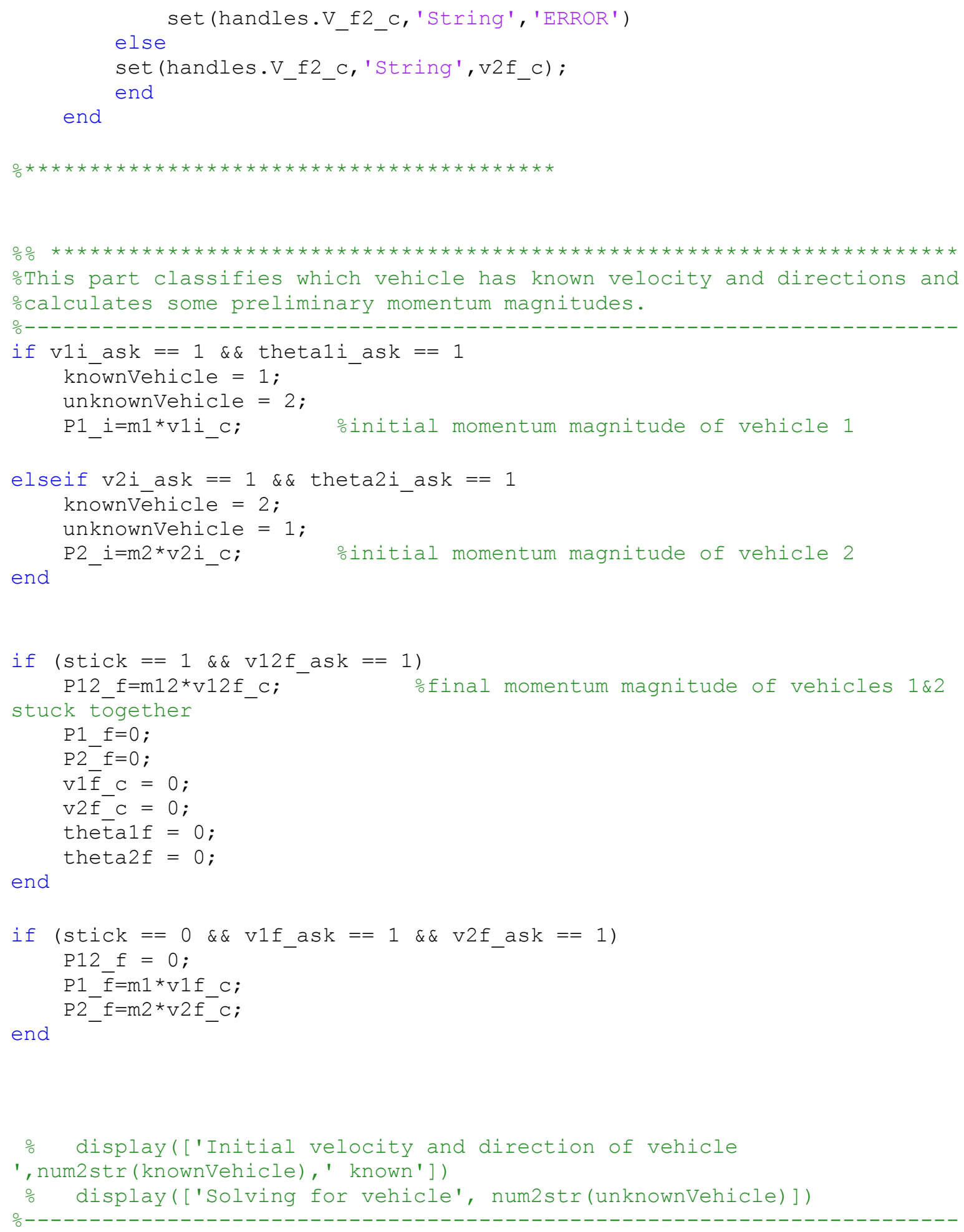


Case A

oThis part solves for the unknown initial velocity vector of a vehicle when othe magnitude and direction of the post-collision vehicle(s) are known, oand the initial velocity magnitude and direction of the other vehicle

ois known.

\%

oknowns:

o-Final Direction and Magnitude of post-collision vehicles

o-Initial Direction and Magnitude of one vehicle

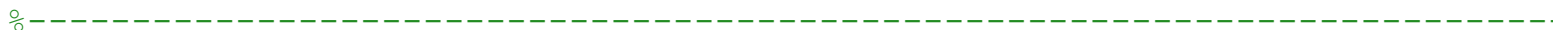

oThe following if statement checks to see if the following conditions are otrue:

o--> (final velocity vector AND (initial velocity of vehicle 1 OR 2)

o--> (final velocity vectors AND (initial velocity of vehicle 1 OR 2)

if $($ headon $==0) \& \&\left(\left(v 12 f \_a s k==1 \& \&\right.\right.$ theta12f_ask $==1 \& \&$ stick $\left.==1\right) \quad|| \ldots$ $(\mathrm{v} 1 \mathrm{f}$ ask $==1$ \&\& thetalf_ask $=1$ \&\& v2f_ask $==1$ \&\& theta2f_ask ==1 \&\&

stick $==0)) \& \& \ldots$

$(v 1$ i_ask $==1 \& \&$ thetali_ask $==1|| \ldots$

v2i a sk $==1 \& \&$ theta2i_ask $==1$ )

display ('Case A')

validCase $=1$;

if $v 1$ i_ask $==0$

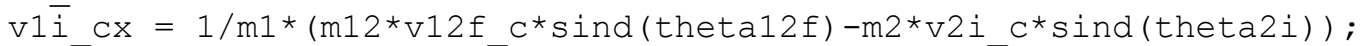

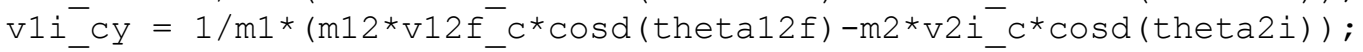

$\mathrm{v} 1 i^{-} \mathrm{c}=\operatorname{sqrt}\left(\mathrm{v} 1 \mathrm{Cx}^{\wedge} 2 \overline{\mathrm{C}} \mathrm{V} 1 \mathrm{i} \mathrm{cy}^{\wedge} 2\right)$;

the tali $=\operatorname{rad} 2 \operatorname{deg}\left(\operatorname{atan} 2\left(v 1 i \_\overline{c x}, v 1 i \_c y\right)\right)$;

elseif v2i_ask $==0$

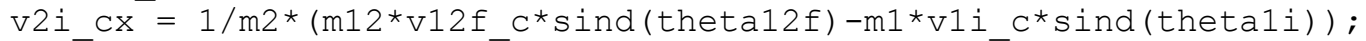

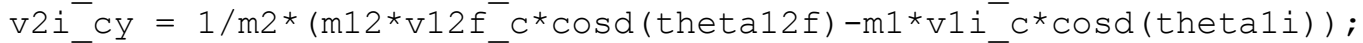

v2i_c ${ }^{-}=\operatorname{sqrt}\left(v 2 i \_c x^{\wedge} 2 \overline{+}\right.$ v2i_cy^2);

end

the ta2i $=\operatorname{rad} 2 \operatorname{deg}(\operatorname{atan} 2(v 2 i \bar{c} x, v 2 i \quad c y))$;

end

。

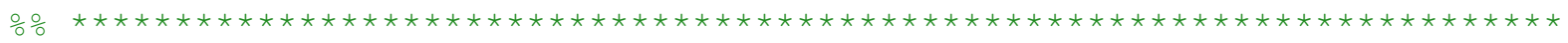

Case C

oThis part solves for the unknown initial velocity magnitude of a vehicle owhen the direction and magnitude of the post-collision vehicle(s) are known, oand the initial velocity direction of both vehicles is known.

$\%$

oknowns:

\%-Final Direction and Magnitude of post-collision vehicles

o-Initial Direction of both vehicles

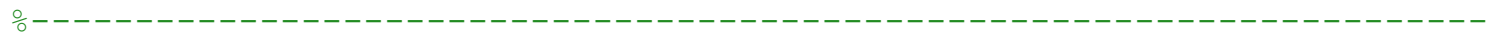

if ( $(\mathrm{v} 12 \mathrm{f}$ _ask $==1 \& \&$ theta12f_ask $==1 \& \&$ stick $==1) \ldots$

| $\mid$ (stick $=0$ \&\& $v 1 f$ ask $==1$ \&\& thetalf_ask $==1$ \&\& v2f_ask $==1$ \&\&

theta2f ask ==1)) $\ldots$

$\& \& \overline{(}(\mathrm{v} 1 \mathrm{i}$ _ask==0 \&\& theta1i_ask $==1 \quad \& \&$ v2i_ask==0 \&\& theta2i_ask $==1))$

display ('Case C')

validCase $=1$; 
v1i_c $=-m 12 * v 12 f *(\operatorname{cosd}($ theta $2 i) * \operatorname{sind}($ theta12 $f)-$

cosd (thēta12f)*sind (theta2i)) /m1/(-

$\operatorname{cosd}($ theta $2 i) * \operatorname{sind}($ theta $1 i)+\operatorname{sind}($ theta $2 i) * \operatorname{cosd}($ theta $i))$;

$\mathrm{v} 2 \mathrm{i} \mathrm{c}=\mathrm{m} 12 * \mathrm{v} 12 \mathrm{f} *(-$

sind (thetali) * cosd (theta12f) +sind (theta12f)* cosd (thetali))/m2/(-

cosd (theta2i)*sind (theta1i) +sind (theta2i) * cosd (theta1i));

end

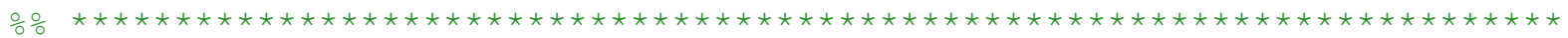

도 $\mathrm{B} \& \mathrm{D}$

oThis part solves for the unknown initial velocity magnitude of a vehicle

owhen the direction of the post-collision vehicle(s) are known,

oand the initial velocity direction of both vehicles is known and the

omagnitude of one initial velocity is known

응

\%Knowns:

o-Final Direction of post-collision vehicles

o-Final Magnitude of one post-collision vehicle

o-Initial Magnitude \& Direction of one vehicle

o-Initial Direction of both vehicles

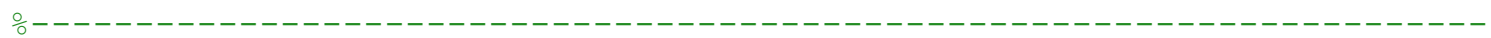

if $((((\mathrm{v} 1 \mathrm{f}$ ask $==0 \& \& \mathrm{v} 2 \mathrm{f}$ ask $==1)||(\mathrm{v} 1 \mathrm{f}$ ask $==1 \& \&$ v2f ask $==$

$0)) \& \&($ theta $\overline{1} f$ ask $==1 \& \&$ theta $\overline{2} f$ ask==1) ) | . .

$(\mathrm{v} 12 \mathrm{f}$-ask $==0$ \&\& theta12f_ask $==1 \& \&$ stick $==1)$ ) $\ldots$

$\& \& \quad\left(\left(v 1 i\right.\right.$ ask $==1 \& \&$ theta1i_ask $==1 \quad \& \& \quad v 2 i \_a s k==0 \quad \& \&$ theta2i_ask $\left.==1\right)|| \ldots$

$\left(v 2 i\right.$ ask $==1 \& \&$ theta2i_ask $==1 \quad \& \& \quad \mathrm{v} 1 i_{\text {_ask}}=0$ \& $\&$ theta1i_ask $\left.==1\right)$ )

display ('Case D')

validCase $=1$;

if $v 2 i$ ask $==0$ \&\& $v 2 f$ ask $==0$ \&\& stick $==0$

$A=\operatorname{sind}($ theta $2 i) / \operatorname{sind}($ theta $2 f)-\operatorname{cosd}($ theta $2 i) / \cos d($ theta $2 f)$;

$B=\operatorname{sind}($ theta $2 f) / \operatorname{sind}($ theta $2 f)-\operatorname{cosd}($ thetalf)/cosd (theta2f);

$\mathrm{C}=\operatorname{sind}($ thetali)/sind(theta2f)-cosd(thetali)/cosd(theta $\mathrm{f})$;

$\mathrm{v} 2 i_{-} \mathrm{c}=1 /\left(\mathrm{m} 2{ }^{\star} \mathrm{A}\right) *\left(\left(\mathrm{~m} 1{ }^{*} \mathrm{~V} 1 \mathrm{f} \_\mathrm{C}\right) * \mathrm{~B}-\mathrm{m} 1{ }^{\star} \mathrm{V} 1 i_{-}{ }^{*} \mathrm{C}\right)$;

$\mathrm{v} 2 \mathrm{f}^{-} \mathrm{C}=$

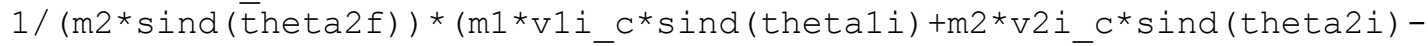
$\mathrm{m} 1{ }^{\star} \mathrm{V} 1 \mathrm{f} \_\mathrm{c}{ }^{\star} \mathrm{sind}($ thetalf) );

en $\bar{d}$

if $\mathrm{V} 2$ i_ask $==0$ \&\& $\mathrm{v} 1 \mathrm{f}$ ask $==0$ \&\& stick $==0$

$\mathrm{A}=\operatorname{sind}($ theta $2 i \overline{)} / \mathrm{sind}($ thetalf)-cosd (theta $2 i) / \cos d$ (theta $1 \mathrm{f})$;

$\mathrm{B}=\operatorname{sind}($ theta $\mathrm{f}$ )/sind(thetalf)-cosd(thetalf)/cosd(thetalf);

$\mathrm{C}=\operatorname{sind}($ thetali)/sind(thetalf)-cosd(thetali)/cosd(thetalf);

$\mathrm{v} 2 i_{-} \mathrm{C}=1 /\left(\mathrm{m} 2{ }^{*} \mathrm{~A}\right) *\left(\left(\mathrm{~m} 2{ }^{*} \mathrm{~V} 2 \mathrm{f}_{-} \mathrm{C}\right){ }^{*} \mathrm{~B}-\mathrm{m} 1{ }^{\star} \mathrm{v} 1 i_{-}{ }^{*} \mathrm{C}\right)$;

$\mathrm{v} 1 \mathrm{f}$ C $=$

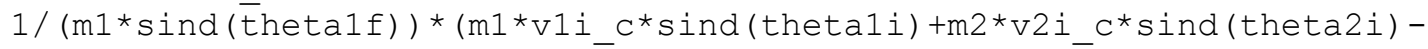
$\mathrm{m} 2{ }^{*} \mathrm{v} 2 \mathrm{f} \_\mathrm{c}{ }^{*} \mathrm{sind}($ theta $\left.2 \mathrm{f})\right)$;

en $\bar{d}$

if $\mathrm{V} 1 \mathrm{i}$ ask==0 \&\& $\mathrm{v} 2 \mathrm{f}$ ask $==0$ \&\& stick $==0$

$A=\operatorname{sind}($ theta $2 i \overline{)} / \operatorname{sind}($ theta $2 f)-\operatorname{cosd}$ (theta2i)/cosd (theta2f);

$B=\operatorname{sind}($ theta2f)/sind(theta2f)-cosd(theta1f)/cosd(theta $2 f)$;

$\mathrm{C}=\operatorname{sind}($ thetali)/sind(theta2f)-cosd(thetali)/cosd(theta2f);

$\mathrm{v} 1 i_{-} \mathrm{c}=1 /\left(\mathrm{m} 1{ }^{*} \mathrm{C}\right){ }^{*}\left(\left(\mathrm{~m} 1{ }^{*} \mathrm{v} 1 f_{-} \mathrm{c}\right){ }^{*} \mathrm{~B}-\mathrm{m} 2{ }^{*} \mathrm{~V} 2 i_{-}{ }^{*} \mathrm{~A}\right)$; 
$\mathrm{v} 2 \mathrm{f} \mathrm{c}=$

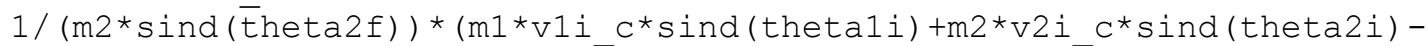
$\mathrm{m} 1{ }^{*} \mathrm{~V} 1 \mathrm{f} \mathrm{C}^{*} \mathrm{sind}($ thetalf) ); en $\bar{d}$

if $\mathrm{V} 1 \mathrm{i}$ ask==0 \&\& $\mathrm{vlf}$ ask==0 \&\& stick $==0$

$A=\operatorname{sind}($ theta $2 i \overline{)} / \operatorname{sind}($ thetalf)-cosd(theta $2 i) / \cos d$ (theta $1 f)$;

$\mathrm{B}=\operatorname{sind}($ theta $2 \mathrm{f}) / \mathrm{sind}($ thetalf)-cosd (thetalf)/cosd (thetalf);

$\mathrm{C}=\operatorname{sind}($ thetali)/sind(thetalf)-cosd(thetali)/cosd(thetalf);

$\mathrm{v} 1 i_{-} \mathrm{c}=1 /(\mathrm{m} 1 * \mathrm{C}) *\left(\left(\mathrm{~m} 2{ }^{*} \mathrm{v} 2 \mathrm{f} \_\mathrm{c}\right){ }^{*} \mathrm{~B}-\mathrm{m} 2 * \mathrm{~V} 2 i_{-}{ }^{*} \mathrm{~A}\right)$;

$\mathrm{v} 1 \mathrm{f} \mathrm{C}=$

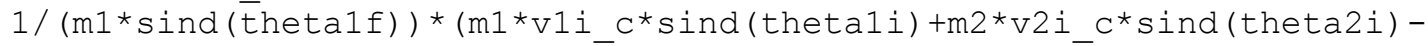
$\mathrm{m} 2{ }^{\star} \mathrm{v} 2 \mathrm{f} \_\mathrm{c}^{\star}$ sind (theta2f));

en $\bar{d}$

if $\mathrm{V} 2 \mathrm{i}$ ask $==0$ \&\& $\mathrm{v} 12 \mathrm{f}$ ask $==0$ \&\& stick $==1$

$\mathrm{A}=\operatorname{sind}($ theta $2 i) / \operatorname{sind}($ theta12f)-cosd(theta2i)/cosd(theta12f);

$B=\operatorname{cosd}($ thetali)/cosd(theta12f)-sind(theta1i)/sind(theta12f);

$\mathrm{v} 2 i_{C} \mathrm{c}=1 /\left(\mathrm{m} 2{ }^{*} \mathrm{~A}\right) *\left(\mathrm{~m} 1{ }^{*} \mathrm{v} 1 i_{C} \mathrm{c}\right) * \mathrm{~B}$;

$\mathrm{V} 12 \overline{\mathrm{f}} \_\mathrm{CX}=1 /(\mathrm{m} 12) *\left(\mathrm{~m} 1{ }^{*} \mathrm{~V} 1 \bar{i}_{-} \mathrm{C}^{*} \mathrm{Sind}\left(\right.\right.$ theta1i) $+\mathrm{m} 2{ }^{*} \mathrm{~V} 2 i_{-} \mathrm{C}^{*} \mathrm{Sind}($ theta2i) $)$;

$\mathrm{v} 12 \mathrm{f}^{-} \mathrm{Cy}=1 /(\mathrm{m} 12) *\left(\mathrm{~m} 1{ }^{*} \mathrm{~V} 1 i^{-} \mathrm{C}^{*} \mathrm{Cosd}(\right.$ theta $1 \mathrm{i})+\mathrm{m} 2{ }^{*} \mathrm{~V} 2 i^{-} \mathrm{C}^{*} \mathrm{Cosd}($ theta2i) $)$;

end

$\mathrm{v} 12 \mathrm{f}_{-}^{-} \mathrm{c}=\operatorname{sqrt}\left(\mathrm{v} 12 \mathrm{f}_{-} \mathrm{cx} \mathrm{x}^{\wedge} 2+\overline{\mathrm{v}} 12 \mathrm{f} \mathrm{f}_{\mathrm{C}} \mathrm{y}^{\wedge}\right)$;

if $\mathrm{V} 1 \mathrm{i}$ ask $==0$ \&\& $\mathrm{v} 12 \mathrm{f}$ ask $==0$ \&\& stick $==1$

$A=\operatorname{sind}($ thetali)/sind(theta12f)-cosd(theta1i)/cosd(theta12f);

$B=\operatorname{cosd}($ theta2i)/cosd(theta12f)-sind(theta2i)/sind(theta12f);

$\mathrm{v} 1 i_{C} \mathrm{c}=1 /(\mathrm{m} 1 * A) *\left(\mathrm{~m} 2{ }^{*} \mathrm{~V} 2 i_{\mathrm{C}} \mathrm{c}\right) * \mathrm{~B}$;

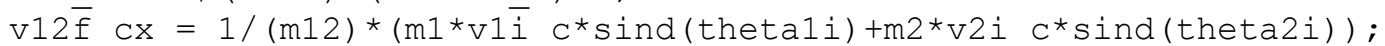

$\mathrm{v} 12 \mathrm{f}_{-} \mathrm{Cy}=1 /(\mathrm{m} 12) *\left(\mathrm{~m} 1{ }^{*} \mathrm{~V} 1 i_{-}{ }^{*}{ }^{*} \cos d\left(\right.\right.$ theta1i) $+\mathrm{m} 2{ }^{*} \mathrm{~V} 2 i_{-}{ }^{*}{ }^{*} \cos d($ theta2i) $)$; end $\mathrm{v} 12 \mathrm{f} \_\mathrm{c}=\operatorname{sqrt}\left(\mathrm{v} 12 \mathrm{f} \_\mathrm{cx} \wedge 2+\mathrm{v} 12 \mathrm{f} \_\mathrm{cy} \mathrm{y}^{\wedge} 2\right)$;

end

$\circ-------------------------$

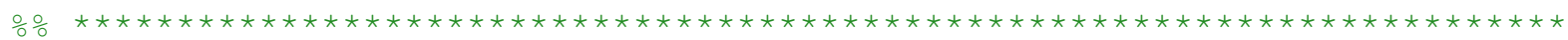

oCase E - Head on collision

oThis part solves for the unknown initial velocity magnitude of a vehicle oduring a head-on collision. All other parameters must be known.

\%

\%Knowns:

o-Final Direction of vehicles

o-Final Magnitude of vehicles

-Initial Magnitude \& Direction of one vehicle

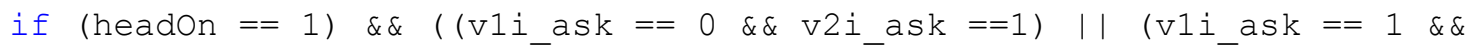

$\mathrm{v} 2 \mathrm{i}$ ask $==0$ ))

validCase $=1$;

display ('Case E')

display (theta2i)

if $\mathrm{vli}$ ask $==0$

$\mathrm{v} 1 \bar{i} \mathrm{cx}=$

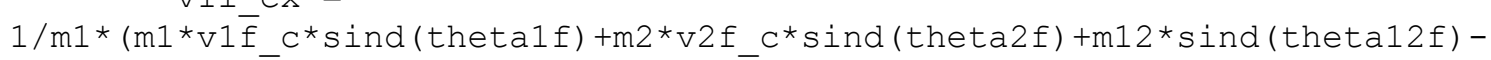
$\mathrm{m} 2{ }^{*} \mathrm{v} 2 i_{-}{ }^{\star} \sin \overline{\mathrm{d}}($ theta2i)) ; 


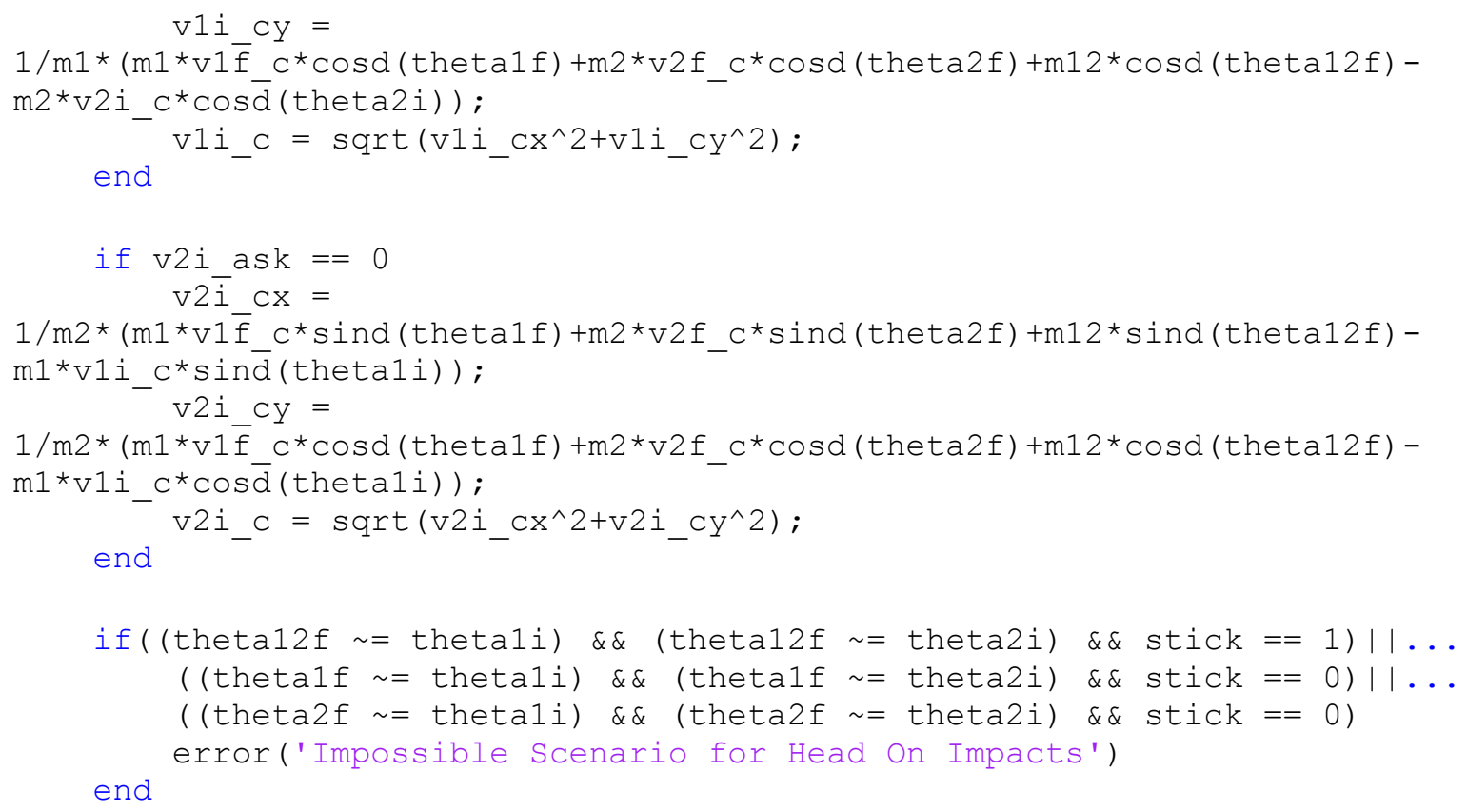




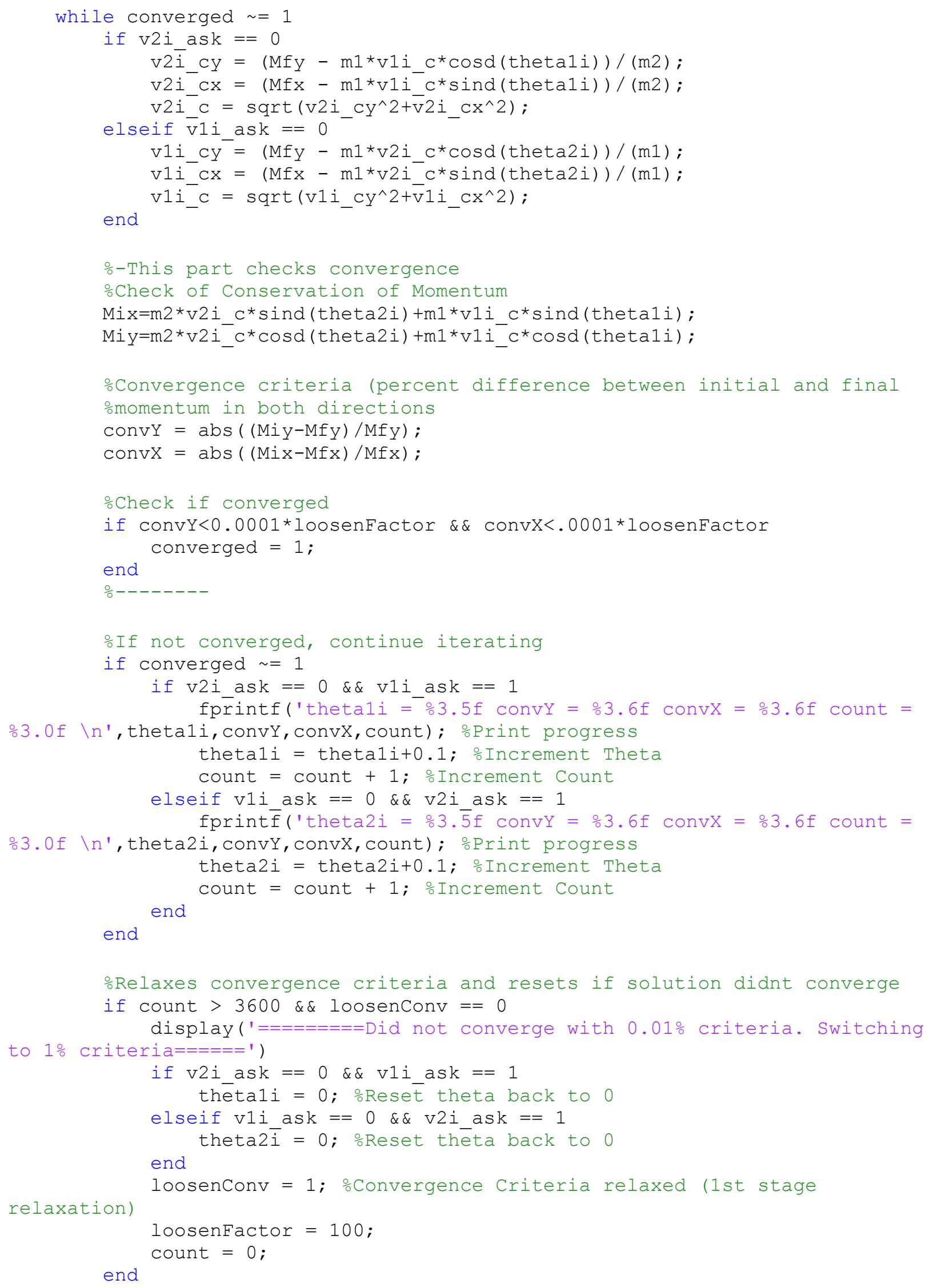




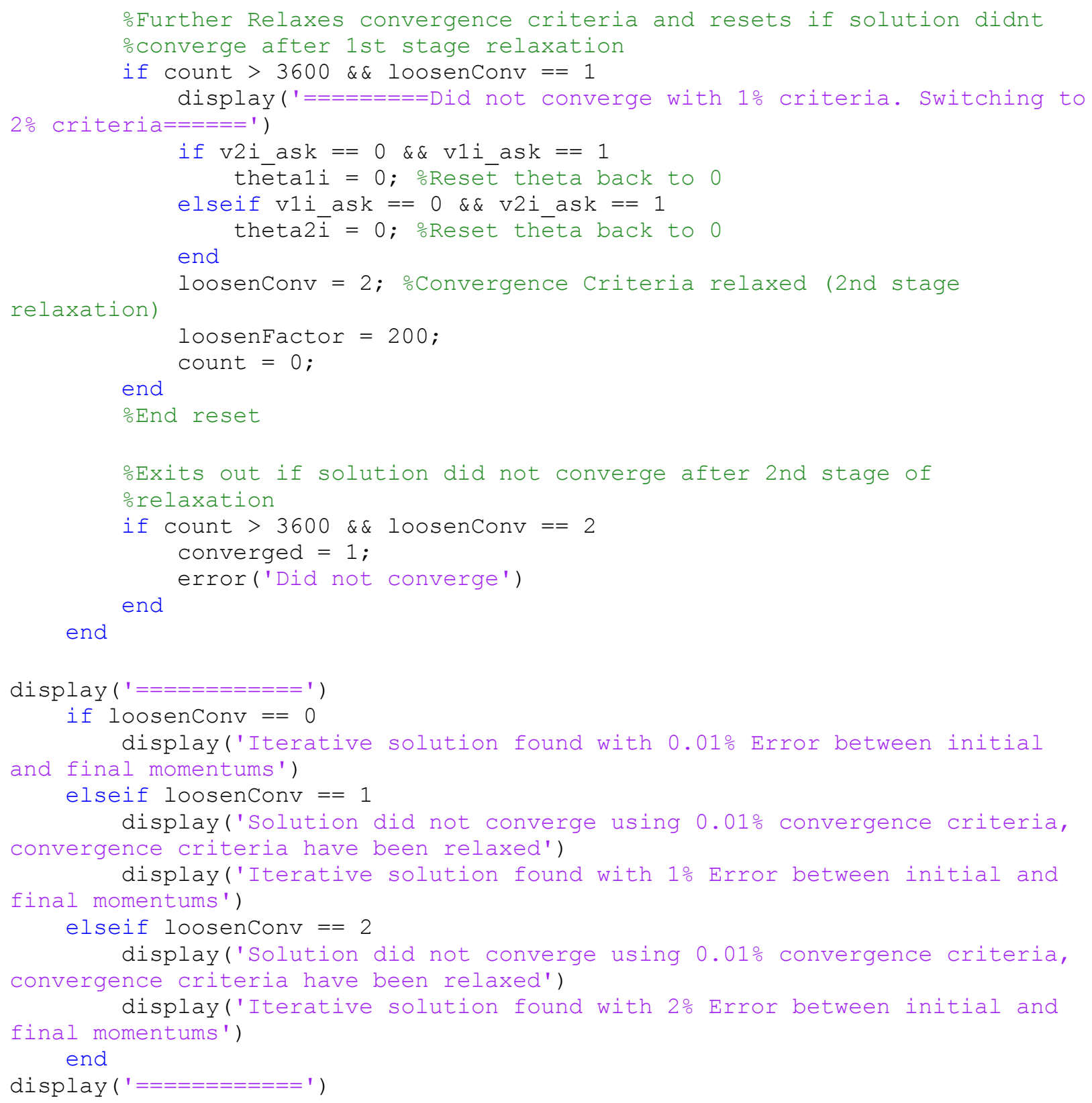

end

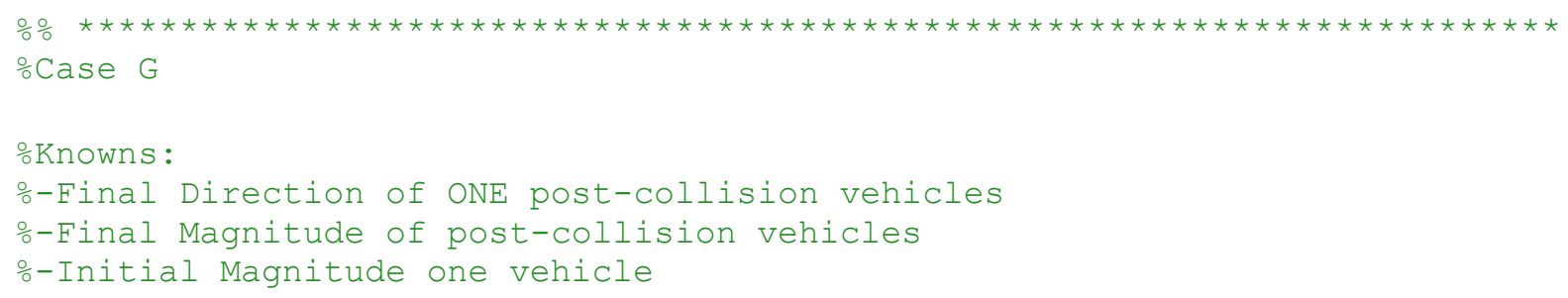




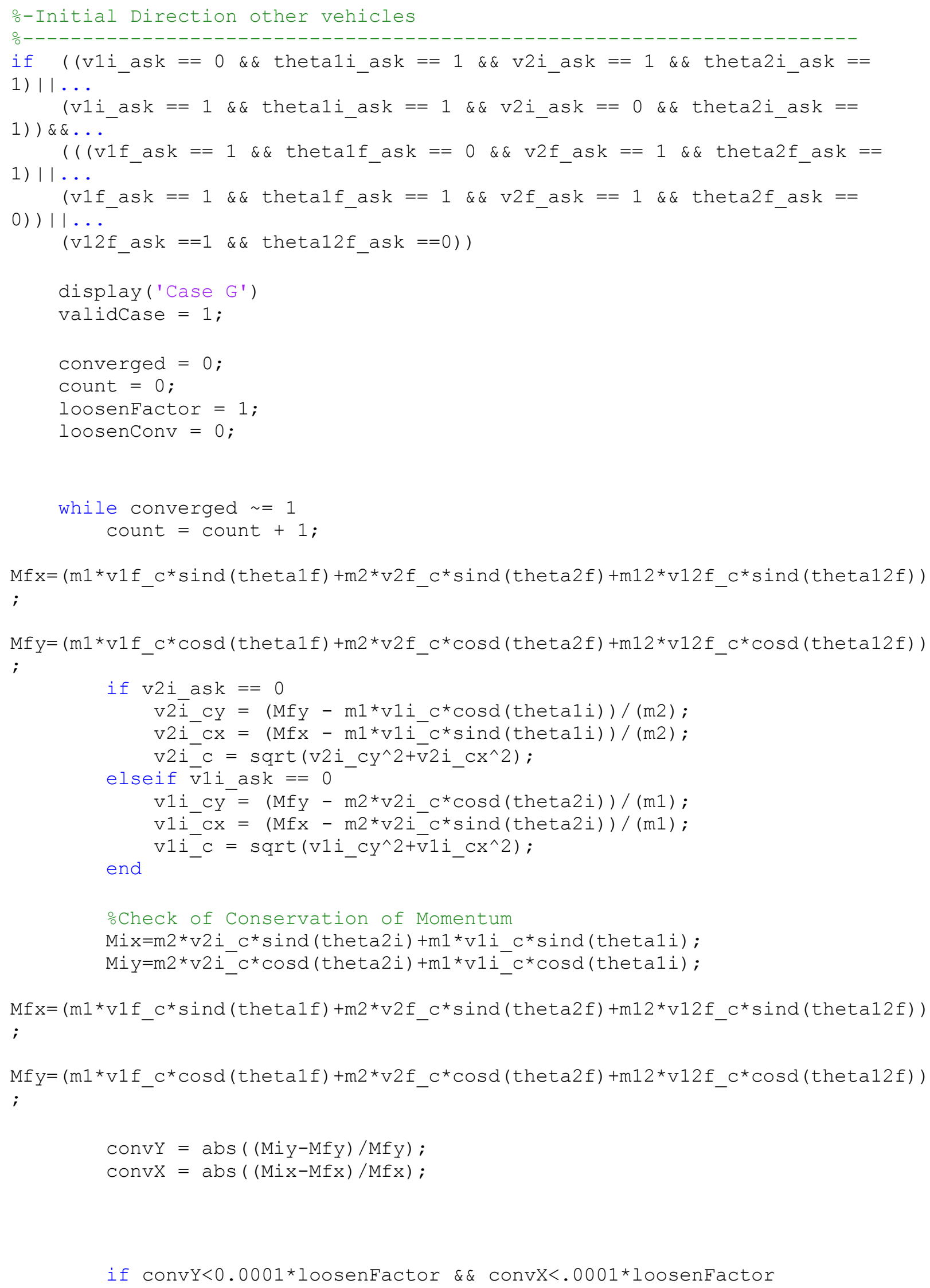




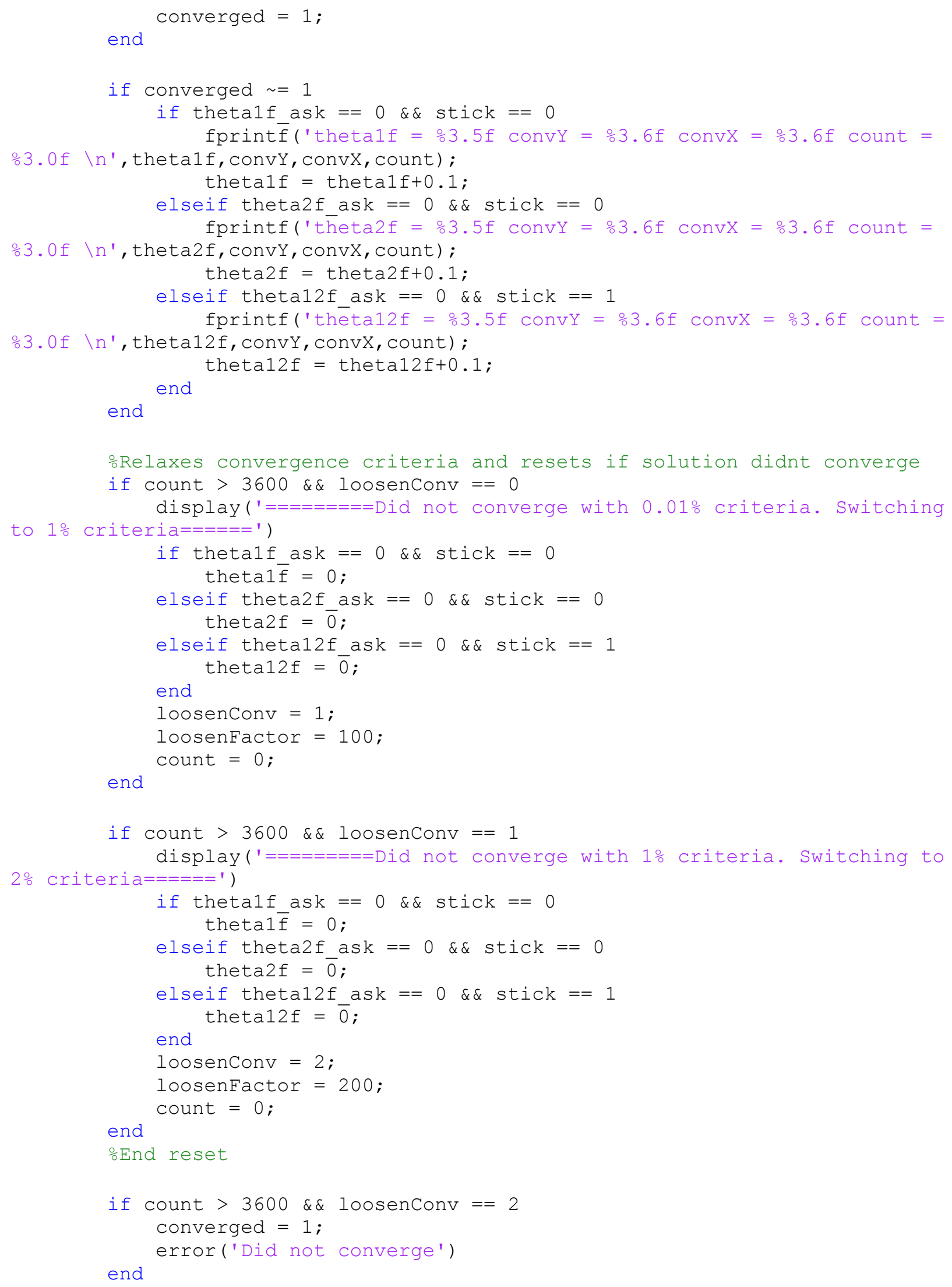




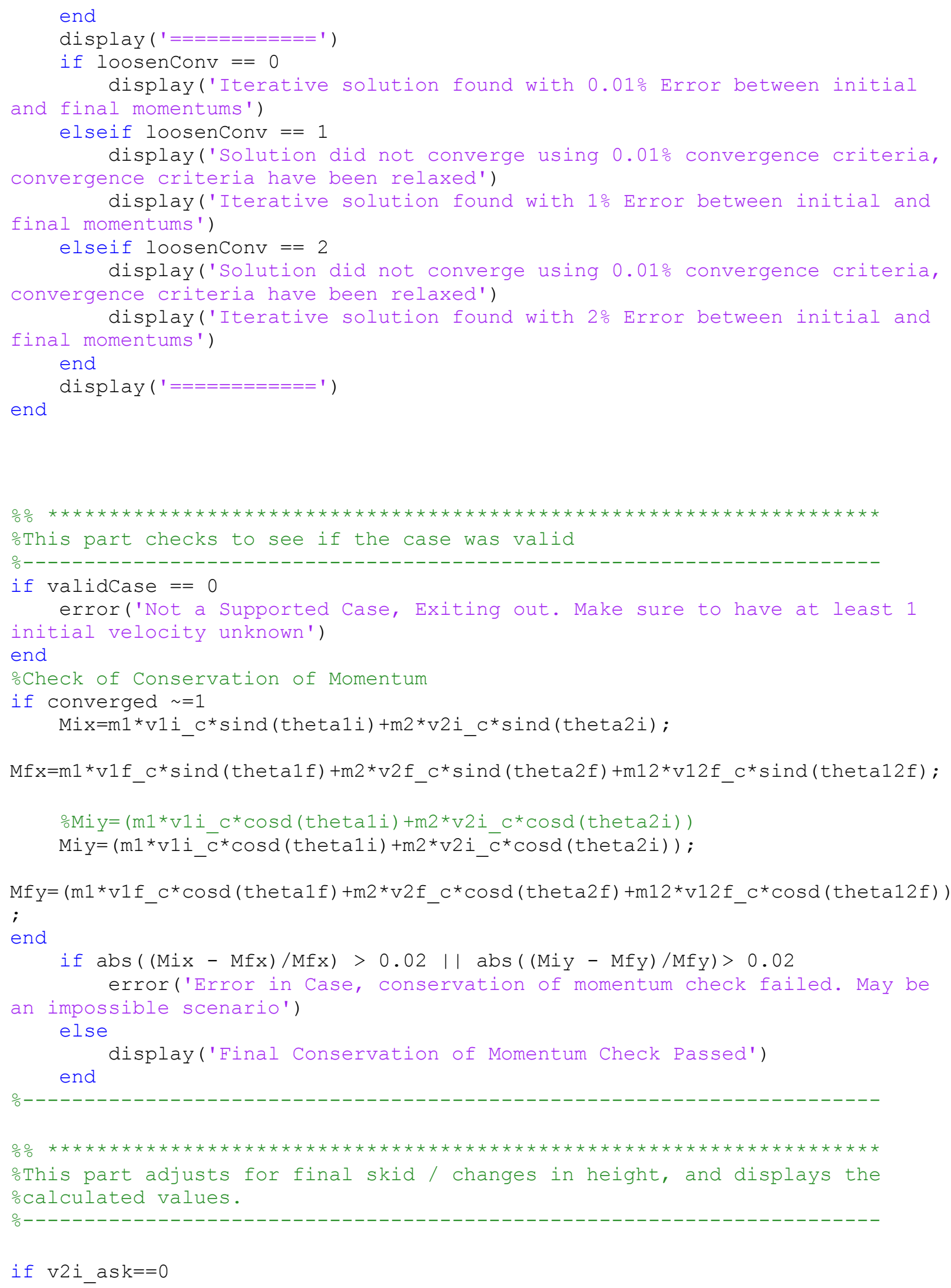




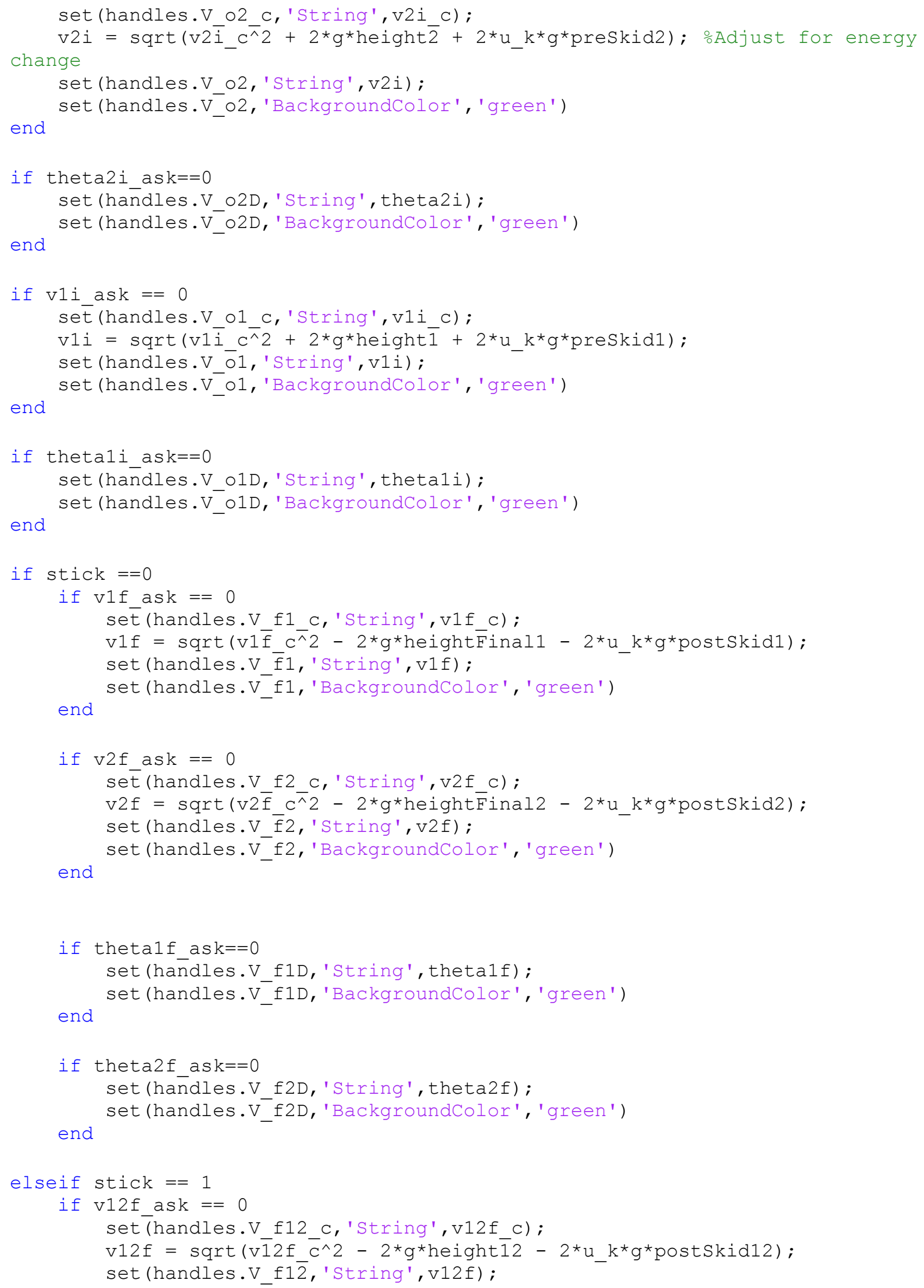


end

set (handles.V_f12, 'BackgroundColor', 'green')

if thetal2f ask $==0$

set (hand̄les.V f12D, 'String', theta12f);

end

set (handles.Vff12D, 'BackgroundColor', 'green')

end

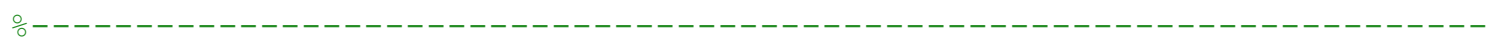

oUpdates all fields with changed values

guidata (hobject, handles);

End update

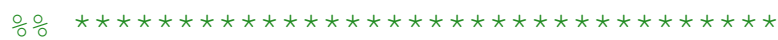

oThis part plots the velocity vectors

\%------------------------------------

if get (handles.velocityplot, 'Value')==1

[initialVelocityl_x, initialVelocityl_y] = pol2cart(deg2rad(thetali), v1i c) ;

[initialVelocity2_x, initialVelocity2_y] = pol2cart(deg2rad(theta2i), v2i_c) ;

[finalVelocity12_x, finalVelocity12_y] = pol2cart(deg2rad(theta12f), $\mathrm{v} 12 \mathrm{f}$ c) ;

[finalVelocityl $x$, finalVelocityl y] = pol2cart(deg2rad(thetalf), v1f c); [finalVelocity2_x, finalVelocity2_y] = pol2cart(deg2rad(theta2f), v2f_c);

figure ㄷeates New Figure

scale_holder $=\operatorname{compass}\left(1.25 * \max \left(\left[\mathrm{v} 1 i_{-} \mathrm{c}, \mathrm{v} 2 i_{-} \mathrm{c}, \mathrm{v} 12 \mathrm{f} \_\mathrm{c}\right]\right), 0\right)$;

title ('Instantaneous pre/post collision velōity vectors')

set(scale_holder, 'Visible', 'off');

hold on

V1i = compass (initialVelocityl x, initialVelocityl_y, 'b-');

V2i = compass (initialVelocity2 $x$, initialVelocity2_y, 'g-');

if stick == 1

V12f = compass (finalVelocity12_x, finalVelocity12_y, 'r-.');

legend([V1i, V2i, V12f], 'Vehicle 1 Initial Velocity', 'Vehicle 2

Initial Velocity', 'Vehicle12 Final Velocity', 'Location',

'NorthWestoutside' )

else

V1f = compass (finalVelocityl_x, finalVelocityl_y, 'm: ') ;

V2f = compass (finalVelocity2 ${ }^{-} \mathrm{x}$, finalVelocity2 $\mathrm{y}, \mathrm{I}^{\prime} \mathrm{c}:$ ') ;

legend([V1i, V2i, V1f, V2f], 'Vehicle 1 Initial Velocity', 'Vehicle 2

Initial Velocity', 'Vehiclel Final Velocity','Vehicle2 Final Velocity',

'Location', 'NorthWestoutside')

end

end

view $(90,-90)$

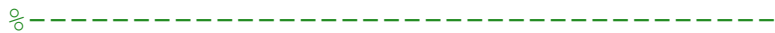




\title{
Appendix H Derivation for VAR Cases
}

\author{
oMatlab Derivation for Cases C, B and D \\ \%-------------------------------------------------------------------- \\ o---This part defines the variables used in the momentum equations--- \\ syms m1 v1i thetali v2i theta2i m2 m12 v12f thetal2f
}

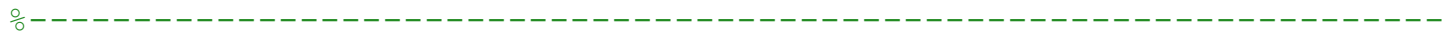

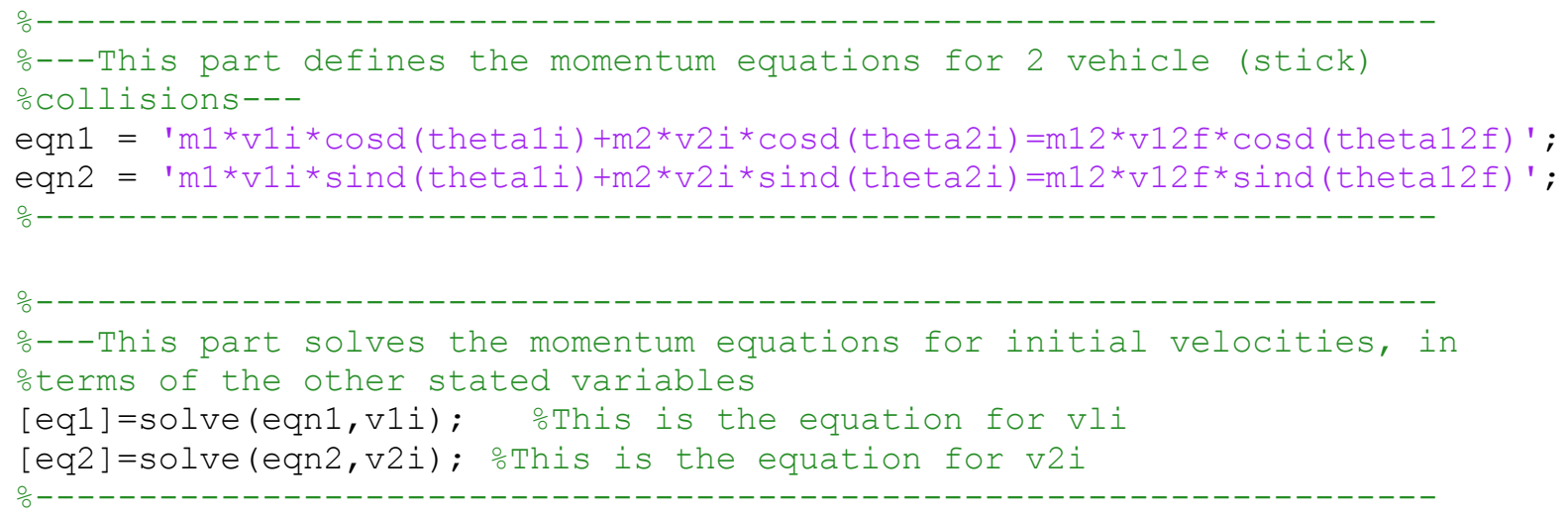

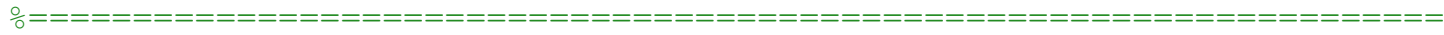

Case C Derivation

은------------------------------------------------------------------

o---This part substitutes in equation 2 into the variable "v2i", which oyields the equation for v1i without v2i in the equation eqn3 = subs (eq1, v2i, eq2); othis is the equation for v1i

o---This part substitutes in equation 1 into the variable "v1i", which oyields the equation for vii without viiin the equation

oCase C Derivation

eqn4 = subs (eq2, v1i, eq1); 은, is the equation for v2i

oThe outputs of eqn3 and eqn4 yield the following in the matlab window. oThey are copy and pasted as follows for convenience:

eqn $3='(-(-$

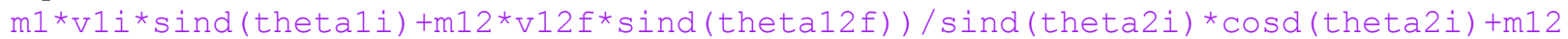
${ }^{*} \mathrm{v} 12 \mathrm{f}{ }^{*} \cos d($ theta12f) )/m1/cosd (theta1i) $=\mathrm{v} 1 \mathrm{i}$ ' ;

solve(eqn3, v1i) oThis is the equation for v1i, without v2i as a contributing variable

oYields this:

ov1i=-m12*V12f* (cosd (theta $2 i) * \operatorname{sind}($ theta12f $)-$

cosd (theta12f)*sind (theta $2 i)) / m 1 /(-$

$\operatorname{cosd}($ theta $2 i){ }^{*} \operatorname{sind}\left(\right.$ theta 1 ) $+\operatorname{sind}($ theta $2 i){ }^{*} \cos d($ theta 1 ) )

eqn $4='(-(-$

$m 2{ }^{*} \mathrm{v} 2 i{ }^{*} \cos d\left(\right.$ theta2i) $+\mathrm{m} 12{ }^{*} \mathrm{~V} 12 \mathrm{f}{ }^{*} \mathrm{cosd}($ theta12f)) / cosd (theta1i)*sind (theta1i) $+\mathrm{m} 12$

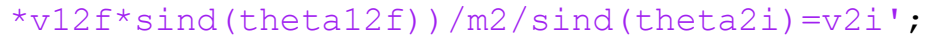

oThis part solves equation 4 to get v2i

H-1 
solve (eqn4, v2i) orhis is the equation for v2i, without v1i as a contributing variable

oYields this:

응 $\mathrm{v} 2 i=\mathrm{m} 12 * \mathrm{v} 12 \mathrm{f} *(-$

sind (thetali)* cosd (theta12f) +sind (theta12f)* cosd (thetali))/m2/(-

$\operatorname{cosd}($ theta $2 i) * \operatorname{sind}\left(\right.$ thetali) $+\operatorname{sind}($ theta $2 i){ }^{*} \cos d($ thetali))

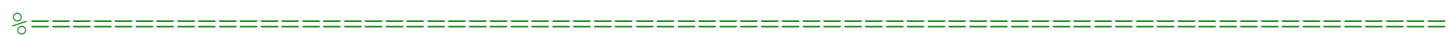

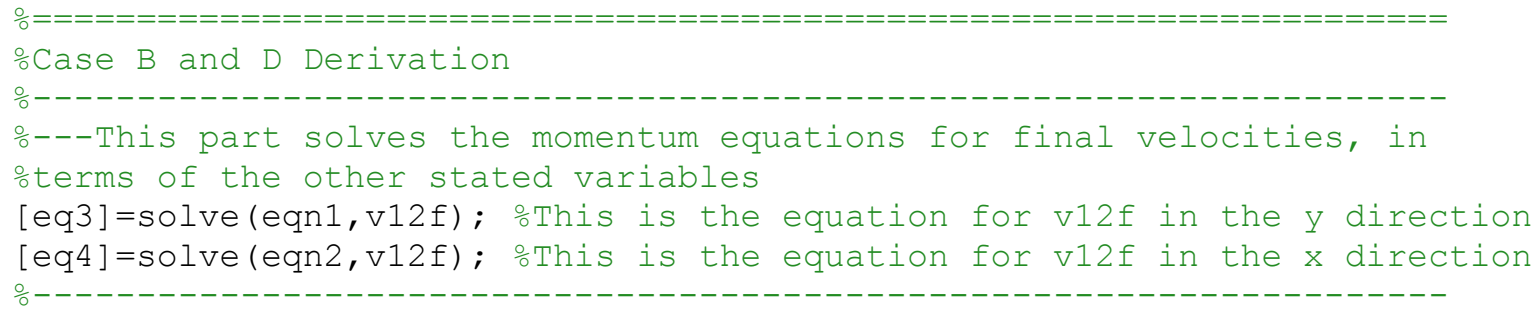

\%---This part substitutes in equation 4 into the variable "v12f", which

oyields the momentum equation without v12f as a variable.

display ('Case $B$ and $D$ ')

eqn5 = subs (eq1, v12f, eq4); oThis is the equation for v1i without v12f in the

equation

eqn $6=$ subs (eq2,v12f, eq3); othis is the equation for v2i without v12f in the equation

oThe outputs of eqn5 and eqn6 yield the following in the matlab window.

othey are copy and pasted as follows for convenience:

oeqn $5=(-$

$\mathrm{m} 2{ }^{*} \mathrm{v} 2 i{ }^{*} \mathrm{cosd}($ theta2 $i)+\left(\mathrm{m} 1{ }^{*} \mathrm{~V} 1 i{ }^{*} \operatorname{sind}\left(\right.\right.$ theta1i) $+\mathrm{m} 2{ }^{*} \mathrm{v} 2 i{ }^{*} \mathrm{sind}($ theta2i))/sind (theta12

f) ${ }^{*} \operatorname{cosd}($ theta12f) ) /m1/cosd (theta1i)

ogn 6

$\frac{\circ}{0}=(-$

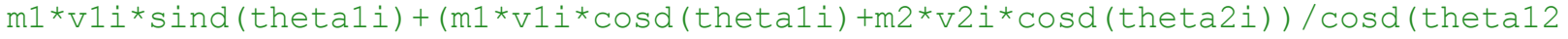

f) *sind (theta12f)) /m2/sind (theta2i)

eqn $5=$ ' $(-$

$\mathrm{m} 2{ }^{*} \mathrm{~V} 2 i{ }^{*} \mathrm{Cosd}\left(\right.$ theta2i) $+\left(\mathrm{m} 1{ }^{*} \mathrm{~V} 1 i{ }^{*} \mathrm{sind}\left(\right.\right.$ theta1i) $+\mathrm{m} 2{ }^{*} \mathrm{~V} 2 i{ }^{*} \mathrm{sind}($ theta2i))/sind(theta12

f) ${ }^{*} \operatorname{cosd}($ theta12f) $) / \mathrm{m} 1 / \operatorname{cosd}\left(\right.$ thetali) $=\mathrm{V} 1 \mathrm{i}^{\prime}$;

eqn $6='-(m 1 * v 1 i * \operatorname{sind}($ thetali) -

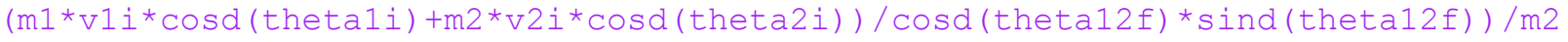

/ sind (theta2i) = v2i';

solve (eqn 5, v1i)

oYields this:

$\circ \mathrm{v} 1 i=m 2 * v 2 i *(-$

$\operatorname{cosd}($ theta $2 i) * \operatorname{sind}($ theta12f) $+\cos d($ theta12f)*sind (theta2i)) /m1/( -

sind (thetali) ${ }^{*} \cos d($ theta $12 f)+\operatorname{sind}($ theta $12 f){ }^{*} \operatorname{cosd}($ thetali))

solve (eqn $6, \mathrm{v} 2 i)$

ov2i $=m 1 * v 1 i *(-$

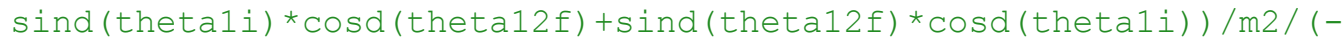

$\operatorname{cosd}($ theta2i)*sind (theta12f) $+\operatorname{cosd}($ theta12f)*sind (theta2i))

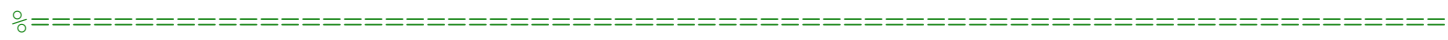




\section{Appendix I Catapult Postprocessing Code}

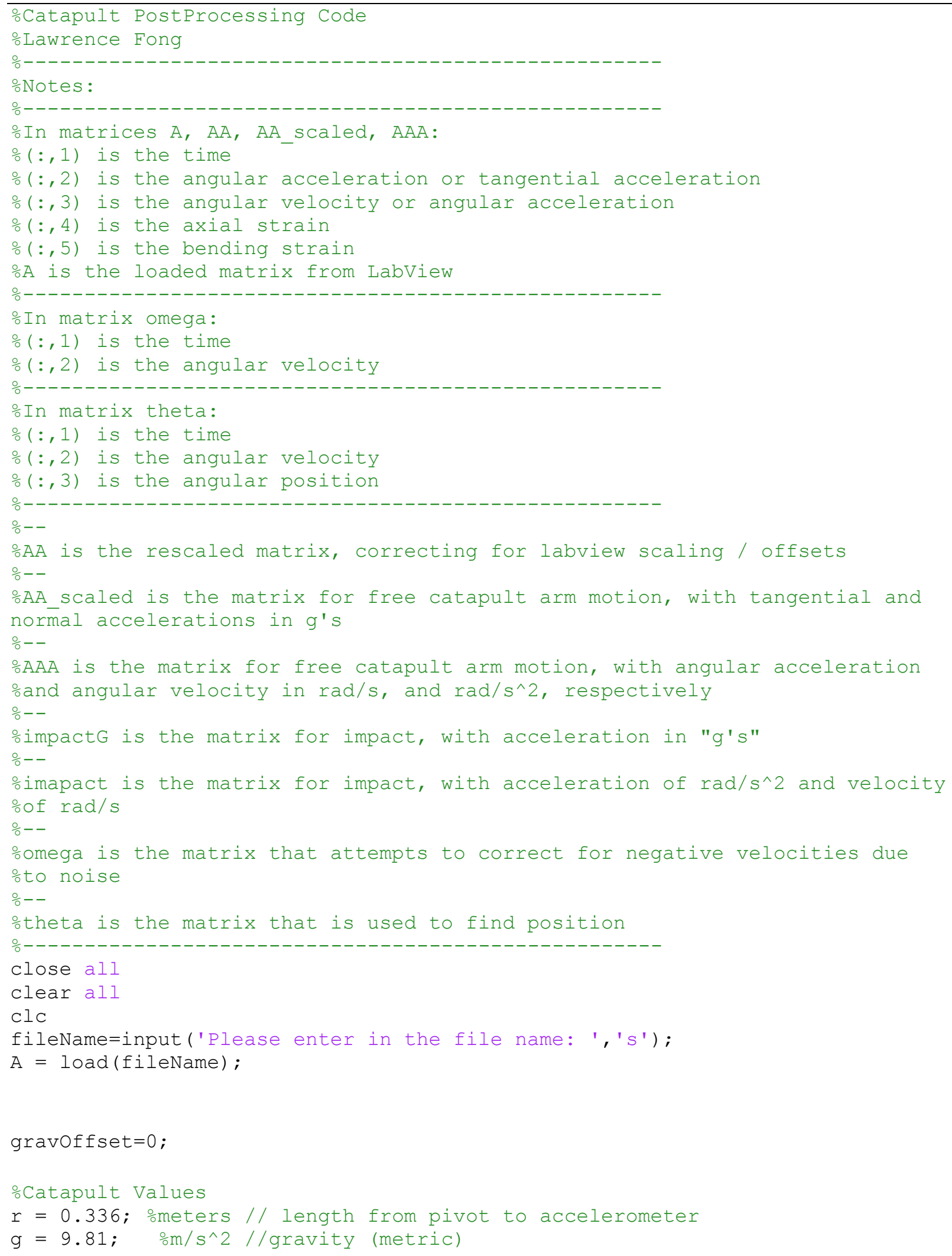




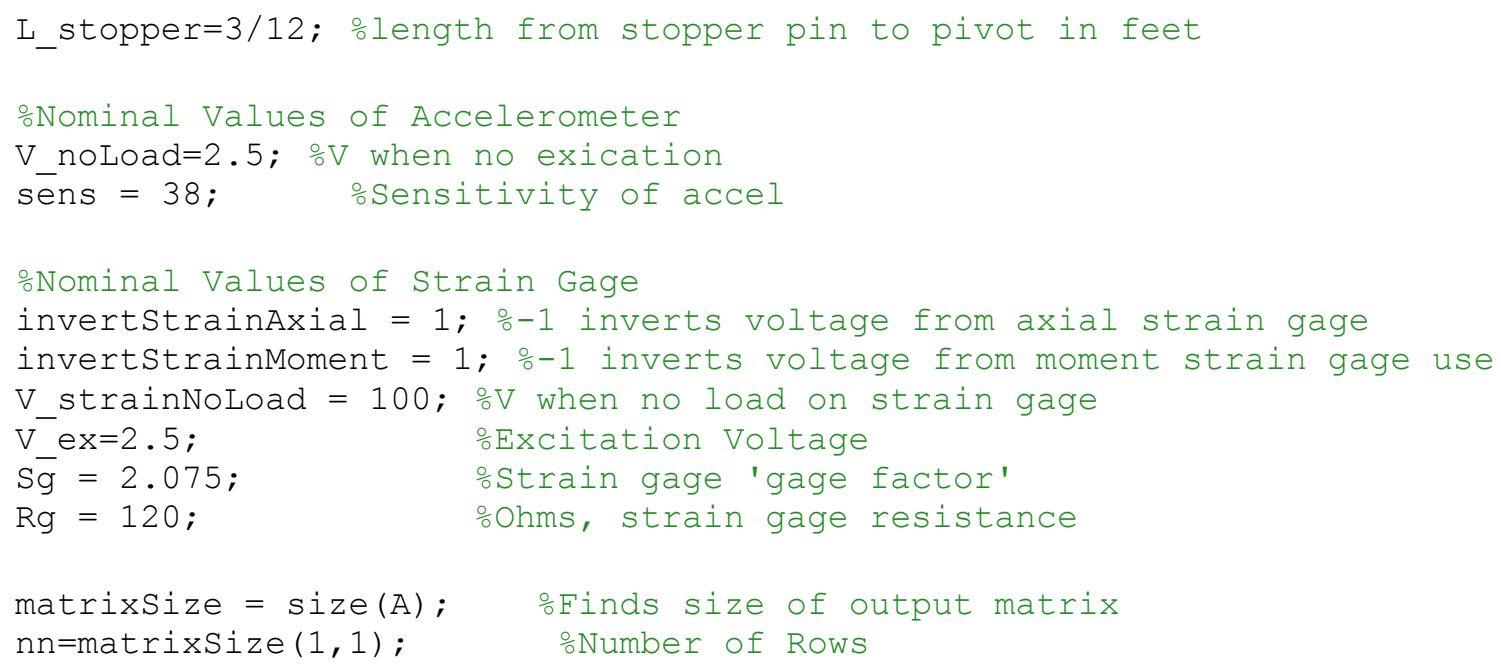


if $(\operatorname{abs}(A A(n, 5))<1.2 * a b s(A A(1,5)))$ \% 1.2 relaxes criteria for ending impact impactEndRow $=\mathrm{n}$; break

end

end

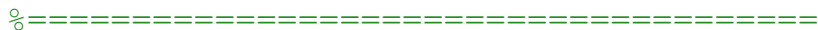

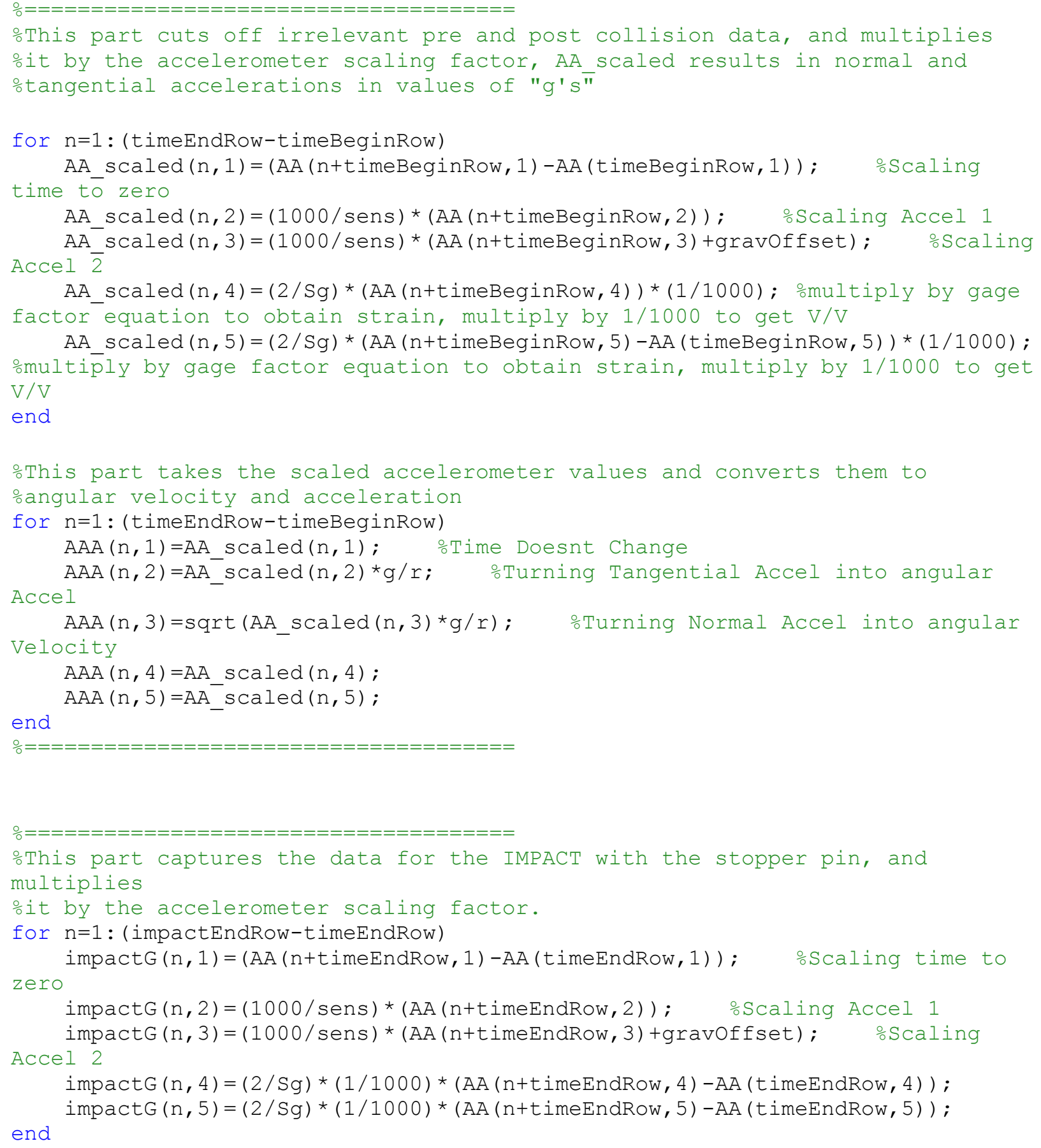


legend('Theoretical Axial Strain', 'Experimental Axial

Strain', 'Location', 'NorthWest')

xlabel ('Rescaled Time, s', 'fontsize', 12, 'fontweight', 'bold')

ylabel('Strain ft/ft', 'color', 'black', 'fontsize', 12, 'fontweight',

'bold' )

subplot $(3,1,3), \operatorname{plotyy}\left(A A \_s c a l e d(:, 1), A A \_s c a l e d(:, 5), t\right.$ theo, strain_moment) legend('Theoretical Axiā Strain', 'Experimental Axial Strain', 'Location', 'NorthWest')

xlabel ('Rescaled Time, s', 'fontsize', 12, 'fontweight', 'bold') ylabel('Strain ft/ft', 'color', 'black', 'fontsize', 12, 'fontweight', 'bold' )

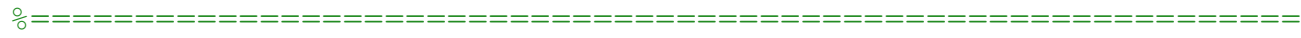

figure (3)

oplots impact data

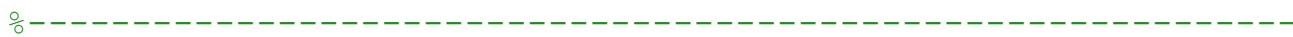

subplot $(4,1,1), \operatorname{plot}\left(i m p a c t(:, 1), \operatorname{impact}(:, 2), \mathrm{o}^{\prime}, \operatorname{impact}(:, 1), \operatorname{impact}(:, 2)\right)$ xlabel ('Impact Time, s', 'fontsize', 12, 'fontweight', 'bold') legend('Angular Acceleration', 'Location', 'NorthEast')

ylabel ('(rad/s^2)', 'fontweight', 'bold')

subplot $(4,1,2), \operatorname{plot}\left(i m p a c t(:, 1), \operatorname{impact}(:, 3),{ }^{\prime} \mathrm{o}^{\prime}, \operatorname{impact}(:, 1), \operatorname{impact}(:, 3)\right)$

xlabel ('Impact Time, s', 'fontsize', 12, 'fontweight', 'bold')

legend('Angular Velocity Magnitude', 'Location', 'NorthEast')

ylabel ('(rad/s) ', 'fontweight', 'bold')

subplot $(4,1,3), \operatorname{plot}\left(i m p a c t(:, 1), \operatorname{impact}(:, 4),{ }^{\prime} \mathrm{\prime}^{\prime}, \operatorname{impact}(:, 1), \operatorname{impact}(:, 4)\right)$ xlabel ('Impact Time, s', 'fontsize', 12, 'fontweight', 'bold')

legend('Axial Strain', 'Location', 'NorthEast')

ylabel('Strain (in/in)', 'fontweight', 'bold')

subplot $(4,1,4), \operatorname{plot}\left(i m p a c t(:, 1), \operatorname{impact}(:, 5), \mathrm{o}^{\prime}, \operatorname{impact}(:, 1), \operatorname{impact}(:, 5)\right)$

xlabel ('Impact Time, s', 'fontsize', 12, 'fontweight', 'bold')

legend ('Moment Strain', 'Location', 'NorthEast')

ylabel('Strain (in/in)', 'fontweight', 'bold')

은-------------------------------------------------------------

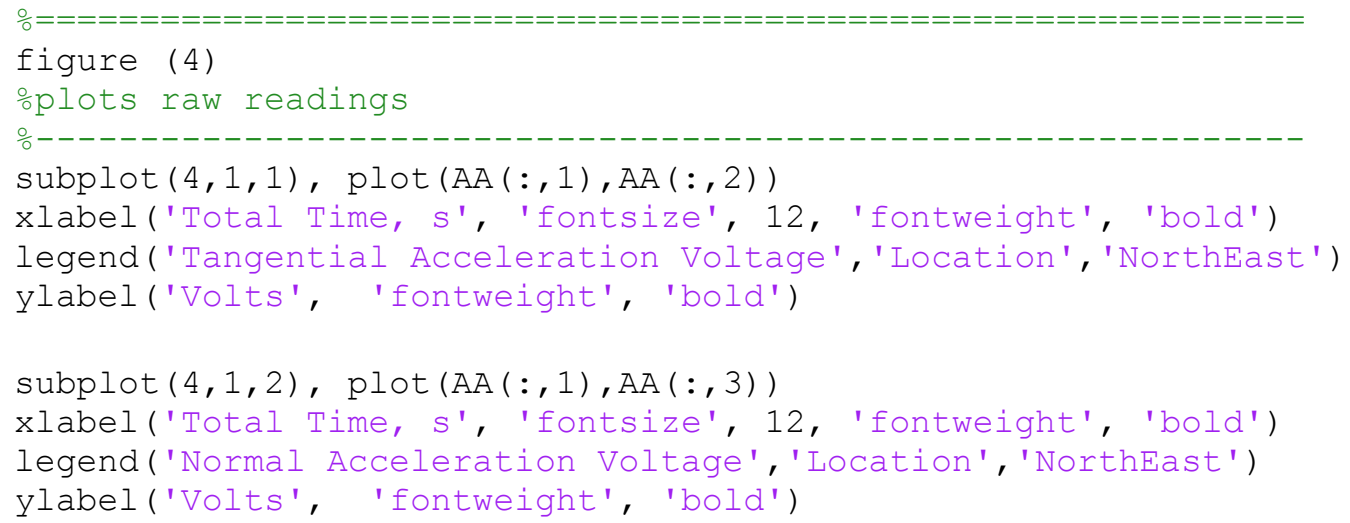


subplot $(4,1,3), \operatorname{plot}(A A(:, 1), A A(:, 4))$

xlabel('Total Time, s', 'fontsize', 12, 'fontweight', 'bold')

legend('Axial Strain Voltage', 'Location', 'NorthEast')

ylabel ('mV/V', 'fontweight', 'bold')

subplot $(4,1,4), \operatorname{plot}(A A(:, 1), A A(:, 5))$

xlabel('Total Time, S', 'fontsize', 12, 'fontweight', 'bold')

legend('Moment Strain Voltage', 'Location', 'NorthEast')

ylabel ('mV/V', 'fontweight', 'bold') 


\section{Appendix J Catapult Theoretical Code}

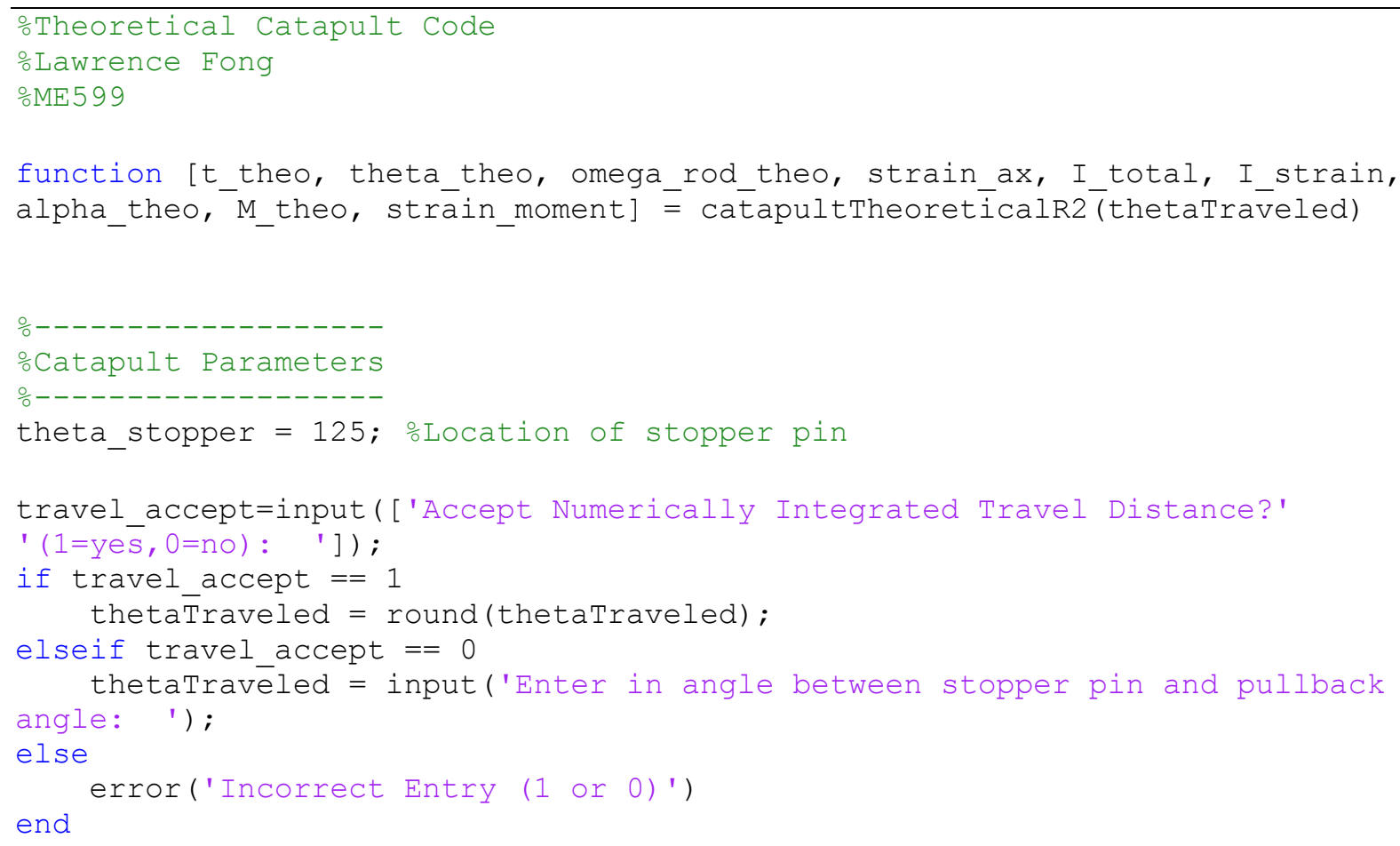




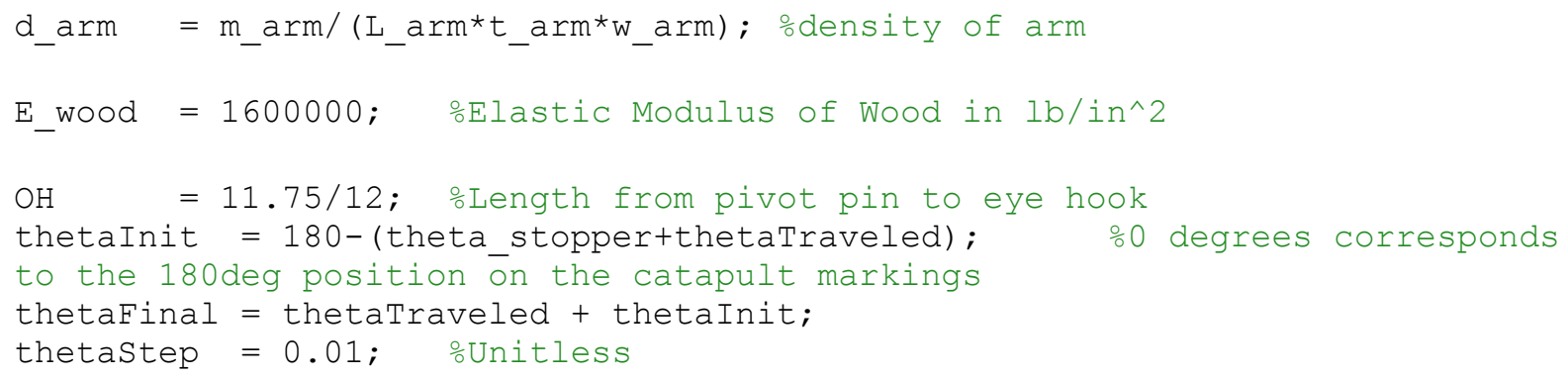


F band=zeros ( (thetaFinal-thetaInit)/thetastep+1,1); \%creates zero matrix to perform for loop

ocreates an array of Energy stored in rubber band and magnitude of Force of the rubber band for every theta position

for $n=1:($ thetaFinal-thetaInit)/thetastep+1

oTaken from experimentally determined equation trendline fit

$0.091) ;$

F_band $(n)=\operatorname{qtyBands} *\left(3.465 * d L(n) \wedge 3-9.677 * d L(n)^{\wedge} 2+13.55 * d L(n)+\right.$

E band $(n)=$ qtyBands* $\left(3.465 / 4 * d L(n)^{\wedge} 4-9.677 / 3 * d L(n)^{\wedge} 3+13.55 / 2 * d L(n) \wedge 2\right.$

$+0.091 * d L(n))$;

end

E_pot $(n)=m \_t o t a l * L \_c m * s i n d($ theta_theo $(n))$;

응-------- - - - - - - - - - - - - - - - - - - - - - - - - - - - - - - - - -

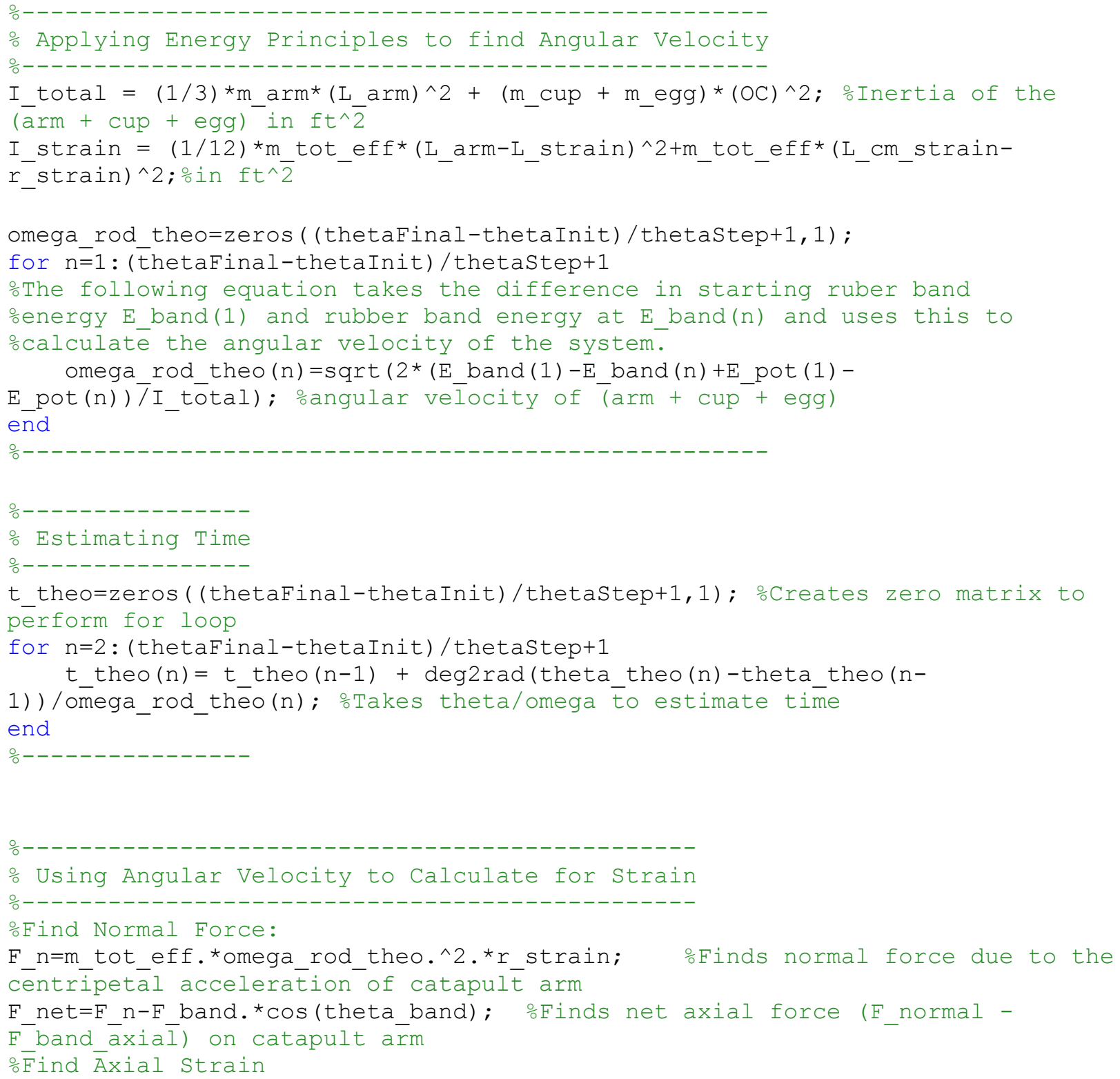




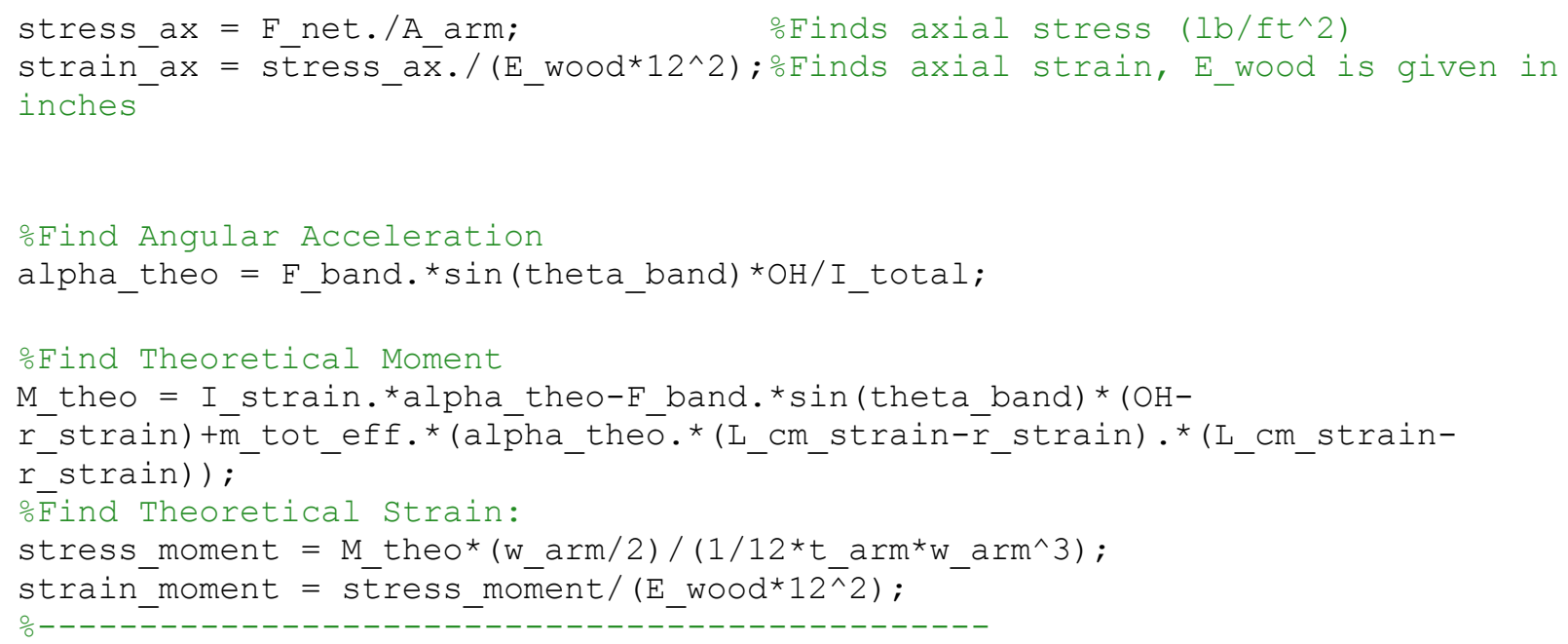




\section{Appendix K Selected Catapult Hand Calculations}

CAMPACT HAMD CALCUATOES

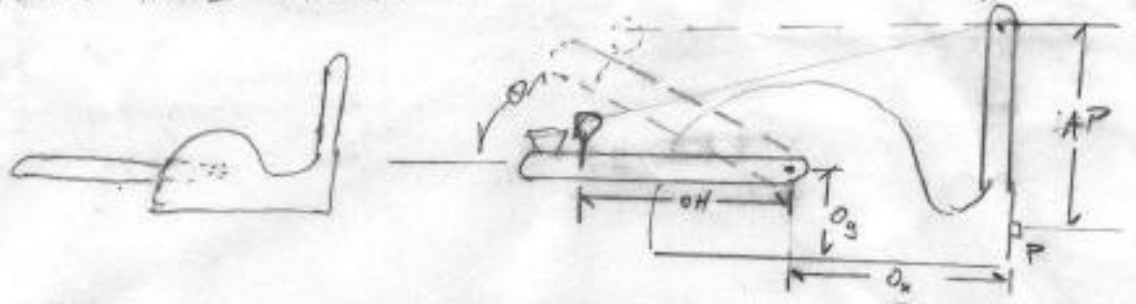

FIRT: NEED RUBEER BMD DSPCNEMENT AS FUNCTEN OF $\theta$

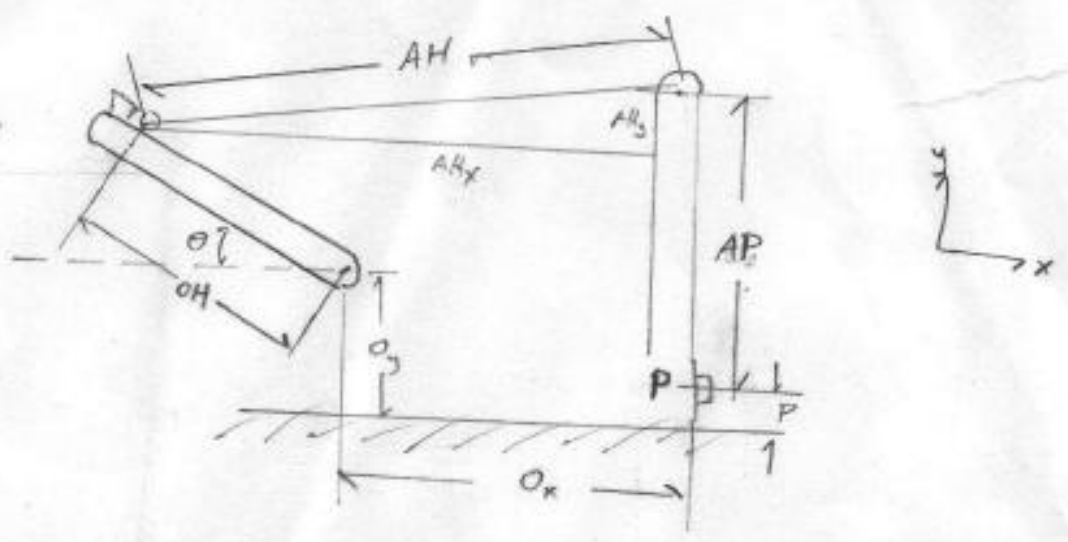

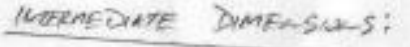

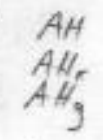

$$
\begin{aligned}
& A H_{y}=(A P+P)-\left(O H \sin \theta+O_{y}\right) \\
& A H_{x}=(O H \cos \theta)+O x \\
& A H=\sqrt{A H_{x}^{2}+A H_{y}^{2}}
\end{aligned}
$$

DSTLAFMENT OF RUBSER SAD D:

TOML ZENGM of BAD: $\angle$ - STRENCH $=A H+A P$

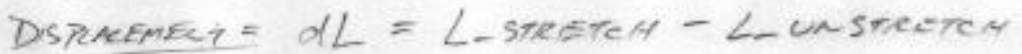

Nmn 


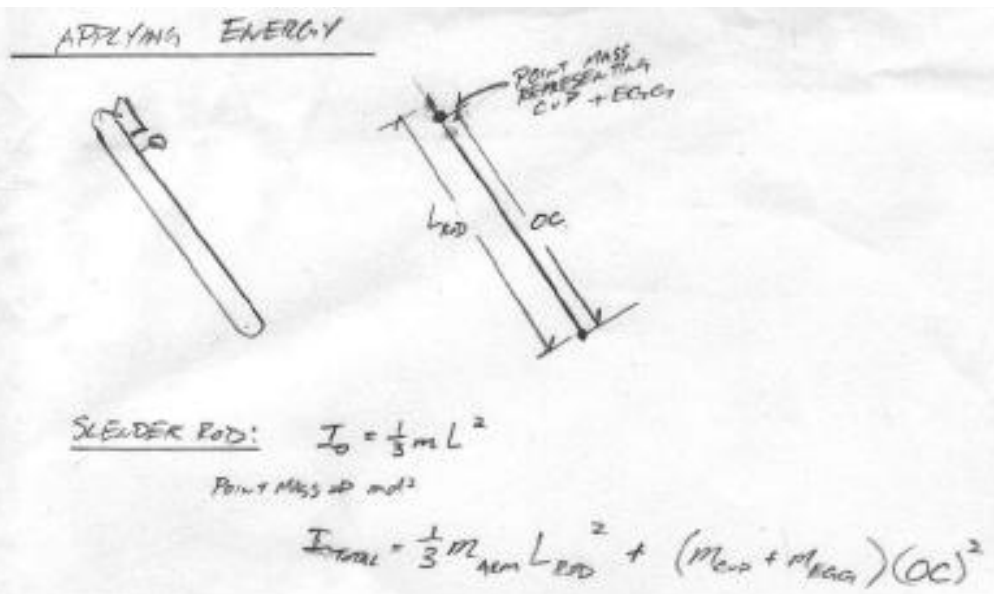

APDWVAT EMAREY:

ENBETEWTLCY DETERMED RUBBER BAND CORVE:

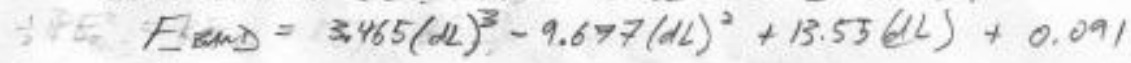

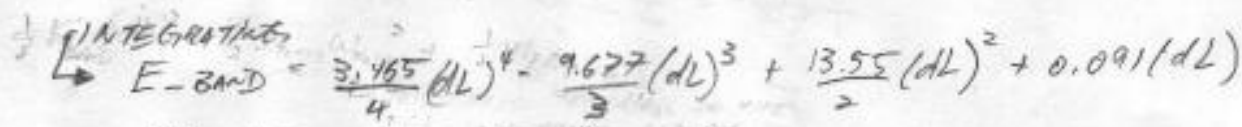

$P E_{0}+K E_{0}=P E_{1}+K E_{1}$

$$
\begin{aligned}
& \frac{K E_{1}}{1}=\left(\frac{F E_{0}}{P E_{1}}\right)+K E_{0} P^{\circ} \\
& K E_{1}^{\prime}=P E_{0}-P E_{1} \\
& \frac{1}{2} I \omega^{2}=E_{\text {Bwix-0 }}-E_{\text {swa }-1} \\
& \omega_{1}=\sqrt{2\left(E_{\text {Bando }}-E_{\text {sand } 1)}\right)} \\
& \omega(n)=\sqrt{\left.\frac{D\left(E_{B+2 D D}-0-E_{8+n D}(n)\right.}{I_{\pi 5 \pi}}\right)}
\end{aligned}
$$


THEORETICAL MOMEAT
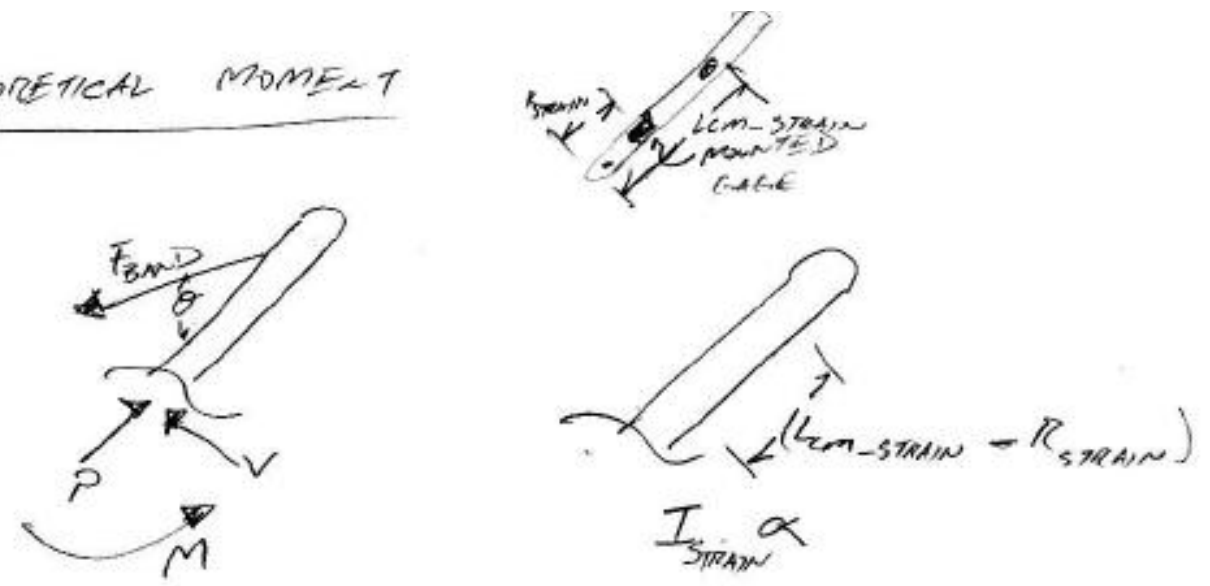

$$
\begin{aligned}
& \Sigma M=I \text { ar } \\
& -M+\left(F_{-B A N D}-\sin \theta\right)\left(O H-R_{-} \text {STRAN }\right)=I_{\text {- STRMN }} \alpha \\
& +m_{E F F} \propto\left(L_{-C M} \operatorname{sTaAN}-\right. \\
& (r-S \operatorname{TrAN} N)^{2}
\end{aligned}
$$

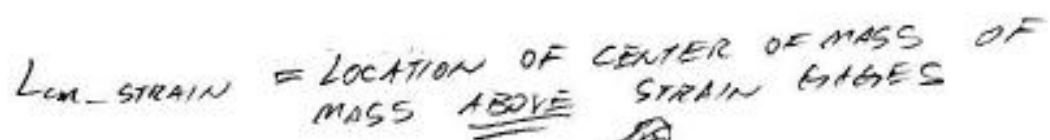

$$
\begin{aligned}
& \text { STEES_moner } 1=\frac{m_{C}}{I}=\frac{m \cdot\left(\frac{N-A \text { an }}{2}\right)}{\left(\frac{1}{2} b h^{3}\right)} \\
& \therefore \text { STRANA }=\frac{\sigma}{E}=\frac{\text { STOESS }}{E}
\end{aligned}
$$

K-3 
WHEATSTONE BRIDEE STRAN CALC'S

$$
\begin{aligned}
& \Delta R=S_{0} \sigma \\
& \Delta V_{0}=\frac{R_{1} R_{2}}{\left(R_{1}+R_{2}\right)}=\left[\frac{\Delta R_{1}}{R_{1}}=\frac{\Delta R_{2}^{2}}{R_{2}}+\frac{\Delta R_{3}}{R_{3}}-\frac{\Delta R_{4}^{2}}{R_{4}}\right]^{0} \\
& \text { IF } R_{1}=R_{2}=R_{3}=R_{4} \\
& \Delta \Delta V_{0}=\frac{E^{2}}{4 R^{2}}\left[\frac{\Delta R_{1}+\Delta R_{3}}{Z}\right] \\
& =\frac{1}{4}\left[\frac{2 \Delta R}{R}\right] \\
& =\frac{1}{4}\left[\frac{2 s_{g} t}{R}\right] \\
& \Delta V_{0}=\frac{1}{2} \frac{S_{g} t}{R} \\
& \epsilon=\frac{2 \pi \Delta V_{0}}{S_{2}}
\end{aligned}
$$

ALTERTATE EQUATON [AS SPECIEIED ON M.COM]

$$
L_{D} \sqrt{\frac{V_{0}}{V_{E x}}}=\frac{S_{g} \theta}{2}
$$

K-4 


\section{Appendix L ADXL-278 Specifications}

\section{ANALOG Dual-Axis, High-g, DEVICES $\quad$ MEMS $^{\circledR}$ Accelerometers \\ ADXL278}

\section{FEATURES}

Complete dual-axis acceleration measurement system on a single monolithic IC

Available in $\pm 35 \mathrm{~g} / \pm 35 \mathrm{~g}, \pm 50 \mathrm{~g} / \pm 50 \mathrm{~g}$, or $\pm 70 \mathrm{~g} / \pm 35 \mathrm{~g}$

output full-scale ranges

Full differential sensor and circuitry for high resistance to EML/RFI

Environmentally robust packaging

Complete mechanical and electrical self-test on digital command

Output ratiometric to supply

Sensitive axes in the plane of the chip

High linearity $(0.2 \%$ of full scale)

Frequency response down to dc

Low noise

Low power consumption

Tight sensitivity tolerance and $0 \mathrm{~g}$ offset capability

Largest available prefilter clipping headroom

$400 \mathrm{~Hz}$, 2-pole Bessel filter

Single-supply operation

Compatible with $\mathrm{Sn} / \mathrm{Pb}$ and $\mathrm{Pb}$-free solder processes

\section{GENERAL DESCRIPTION}

The ADXI.278 is a low power, complete, dual-axis accelerometer with signal conditioned voltage outputs that are on a single monolithic IC. This product measures acceleration with a full-scale range of (X-axis/Y-axis) $\pm 35 \mathrm{~g} / \pm 35 \mathrm{~g}, \pm 50 \mathrm{~g} /$ $\pm 50 \mathrm{~g}$, or $\pm 70 \mathrm{~g} / \pm 35 \mathrm{~g}$ (minimum). The ADXL.278 can also measure both dynamic acceleration (vibration) and static acceleration (gravity).

The ADXI.278 is the fourth-generation surface micromachined iMEMS accelerometer from ADI with enhanced performance and lower cost. Designed for use in front and side impact airbag applications, this product also provides a complete cost-

effective solution useful for a wide variety of other applications.

The ADXL.278 is temperature stable and accurate over the automotive temperature range, with a self-test feature that fully exercises all the mechanical and electrical elements of the sensor with a digital signal applied to a single pin.

The ADXI.278 is available in a $5 \mathrm{~mm} \times 5 \mathrm{~mm} \times 2 \mathrm{~mm}$, 8-terminal ceramic LCC package.

\section{APPLICATIONS}

Vibration monitoring and control

Vehicle collision sensing

Shock detection

FUNCTIONAL BLOCK DIAGRAM

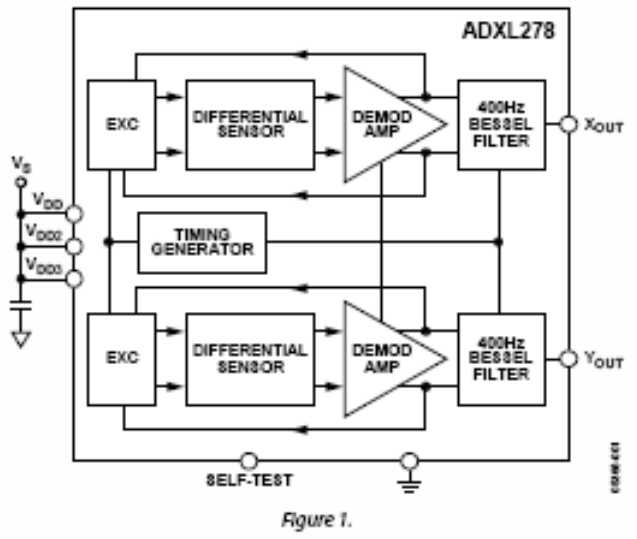

Information furvished by Analog Dovices is belloved to bo accurate and reliable Howevor, no responstblity is assumed by Analog Devicas for its usa, nor for any

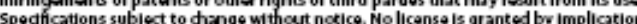
or otherwise under amy patent or patent rights of Analog Dovices. Trademarks and reglster ed trademarks are the property of their respectivo owners.

One Technology Way, P.O. Box 9106, Norwood, MA 02062-9106, U.S.A Tel: 781.329 .4700 Fax1 781.461 .3113 


\section{ADXL278}

\section{TABLE OF CONTENTS}

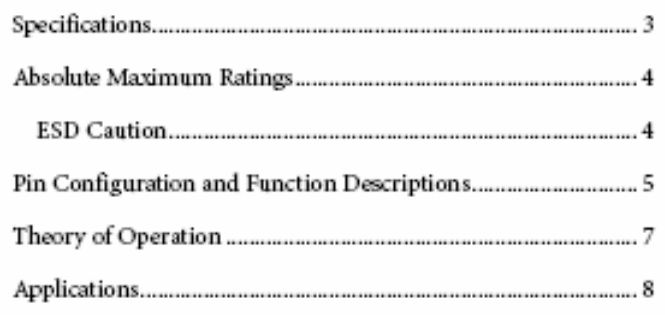

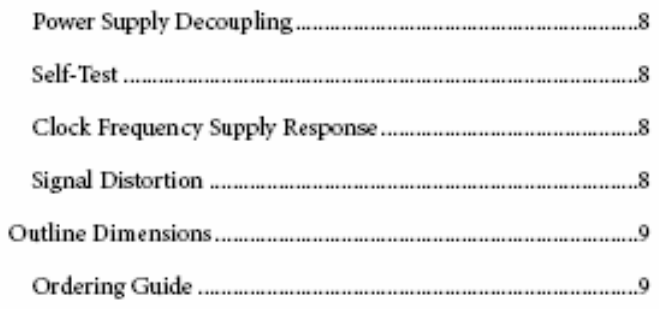

REVISION HISTORY

5/05-Rev. 0 to Rev. A

Rev. A Page 2 of 12 
ADXL278

\section{SPECIFICATIONS 1}

At $\mathrm{T}_{\mathrm{A}}=-40^{\circ} \mathrm{C}$ to $+105^{\circ} \mathrm{C}, 5.0 \mathrm{~V} \mathrm{dc} \pm 5 \%$, acceleration $=0 \mathrm{~g}$ unless otherwise noted.

Table 1 .

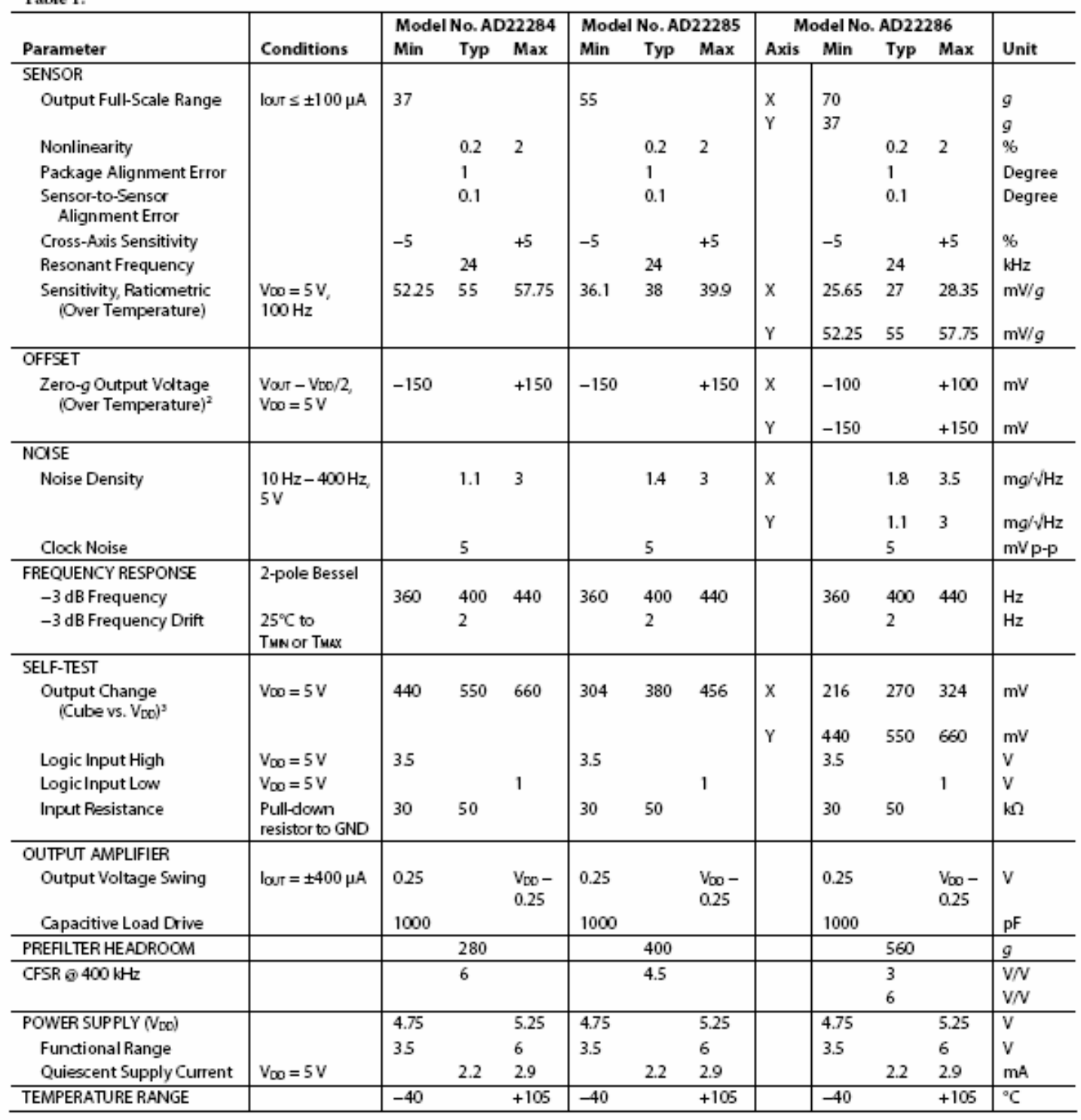

' All minimum and maximum specifications are guaranteed. Typical specifications are not guaranteed. Zero goutput is ratiometic.

iSelfetest cutput at $V_{\infty \infty}=($ Self-Test Output at $5 \mathrm{~V}) \times\left(\mathrm{N}_{\infty} / 5 \mathrm{~V}\right)^{3}$. 


\section{ADXL278}

\section{ABSOLUTE MAXIMUM RATINGS}

\begin{tabular}{l|l} 
Table 2. \\
\hline Parameter & Rating \\
\hline Acceleration (Any Axis, Unpowered) & $4,000 \mathrm{~g}$ \\
Acceleration (Any Axis, Powered) & $4,000 \mathrm{~g}$ \\
Vs & $-0.3 \mathrm{~V}$ to $+7.0 \mathrm{~V}$ \\
All Other Pins & $(\mathrm{COM}-0.3 \mathrm{~V})$ to \\
& $\left(\mathrm{V}_{5}+0.3 \mathrm{~V}\right)$ \\
Output Short-Circuit Duration & Indefinite \\
(Any Pin to Common) & \\
Operating Temperature Range & $-65^{\circ} \mathrm{C}$ to $+150^{\circ} \mathrm{C}$ \\
Storage Temperature & $-65^{\circ} \mathrm{C}$ to $+150^{\circ} \mathrm{C}$ \\
\hline
\end{tabular}

Stresses above those listed under Absolute Maximum Ratings may cause permanent damage to the device. This is a stress rating only; functional operation of the device at these or any other conditions above those indicated in the operational section of this specification is not implied. Exposure to absolute maximum rating conditions for extended periods may affect device reliability.

\section{ESD CAUTION}

ESD (electrostatic discharge) sensitive device. Electrostatic charges as high as $4000 \mathrm{~V}$ readily accumulate on the human body and test equipment and can discharge without detection. Although this product features proprietary ESD protection circuitry, permanent damage may occur on devices subjected to high energy electrostatic discharges. Therefore, proper ESD precautions are recommended to avoid performance degradation or loss of functionality.

WARWING: nivitil meosmatrm daves 


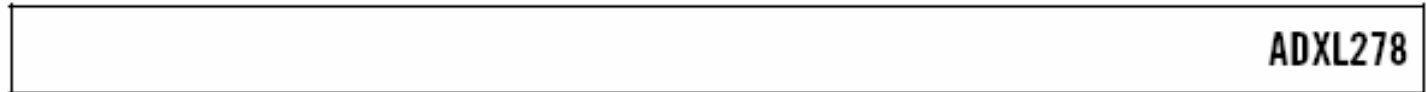

\section{PIN CONFIGURATION AND FUNCTION DESCRIPTIONS}

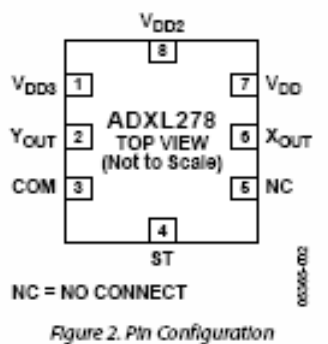

Table 3. Pin Function Descriptions

\begin{tabular}{l|l|l}
\hline Pin No. & Mnemonic & Description \\
\hline 1 & Voos & 35 V to $6 \mathrm{~V}$ \\
2 & YoJr & Y Channel Output \\
3 & COM & Common \\
4 & ST & Self-Test \\
5 & NC & Do Not Connect \\
6 & Xout & X Channel Output \\
7 & Voo & 35 V to $6 \mathrm{~V}$ \\
8 & VoO2 & 35 V to $6 \mathrm{~V}$ \\
\hline
\end{tabular}




\section{ADXL278}

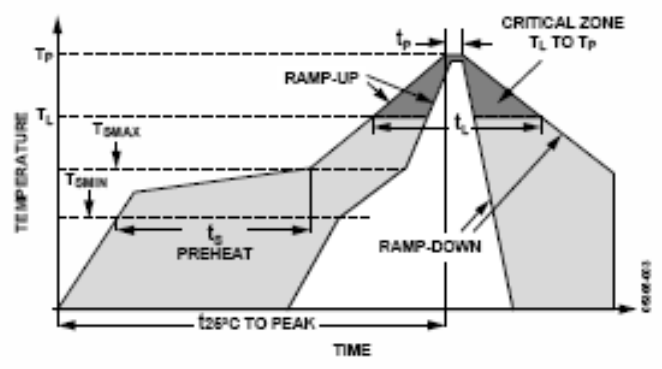

Fgure 3. Recommended Saldering Profile

Table 4. Recommended Soldering Profile

\begin{tabular}{|c|c|c|}
\hline Profile Feature & Sn63/Pb37 & Pb-Free \\
\hline AVERAGE RAMP RATE $\left(T_{L}\right.$ TO T $\left._{\mathrm{P}}\right)$ & $3^{\circ} \mathrm{C} / \mathrm{s} \max$ & $3^{\circ} \mathrm{C} / \mathrm{s} \max$ \\
\hline \multicolumn{3}{|l|}{ PREHEAT } \\
\hline Minimum Temperature $\left(T_{\text {swo }}\right)$ & $100^{\circ} \mathrm{C}$ & $150^{\circ} \mathrm{C}$ \\
\hline Maximum Temperature (Tsux) & $150^{\circ} \mathrm{C}$ & $200^{\circ} \mathrm{C}$ \\
\hline TIME (Tswn TO Tsыax), ts & $60 s-120 s$ & $60 s-150 s$ \\
\hline \multicolumn{3}{|l|}{ Tsmax TOTL } \\
\hline Ramp-Up Rate & $3^{\circ} \mathrm{C} / \mathrm{s}$ & $3^{\circ} \mathrm{C} / \mathrm{s}$ \\
\hline \multicolumn{3}{|l|}{ TIMEMAINTAINED ABOVE UQUIDOUS (T) } \\
\hline Liquidous Temperature (TL) & $183^{\circ} \mathrm{C}$ & $217^{\circ} \mathrm{C}$ \\
\hline Time $\left(t_{L}\right)$ & $60 s-150 s$ & $60 s-150 s$ \\
\hline PEAKTEMPERATURE $(T p)$ & $240^{\circ} \mathrm{C}+0^{\circ} \mathrm{C} /-5^{\circ} \mathrm{C}$ & $260^{\circ} \mathrm{C}+0^{\circ} \mathrm{C} /-5^{\circ} \mathrm{C}$ \\
\hline TIMEWITHIN $5^{\circ} \mathrm{COF}$ ACTUAL PEAKTEMPERATURE (tP) & $10 s-30 s$ & $20 s-40 s$ \\
\hline RAMP-DONN RATE & $6^{\circ} \mathrm{C} / \mathrm{s} \max$ & $6^{\circ} \mathrm{C} / \mathrm{s} \max$ \\
\hline TIME $25^{\circ} \mathrm{C}$ TOPEAKTEMPERATURE & $6 \min \max$ & $8 \min \max$ \\
\hline
\end{tabular}

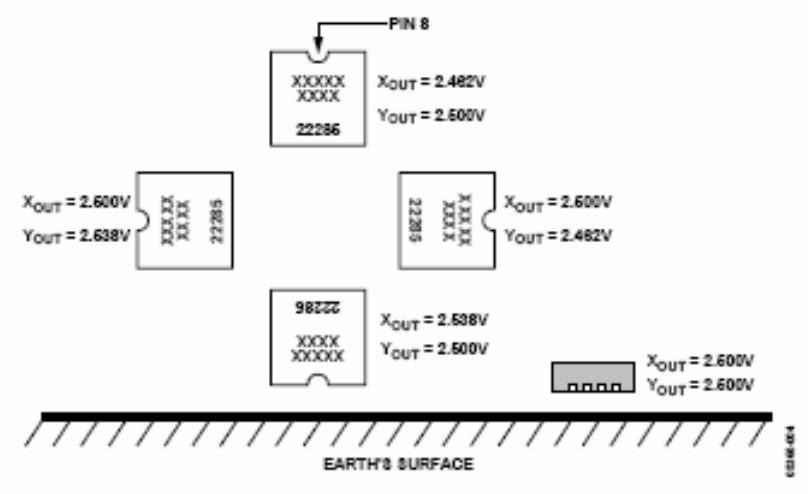

Figure 4. Output Response vs. Orientation 
ADXL278

\section{THEORY OF OPERATION}

The ADXL.278 provides a fully differential sensor structure and circuit path, resulting in the industry's highest resistance to EMI/RFI effects. This latest generation uses electrical feedback with zero-force feedback for improved accuracy and stability. The sensor resonant frequency is significantly higher than the signal bandwidth set by the on-chip filter, avoiding the signal analysis problems caused by resonant peaks near the signal bandwidth.

Figure 5 is a simplified view of one of the differential sensor elements. Each sensor includes several differential capacitor unit cells. Each cell is composed of fixed plates attached to the substrate and movable plates attached to the frame. Displacement of the frame changes the differential capacitance, which is measured by the on-chip circuitry.

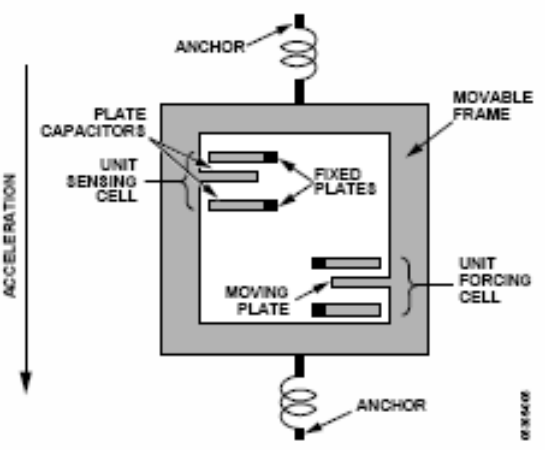

Figure 5. Simplified View of Sensor Under Acceleration

Complementary $200 \mathrm{kHz}$ square waves drive the fixed plates. Electrical feedback adjusts the amplitudes of the square waves such that the ac signal on the moving plates is 0 . The feedback signal is linearly proportional to the applied acceleration. This unique feedback technique ensures that there is no net electrostatic force applied to the sensor. The differential feedback control signal is also applied to the input of the filter where it is filtered and converted to a single-ended signal. 


\section{ADXL278}

\section{APPLICATIONS}

\section{POWER SUPPLY DECOUPLING}

For most applications, a single $0.1 \mu \mathrm{F}$ capacitor, $\mathrm{CDC}$, adequately decouples the accelerometer from noise on the power supply. However, in some cases, particularly where noise is present at the $200 \mathrm{kHz}$ internal clock frequency (or any harmonic thereof), noise on the supply can cause interference on the ADXI.278's output. If additional decoupling is needed, a $50 \Omega$ (or smaller) resistor or ferrite bead cany be inserted in the supply line. Additionally, a larger bulk bypass capacitor (in the $1 \mu \mathrm{F}$ to $4.7 \mu \mathrm{F}$ range) can be added in parallel to $\mathrm{CDC}$

\section{SELF-TEST}

The fixed fingers in the forcing cells are normally kept at the same potential as that of the movable frame. When the self-test digital input is activated, the voltage on the fixed fingers on one side of the moving plate in the forcing cells is changed. This creates an attractive electrostatic force, which causes the frame to move towards those fixed fingers. The entire signal channel is active; therefore, the sensor displacement causes a change in Vour. The ADXL.278's self-test function is a comprehensive method of verifying the operation of the accelerometer.

Because electrostatic force is independent of the polarity of the voltage across capacitor plates, a positive voltage is applied in half of the forcing cells, and its complement in the other half of the forcing cells. Activating self-test causes a step function force to be applied to the sensor, while the capacitive coupling term is canceled. The ADXL.278 has improved self-test functionality; including excellent transient response and high speed switching capabilities. Arbitrary force waveforms can be applied to the sensor by modulating the self-test input, such as test signals to measure the system frequency response or even crash signals to verify algorithms within the limits of the self-test swing.

The ST pin should never be exposed to voltages greater than $\mathrm{V}_{\mathrm{s}}+0.3 \mathrm{~V}$. If this cannot be guaranteed due to the system design (for instance, if there are multiple supply voltages), then alow $\mathrm{V}_{5}$ clamping diode between $\mathrm{ST}$ and $\mathrm{V}_{5}$ is recommended.

\section{CLOCKFREQUENCY SUPPLY RESPONSE}

In any docked system, power supply noise near the clock frequency may have consequences at other frequencies. An internal clock typically controls the sensor excitation and the signal demodulator for micromachined accelerometers.

If the power supply contains high frequency spikes, they may be demodulated and interpreted as an acceleration signal. A signal appears as the difference between the noise frequency and the demodulator frequency. If the power supply spikes are $100 \mathrm{~Hz}$ away from the demodulator clock, there is an output term at
$100 \mathrm{~Hz}$ If the power supply clock is at exactly the same frequency as the accelerometer dock, the term appears as an offset.

If the difference frequency is outside of the signal bandwidth, the filter attenuates it. However, both the power supply clock and the accelerometer clock may vary with time or temperature, which can cause the interference signal to appear in the output filter bandwidth.

The ADXI.278 addresses this issue in two ways. First, the high clock frequency eases the task of choosing a power supply clock frequency such that the difference between it and the accelerometer clock remains well outside of the filter bandwidth. Second, the ADXI.278 is the only micromachined accelerometer to have a fully differential signal path, including differential sensors. The differential sensors eliminate most of the power supply noise before it reaches the demodulator. Good high frequency supply bypassing, such as a ceramic capacitor close to the supply pins, also minimizes the amount of interference.

The clock frequency supply response (CFSR) is the ratio of the response at $V_{C O T}$ to the noise on the power supply near the accelerometer clock frequency. A CFSR of 3 means that the signal at $V_{o u r}$ is $3 \times$ the amplitude of an excitation signal at $V_{D D}$ near the accelerometer internal dock frequency. This is analogous to the power supply response, except that the stimulus and the response are at different frequencies. The ADXL.278's CFSR is $10 \times$ better than a typical single-ended accelerometer system.

\section{SIGNAL DISTORTION}

Signals from crashes and other events may contain high amplitude, high frequency components. These components contain very little useful information and are reduced by the 2-pole Bessel filter at the output of the accelerometer. However, if the signal saturates at any point, the accelerometer output does not look like a filtered version of the acceleration signal.

The signal may saturate anywhere before the filter. For example, if the resonant frequency of the sensor is low, the displacement per unit acceleration is high. The sensor may reach the mechanical limit of travel if the applied acceleration is high enough. This can be remedied by locating the accelerometer where it does not see high values of acceleration and by using a higher resonant frequency sensor, such as the ADXI.278.

Also, the electronics may saturate in an overload condition between the sensor output and the filter input. Ensuring that internal circuit nodes operate linearly to at least several times the full-scale acceleration value can minimize electrical saturation. The ADXI.278 circuit is linear to approximately $8 \times$ full scale. 
ADXL278

\section{OUTLINE DIMENSIONS}

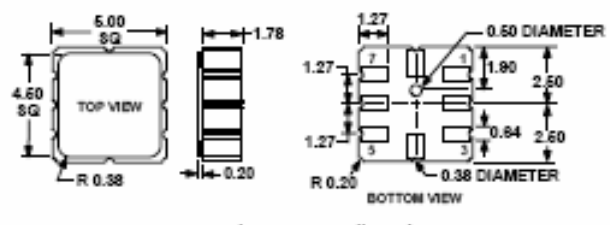

Flgure 6. \&-Terminal Ceramic Leadiess Chip Camier [LCC] (E-8)

AXL 278 ORDERING GUIDE

\begin{tabular}{l|l|l|l|l|l|l}
\hline Model' & $\begin{array}{l}\text { Parts } \\
\text { per Reel }\end{array}$ & $\begin{array}{l}\text { Measurement } \\
\text { Range }\end{array}$ & $\begin{array}{l}\text { Specified } \\
\text { Voltage (V) }\end{array}$ & $\begin{array}{l}\text { Temperature } \\
\text { Range }\end{array}$ & $\begin{array}{l}\text { Package } \\
\text { Option }\end{array}$ \\
\hline AD22284-A-R2 & 250 & $\pm 35 \mathrm{~g} / \pm 35 \mathrm{~g}$ & 5 & $-40^{\circ} \mathrm{C}$ to $+105^{\circ} \mathrm{C}$ & 8-Lead Ceramic Leadless Ghip Carrier & E-8 \\
AD22284-A & 3000 & $\pm 35 \mathrm{~g} / \pm 35 \mathrm{~g}$ & 5 & $-40^{\circ} \mathrm{C}$ to $+105^{\circ} \mathrm{C}$ & 8-Lead Ceramic Leadless Ghip Carrier & E-8 \\
AD22285-R2 & 250 & $\pm 50 \mathrm{~g} / \pm 50 \mathrm{~g}$ & 5 & $-40^{\circ} \mathrm{C}$ to $+105^{\circ} \mathrm{C}$ & 8-Lead Ceramic Leadless Chip Carrier & E-8 \\
AD22285 & 3000 & $\pm 50 \mathrm{~g} / \pm 50 \mathrm{~g}$ & 5 & $-40^{\circ} \mathrm{C}$ to $+105^{\circ} \mathrm{C}$ & 8-Lead Ceramic Leadless Chip Carrier & E-8 \\
AD22286-R2 & 250 & $\pm 70 \mathrm{~g} / \pm 35 \mathrm{~g}$ & 5 & $-40^{\circ} \mathrm{C}$ to $+105^{\circ} \mathrm{C}$ & 8-Lead Ceramic Leadless Chip Carrier & E-8 \\
AD22286 & 3000 & $\pm 70 \mathrm{~g} / \pm 35 \mathrm{~g}$ & 5 & $-40^{\circ} \mathrm{C}$ to $+105^{\circ} \mathrm{C}$ & 8-Lead Ceramic Leadless Chip Carrier & E-8 \\
\hline
\end{tabular}

'All models are on tope and reel and are $\mathrm{Pb}$-free parts 